\title{
VIRAL PROTEIN CAGES AS BUILDING BLOCKS FOR FUNCTIONAL MATERIALS
}

Aijie Liu 


\section{Members of the committee:}
Chairman: Prof. dr. ir. J.W.M. Hilgenkamp
(University of Twente)
Supervisor: $\quad$ Prof. dr. J.J.L.M. Cornelissen
(University of Twente)

\section{Graduation committee:}
Prof. dr. R.J.M. Nolte
(Radboud University Nijmegen)
Prof. X.E. Zhang
(Chinese Academy of Science)
Prof. dr. ir. N.E. Benes
(University of Twente)
Prof. dr. J.G.E. Gardeniers
(University of Twente)
Dr. D. Reardon
(DSM N.V.)

The research described in this thesis was performed within the laboratories of the Biomolecular Nanotechnology (BNT) group, the MESA+ institute for Nanotechnology, and the Department of Science and Technology (TNW) of the University of Twente. This research was supported by the Dutch Polymer Institute (DPI).

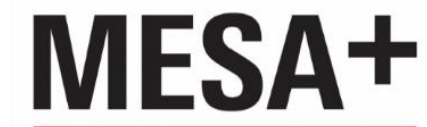

INSTITUTE FOR NANOTECHNOLOGY

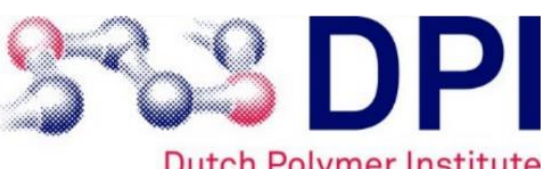

Dutch Polymer Institute

\section{UNIVERSITY OF TWENTE.}

\section{Viral Protein Cages as Building Blocks for Functional Materials}

Copyright (C) 2017, Aijie Liu, Enschede, The Netherlands.

All rights reserved. No part of this thesis may be reproduced or transmitted in any form, by any means, electronic or mechanical without prior written permission of the author.

ISBN: $\quad 978-90-365-4387-3$

DOI: $\quad 10.3990 / 1.9789036543873$

Cover art: $\quad$ Qinshi Lin and Aijie Liu

Printed by: $\quad$ Gildeprint - The Netherlands 


\title{
VIRAL PROTEIN CAGES AS BUILDING BLOCKS FOR FUNCTIONAL MATERIALS
}

\author{
DISSERTATION
}

to obtain

the degree of doctor at the University of Twente,

on the authority of the rector magnificus

Prof. dr. T. T. M. Palstra,

on account of the decision of the graduation committee,

to be publicly defended

on Friday September 29, 2017 at 14.45 h

by

Aijie Liu

Born on July 30, 1988

in Zhejiang, China 
This dissertation has been approved by:

Supervisor: Prof. dr. J.J.L.M. Cornelissen 
This thesis is dedicated to my family 



\section{Table of contents}

Chapter 1: Introduction

Chapter 2: Protein Cages as Building Blocks for Hybrid Functional Materials

2.1 Introduction 6

2.2 Protein nanoparticle based scaffolds 6

2.3 Engineering protein based scaffolds $\quad 8$

2.3.1 Bioconjugate chemistry 9

2.3.2 Mineralization 10

2.3.3 Self-assembly 13

2.4 Self-assembling of protein particle based scaffolds $\quad 15$

2.4.1 One-dimensional (1D) self-assembly (wire) 15

2.4.2 Two-dimensional (2D) self-assembly 15

2.4.3 Three-dimensional (3D) self-assembly 17

2.5 Application of protein nanoparticles 19

2.5.1 Nanoreactors 19

2.5.2 Plasmonic metamaterials 21

$\begin{array}{lll}2.6 & \text { Summary and future directions } & 23\end{array}$

Chapter 3: Nitroarene Reduction by a Virus Protein Cage Based Nanoreactor

$\begin{array}{lll}3.1 & \text { Introduction } & 36\end{array}$

$\begin{array}{lll}3.2 & \text { Results and discussion } & 37\end{array}$

3.2.1 Nanoreactor preparation $\quad 37$

3.2.2 Mechanistic investigation of the reduction 40

3.2.3 Determination of the reduction rate constants 43

3.2.4 Stability of nanoreactors 48

$\begin{array}{lll}3.2 .5 & \text { Sustainability } & 49\end{array}$

$\begin{array}{lll}3.3 & \text { Conclusions } & 50\end{array}$

$\begin{array}{lll}3.4 & \text { Acknowledgements } & 50\end{array}$

3.5 Materials and methods 51 
Chapter 4: Immobilization of Catalytic Virus-like Particles in a Flow Reactor

4.1 Introduction $\quad 66$

$\begin{array}{lll}4.2 & \text { Results and discussion } & 67\end{array}$

4.2.1 Encapsulation of gold nanoparticles 67

$\begin{array}{ll}\text { 4.2.2 Ligand exchange } & 69\end{array}$

4.2.3 CCMV-Au7B immobilized flow reactor 71

4.2.4 Preparation and encapsulation of Au-Pd bimetallic 77 NPs

$\begin{array}{lll}4.3 & \text { Conclusions } & 79\end{array}$

$\begin{array}{lll}4.4 & \text { Acknowledgements } & 80\end{array}$

4.5 Materials and methods $\quad 80$

Chapter 5: Compartmentalized Thin Film with Tunable

Functionality via Interfacial Cross-linking of Protein Cages

$\begin{array}{lll}\mathbf{5 . 1} \text { Introduction } & 88\end{array}$

$\begin{array}{lll}\text { 5.2 Results and discussion } & 89\end{array}$

5.2.1 Characterization of CCMV based thin film 90

5.2.2 Compartmentalized thin film loaded with gold 92 nanoparticles

5.2.3 Compartmentalized thin film loaded with silicon 95 quantum dots

5.2.4 Compartmentalized thin film loaded with an enzyme 97

5.2.5 Functional particles @ compartmentalized thin film 100

$\begin{array}{lll}5.3 & \text { Conclusions } & 103\end{array}$

$\begin{array}{ll}5.4 & 103\end{array}$

5.5 Materials and methods 103

Chapter 6: Construction of Core-Shell Hybrid Nanoparticles Templated by Virus-like Particles

6.1 Introduction

6.2 Results and discussion 
6.2.1 Construction of virus/silica hybrid nanoparticles at 116 different $\mathrm{pH}$

6.2.2 Encapsulation of gold nanoparticles and silication $\quad 120$

$\begin{array}{lll}\text { 6.3 Conclusions } & 123\end{array}$

$\begin{array}{lll}\text { 6.4 Acknowledgements } & 124\end{array}$

$\begin{array}{lll}\text { 6.5 Materials and methods } & 125\end{array}$

Chapter 7: Cowpea Chlorotic Mottle Virus Templated Nanoporous Silica Thin Film

$\begin{array}{lll}7.1 & \text { Introduction } & 132\end{array}$

7.2 Results and discussion 133

7.2.1 CCMV thin film 133

$\begin{array}{ll}\text { 7.2.2 CCMV-Silica thin film } & 135\end{array}$

7.2.3 Anti-reflection coating 139

$\begin{array}{lll}7.3 & \text { Conclusions and outlook } & 143\end{array}$

$\begin{array}{lll}7.4 & \text { Acknowledgements } & 144\end{array}$

$\begin{array}{lll}\text { 7.5 Materials and methods } & 144\end{array}$

$\begin{array}{ll}\text { Summary } & 151\end{array}$

Samenvatting $\quad 153$

Acknowledgements $\quad 155$

About the author $\quad 159$ 


\section{Chapter 1}

\section{General Introduction}

In the course of evolution, Nature, has created life with a bottom-up approach from molecular to functional systems. It assembles each compartment in a correct position to play its specific role in a life circle. ${ }^{1}$ With a library full of wonderful designs Natural systems have inspired multiple research fields including computer science, optical science, chemistry and materials science to follow leads provided by these complex designs. In the field of Biomolecular Nanotechnology, building blocks from biology have been applied in the above mentioned research areas and, next to e.g. lipids, DNA and RNA, protein architectures, such as virus nanoparticles, have been applied in solar cells, ${ }^{2}$ for gene delivery, ${ }^{3}$ in sensors ${ }^{4}$ and as nanoreactors. ${ }^{5}$

The use of protein architectures for (bio-) nanotechnology applications is a rapidly emerging field. By mimicking Nature, reaction compartments were brought together in a confined space to achieve the maximum output. ${ }^{5}$ Furthermore, synthetic vesicles and natural protein assemblies were explored as controllable and responsive nanocontainers and/or nanoreactors, in order to tune the access and release of molecules, for example, by controlling the pore $\operatorname{size}^{6}$ and electrostatic potential of membranes/or coat proteins. The application, however, of these effects to construct functional nanometer-sized building blocks for macroscopic devices, such as sustainable reactors, (bio-) sensors and electronic devices, still remains a challenge and examples are limited.

To address this challenge, we choose the Cowpea Chlorotic Mottle Virus (CCMV) as building block to construct (multi-) functional materials by taking advantages of the welldefined structure and the reversible assembly behavior of this protein nanoparticle.

CCMV is a plant virus infecting the black-eyed pea, ${ }^{7}$ which has been well studied by our group and others. ${ }^{8}$ The key property of CCMV that makes it so attractive for materials science is its reversible assembly-disassembly behavior in vitro. ${ }^{8 a}$ The virus contains 180 identical protein subunits that are kept together by non-covalent interactions. As a function of $\mathrm{pH}$ and ionic strength, the virus dissociates allowing for the removal of the genetic material, but also 
for the controlled re-assembly of the proteins in different, highly organized, protein cages. The latter step can be used for the inclusion of a variety of (often negatively charged) materials, which can give new or different functions to the, so-called, virus-like particles.

The aim of this thesis is to study CCMV as a building block for the inclusion of functional compounds, where the focus is on gold as a catalyst, to further explore its application as a nanoreactor, but also as the construction material for functional films by either cross-linking the protein cages or using them as a template for silica synthesis.

Chapter 2 provides an overview of recently reported protein cages based building blocks that have been used as nanocontainers, nanoreactors and nanotemplates for inorganic or organic material synthesis. Furthermore, the assembly of protein cages into higher-ordered $2 \mathrm{D}$ and $3 \mathrm{D}$ super-structures is described.

Chapter 3 introduces CCMV protein encapsulated gold nanoparticles as nanoreactors. The pore size and the electrostatic potential of protein cages induce substrate selectivity based on the different sizes and the charges of substrates.

Colloidal catalysts always face the challenge of recycling, which is addressed in Chapter 4 where we immobilize CCMV-gold hybrid nanoreactors in a glass flow channel. This enables re-use of the colloidal catalysts, which still display catalytic activity.

As for the majority of proteins, the surface of CCMV or its capsids can be chemically modified. In Chapter 5 the integration of CCMV and derived functional virus-like particles (VLPs) into (free standing) films is discussed by using trimesoyl chloride as a cross-linker. Capsids with different functional materials, i.e. CCMV-gold, CCMV-horseradish peroxidase (HRP), CCMV-Si nanoparticle, were included and their properties were studied. Furthermore, by taking the advantages of the high flexibility of these films, more complex systems were developed; and the biocompatibility of free standing thin films was investigated.

Chapter 6, describes the use of CCMV as a model system for the mineralization of silica nanomaterials. The results point out that whether the silication take place outside or inside the protein capsids can be fine-tuned by $\mathrm{pH}$. This allows for the preparation of functional cargo-hollow porous silica shell hybrid nanomaterials based on silica coated CCMV-gold NPs. 


\section{Chapter 1}

Chapter 7 follows up on chapter 6, where the preparation of CCMV templated nanoporous silica films, with the potential application as anti-reflective coating, is discussed. 


\section{Reference}

1. Renggli, K.; Baumann, P.; Langowska, K.; Onaca, O.; Bruns, N.; Meier, W., Selective and Responsive Nanoreactors. Advanced Functional Materials 2011, 21 (7), 12411259.

2. Chen, P.-Y.; Dang, X.; Klug, M. T.; Qi, J.; Dorval Courchesne, N.-M.; Burpo, F. J.; Fang, N.; Hammond, P. T.; Belcher, A. M., Versatile Three-Dimensional Virus-Based Template for Dye-Sensitized Solar Cells with Improved Electron Transport and Light Harvesting. ACS Nano 2013, 7 (8), 6563-6574.

3. Lizotte, P. H.; Wen, A. M.; Sheen, M. R.; FieldsJ; RojanasopondistP; Steinmetz, N. F.; FieringS, In situ vaccination with cowpea mosaic virus nanoparticles suppresses metastatic cancer. Nat Nano 2016, 11 (3), 295-303.

4. Soto, C. M.; Blaney, K. M.; Dar, M.; Khan, M.; Lin, B.; Malanoski, A. P.; Tidd, C.; Rios, M. V.; Lopez, D. M.; Ratna, B. R., Cowpea mosaic virus nanoscaffold as signal enhancement for DNA microarrays. Biosensors and Bioelectronics 2009, 25 (1), 48-54.

5. Jordan, P. C.; Patterson, D. P.; Saboda, K. N.; Edwards, E. J.; Miettinen, H. M.; Basu, G.; Thielges, M. C.; Douglas, T., Self-assembling biomolecular catalysts for hydrogen production. Nat Chem 2016, 8 (2), 179-185.

6. Ueno, T.; Suzuki, M.; Goto, T.; Matsumoto, T.; Nagayama, K.; Watanabe, Y., SizeSelective Olefin Hydrogenation by a Pd Nanocluster Provided in an Apo-Ferritin Cage. Angewandte Chemie International Edition 2004, 43 (19), 2527-2530.

7. Speir, J. A.; Munshi, S.; Wang, G.; Baker, T. S.; Johnson, J. E., Structures of the native and swollen forms of cowpea chlorotic mottle virus determined by X-ray crystallography and cryo-electron microscopy. Structure (London, England : 1993) 1995, 3 (1), 63-78.

8. (a) Lavelle, L.; Michel, J.-P.; Gingery, M., The disassembly, reassembly and stability of CCMV protein capsids. Journal of Virological Methods 2007, 146 (1-2), 311 316; (b) Comellas-Aragones, M.; Engelkamp, H.; Claessen, V. I.; Sommerdijk, N. A. J. M.; Rowan, A. E.; Christianen, P. C. M.; Maan, J. C.; Verduin, B. J. M.; Cornelissen, J. J. L. M.; Nolte, R. J. M., A virus-based single-enzyme nanoreactor. Nat Nano 2007, 2 (10), 635-639; (c) Uchida, M.; Klem, M. T.; Allen, M.; Suci, P.; Flenniken, M.; Gillitzer, E.; Varpness, Z.; Liepold, L. O.; Young, M.; Douglas, T., Biological Containers: Protein Cages as Multifunctional Nanoplatforms. Advanced Materials 2007, 19 (8), 1025-1042. 


\section{Chapter 2}

\section{Protein Cages as Building Blocks for Hybrid Functional Materials}

Protein assemblies, as natural supramolecular structures, provide unique characteristics compared to synthetically programmed materials. Often these protein cages are virus based and their subunits organize with precise spatial arrangement into three-dimensional architectures with rod-like or spherical shape of different sizes. They also have advantages, such as economically viable, highly reproducible production and chemical/or genetic programmability; for these reasons, viruses and/or virus-like particles (VLPs) have been widely used as building blocks in nanotechnology. Since the applications of these particles are enormous, this chapter provides a review of viruses, or their assemblies, that are applied as nanoreactors and in plasmonic metamaterials.

Part of this chapter is published in: L.Yang, A. Liu, S. Cao, R.M. Putri, P. Jonkheijm, J. J. L. M. Cornelissen, Assemblies of Native Proteins and Artificial Scaffolds, Chem. Eur. J. 2016, 22, 1557015582. 


\subsection{Introduction}

Revolutionary developments in (bio-) nanotechnology have been made possible through the convergence of physics, chemistry, biology, materials science and engineering. Biosystems and biomaterials have been recognized and used as sources of inspiration. Examples of this include the development of big data analysis, inspired by biological neural networks, ${ }^{1}$ the development of sensors based on biological pathways with precise temporal and spatial control ${ }^{2}$ and the development of self-regulating and self-repairing materials inspired by biomaterials. ${ }^{3}$ However, it remains challenging to create and synthesize materials with highly-ordered structures. For example, nature arranges virus particles with protein units and nucleic acid by non-covalent interactions that have low-energy consumption and allow a reversible control over the assembly under local environments with high reproducibility and low cost; these interactions include protein-protein interaction, protein-nucleic acid interactions, van der Waal and various surface forces. ${ }^{4}$ It is difficult for synthetic materials to replicate the structural and functional complexity of natural materials. In the last few decades, the application and engineering of natural materials for (bio-) nanotechnology has been extensively explored, ${ }^{5}$ and in the near future, the development of bio-mimic synthetic materials is expected to lead to a revolutionary breakthrough towards the goal of creating synthetic materials with highly ordered structures. The aim of this review is to highlight the engineering of protein nanoparticles, especially those based on virus and virus-like particles (VLPs), for applications as nanoreactors and in plasmonic metamaterials.

\subsection{Protein nanoparticle based scaffolds}

Nature uses self-assembly to generate supramolecular structures with a wide diversity variety of shapes, sizes, and highly symmetric protein architectures. ${ }^{6}$ Compared with synthetically-programmed materials, protein nanoparticles have certain advantages: protein nanoparticles have a highly precise spatial arrangement of subunits, and can be produced at minimum cost while also being environmentally friendly. ${ }^{7}$ Highly monodisperse building blocks composed of single or multiple types of protein subunits have been viewed as molecular Lego sets. Depending on the shape of the protein compartments, they can be divided into icosahedral, helical symmetries, cubic, or tetrahedral symmetries (Figure 2.1). ${ }^{8}$ 
Further classification of protein nanoparticles depends on the natural properties, as further discussed under the following numbered headings: 1) Ferritin, is used as a host for regulating intracellular iron concentrations and oxidant protection by iron mineralization and sequestration, this protein is produced by almost all living organisms. ${ }^{9}$ 2) Chaperonins, correct protein folding and prevent protein aggregations. ${ }^{10}$ Chaperonins are classified in two groups - Group I and II, depending on their origin. Group I chaperonins are found in bacteria, chloroplasts and mitochondria while Group II chaperonins are found in eukaryotic cytosol and in archaea. 3) Metabolosomes, such as encapsulins, include dye-decolorizing peroxidase (DyP, B.linens) that decrease oxidative stress, and a ferritin-like protein (Flps, T. maritima) that stores ferrous ions. ${ }^{11}$ 4) Viruses, the small infectious agents that delivers a genome inside living cells. ${ }^{12}$ Various methods have been developed to produce large quantities of protein particles in a short time with high reproducibility and batch-to-batch consistency, e.g. in plants, yeast, insect cells, and bacteria. ${ }^{13} \mathrm{~A}$ proper choice and design of protein scaffolds are important for specific applications.

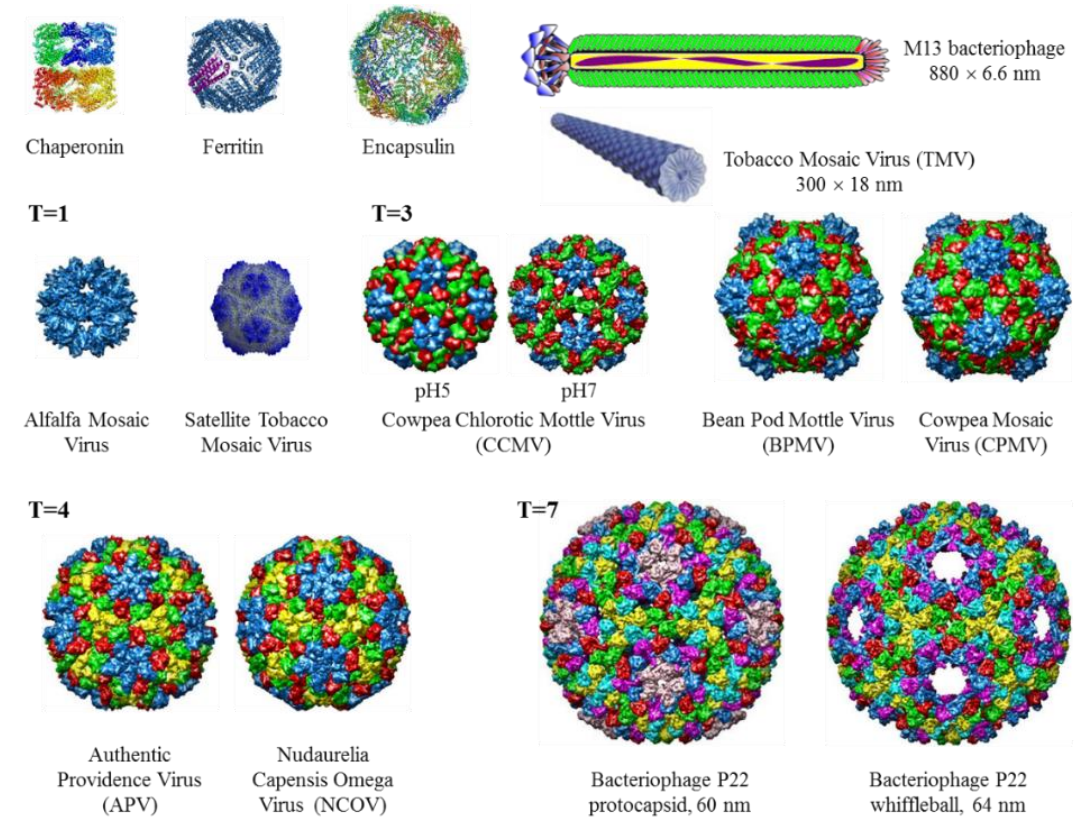

Figure 2.1. Protein nanoparticles of reconstructed images. ${ }^{11,14}$ Reproduced with permission from ref 11, Copyright $\odot$ 2008, rights managed by Nature Publishing Group; Reproduce with permission from ref 14, Copyright (C) 2017 Elsevier B.V. Models were download from RCS Protein Data Bank (www.pdb.org). 


\subsection{Engineering protein based scaffolds}

Engineering of virus based scaffolds can be carried out either genetically or chemically. Viral particles based scaffolds consist of protein shells which separate the interior volume and protect the cargo (i.e. the genome, enzymes or other molecules) from the exterior environment, they are usually 2 to $5 \mathrm{~nm}$ thick and can have selective and/or non-selective pores. ${ }^{15}$ Modifications can therefore be carried out at three faces: the exterior surface of the protein cage, the inter-surface between protein subunits, or the inner surface of the protein shell. The inner cavity of the protein cage can deliver the genome, selectively store and protect ions, molecules, or encapsulate other particles for drug delivery or other use. ${ }^{15}$ Many protein cages are robust enough to tolerate genetic or chemical modifications without affecting the properties of self-assembly. ${ }^{16}$ Methods of modification are shown in Figure 2.2, including genetic engineering, infusion, bio-conjugation, mineralization and self-assembly. Detailed introductions on these methods have been provided in the recent literatures. ${ }^{5,15}$ This chapter will focus on the methods which are closely related to our work, namely bioconjugation, mineralization, and self-assembly of viral or non-viral protein cages.

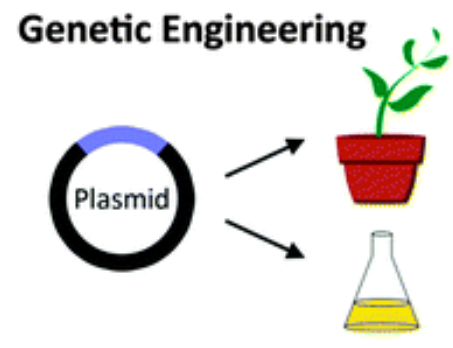

Bioconjugation

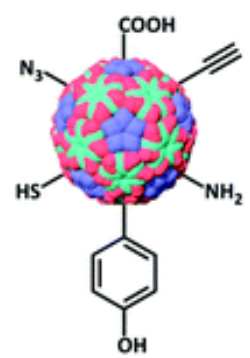

\section{Infusion}

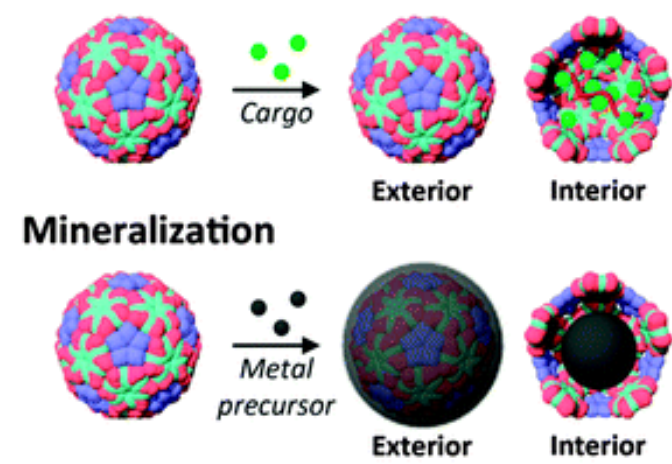

\section{Self-Assembly}

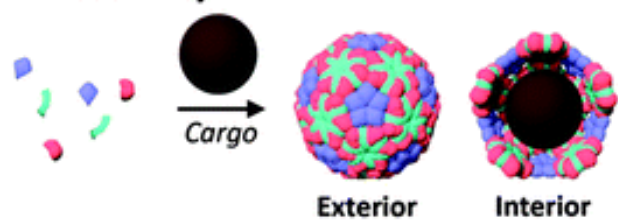

Figure 2.2. Engineering of protein based scaffolds based on genetic engineering, bio-conjugation, infusion, mineralization and self-assembly. Reproduced with permission from ref 5, Copyright $\odot 2016$, Royal Society of Chemistry. 


\subsubsection{Bioconjugate chemistry}

Protein cages of viral particles are composed of single or multiple self-assembling protein units. The complementary use of both genetic and chemical methods opens up many possibilities for protein modification with either natural residues or unnatural residues on the exterior surface and/or the inner surface of protein cages. ${ }^{17}$ Genetic engineering allows for very efficient and controllable production of protein nanoparticles with a highly symmetrical distribution of inserted functional groups. However, it is not yet possible to conjugate unnatural residues on proteins, though this can be achieved through the use of chemical modifications. For example, the Sainsbury's group introduced genetic encoding of a natural molecule, green fluorescent protein (GFP) encapsidating bluetongue virus (BTV). For unnatural molecules, chemical modification was carried out to functionalize the far-red fluorescent dye Cy5 at the inner surface of the protein shells. Both methods of modification show no change to the surface charge or capsid structure of BTV. ${ }^{16}$ The resultant functionalized particles from both methods show high binding affinity with human cells, indicating that BTV has a potential application in receptor-targeted delivery vehicles.

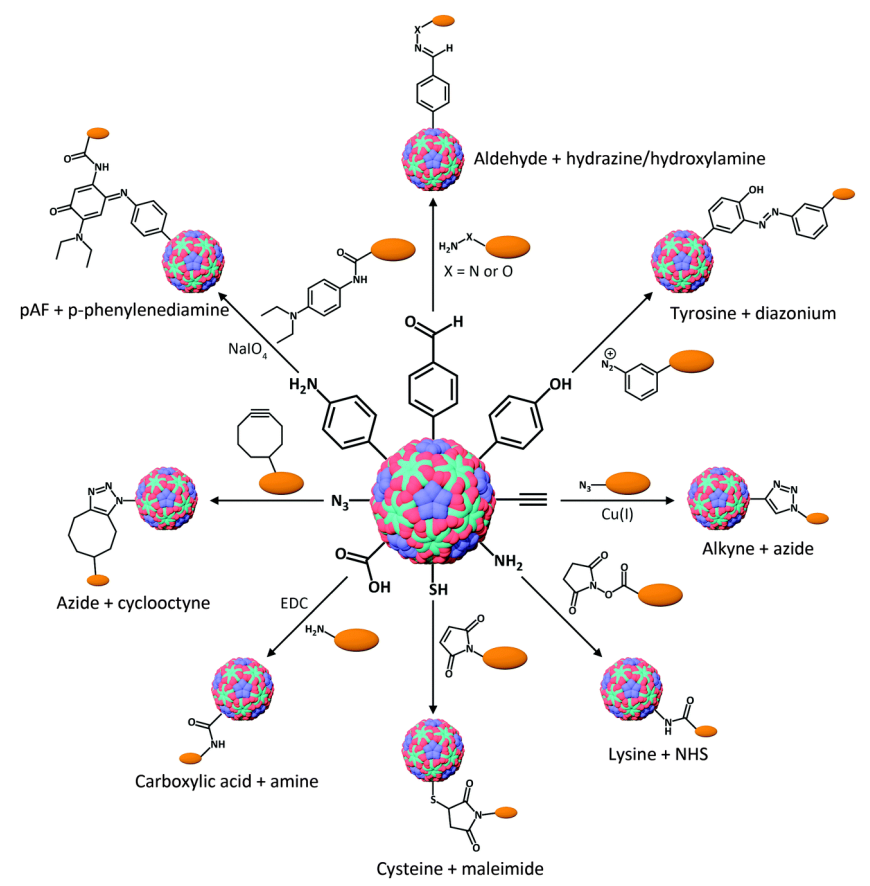

Figure 2.3. Bioconjugation modifications for virus based particles. Reproduced with permission from Ref 5 Copyright (C) 2016, Royal Society of Chemistry. 
Although bioconjugate functionality provides many possibilities, modification of protein units through chemical reactions often results in protein denaturation or viral particle disassembly and aggregation. Furthermore, mild reaction conditions as well as low toxicity of the functionalized groups need to be taken into account if used for in vivo studies. ${ }^{18}$ Classical covalent modification can be achieved via N-hydroxysuccinimide (NHS) ester conjugation with the amine $\left(-\mathrm{NH}_{2}\right)$ at the $\mathrm{N}$-terminus, or carboxylic acid $(-\mathrm{COOH})$ at the $\mathrm{C}$ terminus and thiol (-SH) groups. Pre-modified alkyne-azide cycloaddition represents a powerful tool for further modification by using a click reaction; both metal complex catalysis and metal free catalysis are possible. ${ }^{19}$ A wide range of methods of chemical modification are summarized in Figure 2.3. Multifunctional protein nanoparticles can be obtained through the modification of natural and/or unnatural molecules.

\subsubsection{Mineralization}

By taking advantage of the fact that protein assemblies are highly monodisperse and symmetric, templated mineralization on the exterior surface of protein cages as well as the inner cavities has been carried out with unique size and shape control. The selective deposition of metal nanoparticles on the exterior surface or at the inner surface of protein cages can be achieved by the genetic engineering of specific peptides at the surfaces of protein cages. ${ }^{20}$ This can be carried out at either the exterior or the inner surface. With the selective electrostatic interactions between inorganic precursors and protein cages, the selective synthesizing of inorganic nanomaterials within protein nanocompartments can be realized. ${ }^{21}$ Directed growing of well patterned Au nanoclusters with few nanometers was achieved on self-assembled rosette nanotubes (RNTs) and the spherical cowpea mosaic virus (CPMV), which were pre-introduced with a specific sequence (specific for $\mathrm{Au}$ mineralization) on the exterior surface of a protein shell, through the genetic method. ${ }^{22}$ Nanowires or nanoparticles with highly defined sizes and shapes were obtained in confined nanotubes, such as protein cages and icosahedral virus protein cages (spherical). ${ }^{23}$ The synthesis of metal nanoparticles with high organization of tobacco mosaic virus (TMV), M13, and spherical protein cages have been widely applied to electronic devices and nanoreactors. ${ }^{24-25}$ A detailed summary of templated mineralization on the exterior surface and in the cavity is given in Table 2.1 . 
Table 2.1. Templated mineralization on the exterior surface and inner cavity of protein particles

\begin{tabular}{|c|c|c|c|}
\hline \multicolumn{4}{|c|}{ Mineralization on exterior surface } \\
\hline Materials & Virus & (Potential) Applications & Ref \\
\hline Pd NPs, Ni/Co & TMV & $\begin{array}{l}\text { Catalysis or energy } \\
\text { applications; }\end{array}$ & $\begin{array}{l}26,27,28 \\
24,29,30\end{array}$ \\
\hline $\mathrm{Pt}$ & TMV & Digital memory & 25 \\
\hline $\mathrm{Ni}$ & TMV & Lithium Ion Batteries & 31,32 \\
\hline $\mathrm{Ni}, \mathrm{Pd}$ & TMV & $\begin{array}{l}\text { Thermal and fluidic } \\
\text { applications }\end{array}$ & 33 \\
\hline $\mathrm{Ni}, \mathrm{Sn}$ & TMV & Lithium Ion Batteries & 34 \\
\hline $\mathrm{Ni}, \mathrm{Sn}, \mathrm{C}$ & TMV & Sodium-Ion Battery Anodes & 35 \\
\hline $\mathrm{Ni}, \mathrm{Si}$ & TMV & Lithium Ion Batteries & $36,37,38$ \\
\hline $\begin{array}{r}\mathrm{Ni}, \mathrm{Ti} \\
\mathrm{LiFePO}_{4}, \mathrm{C}\end{array}$ & TMV & Li-Ion Micro-batteries & 39 \\
\hline $\mathrm{CuO}$ & TMV & $\begin{array}{l}\text { Photoelectrochemical cell } \\
\text { applications }\end{array}$ & 40 \\
\hline $\mathrm{Ni} / \mathrm{V}_{2} \mathrm{O}_{5}$ & TMV & Micro-battery electrodes & 41 \\
\hline $\begin{array}{c}\text { Fe oxides, } \\
\mathrm{CdS}, \mathrm{PbS}, \mathrm{SiO}_{2}\end{array}$ & TMV & Templated inorganic synthesis & 42 \\
\hline $\mathrm{Pt}, \mathrm{Au}, \mathrm{Ag}$ & TMV & $\begin{array}{l}\text { Chemical engineering of } \\
\text { internal and external surface }\end{array}$ & 20 \\
\hline $\mathrm{Pd}, \mathrm{Cu}$ & M13, fd phage & Electronics, sensing & 43 \\
\hline $\mathrm{TiO}_{2} / \mathrm{Au}$ & M13 & Solar Cell & 44 \\
\hline $\mathrm{Au}$ & Rosette & $\begin{array}{c}\text { Medicine, molecular } \\
\text { electronics, optics, and catalysis }\end{array}$ & $22 b$ \\
\hline $\mathrm{FePO}_{4}$ & $\mathrm{pVIII}$ & Lithium-ion batteries & 45 \\
\hline Bi NPs & M13 & Templated biomineralization & 46 \\
\hline \multirow{4}{*}{ Silica } & TMV & Core-shell; mesoporous silica & $47,48,49,42$ \\
\hline & CPMV & $\begin{array}{l}\text { Mesoporous silica; } \\
\text { silica NPs }\end{array}$ & 50,51 \\
\hline & TYMV & Mesoporous silica & 52 \\
\hline & $\begin{array}{l}\text { Human enterovirus } \\
\text { type } 71 \text { (EV71) }\end{array}$ & $\begin{array}{l}\text { Core-shell, thermal property } \\
\text { enhanced. }\end{array}$ & 53 \\
\hline \multirow[t]{2}{*}{ Gold } & CPMV & Gold cluster, gold capsid & $22 \mathrm{a}, 54$ \\
\hline & CCMV & Gold cluster & 55 \\
\hline
\end{tabular}


Protein Cages as Building Blocks for Hybrid Functional Materials

\begin{tabular}{|c|c|c|c|}
\hline \multicolumn{4}{|c|}{ Mineralization in the interior cavity } \\
\hline Materials & Virus & (Potential) Applications & Ref \\
\hline Au-Ag alloy & Apoferritin & Nanoreactor & 56 \\
\hline $\mathrm{Pd}$ & Apoferritin & Size selective nanoreactor & $23 b, 57$ \\
\hline $\mathrm{ZnO}$ & Apoferritin & $\begin{array}{c}\text { Varistors, phosphors, transparent } \\
\text { conducting electrodes, et al }\end{array}$ & 58 \\
\hline $\mathrm{MnOOH}, \mathrm{Mn}_{3} \mathrm{O}_{4}$ & Apoferritin & $\begin{array}{l}\text { Templated growth (ferromagnetic } \\
\text { particles) }\end{array}$ & 59 \\
\hline $\mathrm{Co}(\mathrm{O}) \mathrm{OH}, \mathrm{Co}_{3} \mathrm{O}_{4}$ & Apoferritin & Templated growth & 60 \\
\hline $\mathrm{CdSe}$ & Apoferritin & Nanoelectronic device & 61 \\
\hline $\mathrm{ZnSe}$ & Apoferritin & $\begin{array}{l}\text { Nanoelectronic device and bio- } \\
\text { imaging }\end{array}$ & 62 \\
\hline $\mathrm{CoPt}$ & Apoferritin & Data storage & 63 \\
\hline $\mathrm{Ag}$ & Apoferritin & Medical imaging and radiotherapy & 64 \\
\hline CdS clusters & Apoferritin & $\begin{array}{c}\text { Tunable photochemical agents for } \\
\text { diagnosis, sensing and drug delivery }\end{array}$ & 65 \\
\hline $\mathrm{Au}-\mathrm{Pd}$ & Apoferritin & Nanoreactors & 66 \\
\hline \multirow{2}{*}{ Iron oxide } & Ferritin & \multirow{2}{*}{ Fluorescence and MR imaging } & 67 \\
\hline & Lumazine & & 68 \\
\hline $\begin{array}{c}\mathrm{FeS}, \mathrm{Mn}_{3} \mathrm{O}_{4} \\
\text { Uranium oxo-species }\end{array}$ & Ferritin & $\begin{array}{l}\text { Templated growth in constrained } \\
\text { reaction environment }\end{array}$ & 69 \\
\hline Prussian blue & CCMV & $\begin{array}{l}\text { Templated synthesis, molecular } \\
\text { magnets }\end{array}$ & 70 \\
\hline $\mathrm{Fe}_{3} \mathrm{O}_{4}, \mathrm{Co}_{2} \mathrm{O}_{3}$ & CCMV & Templated growth & 21 \\
\hline $\mathrm{H}_{2} \mathrm{~W}_{12} \mathrm{O}_{42}{ }^{10-}, \mathrm{V}_{10} \mathrm{O}_{28}{ }^{6-}$ & CCMV & $\begin{array}{c}\text { Host-guest, entrapped } \\
\text { polymerization }\end{array}$ & 71 \\
\hline \multirow{2}{*}{$\mathrm{TiO}_{2}$} & CCMV & Photo-catalysis & 72 \\
\hline & $\mathrm{P} 22$ & Photo-catalysis & 73 \\
\hline $\mathrm{Au} / \mathrm{CdS}$ & $\mathrm{P} 22$ & Photocatalyst & 74 \\
\hline $\mathrm{Ni} / \mathrm{Pd}, \mathrm{Co} / \mathrm{Pd}$ & Chaperonins & Templated growth & 75 \\
\hline Co particles & $\begin{array}{c}\text { Bacteriophage } \\
\text { T7 } \\
\end{array}$ & ferromagnetic & 76 \\
\hline Ag NPs & TMV & $\begin{array}{c}\text { Chemical engineering of internal } \\
\text { and external surface }\end{array}$ & 20 \\
\hline $\mathrm{Ni}$, Co nanowire & TMV & $\begin{array}{c}\text { Growth in constrained reaction } \\
\text { environment }\end{array}$ & 77 \\
\hline $\mathrm{Cu}$ nanowire & TMV & $\begin{array}{c}\text { Growth in constrained reaction } \\
\text { environment }\end{array}$ & $23 a$ \\
\hline
\end{tabular}




\subsubsection{Self-assembly}

Native viruses are protein assemblies which act as the host containers, present various functions, such as for nucleic acid storage, maturation and transport. Therefore, most virus protein cages are meta-stable, and protein cages can be disassembled by adjusting the $\mathrm{pH}$ and ionic strength of the solution. Some of the capsid proteins can be reassembled into virus-like particles under certain conditions, without the mediation of RNA. It has been suggested that the mechanism of the cargo templated self-assembling process of icosahedral capsid follows a cascade of lower-order reactions, specifically an equilibrium polymerization consists of nucleation-and-growth steps. ${ }^{78}$ An investigation into self-assembly of cowpea chlorotic mottle virus (CCMV) shows two different pathways to form hybrid VLPs, ${ }^{79}$ by varying the protein-protein interaction or the protein-cargo interaction affinities under acidic or neutral $\mathrm{pH}$. The efficiency of self-assembly and the resultant capsid structures are highly dependent on the cargo materials. For example, for Au NPs encapsulations in CPMV, the efficiency is dependent on the size of cargo nanoparticles as well as the ratio of the coat protein $(\mathrm{CP})$ to Au NPs (Figure 2.4). Successful encapsulation is obtained when the CP/Au ratio is higher than 100, the efficiency increases as the amount of $\mathrm{CP}$ increases. The maximum encapsulation efficiency was found at an Au NP diameter of $12 \mathrm{~nm} .{ }^{80}$ By varying the ratio of PEG- $\mathrm{CO}_{2} \mathrm{H}$ to PEG-OH on the surface of the Au NPs (Figure 2.5a), the encapsulation efficiency of foreign cargos in icosahedral protein cages was also found to be surface charge density dependent. ${ }^{78 a}$ Sufficient surface charge density is required for protein assembly; even if the total charge was sufficient, the protein shell did not close if the surface charge density was below the critical value (Figure 2.5b). The final size of virus like particles (VLPs) is independent on the surface charge density and is instead determined by the size of cargos (Figure 2.5c). This assembly process can also be adapted to other cargo materials, such as negatively charged polystyrene sulfonate (PSS). ${ }^{81}$ The encapsulation efficiency results are similar to those reported in ref ${ }^{80}$, Au NPs with $12 \mathrm{~nm}$ result in the highest encapsulation efficiency rate (Figure $2.5 \mathrm{~d}$ ). 

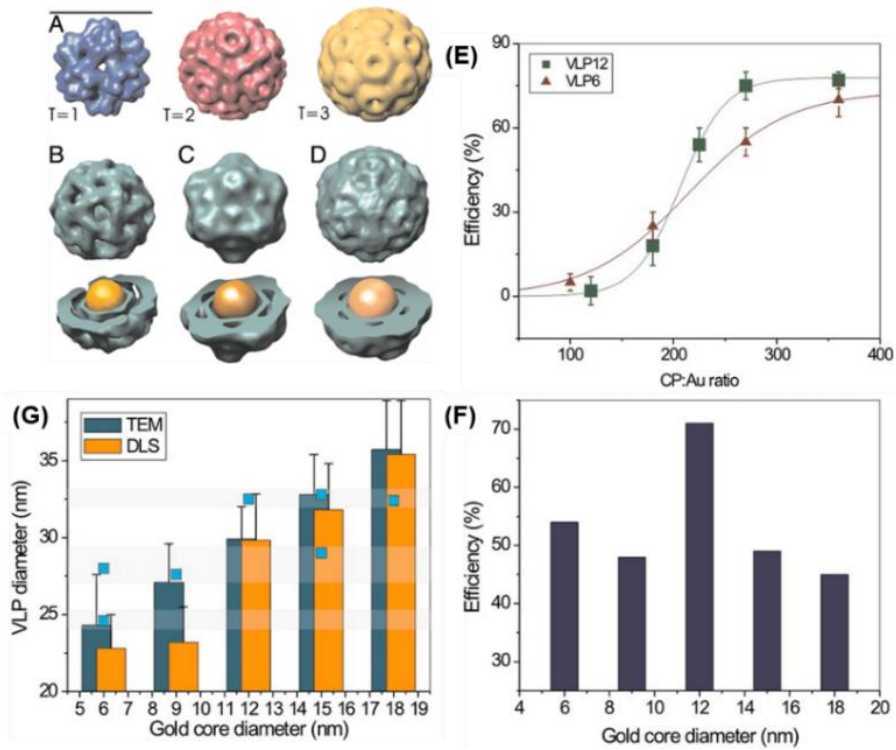

Figure 2.4. Encapsulation of $\mathrm{Au}-\mathrm{PEG}-\mathrm{CO}_{2} \mathrm{H}$ (A) $3 \mathrm{D}$ reconstructions of $\mathrm{T}=1, \mathrm{~T}=2$, and $\mathrm{T}=3$; (B) $\mathrm{T}=1$ VLPs with $6 \mathrm{~nm}$ core Au-PEG-CO ${ }_{2} \mathrm{H}$; (C) Pseudo T=2 VLPs with $9 \mathrm{~nm}$ core Au-PEG-CO ${ }_{2} \mathrm{H}$; (D) $\mathrm{T}=3$ VLPs with $12 \mathrm{~nm}$ core Au-PEG-CO $2 \mathrm{H}$; (E) Encapsulation efficiency as a function of CP/Au; (F) Encapsulation efficiency as a functions of Au NPs diameter and (G) VLP average diameter with various $\mathrm{Au}$ NPs diameter $(\mathrm{CP} / \mathrm{Au}=270: 1)$. Reproduced with permission from $\operatorname{Ref}^{80}$ @ 2007 by The National Academy of Sciences of the USA.

(a)

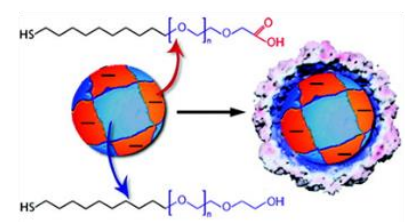

(b)

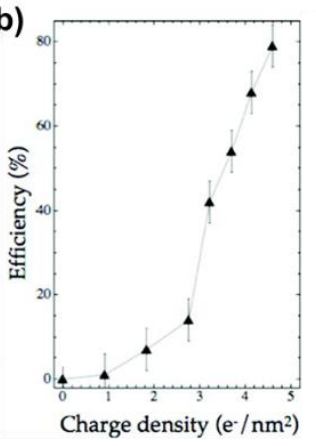

(c)

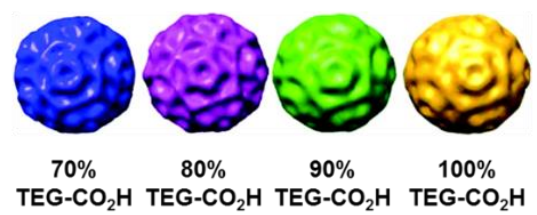

(d)

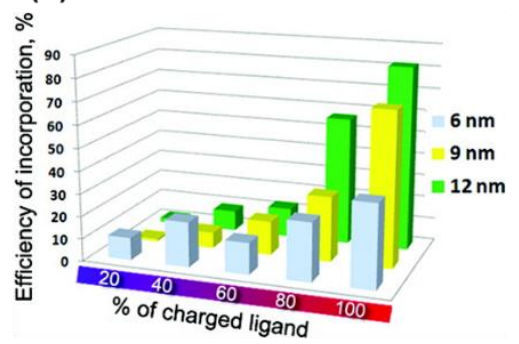

Figure 2.5. (a) TEG-OH and TEG- $\mathrm{CO}_{2} \mathrm{H}$ modified AuNPs for capsid encapsulation; (b) encapsulation efficiency of AuNPs as a function of surface charge density and (d) efficiency of incorporation as function of percentage of charged ligand and particle sizes. Reproduced with permission from Ref $78 \mathrm{a}$ Copyright @ 2010 American Chemical Society. 
Apart from single icosahedral capsid formation with templated assembly, capsid clustering with large ssRNA and rod like assembly with double stranded DNA (dsDNA) based polymers was also reported. ${ }^{82}$ This indicates a flexible organization of protein units in the directed assembly processes. The encapsulation of foreign particles can also be achieved by genetic modification of the protein units, such as the introduction of histidine tags into protein, protein assembly can then occur using the high binding of nickel-nitrilotriacetic acid (Ni-NTA) chelate. ${ }^{83}$ Our group also introduced the use of leucine zipper coiled-coil peptides interactions to encapsulate green fluorescent proteins (GFPs) into capsids with accurate loading ${ }^{84}$ which is usually difficult to achieve for non-covalent systems.

\subsection{Self-assembling of protein particles based scaffolds}

\subsubsection{One-dimensional (1D) self-assembly (wire)}

The assembly of protein particles into rod-like or wire-like structures has been reported for protein particles which have asymmetric structures, for examples, genetic and chemical modified chaperonin protein GroEL with 28 photochromic units (spiropyran and merocyanine) at two entrance parts of its cavity (GroEL SP/MC $^{85}{ }^{85}$ The addition of divalent metal ions such as $\mathrm{Mg}^{2+}$ results in the one dimensional (1D) assembly of GroELSP/MC. UV/Vis can be used to control the conversion of SP to MC and vice versa, allowing for a reversible assembly process. ${ }^{86}$ By applying the single-ring (SR) mutation of GroEL with cysteine mutations, the length of tube can be controlled and optimized for cellular uptake. ${ }^{87}$ A higher order of assembling - from 1D nanotubes into 1D bundles - can be achieved by applying an external magnetic field, when magnetic particles were encapsulated in the chaperonins. ${ }^{88} 1 \mathrm{D}$ assembly of virus particles have been found for TMV and M13. ${ }^{89}$ Both of these have an anisotropic structure with a high aspect ratio. Nanofibers can be fabricated by the head-to-tail self-assembly of TMV building blocks, and can be stabilized with the assistance of polyaniline..$^{90}$

\subsubsection{Two-dimensional (2D) self-assembly}

The two-dimensional (2D) self-assembly of protein nanoparticles has been widely studied. This has been performed at a liquid-solid interface, liquid-air interface and liquid-liquid interface. A monolayer of nanoparticles assembling on glass or silicon substrates can be 
achieved either through layer by layer-electrostatic interaction between a positively charged aminopropyltriethoxysilane (APS) modified substrate surface and negatively charged viral particles, ${ }^{91}$ or through dip-coating by controlling the deposition velocity. ${ }^{92}$ Recently, our group developed a new method to realize a reversible immobilization by using the optical responsive assembling of virus particles on supramolecular platforms. CCMV was functionalized with an azobenzene complex, and the surface of the wafer was functionalized with methyl viologen; a reversible photoresponsive assembly is achieved by applying cucurbituril (CB), through host-guest interactions among methyl viologen, azobenzene and $\mathrm{CB} .{ }^{93}$ This reversible immobilization of protein cages has applications in sustainable chemistry.

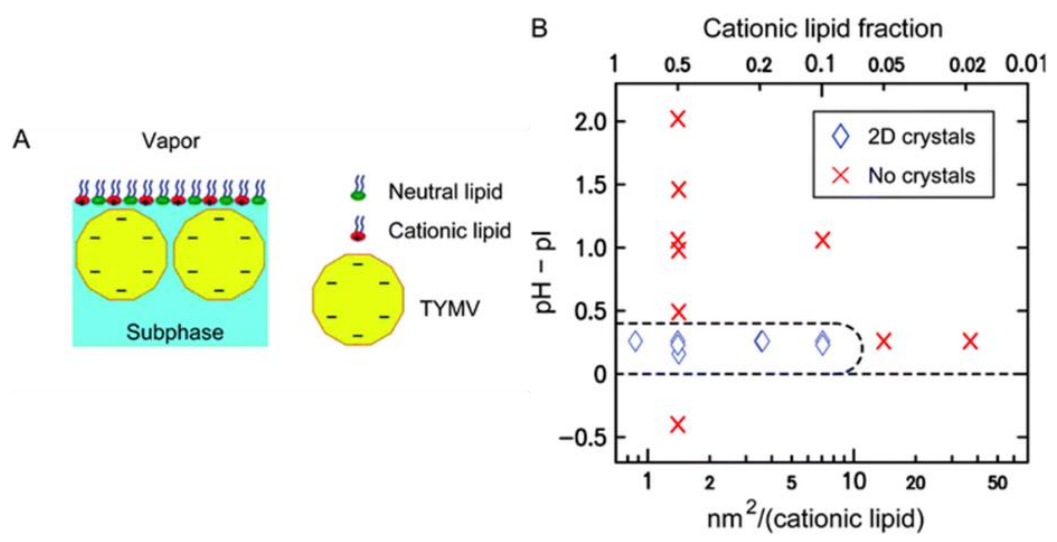

Figure 2.6. (A) Turnip yellow mosaic virus (TYMV) at cationic lipid terminated solution-air interface; (B) Observed 2D assembly behavior of TYMV as a function of the solution relative to $\mathrm{pI}=3.6$ and the area per cationic lipid. (Reprinted with permission from Ref 94, permission from the Centre National de la Recherche Scientifique (CNRS) and The Royal Society of Chemistry.).

(a)

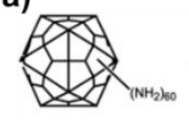

w-CPMV

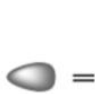

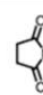

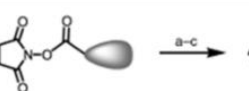

1a or 16

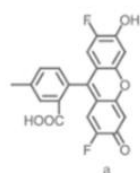

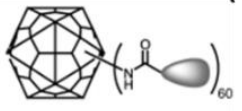

2a or $2 b$

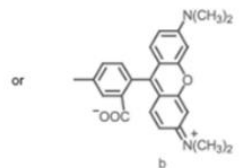

(b)

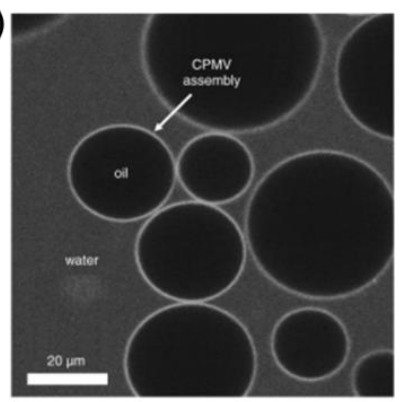

Figure 2.7. Covalent labeling of wt-CPMV with fluorescent Oregon green 488; (b) confocal fluorescence microscope image of CPMV-particle assembly at perfluorodecalin droplet in water. (Reprinted with permission from Ref 103, Copyright (C) 2005 WILEY-VCH Verlag GmbH \& Co. KGaA, Weinheim) 
A multilayered thin film of viral proteins can be created by electrostatic interaction between positively charged polymer layers and the negatively charged viral particle layers. ${ }^{94}$ A high ordered (or 2D crystalline) assembly of monolayers on a substrate can be achieved through drying mediated self-assembly. ${ }^{95} \mathrm{~A}$ method to pattern electrostatic assemblies of viruses onto a multilayer of polyelectrolytes with the assistance of solvent was introduced by Paula and co-authors, but up to 10 polyelectrolyte multilayers are required for high ordered assembly. ${ }^{96}$ Dip-coating can be used to generate long-range ordered virus based thin films; an example of this is the self-assembly of chiral colloidal M13 phage based supramolecular films, the result of which show multiple levels of hierarchical organization and a helical twist. ${ }^{97}$ The self-assembly process of viral particles at the water-air interface was also introduced. It was reported that the assembly is greatly affected by the $\mathrm{pH}$ due to the fact that changes in the net surface charge influences the interactions between the viral particles. ${ }^{98} 2 \mathrm{D}$ crystalline ordered icosahedral viruses at the water-air interface can also be obtained by assembling nanoparticles on a cationic lipid monolayer (Figure 2.6), though the formation of 2D crystals was only found in a narrow $\mathrm{pH}$ range (close to the isoelectric point of the virus NPs). ${ }^{99} \mathrm{~A}$ simple and fast method to direct protein particles into hierarchical ordering is still needed. The assembly of viral nanoparticles at the liquid-liquid interface provides a good example of this approach. ${ }^{100}$ The wild type (wt)-CPMV particles were cross-linked at wateroil interface to lock the assembly into place using the cross-linker glutaraldehyde. ${ }^{101}$ Dye labelled wt-CPMV with high fluorescence contrast at the oil-water interface was observed by confocal fluorescence microscope (Figure 2.7). A higher level of control over the crosslinking reaction can be achieved with biotin/avidin binding if CPMV is genetically modified with cysteine residues to provide orthogonal reactive sites. This method can be applied simply into either liquid-liquid 2D assembly or 3D assembly.

\subsubsection{Three-dimensional (3D) self-assembly}

For 3D crystal self-assembly, it has been demonstrated that CCMV and ferritin cages can be used to direct self-assembly of 3D binary superlattices with gold nanoparticles. ${ }^{54 a}$ Protein cages that carry negative net charges on their outer surfaces under certain conditions can be used, to build 3D superlattices through electrostatic interactions with positively charged gold nanoparticles. To this end, the particle-particle interactions must be carefully tailored to 
ensure that they are strong enough to produce assembly, but not too strong to prevent the formation of gel-like aggregates. It is quite interesting that CCMV and gold nanoparticles form an unusual (AB8) fcc superlattice, which is not isostructural with any known crystal structures. The apoferritin (apoFT) and Au NPs form two interpenetrating simple cubic structures (Figure 2.8). ${ }^{54 a}$ The same strategy was used to build a binary crystal from two oppositely charged proteins, CCMV and avidin. ${ }^{54 a}$ The use of avidin allows direct functionalization of the nanostructures through avidin-biotin technology. Crystals can be preor post-functionalized with various biotin-tagged building blocks, including fluorescent dyes, enzymes and gold nanoparticles. ${ }^{54 a}$ This multi-level self-assembly strategy paves the way for the design and preparation of complex protein assemblies, as well as protein based functional materials.
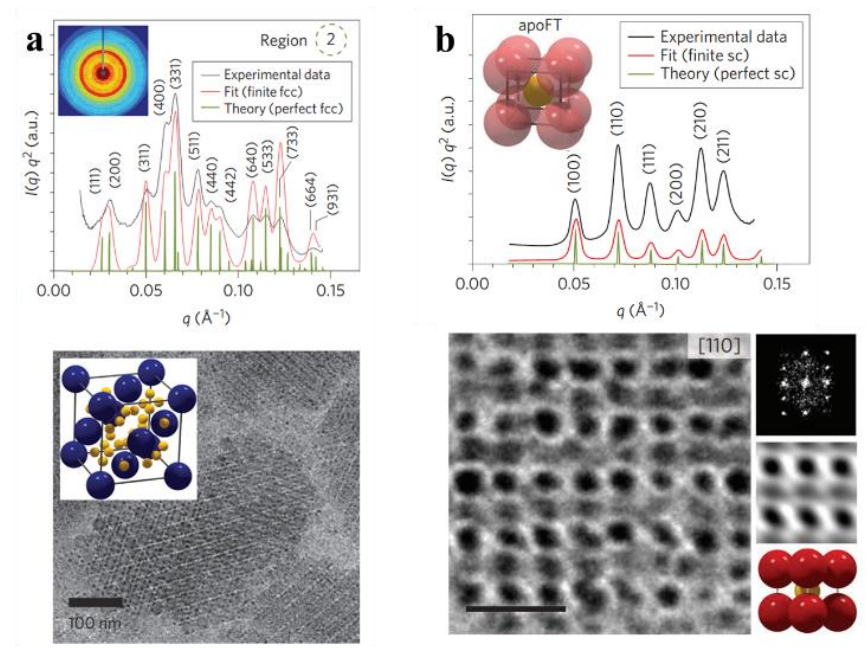

Figure 2.8. a) Top: Two-dimensional (inset) and integrated one-dimensional SAXS data for crystalline protein cage-nanoparticle superlattices indexed with $\mathrm{AB}_{8}{ }^{\mathrm{fcc}}$-type lattice. The experimental scattering pattern (black trace) matches well with the respective theoretical scattering pattern (red and green traces). Bottom: Crystalline superlattices are also observed with cryo-TEM. The particles arrange into an $\mathrm{AB}_{8}{ }^{\mathrm{fcc}}$-type lattice, where CCMV adopts an fcc structure and the voids between the CCMVs are filled with eight Au NPs. A model unit cell is shown in the inset (CCMV, blue spheres; Au NP, yellow spheres; the radii of the particles have been reduced by $50 \%$ for clarity). b) Top: SAXS data for crystalline apoFT-gold nanoparticles superlattices indexed with $\mathrm{AB}^{\mathrm{sc}}$-type lattice. apoFT and gold nanoparticles each form a separate simple cubic lattice that creates an interpenetrating structure with an apoFT particle at the centre of each Au NP cube. Bottom: cryo-TEM image of the superlattices viewed along the ${ }^{79}$ projection axis (scale bar, $25 \mathrm{~nm}$ ). The panel also contains an image Fourier transform (top), inverse Fourier transform calculated with selected Fourier components (middle) and a unit cell viewed along the ${ }^{79}$ projection axis (bottom). Reprinted with permission from Ref 54a. Copyright (C) 2012, Nature Publishing Group. 


\subsection{Applications of protein nanoparticles}

Given the enormous number of applications of virus based particles, we would like to focus on just two applications: nanoreactors and plasmonic metamaterials.

\subsubsection{Nanoreactors}

Catalysts, such as metal nanoparticles or enzymes, can be encapsulated in protein cages and used as nanoreactors. The enzyme horseradish peroxidase (HRP) encapsulated CCMV capsid was the first protein cage based nanoreactor, and this was used to investigate its behavior at single molecule level. ${ }^{102}$ The protein cage provided protection for the natural enzyme, allowing for a longer catalytic activity while the non-encapsulated enzymes, lacking the protection of the protein cage, are denatured quickly on the glass substrate. Therefore, the reaction behavior (e.g. catalytic activity) was investigated in the CCMV protein cage. However, the encapsulation approach was statistical, which means that empty capsids remain in the sample. A more controlled encapsulation approach was introduced by our group recently, namely template directed assembly of protein capsids to encapsulate the chosen enzymes. In this method, negatively charged nucleic acid tags are chemically attached to the exterior of the chosen enzymes. Two kinds of cascade reactions were introduced: in the first system, hydrogen peroxide produced by GOx is consumed by the so-called DNAzyme, a peroxidase-mimic formed in situ by a specific sequence of ssDNA in the presence of hemin, which is used for the subsequent reaction with ABTS. The second system, the cascade reaction is performed by co-encapsulated GOx and GCK (Figure 2.9). ${ }^{103}$ There is increasing interest towards the encapsulation of multiple enzymes to realize high local concentrations of enzymes and short distances between different kinds of enzymes for use in cascade reactions. This can be used in the development of catalytic materials by mimicking the complexity and high efficiency of cells or by redesigning natural containers to improve the efficiency of catalytic reactions. A recent breakthrough in the technology of nanoreactors is to use bacteriophage P22 as a nanocontainer for enzyme encapsulation. P22 is T = 7 icosahedral capsid which can be used to encapsulate and protect an active hydrogen producing and oxygen-tolerant-hydrogenase through directed self-assembly. ${ }^{104}$ After encapsulation, the proton reduction activity was observed to be nearly 100 times greater than that of free enzyme. Co-localization of photosensitizer (Eosin-Y) and a NADH/hydrogen 
catalyst facilitated the photochemical production of $\mathrm{NADH}$ from $\mathrm{NAD}^{+}$under aqueous conditions. ${ }^{105}$ With this design using biomimetic materials, an efficient photochemical production of both NADH and hydrogen can be controlled by the encapsulation of multiple kinds of enzymes.

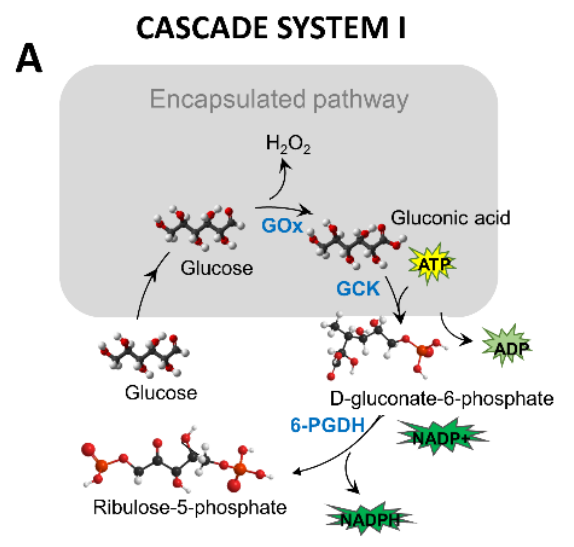

\section{B CASCADE SYSTEM II}

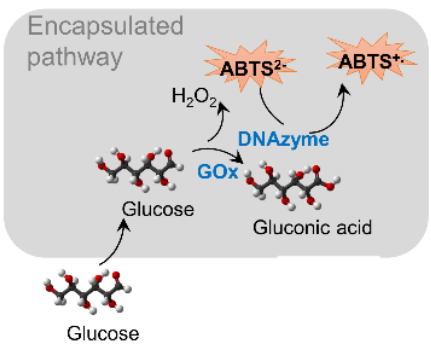

Figure 2.9. Schematic representation of the enzyme pathways (encapsulated processes shown in gray boxes). (A) Cascade reaction by GOx-DNAzyme. GOx oxidizes glucose to gluconic acid and produces $\mathrm{H} 2 \mathrm{O} 2$, which DNAzyme uses for subsequent reaction with ABTS inside CCMV capsid. (B) Cascade reaction performed by co-encapsulated GOx and GCK. The conversion of glucose to d-gluconate-6-P occurs at the interior of the CCMV capsids, whereas the conversion of d-gluconate-6-P into ribulose5-P occurs at the exterior of the CCMV capsid catalyzed by tertiary enzyme, 6-PGDH. (Reprinted with permission from Ref ${ }^{103}$, Copyright $\odot 2017$ American Chemical Society)

In addition to mimicking the complexity of cells, protein compartments can be used to control enzymatic pathways which holds great promise for synthetic biology. The selection of which foreign molecules are allowed to diffuse into the protein compartment for further reaction can be controlled by the size of pores, ${ }^{57}$ the charge effect around the pores, ${ }^{106}$ the charge effects on the exterior and the interior surface of protein shell, ${ }^{107}$ and the effect of charged cargo materials in protein cages. ${ }^{108}$ Detailed studies on size and charge selectivity, based on the pore size and charge distribution of CCMV protein shells based on nitroarene reductions are presented in Chapter 3. However, selectivity towards specific chemicals remains challenging in practical applications, due to the limited selectivity of natural materials. ${ }^{109}$ Comprehensive and complex nanoarchitectures of these protein based nanoreactors are required to achieve highly efficient, low cost and environmentally friendly systems. 


\section{Chapter 2}

\subsubsection{Plasmonic metamaterials}

Metal nanoparticles, including gold nanoparticles, have attracted great interest in the fields of nanotechnology and biomedicine. Metal nanoparticles can show unique surface plasmon resonances (SPR). SPR is highly dependent on the particle size, particle shape, interparticle distance and the surrounding environment. For example, the photoacoustic signal of gold nanorods (Au NRs) can be increased three-fold by coating it with a silica shell. ${ }^{110} \mathrm{Au}$ NRs have been widely used for photothermal therapy, since they can absorb and scatter strongly in the near-infrared (NIR) region; this range of the radiation spectrum can minimize light extinction by intrinsic chromophores in native tissue. ${ }^{111}$ However, the relatively low stability of Au NRs limits its lifetime in this application, as Au NRs transform into spherical $\mathrm{Au}$ NPs under the effect of heat and lose the optical property of absorption in the NIR region. ${ }^{12}$ To solve this problem, there has been extensive research on templated clustering (or polymerization) of metal nanoparticles into particles dimer, trimer or nanoparticle chains with controllable inter-particle distance to control the optical properties. ${ }^{113} \mathrm{~A}$ common method to control particle distance or the organization of metal nanoparticles is to use a programmable DNA (origami) scaffold. ${ }^{114,115}$ Methods to build plasmonic nanostructures using biomolecules, such as using the communication of DNA scaffolds with virus nanoparticles, were introduced. ${ }^{116}$ The Francis group introduced the use of MS2 bacteriophage to encapsulate gold nanoparticles; and dye labeled DNA strands were then attached to the exterior surface of the protein shells. The protein shell successfully separated the dye and gold nanoparticles, avoiding photobleaching and improving the quantum yields. The distance between the dye and the gold nanoparticles can be easily controlled by using different DNA strands. ${ }^{116 \mathrm{~b}}$ Another solution is to assemble both gold nanoparticles and the dye labelled virus nanoparticles on a DNA origami rectangle, the DNA origami provides a programmable scaffold to control the distance between the metal nanoparticles and fluorophores. ${ }^{116 a}$ 


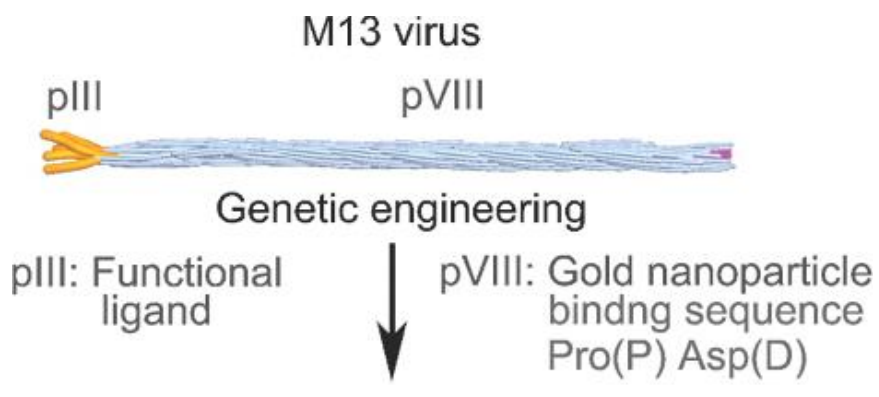

Bifunctional M13 virus

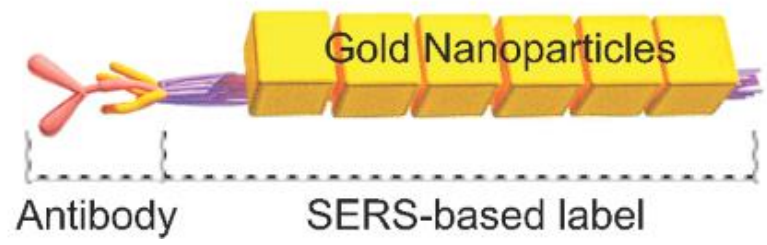

Figure 2.10. Schematic of the virus-based SERS nanoprobe. Pro (P) Asp (D) sequence was expressed on the pVIII part for attaching cetyltrimethylammonium bromide (CTAB)-coated gold nanoparticles, and the PIII part was functionalized with an antibody for capturing target analyte. PD can interact with $\mathrm{CTAB}$ via hydrophobic and electrostatic interaction. Reprinted with permission from Ref 112, Copyright () 2014 WILEY-VCH Verlag GmbH \& Co. KGaA, Weinheim.

A method for clustering Au NPs and adjusting the inter-particle distance by using genetically modified rod-like viral nanoparticles was reported as well. Nam's group introduced the use of M13 bacteriophage as a template to closely align gold nanocurved into chains along the length of the virus particles (Figure 2.10). The gold nanocubes are closely aligned along the genetically modified M13 coat proteins, intensifying the electromagnetic field generated at the junction of the nanoparticles, serving as a Surface-Enhanced Raman Scattering (SERS) nanoprobe. 3D assembly of icosahedral plasmonic nanoclusters along CPMV particles was also reported. Genetically modified protein cages are able to be covered with 6 to 12 gold nanoclusters, resulting in an increase of surface plasmon resonances in the NIR region. When the nanoclusters are fully packed (a distance of approximately $0.79 \mathrm{~nm}$ ), the near-field coupling of NPs results in a ten-fold increase in the local electromagnetic field. In addition to these designable properties, virus nanoparticles can also be produced by a variety of methods which are easy to scale up (through production in bacteria, yeast, insect cells, plants and cell-free systems). ${ }^{5}$ Therefore, the use of virus nanoparticles as selfassembling templates can provide a new strategy to realize the required quantities for material applications. 


\section{Chapter 2}

\subsection{Summary and future directions}

In summary, protein-based nanoparticles have been exploited as functional scaffolds in the development of nanotechnology and bio-nanotechnology. Natural protein nanoparticles are monodisperse, have highly symmetrical structures, can be produced using a variety of methods which are both low cost and environmentally friendly, and can be easily modified through genetic and chemical methods. The templated synthesis of inorganic nanoparticles or nanowires with high organized arrays allows them to be used in the application of electronic devices. In addition, protein cages can be utilized as an efficient nanocontainer for cargo materials such as metal nanoparticles, metal oxides and enzymes. The confined compartment protects the cargo from aggregation or denaturing while retaining their unique chemical and physical properties, such as high catalytic activity and plasmonic properties. Although the protein cage acts as a diffusion barrier which slows the reaction rate, this problem can be mitigated by encapsulating multiple enzymes or nanoparticles with cascade reactions. In chapter 3, protein cage encapsulation with gold nanoparticles for the use as nanoreactors for reduction reaction was studied, mild reaction conditions are required and need to be properly maintained for long-term use.

Higher-ordered assembly of protein nanoparticles has also been widely studied and applied in nanotechnologies. Chapters 4 and 5 study the immobilization of protein cages into glass chips and functional protein cages integrated thin films as easily handled reactors. In recent years, the design of highly controllable bio-mimicking synthetic materials has shown much promise. New methods could be developed and applied into natural materials to control the size and shape of protein nanoparticles, as well as their self-assembly properties based on light, $\mathrm{pH}$ or temperature. It is a certainty that smart materials based on protein based nanoparticles are required in the future. 


\subsection{Reference}

1. Augasta, M. G.; Kathirvalavakumar, T., Pruning algorithms of neural networks a comparative study. Central European Journal of Computer Science 2013, 3 (3), 105-115. 2. $\quad$ Eckert, M. A.; Vu, P. Q.; Zhang, K.; Kang, D.; Ali, M. M.; Xu, C.; Zhao, W., Novel Molecular and Nanosensors for In Vivo Sensing. Theranostics 2013, 3 (8), 583-594.

3. Webber, M. J.; Appel, E. A.; Meijer, E. W.; Langer, R., Supramolecular biomaterials. Nat Mater 2016, 15 (1), 13-26.

4. (a) Vriend, G.; Verduin, B. J. M.; Hemminga, M. A.; Schaafsma, T. J., Mobility involved in protein - RNA interaction in spherical plant viruses, studied by nuclear magnetic resonance spectroscopy. FEBS Letters 1982, 145 (1), 49-52; (b) Aronson, M. N.; Complainville, A.; Clérot, D.; Alcalde, H.; Katul, L.; Vetten, H. J.; Gronenborn, B.; Timchenko, T., In planta protein-protein interactions assessed using a nanovirus-based replication and expression system. The Plant Journal 2002, 31 (6), 767-775.

5. Wen, A. M.; Steinmetz, N. F., Design of virus-based nanomaterials for medicine, biotechnology, and energy. Chemical Society Reviews 2016, 45 (15), 4074-4126.

6. Culver, J. N.; Brown, A. D.; Zang, F.; Gnerlich, M.; Gerasopoulos, K.; Ghodssi, R., Plant virus directed fabrication of nanoscale materials and devices. Virology 2015, 479-480, sa200-212.

7. Liu, Z.; Qiao, J.; Niu, Z.; Wang, Q., Natural supramolecular building blocks: from virus coat proteins to viral nanoparticles. Chemical Society Reviews 2012, 41 (18), 61786194.

8. Uchida, M.; Klem, M. T.; Allen, M.; Suci, P.; Flenniken, M.; Gillitzer, E.; Varpness, Z.; Liepold, L. O.; Young, M.; Douglas, T., Biological Containers: Protein Cages as Multifunctional Nanoplatforms. Advanced Materials 2007, 19 (8), 1025-1042.

9. Tosha, T.; Behera, R. K.; Theil, E. C., Ferritin Ion Channel Disorder Inhibits $\mathrm{Fe}(\mathrm{II}) / \mathrm{O} 2$ Reactivity at Distant Sites. Inorganic Chemistry 2012, 51 (21), 11406-11411.

10. Spiess, C.; Meyer, A. S.; Reissmann, S.; Frydman, J., Mechanism of the eukaryotic chaperonin: protein folding in the chamber of secrets. Trends in cell biology 2004, 14 (11), 598-604.

11. Sutter, M.; Boehringer, D.; Gutmann, S.; Gunther, S.; Prangishvili, D.; Loessner, M. J.; Stetter, K. O.; Weber-Ban, E.; Ban, N., Structural basis of enzyme encapsulation into a bacterial nanocompartment. Nat Struct Mol Biol 2008, 15 (9), 939-947.

12. Govero, J.; Esakky, P.; Scheaffer, S. M.; Fernandez, E.; Drury, A.; Platt, D. J.; Gorman, M. J.; Richner, J. M.; Caine, E. A.; Salazar, V.; Moley, K. H.; Diamond, M. S., Zika virus infection damages the testes in mice. Nature 2016, 540 (7633), 438-442.

13. (a) Rosano, G. L.; Ceccarelli, E. A., Recombinant protein expression in Escherichia coli: advances and challenges. Frontiers in Microbiology 2014, 5, 172; (b) Phelps, J. P.; Dao, P.; Jin, H.; Rasochova, L., Expression and self-assembly of cowpea chlorotic mottle viruslike particles in Pseudomonas fluorescens. Journal of Biotechnology 2007, 128 (2), 290-296; (c) Bessa, J.; Schmitz, N.; Hinton, H. J.; Schwarz, K.; Jegerlehner, A.; Bachmann, M. F., Efficient induction of mucosal and systemic immune responses by virus-like particles administered intranasally: implications for vaccine design. European Journal of Immunology 2008, 38 (1), 114-126; (d) Pickett, G. G.; Peabody, D. S., Encapsidation of heterologous RNAs by bacteriophage MS2 coat protein. Nucleic Acids Research 1993, 21 (19), 4621 4626; (e) Hwang, D. J.; Roberts, I. M.; Wilson, T. M., Expression of tobacco mosaic virus 
coat protein and assembly of pseudovirus particles in Escherichia coli. Proceedings of the National Academy of Sciences 1994, 91 (19), 9067-9071; (f) Birnbaum, F.; Nassal, M., Hepatitis B virus nucleocapsid assembly: primary structure requirements in the core protein. Journal of Virology 1990, 64 (7), 3319-3330.

14. (a) Parent, K. N.; Khayat, R.; Tu, L. H.; Suhanovsky, M. M.; Cortines, J. R.; Teschke, C. M.; Johnson, J. E.; Baker, T. S., P22 coat protein structures reveal a novel mechanism for capsid maturation: Stability without auxiliary proteins or chemical crosslinks. Structure (London, England: 1993) 2010, 18 (3), 390-401; (b) Helgstrand, C.; Munshi, S.; Johnson, J. E.; Liljas, L., The refined structure of Nudaurelia capensis $\omega$ Virus reveals control elements for a T = 4 capsid maturation. Virology 2004, 318 (1), 192-203; (c) Pringle, F. M.; Johnson, K. N.; Goodman, C. L.; McIntosh, A. H.; Ball, L. A., Providence virus: a new member of the tetraviridae that infects cultured insect cells. Virology 2003, 306 (2), 359370; (d) Lin, T.; Chen, Z.; Usha, R.; Stauffacher, C. V.; Dai, J.-B.; Schmidt, T.; Johnson, J. E., The Refined Crystal Structure of Cowpea Mosaic Virus at $2.8 \AA$ Resolution. Virology 1999, 265 (1), 20-34; (e) Lin, T.; Cavarelli, J.; Johnson, J. E., Evidence for assemblydependent folding of protein and RNA in an icosahedral virus. Virology 2003, 314 (1), 2633; (f) Tama, F.; Brooks Iii, C. L., The Mechanism and Pathway of pH Induced Swelling in Cowpea Chlorotic Mottle Virus. Journal of Molecular Biology 2002, 318 (3), 733-747; (g) Goddard, T. D.; Huang, C. C.; Ferrin, T. E., Software Extensions to UCSF Chimera for Interactive Visualization of Large Molecular Assemblies. Structure 2005, 13 (3), 473-482; (h) Lee, L. A.; Nguyen, H. G.; Wang, Q., Altering the landscape of viruses and bionanoparticles. Organic \& Biomolecular Chemistry 2011, 9 (18), 6189-6195; (i) Madej, T.; Lanczycki, C. J.; Zhang, D.; Thiessen, P. A.; Geer, R. C.; Marchler-Bauer, A.; Bryant, S. H., MMDB and VAST+: tracking structural similarities between macromolecular complexes. Nucleic Acids Research 2014, 42 (Database issue), D297-D303.

15. Zhang, Y.; Ardejani, M. S.; Orner, B. P., Design and Applications of Protein-CageBased Nanomaterials. Chemistry - An Asian Journal 2016, 11 (20), 2814-2828.

16. Brillault, L.; Jutras, P. V.; Dashti, N.; Thuenemann, E. C.; Morgan, G.; Lomonossoff, G. P.; Landsberg, M. J.; Sainsbury, F., Engineering Recombinant Virus-like Nanoparticles from Plants for Cellular Delivery. ACS Nano 2017.

17. Boutureira, O.; Bernardes, G. J. L., Advances in Chemical Protein Modification. Chemical Reviews 2015, 115 (5), 2174-2195.

18. Hong, V.; Presolski, S. I.; Ma, C.; Finn, M. G., Analysis and Optimization of Copper-Catalyzed Azide-Alkyne Cycloaddition for Bioconjugation. Angewandte Chemie International Edition 2009, 48 (52), 9879-9883.

19. (a) Debets, M. F.; van Berkel, S. S.; Dommerholt, J.; Dirks, A. J.; Rutjes, F. P. J. T.; van Delft, F. L., Bioconjugation with Strained Alkenes and Alkynes. Accounts of Chemical Research 2011, 44 (9), 805-815; (b) Hommersom, C. A.; Matt, B.; van der Ham, A.; Cornelissen, J. J. L. M.; Katsonis, N., Versatile post-functionalization of the external shell of cowpea chlorotic mottle virus by using click chemistry. Organic \& Biomolecular Chemistry 2014, 12 (24), 4065-4069.

20. Dujardin, E.; Peet, C.; Stubbs, G.; Culver, J. N.; Mann, S., Organization of Metallic Nanoparticles Using Tobacco Mosaic Virus Templates. Nano Letters 2003, 3 (3), 413-417.

21. Douglas, T.; Strable, E.; Willits, D.; Aitouchen, A.; Libera, M.; Young, M., Protein Engineering of a Viral Cage for Constrained Nanomaterials Synthesis. Advanced Materials 2002, 14 (6), 415-418. 
22. (a) Wang, Q.; Lin, T.; Tang, L.; Johnson, J. E.; Finn, M. G., Icosahedral Virus Particles as Addressable Nanoscale Building Blocks. Angewandte Chemie International Edition 2002, 41 (3), 459-462; (b) Chhabra, R.; Moralez, J. G.; Raez, J.; Yamazaki, T.; Cho, J.-Y.; Myles, A. J.; Kovalenko, A.; Fenniri, H., One-Pot Nucleation, Growth, Morphogenesis, and Passivation of $1.4 \mathrm{~nm}$ Au Nanoparticles on Self-Assembled Rosette Nanotubes. Journal of the American Chemical Society 2010, 132 (1), 32-33.

23. (a) Balci, S.; Bittner, A. M.; Hahn, K.; Scheu, C.; Knez, M.; Kadri, A.; Wege, C.; Jeske, H.; Kern, K., Copper nanowires within the central channel of tobacco mosaic virus particles. Electrochimica Acta 2006, 51 (28), 6251-6257; (b) Kanbak-Aksu, S.; Nahid Hasan, M.; Hagen, W. R.; Hollmann, F.; Sordi, D.; Sheldon, R. A.; Arends, I. W. C. E., Ferritinsupported palladium nanoclusters: selective catalysts for aerobic oxidations in water. Chemical Communications 2012, 48 (46), 5745-5747.

24. Yang, C.; Manocchi, A. K.; Lee, B.; Yi, H., Viral-templated palladium nanocatalysts for Suzuki coupling reaction. Journal of Materials Chemistry 2011, 21 (1), 187-194.

25. Tseng, R. J.; Tsai, C.; Ma, L.; Ouyang, J.; Ozkan, C. S.; Yang, Y., Digital memory device based on tobacco mosaic virus conjugated with nanoparticles. Nat Nano 2006, 1 (1), $72-77$.

26. Yang, C.; Choi, C.-H.; Lee, C.-S.; Yi, H., A Facile Synthesis-Fabrication Strategy for Integration of Catalytically Active Viral-Palladium Nanostructures into Polymeric Hydrogel Microparticles via Replica Molding. ACS Nano 2013, 7 (6), 5032-5044.

27. Royston, E.; Ghosh, A.; Kofinas, P.; Harris, M. T.; Culver, J. N., Self-Assembly of Virus-Structured High Surface Area Nanomaterials and Their Application as Battery Electrodes. Langmuir 2008, 24 (3), 906-912.

28. Manocchi, A. K.; Seifert, S.; Lee, B.; Yi, H., On the Thermal Stability of SurfaceAssembled Viral-Metal Nanoparticle Complexes. Langmuir 2010, 26 (10), 7516-7522.

29. Yang, C.; Meldon, J. H.; Lee, B.; Yi, H., Investigation on the catalytic reduction kinetics of hexavalent chromium by viral-templated palladium nanocatalysts. Catalysis Today 2014, 233, 108-116.

30. Freer, A. S.; Guarnaccio, L.; Wafford, K.; Smith, J.; Steilberg, J.; Culver, J. N.; Harris, M. T., SAXS characterization of genetically engineered tobacco mosaic virus nanorods coated with palladium in the absence of external reducing agents. Journal of Colloid and Interface Science 2013, 392, 213-218.

31. Gerasopoulos, K.; McCarthy, M.; Banerjee, P.; Fan, X.; Culver, J. N.; Ghodssi, R., Biofabrication methods for the patterned assembly and synthesis of viral nanotemplates. Nanotechnology 2010, 21 (5), 055304.

32. Konstantinos, G.; Matthew, M.; Elizabeth, R.; James, N. C.; Reza, G., Nanostructured nickel electrodes using the Tobacco mosaic virus for microbattery applications. Journal of Micromechanics and Microengineering 2008, 18 (10), 104003.

33. Rahman, M. M.; Ölçeroğlu, E.; McCarthy, M., Scalable Nanomanufacturing of Virus-templated Coatings for Enhanced Boiling. Advanced Materials Interfaces 2014, 1 (2), 1300107-n/a.

34. Chen, X.; Guo, J.; Gerasopoulos, K.; Langrock, A.; Brown, A.; Ghodssi, R.; Culver, J. N.; Wang, C., 3D tin anodes prepared by electrodeposition on a virus scaffold. Journal of Power Sources 2012, 211, 129-132. 
35. Liu, Y.; Xu, Y.; Zhu, Y.; Culver, J. N.; Lundgren, C. A.; Xu, K.; Wang, C., TinCoated Viral Nanoforests as Sodium-Ion Battery Anodes. ACS Nano 2013, 7 (4), 3627-3634. 36. Chen, X.; Gerasopoulos, K.; Guo, J.; Brown, A.; Wang, C.; Ghodssi, R.; Culver, J. N., Virus-Enabled Silicon Anode for Lithium-Ion Batteries. ACS Nano 2010, 4 (9), 53665372.

37. Chen, X.; Gerasopoulos, K.; Guo, J.; Brown, A.; Ghodssi, R.; Culver, J. N.; Wang, C., High rate performance of virus enabled 3D n-type $\mathrm{Si}$ anodes for lithium-ion batteries. Electrochimica Acta 2011, 56 (14), 5210-5213.

38. Chen, X.; Gerasopoulos, K.; Guo, J.; Brown, A.; Wang, C.; Ghodssi, R.; Culver, J. N., A Patterned 3D Silicon Anode Fabricated by Electrodeposition on a Virus-Structured Current Collector. Advanced Functional Materials 2011, 21 (2), 380-387.

39. Liu, Y.; Zhang, W.; Zhu, Y.; Luo, Y.; Xu, Y.; Brown, A.; Culver, J. N.; Lundgren, C. A.; Xu, K.; Wang, Y.; Wang, C., Architecturing Hierarchical Function Layers on SelfAssembled Viral Templates as 3D Nano-Array Electrodes for Integrated Li-Ion Microbatteries. Nano Letters 2013, 13 (1), 293-300.

40. Chiang, C.-Y.; Epstein, J.; Brown, A.; Munday, J. N.; Culver, J. N.; Ehrman, S., Biological Templates for Antireflective Current Collectors for Photoelectrochemical Cell Applications. Nano Letters 2012, 12 (11), 6005-6011.

41. Gerasopoulos, K.; Pomerantseva, E.; McCarthy, M.; Brown, A.; Wang, C.; Culver, J.; Ghodssi, R., Hierarchical Three-Dimensional Microbattery Electrodes Combining Bottom-Up Self-Assembly and Top-Down Micromachining. ACS Nano 2012, 6 (7), 64226432.

42. Shenton, W.; Douglas, T.; Young, M.; Stubbs, G.; Mann, S., Inorganic-Organic Nanotube Composites from Template Mineralization of Tobacco Mosaic Virus. Advanced Materials 1999, 11 (3), 253-256.

43. Zhou, J. C.; Soto, C. M.; Chen, M.-S.; Bruckman, M. A.; Moore, M. H.; Barry, E.; Ratna, B. R.; Pehrsson, P. E.; Spies, B. R.; Confer, T. S., Biotemplating rod-like viruses for the synthesis of copper nanorods and nanowires. Journal of Nanobiotechnology 2012, 10, 18-18.

44. Chen, P.-Y.; Dang, X.; Klug, M. T.; Qi, J.; Dorval Courchesne, N.-M.; Burpo, F. J.; Fang, N.; Hammond, P. T.; Belcher, A. M., Versatile Three-Dimensional Virus-Based Template for Dye-Sensitized Solar Cells with Improved Electron Transport and Light Harvesting. ACS Nano 2013, 7 (8), 6563-6574.

45. Lee, Y. J.; Yi, H.; Kim, W.-J.; Kang, K.; Yun, D. S.; Strano, M. S.; Ceder, G.; Belcher, A. M., Fabricating Genetically Engineered High-Power Lithium-Ion Batteries Using Multiple Virus Genes. Science 2009, 324 (5930), 1051-1055.

46. Vera-Robles, L. I.; Escobar-Alarcón, L.; Picquart, M.; Hernández-Pozos, J. L.; Haro-Poniatowski, E., A Biological Approach for the Synthesis of Bismuth Nanoparticles: Using Thiolated M13 Phage as Scaffold. Langmuir 2016, 32 (13), 3199-3206.

47. Royston, E.; Lee, S.-Y.; Culver, J. N.; Harris, M. T., Characterization of silicacoated tobacco mosaic virus. Journal of Colloid and Interface Science 2006, 298 (2), 706712 .

48. Royston, E. S.; Brown, A. D.; Harris, M. T.; Culver, J. N., Preparation of silica stabilized Tobacco mosaic virus templates for the production of metal and layered nanoparticles. Journal of Colloid and Interface Science 2009, 332 (2), 402-407. 
49. Fowler, C. E.; Shenton, W.; Stubbs, G.; Mann, S., Tobacco Mosaic Virus Liquid Crystals as Templates for the Interior Design of Silica Mesophases and Nanoparticles. Advanced Materials 2001, 13 (16), 1266-1269.

50. Kumar, K.; Kumar Doddi, S.; Kalle Arunasree, M.; Paik, P., CPMV-induced synthesis of hollow mesoporous $\mathrm{SiO} 2$ nanocapsules with excellent performance in drug delivery. Dalton Transactions 2015, 44 (9), 4308-4317.

51. Steinmetz, N. F.; Shah, S. N.; Barclay, J. E.; Rallapalli, G.; Lomonossoff, G. P.; Evans, D. J., Virus-Templated Silica Nanoparticles. Small 2009, 5 (7), 813-816.

52. Niu, Z.; Kabisatpathy, S.; He, J.; Lee, L. A.; Rong, J.; Yang, L.; Sikha, G.; Popov, B. N.; Emrick, T. S.; Russell, T. P.; Wang, Q., Synthesis and characterization of bionanoparticle-Silica composites and mesoporous silica with large pores. Nano Research 2009, 2 (6), 474-483.

53. Wang, G.; Wang, H.-J.; Zhou, H.; Nian, Q.-G.; Song, Z.; Deng, Y.-Q.; Wang, X.; Zhu, S.-Y.; Li, X.-F.; Qin, C.-F.; Tang, R., Hydrated Silica Exterior Produced by Biomimetic Silicification Confers Viral Vaccine Heat-Resistance. ACS Nano 2015, 9 (1), 799-808.

54. (a) Aljabali, A. A. A.; Lomonossoff, G. P.; Evans, D. J., CPMV-PolyelectrolyteTemplated Gold Nanoparticles. Biomacromolecules 2011, 12 (7), 2723-2728; (b) Blum, A. S.; Soto, C. M.; Wilson, C. D.; Cole, J. D.; Kim, M.; Gnade, B.; Chatterji, A.; Ochoa, W. F.; Lin, T.; Johnson, J. E.; Ratna, B. R., Cowpea Mosaic Virus as a Scaffold for 3-D Patterning of Gold Nanoparticles. Nano Letters 2004, 4 (5), 867-870.

55. Slocik, J. M.; Naik, R. R.; Stone, M. O.; Wright, D. W., Viral templates for gold nanoparticle synthesis. Journal of Materials Chemistry 2005, 15 (7), 749-753.

56. Shin, Y.; Dohnalkova, A.; Lin, Y., Preparation of Homogeneous Gold-Silver Alloy Nanoparticles Using the Apoferritin Cavity As a Nanoreactor. The Journal of Physical Chemistry C 2010, 114 (13), 5985-5989.

57. Ueno, T.; Suzuki, M.; Goto, T.; Matsumoto, T.; Nagayama, K.; Watanabe, Y., SizeSelective Olefin Hydrogenation by a Pd Nanocluster Provided in an Apo-Ferritin Cage. Angewandte Chemie International Edition 2004, 43 (19), 2527-2530.

58. Suzumoto, Y.; Okuda, M.; Yamashita, I., Fabrication of Zinc Oxide Semiconductor Nanoparticles in the Apoferritin Cavity. Crystal Growth \& Design 2012, 12 (8), 4130-4134. 59. (a) Mann, S.; Meldrum, F. C., Controlled synthesis of inorganic materials using supramolecular assemblies. Advanced Materials 1991, 3 (6), 316-318; (b) Meldrum, F. C.; Douglas, T.; Levi, S.; Arosio, P.; Mann, S., Reconstitution of manganese oxide cores in horse spleen and recombinant ferritins. Journal of Inorganic Biochemistry 1995, 58 (1), 59-68; (c) Mackle, P.; Charnock, J. M.; Garner, C. D.; Meldrum, F. C.; Mann, S., Characterization of the manganese core of reconstituted ferritin by x-ray absorption spectroscopy. Journal of the American Chemical Society 1993, 115 (18), 8471-8472.

60. (a) Douglas, T.; Stark, V. T., Nanophase Cobalt Oxyhydroxide Mineral Synthesized within the Protein Cage of Ferritin. Inorganic Chemistry 2000, 39 (8), 1828-1830; (b) Tsukamoto, R.; Iwahori, K.; Muraoka, M.; Yamashita, I., Synthesis of Co3O4 Nanoparticles Using the Cage-Shaped Protein, Apoferritin. Bulletin of the Chemical Society of Japan 2005, 78 (11), 2075-2081.

61. Ichiro, Y.; Junko, H.; Masahiko, H., Bio-template Synthesis of Uniform CdSe Nanoparticles Using Cage-shaped Protein, Apoferritin. Chemistry Letters 2004, 33 (9), 11581159. 
62. Iwahori, K.; Yoshizawa, K.; Muraoka, M.; Yamashita, I., Fabrication of ZnSe Nanoparticles in the Apoferritin Cavity by Designing a Slow Chemical Reaction System. Inorganic Chemistry 2005, 44 (18), 6393-6400.

63. Warne, B.; Kasyutich, O. I.; Mayes, E. L.; Wiggins, J. A. L.; Wong, K. K. W., Self assembled nanoparticulate Co:Pt for data storage applications. IEEE Transactions on Magnetics 2000, 36 (5), 3009-3011.

64. $\quad$ Kramer, R. M.; Li, C.; Carter, D. C.; Stone, M. O.; Naik, R. R., Engineered Protein Cages for Nanomaterial Synthesis. Journal of the American Chemical Society 2004, 126 (41), $13282-13286$.

65. Wong, K. K. W.; Mann, S., Biomimetic synthesis of cadmium sulfide-ferritin nanocomposites. Advanced Materials 1996, 8 (11), 928-932.

66. Suzuki, M.; Abe, M.; Ueno, T.; Abe, S.; Goto, T.; Toda, Y.; Akita, T.; Yamada, Y.; Watanabe, Y., Preparation and catalytic reaction of Au/Pd bimetallic nanoparticles in Apoferritin. Chemical Communications 2009, (32), 4871-4873.

67. (a) Li, K.; Zhang, Z.-P.; Luo, M.; Yu, X.; Han, Y.; Wei, H.-P.; Cui, Z.-Q.; Zhang, X.-E., Multifunctional ferritin cage nanostructures for fluorescence and MR imaging of tumor cells. Nanoscale 2012, 4 (1), 188-193; (b) Gider, S.; Awschalom, D.; Douglas, T.; Mann, S.; Chaparala, M., Classical and quantum magnetic phenomena in natural and artificial ferritin proteins. Science 1995, 268 (5207), 77-80.

68. Shenton, W.; Mann, S.; Cölfen, H.; Bacher, A.; Fischer, M., Synthesis of Nanophase Iron Oxide in Lumazine Synthase Capsids. Angewandte Chemie International Edition 2001, 40 (2), 442-445.

69. Meldrum, F. C.; Wade, V. J.; Nimmo, D. L.; Heywood, B. R.; Mann, S., Synthesis of inorganic nanophase materials in supramolecular protein cages. Nature 1991, 349 (6311), 684-687.

70. de la Escosura, A.; Verwegen, M.; Sikkema, F. D.; Comellas-Aragones, M.; Kirilyuk, A.; Rasing, T.; Nolte, R. J. M.; Cornelissen, J. J. L. M., Viral capsids as templates for the production of monodisperse Prussian blue nanoparticles. Chemical Communications 2008, (13), 1542-1544.

71. Douglas, T.; Young, M., Host-guest encapsulation of materials by assembled virus protein cages. Nature 1998, 393 (6681), 152-155.

72. Klem, M. T.; Young, M.; Douglas, T., Biomimetic synthesis of [small beta]-TiO2 inside a viral capsid. Journal of Materials Chemistry 2008, 18 (32), 3821-3823.

73. Bedwell, G. J.; Zhou, Z.; Uchida, M.; Douglas, T.; Gupta, A.; Prevelige, P. E., Selective Biotemplated Synthesis of TiO2 Inside a Protein Cage. Biomacromolecules 2015, 16 (1), 214-218.

74. Zhou, Z.; Bedwell, G. J.; Li, R.; Bao, N.; Prevelige, P. E.; Gupta, A., P22 virus-like particles constructed $\mathrm{Au} / \mathrm{CdS}$ plasmonic photocatalytic nanostructures for enhanced photoactivity. Chemical Communications 2015, 51 (6), 1062-1065.

75. McMillan, R. A.; Howard, J.; Zaluzec, N. J.; Kagawa, H. K.; Mogul, R.; Li, Y.-F.; Paavola, C. D.; Trent, J. D., A Self-Assembling Protein Template for Constrained Synthesis and Patterning of Nanoparticle Arrays. Journal of the American Chemical Society 2005, 127 (9), 2800-2801.

76. Liu, C.; Chung, S.-H.; Jin, Q.; Sutton, A.; Yan, F.; Hoffmann, A.; Kay, B. K.; Bader, S. D.; Makowski, L.; Chen, L., Magnetic viruses via nano-capsid templates. Journal of Magnetism and Magnetic Materials 2006, 302 (1), 47-51. 
Protein Cages as Building Blocks for Hybrid Functional Materials

77. Knez, M.; Bittner, A. M.; Boes, F.; Wege, C.; Jeske, H.; Maiß, E.; Kern, K., Biotemplate Synthesis of 3-nm Nickel and Cobalt Nanowires. Nano Letters 2003, 3 (8), 1079-1082.

78. (a) Daniel, M.-C.; Tsvetkova, I. B.; Quinkert, Z. T.; Murali, A.; De, M.; Rotello, V. M.; Kao, C. C.; Dragnea, B., Role of Surface Charge Density in Nanoparticle-templated Assembly of Bromovirus Protein Cages. ACS Nano 2010, 4 (7), 3853-3860; (b) Zandi, R.; van der Schoot, P.; Reguera, D.; Kegel, W.; Reiss, H., Classical Nucleation Theory of Virus Capsids. Biophysical Journal 2006, 90 (6), 1939-1948.

79. Brasch, M.; de la Escosura, A.; Ma, Y.; Uetrecht, C.; Heck, A. J. R.; Torres, T.; Cornelissen, J. J. L. M., Encapsulation of Phthalocyanine Supramolecular Stacks into Viruslike Particles. Journal of the American Chemical Society 2011, 133 (18), 6878-6881.

80. Sun, J.; DuFort, C.; Daniel, M.-C.; Murali, A.; Chen, C.; Gopinath, K.; Stein, B.; De, M.; Rotello, V. M.; Holzenburg, A.; Kao, C. C.; Dragnea, B., Core-controlled polymorphism in virus-like particles. Proceedings of the National Academy of Sciences 2007, 104 (4), 1354-1359.

81. Hu, Y.; Zandi, R.; Anavitarte, A.; Knobler, C. M.; Gelbart, W. M., Packaging of a Polymer by a Viral Capsid: The Interplay between Polymer Length and Capsid Size. Biophysical Journal 2008, 94 (4), 1428-1436.

82. de la Escosura, A.; Janssen, P. G. A.; Schenning, A. P. H. J.; Nolte, R. J. M.; Cornelissen, J. J. L. M., Encapsulation of DNA-Templated Chromophore Assemblies within Virus Protein Nanotubes. Angewandte Chemie International Edition 2010, 49 (31), 5335 5338.

83. Shen, L.; Zhou, J.; Wang, Y.; Kang, N.; Ke, X.; Bi, S.; Ren, L., Efficient Encapsulation of Fe3O4 Nanoparticles into Genetically Engineered Hepatitis B Core VirusLike Particles Through a Specific Interaction for Potential Bioapplications. Small 2015, 11 (9-10), 1190-1196.

84. Rurup, W. F.; Verbij, F.; Koay, M. S. T.; Blum, C.; Subramaniam, V.; Cornelissen, J. J. L. M., Predicting the Loading of Virus-Like Particles with Fluorescent Proteins. Biomacromolecules 2014, 15 (2), 558-563.

85. Biswas, S.; Kinbara, K.; Oya, N.; Ishii, N.; Taguchi, H.; Aida, T., A Tubular Biocontainer: Metal Ion-Induced 1D Assembly of a Molecularly Engineered Chaperonin. Journal of the American Chemical Society 2009, 131 (22), 7556-7557.

86. Sendai, T.; Biswas, S.; Aida, T., Photoreconfigurable Supramolecular Nanotube. Journal of the American Chemical Society 2013, 135 (31), 11509-11512.

87. Sim, S.; Niwa, T.; Taguchi, H.; Aida, T., Supramolecular Nanotube of Chaperonin GroEL: Length Control for Cellular Uptake Using Single-Ring GroEL Mutant as EndCapper. Journal of the American Chemical Society 2016, 138 (35), 11152-11155.

88. Sim, S.; Miyajima, D.; Niwa, T.; Taguchi, H.; Aida, T., Tailoring Micrometer-Long High-Integrity 1D Array of Superparamagnetic Nanoparticles in a Nanotubular Protein Jacket and Its Lateral Magnetic Assembling Behavior. Journal of the American Chemical Society 2015, 137 (14), 4658-4661.

89. Hess, G. T.; Guimaraes, C. P.; Spooner, E.; Ploegh, H. L.; Belcher, A. M., Orthogonal Labeling of M13 Minor Capsid Proteins with DNA to Self-Assemble End-toEnd Multiphage Structures. ACS Synthetic Biology 2013, 2 (9), 490-496.

90. (a) Niu, Z.; Bruckman, M. A.; Li, S.; Lee, L. A.; Lee, B.; Pingali, S. V.; Thiyagarajan, P.; Wang, Q., Assembly of Tobacco Mosaic Virus into Fibrous and 
Macroscopic Bundled Arrays Mediated by Surface Aniline Polymerization. Langmuir 2007, 23 (12), 6719-6724; (b) Niu, Z.; Bruckman, M.; Kotakadi, V. S.; He, J.; Emrick, T.; Russell, T. P.; Yang, L.; Wang, Q., Study and characterization of tobacco mosaic virus head-to-tail assembly assisted by aniline polymerization. Chemical Communications 2006, (28), 30193021.

91. Suci, P. A.; Klem, M. T.; Douglas, T.; Young, M., Influence of Electrostatic Interactions on the Surface Adsorption of a Viral Protein Cage. Langmuir 2005, 21 (19), 8686-8693.

92. Yuan, Z.; Petsev, D. N.; Prevo, B. G.; Velev, O. D.; Atanassov, P., TwoDimensional Nanoparticle Arrays Derived from Ferritin Monolayers. Langmuir 2007, 23 (10), 5498-5504.

93. Weineisen, N. L.; Hommersom, C. A.; Voskuhl, J.; Sankaran, S.; Depauw, A. M. A.; Katsonis, N.; Jonkheijm, P.; Cornelissen, J. J. L. M., Photoresponsive, reversible immobilization of virus particles on supramolecular platforms. Chemical Communications 2017, 53 (11), 1896-1899.

94. (a) Suci, P. A.; Klem, M. T.; Arce, F. T.; Douglas, T.; Young, M., Assembly of Multilayer Films Incorporating a Viral Protein Cage Architecture. Langmuir 2006, 22 (21), 8891-8896; (b) Yang, L.; Liang, H.; Angelini, T. E.; Butler, J.; Coridan, R.; Tang, J. X.; Wong, G. C. L., Self-assembled virus-membrane complexes. Nat Mater 2004, 3 (9), 615619.

95. van Rijn, P.; Tutus, M.; Kathrein, C.; Mougin, N. C.; Park, H.; Hein, C.; Schürings, M. P.; Böker, A., Ultra-Thin Self-Assembled Protein-Polymer Membranes: A New Pore Forming Strategy. Advanced Functional Materials 2014, 24 (43), 6762-6770.

96. (a) Yoo, P. J.; Nam, K. T.; Belcher, A. M.; Hammond, P. T., Solvent-Assisted Patterning of Polyelectrolyte Multilayers and Selective Deposition of Virus Assemblies. Nano Letters 2008, 8 (4), 1081-1089; (b) Yoo, P. J.; Nam, K. T.; Qi, J.; Lee, S.-K.; Park, J.; Belcher, A. M.; Hammond, P. T., Spontaneous assembly of viruses on multilayered polymer surfaces. Nat Mater 2006, 5 (3), 234-240.

97. Chung, W.-J.; Oh, J.-W.; Kwak, K.; Lee, B. Y.; Meyer, J.; Wang, E.; Hexemer, A.; Lee, S.-W., Biomimetic self-templating supramolecular structures. Nature 2011, 478 (7369), 364-368.

98. Torres-Salgado, J. F.; Comas-Garcia, M.; Villagrana-Escareño, M. V.; Durán-Meza, A. L.; Ruiz-García, J.; Cadena-Nava, R. D., Physicochemical Study of Viral Nanoparticles at the Air/Water Interface. The Journal of Physical Chemistry B 2016, 120 (26), 5864-5873. 99. (a) Fukuto, M.; Nguyen, Q. L.; Vasilyev, O.; Mank, N.; Washington-Hughes, C. L.; Kuzmenko, I.; Checco, A.; Mao, Y.; Wang, Q.; Yang, L., Crystallization, structural diversity and anisotropy effects in 2D arrays of icosahedral viruses. Soft Matter 2013, 9 (40), 9633 9642; (b) Yoshimura, H.; Edwards, E.; Uchida, M.; McCoy, K.; Roychoudhury, R.; Schwarz, B.; Patterson, D.; Douglas, T., Two-Dimensional Crystallization of P22 Virus-Like Particles. The Journal of Physical Chemistry B 2016, 120 (26), 5938-5944; (c) Kewalramani, S.; Wang, S.; Lin, Y.; Nguyen, H. G.; Wang, Q.; Fukuto, M.; Yang, L., Systematic approach to electrostatically induced 2D crystallization of nanoparticles at liquid interfaces. Soft Matter 2011, 7 (3), 939-945.

100. Kaur, G.; He, J.; Xu, J.; Pingali, S.; Jutz, G.; Böker, A.; Niu, Z.; Li, T.; Rawlinson, D.; Emrick, T.; Lee, B.; Thiyagarajan, P.; Russell, T. P.; Wang, Q., Interfacial Assembly of Turnip Yellow Mosaic Virus Nanoparticles. Langmuir 2009, 25 (9), 5168-5176. 
101. Russell, J. T.; Lin, Y.; Böker, A.; Su, L.; Carl, P.; Zettl, H.; He, J.; Sill, K.; Tangirala, R.; Emrick, T.; Littrell, K.; Thiyagarajan, P.; Cookson, D.; Fery, A.; Wang, Q.; Russell, T. P., Self-Assembly and Cross-Linking of Bionanoparticles at Liquid-Liquid Interfaces. Angewandte Chemie International Edition 2005, 44 (16), 2420-2426.

102. Comellas-Aragones, M.; Engelkamp, H.; Claessen, V. I.; Sommerdijk, N. A. J. M.; Rowan, A. E.; Christianen, P. C. M.; Maan, J. C.; Verduin, B. J. M.; Cornelissen, J. J. L. M.; Nolte, R. J. M., A virus-based single-enzyme nanoreactor. Nat Nano 2007, 2 (10), 635-639. 103. Brasch, M.; Putri, R. M.; de Ruiter, M. V.; Luque, D.; Koay, M. S. T.; Castón, J. R.; Cornelissen, J. J. L. M., Assembling Enzymatic Cascade Pathways inside Virus-Based Nanocages Using Dual-Tasking Nucleic Acid Tags. Journal of the American Chemical Society 2017, 139 (4), 1512-1519.

104. Jordan, P. C.; Patterson, D. P.; Saboda, K. N.; Edwards, E. J.; Miettinen, H. M.; Basu, G.; Thielges, M. C.; Douglas, T., Self-assembling biomolecular catalysts for hydrogen production. Nat Chem 2016, 8 (2), 179-185.

105. Edwards, E.; Roychoudhury, R.; Schwarz, B.; Jordan, P.; Lisher, J.; Uchida, M.; Douglas, T., Co-localization of catalysts within a protein cage leads to efficient photochemical NADH and/or hydrogen production. Journal of Materials Chemistry B 2016, 4 (32), 5375-5384.

106. Glasgow, J. E.; Asensio, M. A.; Jakobson, C. M.; Francis, M. B.; Tullman-Ercek, D., Influence of Electrostatics on Small Molecule Flux through a Protein Nanoreactor. ACS Synthetic Biology 2015, 4 (9), 1011-1019.

107. Liu, A.; Traulsen, C. H. H.; Cornelissen, J. J. L. M., Nitroarene Reduction by a Virus Protein Cage Based Nanoreactor. ACS Catalysis 2016, 6 (5), 3084-3091.

108. (a) Loo, L.; Guenther, R. H.; Lommel, S. A.; Franzen, S., Infusion of dye molecules into Red clover necrotic mosaic virus. Chemical Communications 2008, (1), 88-90; (b) Cao, J.; Guenther, R. H.; Sit, T. L.; Lommel, S. A.; Opperman, C. H.; Willoughby, J. A., Development of Abamectin Loaded Plant Virus Nanoparticles for Efficacious Plant Parasitic Nematode Control. ACS Applied Materials \& Interfaces 2015, 7 (18), 9546-9553.

109. Oh, J.-W.; Chung, W.-J.; Heo, K.; Jin, H.-E.; Lee, B. Y.; Wang, E.; Zueger, C.; Wong, W.; Meyer, J.; Kim, C.; Lee, S.-Y.; Kim, W.-G.; Zemla, M.; Auer, M.; Hexemer, A.; Lee, S.-W., Biomimetic virus-based colourimetric sensors. Nature Communications 2014, 5 , 3043 .

110. Chen, Y.-S.; Frey, W.; Kim, S.; Kruizinga, P.; Homan, K.; Emelianov, S., SilicaCoated Gold Nanorods as Photoacoustic Signal Nanoamplifiers. Nano Letters 2011, 11 (2), 348-354.

111. Huang, X.; El-Sayed, I. H.; Qian, W.; El-Sayed, M. A., Cancer Cell Imaging and Photothermal Therapy in the Near-Infrared Region by Using Gold Nanorods. Journal of the American Chemical Society 2006, 128 (6), 2115-2120.

112. (a) Link, S.; Wang, Z. L.; El-Sayed, M. A., How Does a Gold Nanorod Melt? The Journal of Physical Chemistry B 2000, 104 (33), 7867-7870; (b) Lee, H.-E.; Lee, H. K.; Chang, H.; Ahn, H.-Y.; Erdene, N.; Lee, H.-Y.; Lee, Y.-S.; Jeong, D. H.; Chung, J.; Nam, K. T., Virus Templated Gold Nanocube Chain for SERS Nanoprobe. Small 2014, 10 (15), 3007 3011; (c) Paul, A. M.; Fan, Z.; Sinha, S. S.; Shi, Y.; Le, L.; Bai, F.; Ray, P. C., Bioconjugated Gold Nanoparticle Based SERS Probe for Ultrasensitive Identification of Mosquito-Borne Viruses Using Raman Fingerprinting. The Journal of Physical Chemistry C 2015, 119 (41), 23669-23675. 


\section{Chapter 2}

113. (a) Lin, M.; Guo, C.; Li, J.; Zhou, D.; Liu, K.; Zhang, X.; Xu, T.; Zhang, H.; Wang, L.; Yang, B., Polypyrrole-Coated Chainlike Gold Nanoparticle Architectures with the 808 $\mathrm{nm}$ Photothermal Transduction Efficiency up to 70\%. ACS Applied Materials \& Interfaces 2014, 6 (8), 5860-5868; (b) Sun, M.; Peng, D.; Hao, H.; Hu, J.; Wang, D.; Wang, K.; Liu, J.; Guo, X.; Wei, Y.; Gao, W., Thermally Triggered in Situ Assembly of Gold Nanoparticles for Cancer Multimodal Imaging and Photothermal Therapy. ACS Applied Materials \& Interfaces 2017, 9 (12), 10453-10460.

114. Edwardson, T. G. W.; Lau, K. L.; Bousmail, D.; Serpell, C. J.; Sleiman, H. F., Transfer of molecular recognition information from DNA nanostructures to gold nanoparticles. Nat Chem 2016, 8 (2), 162-170.

115. (a) Sinha, S. S.; Paul, D. K.; Kanchanapally, R.; Pramanik, A.; Chavva, S. R.; Viraka Nellore, B. P.; Jones, S. J.; Ray, P. C., Long-range two-photon scattering spectroscopy ruler for screening prostate cancer cells. Chemical Science 2015, 6 (4), 2411-2418; (b) Bidault, S.; Devilez, A.; Maillard, V.; Lermusiaux, L.; Guigner, J.-M.; Bonod, N.; Wenger, J., Picosecond Lifetimes with High Quantum Yields from Single-Photon-Emitting Colloidal Nanostructures at Room Temperature. ACS Nano 2016, 10 (4), 4806-4815; (c) Zhang, T.; Gao, N.; Li, S.; Lang, M. J.; Xu, Q.-H., Single-Particle Spectroscopic Study on Fluorescence Enhancement by Plasmon Coupled Gold Nanorod Dimers Assembled on DNA Origami. The Journal of Physical Chemistry Letters 2015, 6 (11), 2043-2049.

116. (a) Wang, D.; Capehart, S. L.; Pal, S.; Liu, M.; Zhang, L.; Schuck, P. J.; Liu, Y.; Yan, H.; Francis, M. B.; De Yoreo, J. J., Hierarchical Assembly of Plasmonic Nanostructures Using Virus Capsid Scaffolds on DNA Origami Templates. ACS Nano 2014, 8 (8), 78967904; (b) Capehart, S. L.; Coyle, M. P.; Glasgow, J. E.; Francis, M. B., Controlled Integration of Gold Nanoparticles and Organic Fluorophores Using Synthetically Modified MS2 Viral Capsids. Journal of the American Chemical Society 2013, 135 (8), 3011-3016. 
Protein Cages as Building Blocks for Hybrid Functional Materials 


\section{Chapter 3}

\section{Nitroarene Reduction by a Virus Protein Cage Based Nanoreactor}

Gold nanoparticles have recently gained attention as heterogeneous catalysts in a variety of industrially relevant processes. The catalytic activity of the particles is directly related to the available surface area, which increases with decreasing particle size. However, their stability in solution decreases along with the size, and surface modifications have to be carried out to enable efficient catalysis also for elongated reaction times. To prolong catalyst lifetime and to study the substrate selectivity, we encapsulated colloidal gold nanoparticles in cowpea chlorotic mottle virus cages and catalyzed the reduction of nitroarenes with different substituents. The reduction mechanism has been investigated carefully, revealing the reduction sequence nitro $\rightarrow$ hydroxylamine $\rightarrow$ amine to take place. The reduction rate is slowed by the introduction of the diffusion barrier imposed by the virus cage, and a nonconventional relation between electronic effects and reduction rate constants is reported that originates from the limited pore sizes and charged exterior/interior of the virus cage. Finally, a significantly increased stability of the hybrid nanoreactors and their recyclability are demonstrated.

Part of this chapter is published in: A. Liu, C.H.-H. Traulsen (co-first author), J. J. L. M. Cornelissen, ACS Catal., 2016, 6(5), 3084-3091. 


\subsection{Introduction}

Sustainable chemistry is a major topic of current research in academia as well as in industry. Conventional approaches using (over-) stoichiometric amounts of reagents are replaced by more efficient setups. ${ }^{1}$ In this context, heterogeneous catalysts such as dispersed transition metals under $\mathrm{H}_{2}$ atmosphere are applied to e.g. reduce ketones and aldehydes to alcohols. Transition metals such as palladium and platinum are used frequently whereas gold as bulk or microstructured material is considered to be inert. ${ }^{2}$ However, decreasing the size of colloidal gold particles to the nanometer regime significantly increases their catalytic activity due to an increase of the surface available for absorption/desorption processes of active species. ${ }^{3}$ Gold nanoparticle (Au NP) catalysts are especially interesting because they enable mild reaction conditions and high chemoselectivity in reduction reactions. ${ }^{4}$ Among others, the reduction of nitroarenes to the corresponding amines using Au NPs is of interest because of their toxicity and environmental concerns. ${ }^{5}$

The reduction of 4-nitrophenol (4NP) with $\mathrm{NaBH}_{4}$ as a hydride source is a model reaction to evaluate the performances of nanoparticle catalysts. ${ }^{6}$ One of the main problems using $\mathrm{Au}$ NP catalyst is the inverse relation between catalyst activity and stability of the colloid. ${ }^{7}$ In order to circumvent this issue, gold nanoparticles can be stabilized by small molecules such as $\mathrm{DMF}^{8}$ or be deposited on colloids such as polymer brushes, core shell particles or similar carriers. ${ }^{9}$ Carriers such as mesoporous silica particles, ${ }^{10}$ tea-bag-like nanoparticle assemblies, ${ }^{11}$ amphiphilic nanoreactors ${ }^{12}$ and polymeric assemblies have been reported. ${ }^{11}$ Furthermore, gold nanotube membranes have been developed and successfully applied for the reduction of nitrophenol. ${ }^{13}$

Besides synthetic carrier systems, natural assemblies such as protein cages as confined nanoreactors have promising features and recently gained attention in materials science. ${ }^{14}$ The main improvement compared to artificial carriers is their uniformity with respect to size and shape as well as the control over catalytic and substrate selectivity. ${ }^{15}$ In this context the application of nanoreactors for catalysis has been investigated by Douglas and coworkers taking advantage of encapsulated NADH oxidase for the production of hydrogen peroxide ${ }^{16}$ and encapsulated $\mathrm{TiO}_{2}$ particles for methylene blue decomposition. ${ }^{17}$ They demonstrated that enzymes encapsulated in the P22 cavity have a high efficiency of hydrogen production by 
taking advantage of the confined environment of viral cages. ${ }^{18}$ Horse spleen apoferritin has been used by Shin et al. as a template for the synthesis of gold-silver alloys by diffusion based method and used as a catalyst for nitro-phenol reduction. ${ }^{19}$ However, the size of ferritin cages does not expand beyond a diameter of $12 \mathrm{~nm}$ and the pore sizes is comparably small as well. ${ }^{20}$ Thus, the particle sizes selection as well as possible size of substrates is limited as it has been investigated by Ueno et al. ${ }^{21}$ For further reading on the application of metal catalysts we refer to a review by $\mathrm{Hu}$ et al. and references herein. ${ }^{22}$

Protein cages such as the cowpea chlorotic mottle virus (CCMV) form monodisperse spheres in aqueous solutions. ${ }^{23}$ The RNA cargo of CCMV can be removed by particle disassembly. Reassembly around a negatively charged templated provides nanocarriers which can be used for e.g. drug delivery. ${ }^{24}$ Decent knowledge about the properties, possible modifications and applications of the CCMV protein cage have been acquired lately by us and others. ${ }^{24-25}$ In contrast to other available protein cages such as ferritin, CCMV can be assembled around a variety of templates with different sizes forming highly monodisperse shapes enabling the investigation of a variety of heterogeneous catalysts. ${ }^{26}$ The stimuli responsive reversible swelling of CCMV can be used to increase the pore size significantly. ${ }^{27}$ Therefore, a broader range of catalysts can be encapsulated and numerous substrates can be investigated systematically.

In the present study we are aiming at the combination of the catalytic activity of Au NPs and the high biocompatibility and homogeneity of CCMV virus cages. Therefore, we encapsulated commercially available Au NPs into protein cages and catalyzed the reduction of differently substituted nitroarenes. The influence of the virus cage on the reduction is investigated with respect to charge and size selectivity, yield and stability.

\subsection{Results and discussion}

\subsubsection{Nanoreactor preparation}

Wild-type CCMV is obtained from infected vigna unguiculata plants (cowpea) and stored in virus buffer solution at $4{ }^{\circ} \mathrm{C}$ according to a well-established protocol. ${ }^{25 \mathrm{~d},}{ }^{28}$ Disassembly and removal of the single stranded RNA is carried out by dialysis against RNA buffer solution at $\mathrm{pH} 7.5 .^{23}$ Encapsulation of Au NPs is carried out by injection of aqueous tannic 
acid-stabilized Au NPs into a solution of the disassembled coat protein subunits (Figure $3.1) .^{25 a}$

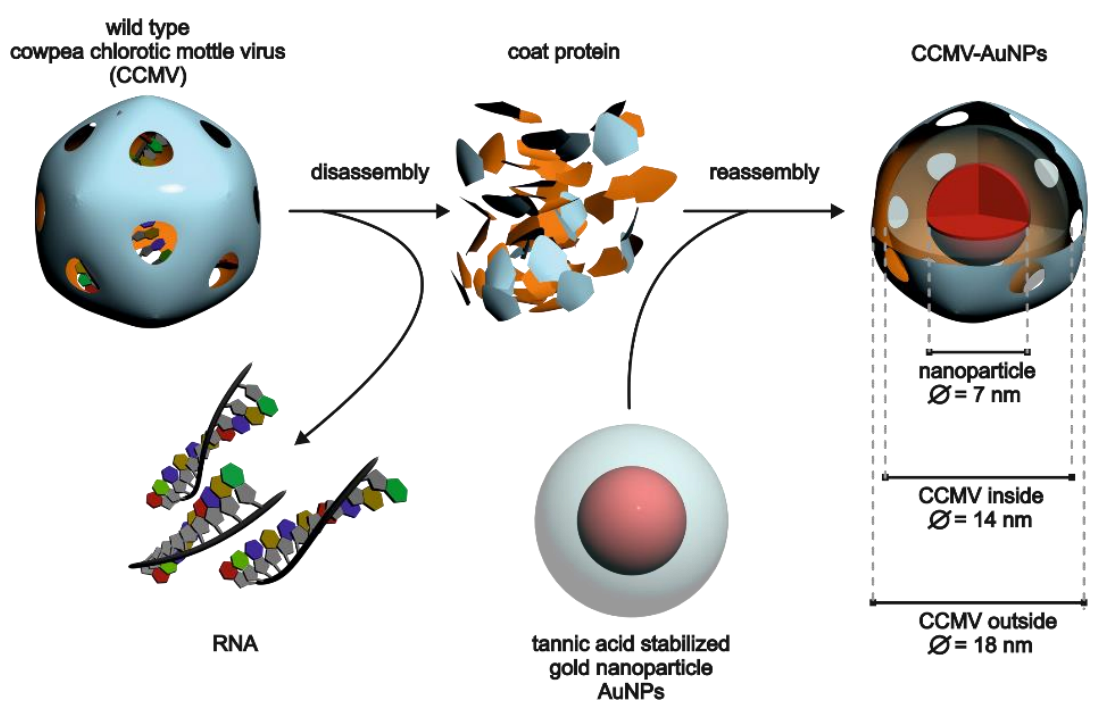

Figure 3.1. Preparation of gold nanoparticle-loaded $\mathrm{T}=1$ cowpea chlorotic mottle virus cage.

The commercially available anionic gold nanoparticles have a hydrodynamic diameter of $\mathrm{d}=7 \mathrm{~nm}$ and template the formation of protein cages, likely of icosahedral nature. ${ }^{29}$ Transmission electron spectroscopy (TEM) revealed a very regular shape and size of the isolated wild-type CCMV cages even after staining with uranyl acetate. The cages exhibit a mean diameter of $\mathrm{D}=26 \pm 2 \mathrm{~nm}$ according to the statistical particle shape analysis (Figure 3.2A). Due to drying and staining processes this value is slightly smaller than the $\mathrm{D}=28.6$ $\mathrm{nm}$ determined by Johnson and coworkers using $\mathrm{x}$-ray diffraction. ${ }^{30}$ 

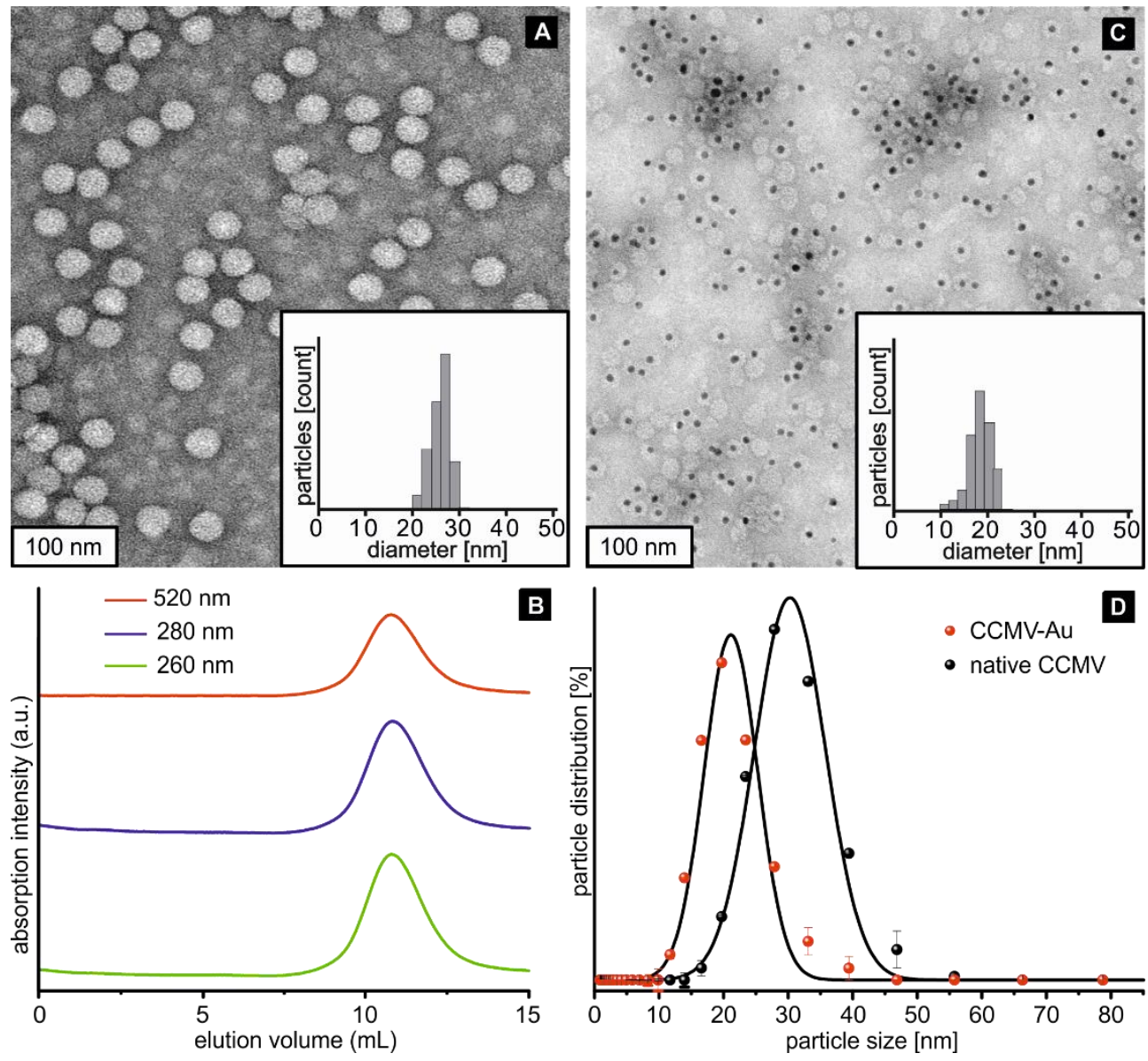

Figure 3.2. Analytical data of the native cowpea chlorotic mottle virus (CCMV) and the corresponding protein cage loaded with gold-nanoparticles (CCMV-Au). A: Transmission electron microscopy (TEM) image of CCMV (inset: statistical analysis), B: UV-Vis absorption intensities of the main CCMV-Au fraction obtained by fast protein liquid chromatography (FPLC), C: TEM image of CCMV-Au (inset: statistical analysis), D: dynamic light scattering (DLS) data of CCMV (black dots) and CCMV-Au (red dots). Curves in D have been obtained by Gaussian non-linear fit of the data.

Encapsulation of tannic acid stabilized gold nanoparticles yields hybrid nanoparticles (CCMV-Au) which are utilized as nanoreactors for the reduction of nitroarenes. Particle purification by fast liquid protein chromatography (FPLC) provides monodisperse virus cages which elute at $\mathrm{V}=11 \mathrm{~mL}$. This fraction exhibit absorption bands at $\lambda=520 \mathrm{~nm}$ resulting from the plasmon resonance of the encapsulated gold particles and with bands at $\lambda$ $=260 \mathrm{~nm}$ and $\lambda=280 \mathrm{~nm}$ which are assigned to the virus cages in accordance to one of our 
previous reports (Figure 3.2B). ${ }^{25 \mathrm{c}, 25 \mathrm{e}}$ Additional absorption at $\lambda=280 \mathrm{~nm}$ was found for $\mathrm{Au}$ NPs after encapsulating in coat protein (Figure 3.8). The reassembled Au NP containing cages yield smaller $\mathrm{T}=1$ particles, as determined using TEM. This is in accordance with results obtained by Bancroft and Dragnea and point to an assembly of 12 subunits each fivefolded and positioned on the vertices of an icosahedron. ${ }^{31}$ The $\mathrm{T}=1$ cage in total consists of 60 coat identical protein subunits. ${ }^{29,31}$ Statistical analysis reveals a diameter of the hard-coresoft-shell particles of $\mathrm{D}=18 \pm 2 \mathrm{~nm}$ (Figure 3.2C).

The encapsulated gold-nanoparticles are clearly visible by areas of higher contrast inside the light particle cages and exhibit a measured diameter of $\mathrm{D}=6.0 \pm 1 \mathrm{~nm}$. The loading efficiency is $55 \%$ (123 out of the 222 detected virus cages are loaded with Au NP cargo). The origin of the limited loading efficiencies presumably originates from free tannic acid molecules in solution templating the protein cage formation as well. Nevertheless, most nanoparticles can be encapsulated (encapsulation efficiency up to 97\%). The tannic acid loaded protein cages elute at the same volume with the gold encapsulated nanoparticles, thus separating is not possible by size exclusion chromatography. The size of the virus cages is analyzed using dynamic light scattering (Figure 3.2D). The resulting hydrodynamic radius of the native CCMV is $\mathrm{D}=30 \pm 1 \mathrm{~nm}$, whereas the nanoparticle loaded protein cage (CCMV$\mathrm{Au}$ ) exhibits a diameter of $\mathrm{D}=21 \pm 1 \mathrm{~nm}$. The size differences compared to TEM results are assigned to solvent effects, the solvent shell contribute to the particles' velocity in solution. ${ }^{32}$ Due to the slightly anionic outer shell of the virus-cage this effect is rather large, however, similar values have been obtained for $\mathrm{T}=1$ particles which supports the formation of CCMV$\mathrm{Au}$ nanoreactors. ${ }^{25 \mathrm{~b}}$ The analytical data points to successful encapsulation of gold nanoparticles in CCMV based protein cages that show superior stability in aqueous solution (see below).

\subsubsection{Mechanistic investigation of the reduction}

The reduction of meta- substituted nitroarenes is carried out under ambient conditions in a quartz-glass cuvette. In order to evaluate the influence of the virus shell on nitroarenes with different charges and electronic structures we chose 3-nitrobenzenesulfonate (NBS), 1methyl-3-nitrobenzene (NTT) and N,N,N-trimethyl-1-(3-nitrophenyl)methanaminium (NTA) as substrates introducing a negatively-charged substituent, a neutral species and a 


\section{Chapter 3}

positively charged species, respectively. Substitution in the meta position has been chosen in order to minimize electronic, especially mesomeric, effects which would further complicate the mechanistic analysis. We expect to see an influence of the charged substituents on the reduction reaction. The exterior of the protein cage is slightly negatively charged with a charge density of $<0.1 \mathrm{e} / \mathrm{nm}^{2}$, while the inner-surface is highly positively charged with a charge density of $>0.8 \mathrm{e} / \mathrm{nm}^{2} .{ }^{33}$ This might induce a diffusion barrier and thus a charge selectivity. Furthermore, CCMV exhibits pores with a limited diameter, which is expected to have a retarding effect on the rates of reduction. The reductions are carried out by adding the corresponding nitroarene to a solution of either gold nanoparticles or CCMV-Au nanoreactors before injecting sodium borohydride in the reaction-container. The progression of the reactions was monitored by UV-Vis-spectroscopy and mass spectrometry. Reaction yields are determined by HPLC.

The reduction of nitroarenes can be catalyzed by e.g. a dispersed transition metal, a colloidal nanoparticles, a metal-ion complexes or a hybrid assembly and starts with the addition of the hydride (source e.g. $\mathrm{NaBH}_{4}$ ) to the catalyst surface. ${ }^{34}$ According to the Langmuir-Hinshelwood model the nitro compound is absorbed on the catalysts surface as well as the reactive hydride. ${ }^{35}$ Detailed investigations have been carried out by Ballauf and coworkers, using metallic nanoparticle/polymer brush assemblies for the reduction of nitrophenol monitoring the reaction kinetics by UV-Vis spectroscopy. ${ }^{10}$ Three constants influence the reaction rates: I) the surface reactivity of the bound components, II) the adsorption constant of the hydride, and III) the adsorption constant of the nitrophenol. ${ }^{9 \mathrm{a}}$ The adsorption processes lead to an induction period without significant conversion before a quasi-stationary state is reached in which the slowest process is dominating the overall reaction rate constant. For very detailed investigations on the catalytic nitro reduction by nanoparticles we refer to studies carried out by Yoshimura et al., Pal et al. and Peng and coworkers. ${ }^{36}$ The focus of the mechanistic investigations of the present study is on the molecular conversion processes and the influence of the protein cage shell on the reaction rate constants. 
A<smiles>[R]c1cccc([N+](=O)[O-])c1</smiles>

I. substrate

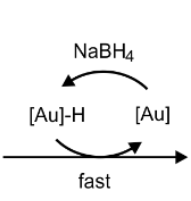

${ }_{\mathrm{HO}}^{\mathrm{N}} \mathrm{H}_{\mathrm{H}}$

II. intermediate

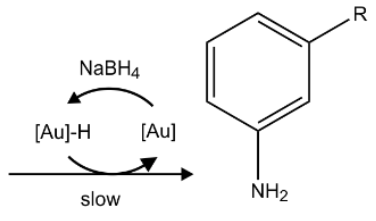

III. product
NBS: $\mathrm{R}=\mathrm{SO}_{3}$

NTT: $\mathrm{R}=\mathrm{CH}_{3}$

NTA: $\mathrm{R}=\mathrm{N}\left(\mathrm{CH}_{3}\right)_{3}^{+}$

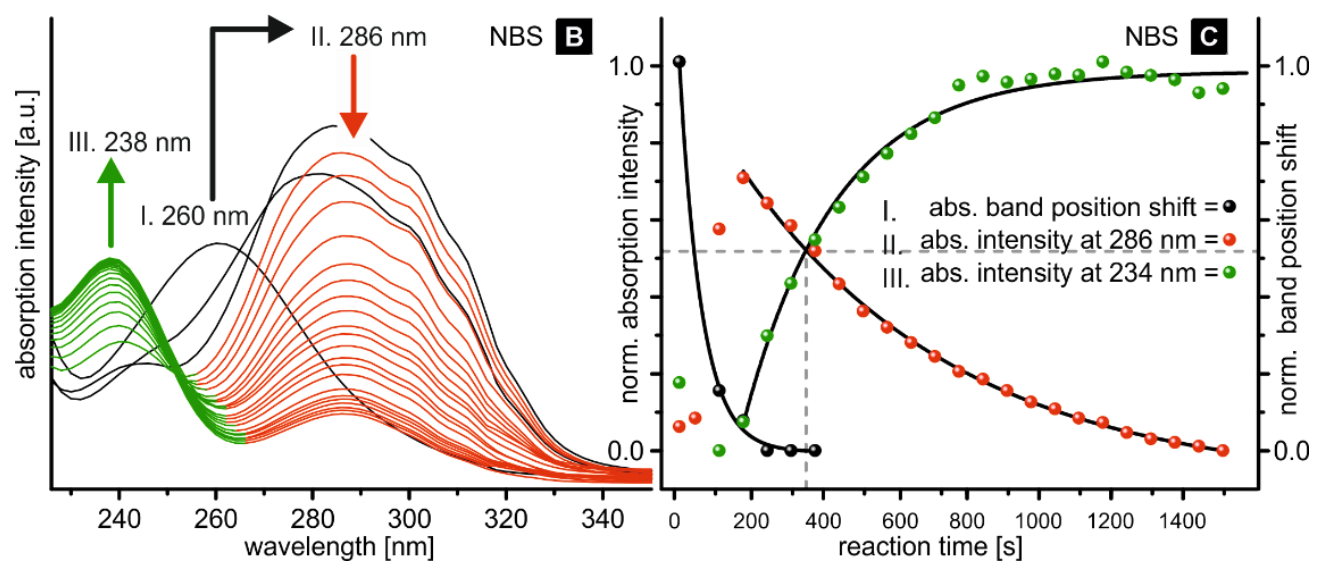

Figure 3.3. Reduction of meta-substituted nitroarenes with gold nanoparticle-loaded $T=1$ cowpea chlorotic mottle protein cage (CCMV-Au) nanoreators in the presence of sodium borohydride. A: Reaction scheme, B: UV-Vis spectra of the reduction of 3-nitrobenzenesulfonate (NBS) to 3aminobenzenesulfonate with sodium borohydride catalyzed by CCMV-Au; C: plotted normalized absorption intensity (I) (intermediate and product) and absorption maximum shift (reactant). The $\mathrm{I}=100 \%$ value of the intermediate is determined by non-linear curve fitting (Figure 3.9).

The progression of the reduction of nitroarenes catalyzed by titanium/gold nanoparticle assemblies has lately been investigated by Lykakis and coworkers. ${ }^{37}$ They revealed hydroxylamines to be intermediately formed during the reduction. Accordingly, we propose a three steps reaction mechanism starting with the reduction of the nitro-groups to the corresponding hydroxylamine. According to Lykakis, this step is slow compared to the subsequent reduction of the hydroxylamine to the final aminoarene (Figure 3.3A). The CCMV-Au catalyzed reduction of 3-nitrobenzenesulfonate (NBS) to 3-aminobenzenesulfonate is monitored by UV-Vis spectroscopy which provides mechanistic information in particular on the reduction sequence I $\rightarrow$ II $\rightarrow$ III. I) The production of the intermediate hydroxylamine is represented by a shift of the main absorption at $\lambda=260 \mathrm{~nm}$ to $\lambda=286 \mathrm{~nm}$ (from black to red band in Figure 3.3B), II) the consumption of this intermediate during amine formation by the decrease of the $\lambda=286 \mathrm{~nm}$ absorption band (decreasing signal in red in Figure 3.3B) and III) the 
formation of the aminoarene by the appearance and increase of the band at $\lambda=238 \mathrm{~nm}$ (green signal in Figure 3.3B). Plots of the normalized absorption intensities at $\lambda=260 \mathrm{~nm}$ and $\lambda=$ $286 \mathrm{~nm}$ and the shift of the absorption maximum lead to a reaction profile in agreement with a consecutive reaction (Figure 3.3C). The initial consumption of the starting material is fast (black dots in Figure 3.3C) whereas the consumption of the intermediately formed species is comparably slow (red dots in Figure 3.3C). Thus, the second reaction is slow which can also be monitored by the increase of the product absorption band (green dots in Figure 3.3C) and consequently is the rate determining step in the sequence. The half life time of the intermediate is reached at $\mathbf{t}_{1 / 2}=350 \mathrm{~s}$ (dotted grey line).

To provide evidence for the presence of hydroxylamine, we investigated the reaction mixture of the NTA reduction after the addition of the hydride (Figure 3.10). A solution of CCMV-Au and NTA is prepared and after injecting the $\mathrm{NaBH}_{4}$ solution the reaction mixture is transferred into a Hamiltonian syringe $(250 \mu \mathrm{l})$ and injected with a flow rate of $10 \mu \mathrm{L} / \mathrm{min}$ into the ESI mass spectrometer providing a stable spray. Ions are detected in positive mode of the ToF analyzer. Each spectrum has been produced out of ten scans (1 s each). The starting material provides a single species at $\mathrm{m} / \mathrm{z}=195.1$ corresponding to the $[\mathrm{M}]^{+}$molecular ion of NTA. The expected intermediate 1-(3-(hydroxyamino)phenyl)-N,N,Ntrimethylmethanaminium was identified by an ion peak at $\mathrm{m} / \mathrm{z}=181.1$ followed by the main product 1-(3-aminophenyl)-N,N,N-trimethylmethanaminium detected at $\mathrm{m} / \mathrm{z}=165.1$. After $21 \mathrm{~min}$ the MS spectrum reveals a domination of the product ion. Please note that the ratio between product/intermediate/reagent does not necessarily correspond to the molar ratio in the reaction solution due to differences in ion formation.

\subsubsection{Determination of the reduction rate constants}

The formation of the reactive $[\mathrm{Au}]-\mathrm{H}$ species is considered to be very fast and remain constant during the reaction due the large excess of $\mathrm{BH}_{4}^{-}$in the solution. According to the Langmuir-Hinshelwood model, the adsorption/desorption of the substrate and product on the catalysts surface significantly contribute to the reaction rate. The diffusion barrier introduced by the encapsulation of the gold nanoparticles inside the protein cage will change the overall rate constant of the differently charged nitroarenes. For the determination of these overall rate-constants the starting period, without significant spectral changes is not taken into 
account and the analysis is carried out in the quasi-steady state regime in which the concentration of the substrate is significantly higher than the catalytic centers and does not change over time.
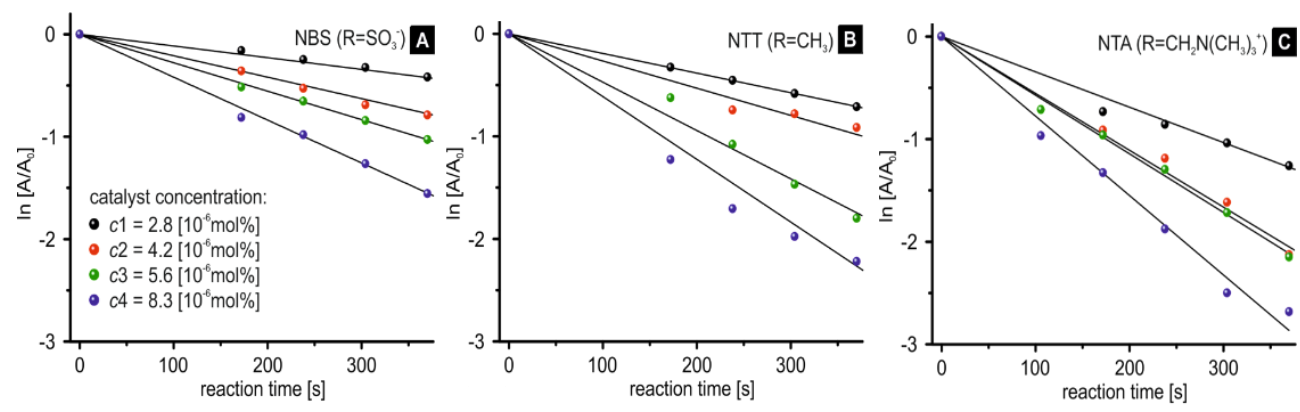

Figure 3.4. Plotted absorption maxima obtained during the reduction of A: 3-nitrobenzenesulfonate (NBS), B: 1-methyl-3-nitrobenzene (NTT) C: N,N,N-trimethyl-1-(3-nitrophenyl) methanaminium (NTA), with gold nanoparticle-loaded $\mathrm{T}=1$ cowpea chlorotic mottle virus cage nanoreactors.

An indirect measure of the reactant concentration is the absorption band at $\lambda=286 \mathrm{~nm}$, which decreases upon conversion to the amine product. To properly analyze the reductions we do need the initial absorption intensity of the intermediate $\mathrm{A}_{0}$. The direct measurement of this value is not possible due to the initial induction period of the first reaction. Thus, the absorption intensity of the intermediate at $\mathrm{t}=0$ is determined by fitting an exponential decay to the absorption intensity at $\lambda=286 \mathrm{~nm}$ and by locating of the corresponding intercept. $\mathrm{A}_{0}$ is used for the determination of the rate constants by plotting the logarithm of the obtained data versus the reaction time (Figure 3.4).

The reduction of NBS (Figure 3.4A), NTT (Figure 3.4B) and NTA (Figure 3.4C) is investigated. The concentration of the reactants was kept constant whereas the amount of catalyst is systematically changed. The reactions were carried out using catalyst concentrations of $\mathrm{c} \cdot 10^{-6} \mathrm{~mol} \%$. The fit of each concentration series is negative due to the decrease of the absorption intensity and their absolute slopes increase with increasing catalyst concentration. According to the differential (1) and the corresponding integrated (2) rate laws the slope of these kinetic plots are equal to the rate constants of the reactions.

$$
\begin{aligned}
& -\frac{d[A]}{d t}=k[A] \\
& {[A]=[A]_{0} e^{-k t}}
\end{aligned}
$$


The determined rate fits with a first order reaction, of which the rate constants are summarized in Table.

Table 1. Reduction rate constants of the catalytic reduction of differently substituted nitroarenes.

\begin{tabular}{|c|c|c|c|}
\hline & $\mathrm{NBS}\left[\mathrm{s}^{-1}\right]$ & $\mathrm{NTT}\left[\mathrm{s}^{-1}\right]$ & NTA $\left[\mathrm{s}^{-1}\right]$ \\
\hline $\mathrm{c} 1$ & $1.14 \cdot 10^{-3} \pm 4.39 \cdot 10^{-5}$ & $1.93 \cdot 10^{-3} \pm 2.01 \cdot 10^{-5}$ & $3.45 \cdot 10^{-3} \pm 4.86 \cdot 10^{-5}$ \\
\hline $\mathrm{c} 2$ & $2.09 \cdot 10^{-3} \pm 5.57 \cdot 10^{-5}$ & $2.65 \cdot 10^{-3} \pm 9.75 \cdot 10^{-5}$ & $5.54 \cdot 10^{-3} \pm 1.16 \cdot 10^{-4}$ \\
\hline c3 & $2.78 \cdot 10^{-3} \pm 2.46 \cdot 10^{-5}$ & $4.72 \cdot 10^{-3} \pm 1.29 \cdot 10^{-4}$ & $5.72 \cdot 10^{-3} \pm 1.03 \cdot 10^{-4}$ \\
\hline $\mathrm{c} 4$ & $4.19 \cdot 10^{-3} \pm 6.0910^{-5}$ & $6.12 \cdot 10^{-3} \pm 2.57 \cdot 10^{-4}$ & $7.75 \cdot 10^{-3} \pm 2.17 \cdot 10^{-4}$ \\
\hline
\end{tabular}

In line with pseudo first order kinetics in the intermediate hydroxylammonium a linear relation between the obtained rate constants and the initial catalyst concentration was found (Figure 3.5A).

For the interpretation of the influence of the virus protein cage on the reduction, four main effects have to be taken into account. I) The electronic effects of the substituents on the aromatic core, II) the diffusion barrier introduced by the negatively charged tannic acid layer, III) the diffusion barrier introduced by the negatively (outside)/positively (inside) charged virus cage, and IV) the influence of the diffusion barrier introduced by the pores of the protein cage.

I) Electronic effects of the substituents on the aromatic core. Usually, substituents with electron withdrawing substituents increase the reduction rates of nitroarenes with hydrides. The strongly electron withdrawing nitrosubstituent is converted to an electron donating hydroxylamine and finally amine group. Consequently, the reduction should be faster for the $\mathrm{R}=\mathrm{SO}_{3}{ }^{-}$and slower for $\mathrm{R}=\mathrm{CH}_{3}$, corresponding to NBS and NTT, respectively. Due to the benzylic position of the trimethylamine substituent the reduction of NTA is expected to be the fastest with $\mathrm{R}=\mathrm{CH}_{2} \mathrm{~N}^{+}\left(\mathrm{CH}_{3}\right)_{3}$. The reduction rates are expected to follow a sequence of $k_{\mathrm{NTA}}>k_{\mathrm{NBS}}>k_{\mathrm{NTT}}$. Surprisingly, already for the reduction carried out using bare tannic acid stabilized gold nanoparticles (Au NPs) the sequence is $k_{\mathrm{NTA}}>k_{\mathrm{NTT}}>k_{\mathrm{NBS}}$ (Figure 3.11). This behavior can only be explained by taking into account the influence of the negatively charged layer surrounding of the gold nanoparticles.

II) Influence of the negatively charged Au NP diffusion barrier. The layer stabilizing the colloidal gold particles is composed of tannic acid. Besides the steric stabilization of the 
nanoparticles, the phenol groups are partially deprotonated increasing the water solubility. This charged shell is acting as a barrier for the diffusion of the negatively charged NBS and is reducing the reduction rate significantly. The methyl substituent of NTT is not charged and therefore less influenced by this layer. NTA is positively charged, which leads to an accelerated reduction of this substrate. To confirm the inversion in reaction rate trends Hammett plot of the reduction using bare gold nanoparticles (Figure 3.12, values obtained from Hansch, Leo and Taft ${ }^{38}$ was made, which does not yield a positive slope as is commonly observed for the reduction of nitroarenes using hydrides. ${ }^{37}$

III) Influence of the diffusion barrier introduced by the negatively (outside)/positively (inside) charged protein cage. Only negatively charged cargos can be encapsulated in CCMV due to the positively charged arginine rich motif of the coat protein (CP). The charge match between the cargo and the CPs is important for the capsid formation as well as the electrostatic interactions. ${ }^{26}$ In order to evaluate the effect of the nanoparticle encapsulation on the reduction rate, we subtracted the obtained rate constants of the CCMV$\mathrm{Au}$ catalyzed reduction by the Au NP-catalyzed reduction according to Figure 3.5A. All reduction rates are reduced by the introduction of the virus protein cage as it can be seen by negative values (grey bars). The effect can be traced down to the influence of the protein cage because all other reaction conditions were kept constant. We assign this effect to a combination of steric hindrance and charge repulsion because it is most prominent for the positively charged substrate NTA. The substrates must pass the positively charged interior of the coat protein to access the gold catalyst. The related electrostatic repulsion explains the differences in reduction rates. Combined with the slight enhancement of NBS (negatively charge) reduction, it seems that these charges play an important role.

The same trend is observed for the yield of the reduction as determined by HPLC (Figure $3.5 \mathrm{~B}$, red bar), which in case of the reduction of NTA is reduced from $99 \%$ to $42 \%(-57 \%)$ for bare Au NP and CCMV-Au catalysis, respectively. The yield of NBS and NTT reduction is increased by $13 \%$ and $3 \%$ respectively. This is attributed to the increased stability of the gold catalyst upon encapsulation which is only important for prolonged reaction time. 

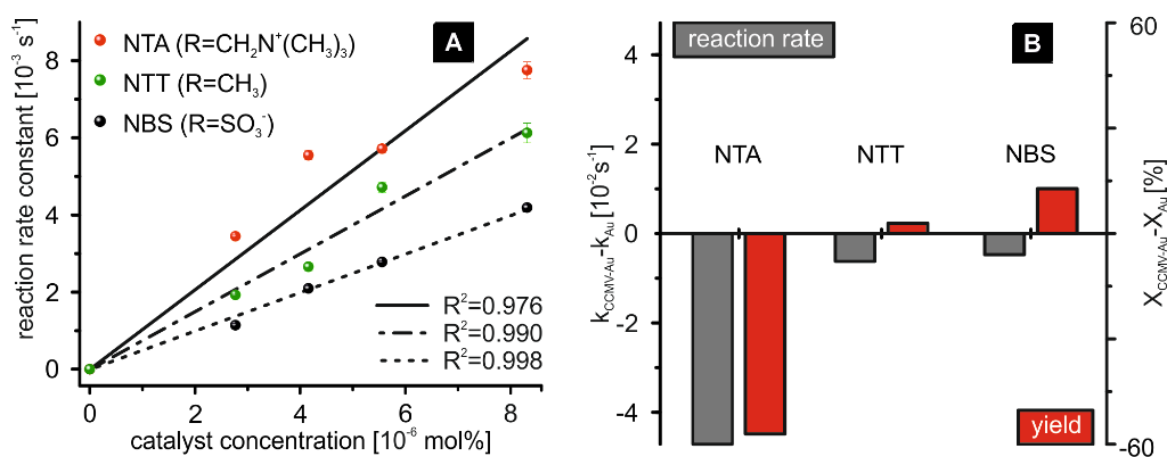

Figure 3.5. Kinetic investigation of the catalytic reduction of 3-nitrobenzenesulfonate (NBS), 1methyl-3-nitrobenzene (NTT), N,N,N-trimethyl-1-(3-nitrophenyl) methanaminium (NTA) with CCMV-Au nanoparticle-loaded $\mathrm{T}=1$ cowpea chlorotic mottle virus cage nanoreactors. A: reaction rate constants plotted versus the catalyst concentration and $\mathrm{B}$ : reduction rate constants of the CCMV-Au subtracted by the $k$ values of reductions using tannic acid stabilized gold nanoparticles ( $\mathrm{k}_{C C M V}-\mathrm{Au}-\mathrm{k}_{\mathrm{Au}}$; grey bar) and the corresponding yields of the reductions (red bar) determined by HPLC.

IV) Influence of the diffusion barrier introduced by the pores of the protein cage. Next to the effect of the charges of the protein cage, it might also induce size selectivity towards substrate conversion as small molecules might penetrate the capsids' interior easier compared to larger substrate molecules. In a preliminary study, Eriochrome Black T was compared to $3 \mathrm{NBS}$, the former substrate is larger, although both should, in principle, be able to access the capsid interior (Figure 3.6). ${ }^{81}$

(a) 3 NBS Eriochrome Blakc T
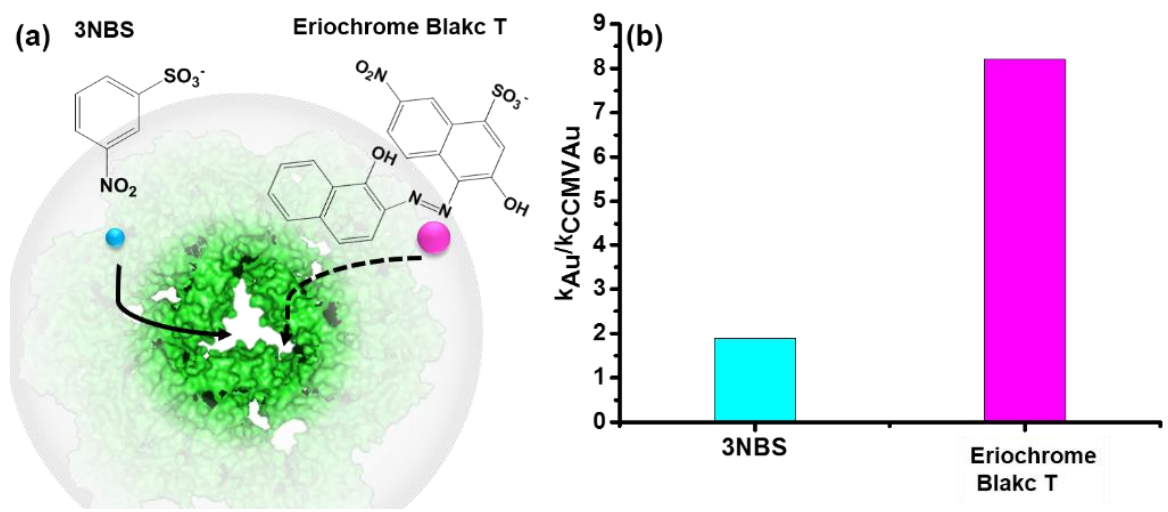

Figure 3.6. (a) scheme of substrates 3 NBS and Eriochrome Black T diffuse into capsid; (b) Relative reactions rates $\left(k_{\mathrm{Au}} / k_{\mathrm{CCMV}} \mathrm{Au}\right)$ comparing the substrate Eriochrome Black $\mathrm{T}$ with the smaller $3 \mathrm{NBS}$. 
Upon comparison with unmodified Au NP, Eriochrome Black T reacted about 4 times slower than 3 NBS, pointing to some size selectivity. This can have implications for the application of these types of hybrid nanoparticles in networks for cascade reactions.

\subsubsection{Stability of nanoreactors}

The instability of colloidal micro- or nanoparticle catalysts can be a major problem in heterogeneous catalysis. The particles form clusters, crush out of solution, remain insoluble and cannot act as catalyst anymore. Pristine tannic acid stabilized nanoparticles precipitate from aqueous solution already after several hours, forming a black precipitate (Figure 3.7A, left). In marked contrast, CCMV protein capped nanoparticles do not coagulate and remain stable in solution (Figure 3.7A, right).
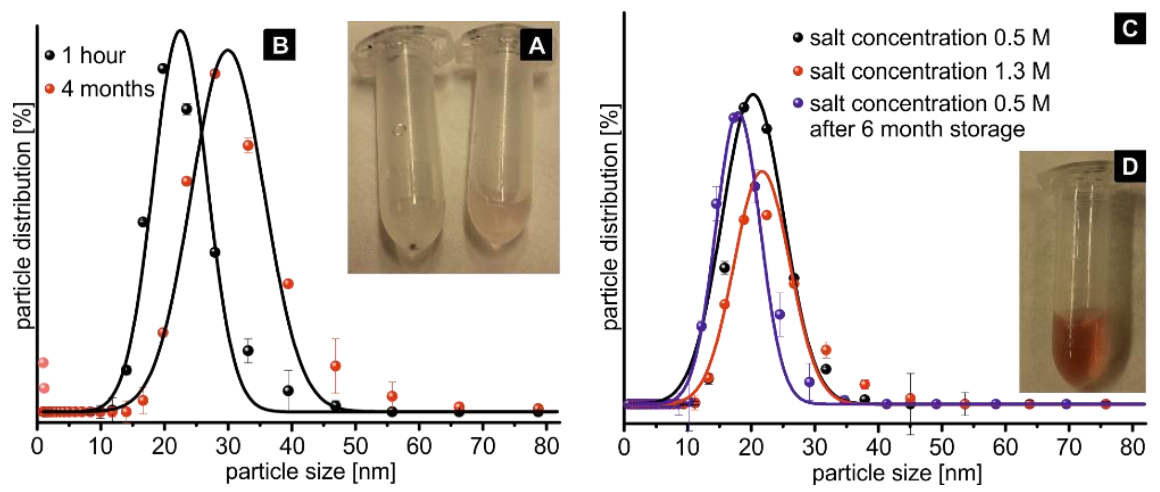

Figure 3.7. Stability of cowpea chlorotic mottle virus cages loaded with tannic acid stabilized gold nanoparticles (CCMV-Au). A: Optical image of pristine tannic acid capped nanoparticles (left) and virus cage encapsulated gold nanoparticles (right) after reaction B: Dynamic light scattering (DLS) data obtained of CCMV-Au after reaction after $1 \mathrm{~h}$ (black dots) and 4 month (red dots), respectively. The observed light red data points have not been taken into account for Gaussian fit. C: Dynamic light scattering (DLS) data obtained from CCMV-Au nanoreactors in tris $\mathrm{HCl}$ buffered solutions with high $\mathrm{NaCl}$ concentrations: $0.5 \mathrm{M} \mathrm{NaCl}$ (black dots), $1.3 \mathrm{M} \mathrm{NaCl}$ (red dots) 1 hour after preparation and in $0.5 \mathrm{M} \mathrm{NaCl}$ after 6 month storage. No particle degeneration is observed. D: Optical image of virus cage encapsulated gold nanoparticles (right) in $0.5 \mathrm{M} \mathrm{NaCl}$ after 6 month storage.

DLS investigations reveal the high stability of protein based colloidal gold nanoreactors (Figure 3.7C), CCMV-Au nanoreactors remain a stable dispersion after four month, although a slight increase in particle diameter is observed in Figure 3.7B (red dots). The reason of this increase is currently under further investigation. The nanoreactors remain stable also in buffered solutions with a high salt concentration (Figure 3.7C). Usually, nanoparticles 
coagulate over time in high salt buffers. ${ }^{39}$ Our CCMV-Au nanoreactors stay intact even after 6 month storage in Tris-HCl buffer solution with $0.5 \mathrm{M} \mathrm{NaCl}$ (Figure 3.7C and D).

\subsubsection{Sustainability}

To provide further evidence for the advantages of encapsulated Au NP, several reaction cycles were carried out. After each cycle the CCMV-Au nanoreactors were regained by centrifuge filtration and reused for the reduction of NTA (Figure 3.14). No catalyst degeneration nor particle coagulation is observed after four subsequent cycles. The reduction rate. The corresponding reduction rate constants remain constant under the applied conditions (Table 2, Figure 3.13-3.14).

Table 2. Reduction rate constants of the catalytic reduction of N,N,N-trimethyl-1-(3nitrophenyl) methanaminium (NTA) performed with the same (recycled) CCMV-Au nanoreactors .

\begin{tabular}{l|c}
\multicolumn{2}{c}{ NTA $\left[\mathrm{s}^{-1}\right]$} \\
\hline recycled 0 & $5.70 \cdot 10^{-3} \pm 2.54 \cdot 10^{-4}$ \\
recycled 1 & $5.45 \cdot 10^{-3} \pm 5.98 \cdot 10^{-4}$ \\
recycled 2 & $6.64 \cdot 10^{-3} \pm 2.41 \cdot 10^{-4}$ \\
recycled 3 & $6.90 \cdot 10^{-3} \pm 3.37 \cdot 10^{-4}$
\end{tabular}

The nanoreactors can also be disassembled and reassembled, suggesting straightforward recycling of the gold particles. We carried out a reduction reaction, separated the product and subsequently disassembled the CCMV-Au particles. The capsid protein and the tannic acid stabilized gold nanoparticle are reassembled. TEM investigation of the reassembled CCMV$\mathrm{Au}$ reveals successful particle re-encapsulation, the loading efficiency is decreased to $38 \%$ (44 of 115 CCMV loaded with gold nanoparticles), likely because of precipitation of Au NPs or formation of additional capsids. However, the particles can be used afterwards for further reduction reactions (Figure 3.15-3.17). 


\subsection{Conclusions}

CCMV-Au nanoreactors were synthesized by loading cowpea chlorotic mottle virus cages with tannic acid stabilized gold nanoparticles. The particles have been used to catalyze the reduction of nitroarenes with different substituents which was monitored using UV-Vis spectroscopy and MS spectrometry. The reaction sequence is initiated with a short induction period followed by the fast conversion of the nitro-group to a hydroxylamine and a final reaction step forming the amine product which is relatively slow.

The reduction of three differently meta-substituted nitroarenes has been investigated, $\mathrm{R}=\mathrm{SO}^{3-}, \mathrm{R}=\mathrm{CH}_{3}$ and $\mathrm{R}=\mathrm{CH}_{2} \mathrm{~N}^{+}\left(\mathrm{CH}_{3}\right)_{3}$. The rate constants of all compound reduction depend linearly on the catalyst concentration pointing to pseudo first order kinetics where $k_{\mathrm{NTA}}>k_{\mathrm{NTT}}>k_{\mathrm{NBS}}$. This sequence is attributed to the electrostatic barrier of the negatively charged tannic acid layer encountered inside the oppositely charged protein cage interior. The virus cage introduces an additional diffusion barrier which significantly reduces the reduction rate of the positively charged NTA. The retarding effect of the barrier is traced down to the steric hindrance imposed by the capsid as well as the positively charged interior of the cage.

Nanoreactors based on the CCMV protein cage and a gold nanoparticle have been successfully constructed and are active in the catalytic reduction of nitroarenes. These results show that protein cages assist in improving the stability of the catalytic nanoparticles, eventually leading to a longer life time and therewith an increased conversion, despite the reduced reaction rates. Furthermore, the catalytic nanoparticles can be re-used after isolation and re-encapsulation in the protein cage or isolated as intact nanoreactors and re-used for catalytic reduction. The highly organized supramolecular assembly of virus capsid proteins around catalytically active nanoparticles opens the way to influence the reactivity and has the potential to control substrate selectivity based on charges and sizes. ${ }^{21 a}$

\subsection{Acknowledgments}

Dr. Christoph Traulsen is gratefully acknowledged for his help in images and manuscript preparation. Many thanks to Rianne Hommersom and Dr. Martijn Verwegen for the 
introduction of virus isolation and Au NPs encapsulation; many thanks to Dr. Jie Zhu and Dr. Wei Zhu for their help and fruitful discussions.

\subsection{Materials and methods}

\subsubsection{General}

All reagent and reactants have been purchased by Sigma Aldrich and 3-Nitrophenol (Reagent Plus® 99\%), (3-Nitrobenzyl)Trimethylammonium Chloride, Nitrobenzene (ACS reagent $\geq 99 \%$ ), Sodium 3-nitrobenzenesulfonate (98\% Aldrich), Sodium borohydride (Reagent Plus® 99\%), Eriochrome Black T (ACS reagent) and were used as received without further purification. Water used for buffer and reaction was of MilliQ quality (Millipore, $\left.\mathrm{R}=18.2 \mathrm{M} \Omega \mathrm{cm}^{-1}\right)$. Quartz glass cuvette were purchased from Hellma-analytics, Quartz SUPRASIL (QS) for UV-vis analysis. Tannic acid stabilized gold nanoparticles have been purchased from NanoComposix with mass concentration of $0.05 \mathrm{mg} / \mathrm{ml}$, dispersed in MilliQ water and Amicon Ultra centrifuge filter with 10K MWCO from Pall MicrosepTM Advance Centrifuge Device with Omega Membrane.

\subsubsection{Instrumentation and data processing}

Ultra-Centrifugation. Fiberlight F14S-6x250 and Step Saver 70V6 rotors (Thermo Fisher Scientific), have been used.

UV-vis Spectroscopy. UV/Vis absorption spectra were acquired using a PerkinElmer Lambda 850 UV/vis Spectrometer. Samples are prepared in a $1 \mathrm{~cm}$ quartz glass cuvette. Each recording cycle was performed within $44 \mathrm{~s}$.

Transmission electron microscopy (TEM). TEM analysis was performed using Philips CM300 microscope operating at $300 \mathrm{kV}$. A droplet of the samples was casted on a 200 mesh copper grid for 2 min before the excess solvent was blotted away with using a sterile paper. Samples were negatively stained by applying $5 \mu \mathrm{L} 1 \%(\mathrm{w} / \mathrm{v})$ uranyl acetate in MilliQ water onto the grid for $30 \mathrm{~s}$ and removed afterwards.

Fast protein liquid chromatography (FPLC). FPLC analysis were performed on a GE Healthcare ÄKTApurifierTM system equipped with a Superose 610/300 GL column from GE Healthcare and a fractionating device. Injection of $500 \mu \mathrm{L}$ pre-filtered samples which are 
injected on a $24 \mathrm{~mL}$ superpose- 6 column. Compound elution is monitored using a UV-vis spectrometer at $\lambda=260 \mathrm{~nm}, 280 \mathrm{~nm}$ and $520 \mathrm{~nm}$. Fractionates are collected separately.

Dynamic light scattering (DLS). DLS analysis was performed using a Nanotrac (Anaspec) instrument. Microtrac FLEX Operating software was used at $25^{\circ} \mathrm{C}$ with laser wavelength of $780 \mathrm{~nm}$ and a scattering angle of $90^{\circ}$. The observed size and standard deviation of the nanoparticles were calculated by taking an average of 5 measurements.

High-performance liquid chromatography (HPLC). HPLC experiments were performed with a Waters assembly consisting of a 2535 Quarternary Gradient Module with FlexInject setup and a 2998 Photodiode Array Detector. Experiments were carried out on regular 200 $\mathrm{nm}$ pore size column by injecting $100 \mu \mathrm{L}$ of pre-filtered reduction solution. 2-Methyl-4nitrophenol has been used as an internal standard to determine the reaction yield. The injections were repeated for 3 times to get an average. The area of the peak for each compound was integrated and calculated. Gold nanoparticles or gold-protein hybrid nanoparticles were removed by Amicon Ultra centrifuge filter (10k MWCO, centrifuge at 2.7k r.p.m, $4{ }^{\circ} \mathrm{C}$ ) before injection into the HPLC machine. $174 \mu \mathrm{L}$ of sample taken from the bottom of the centrifuge filter mixed with $3 \mu \mathrm{L}$ of $2 \mathrm{mM} 2 \mathrm{M} 4 \mathrm{NP}$ solution, samples were prefiltered by using standard HPLC syringe filters before injection. The amount of non-reacted nitroaromatic component was determined by integrating the absorption.

\subsubsection{Synthesis protocols}

Gold nanoparticle encapsulation. Tannic acid modified gold nanoparticles were encapsulated into CCMV protein cage by assembling the coat protein around the anionic gold nanoparticles. In a typical experiment, $4 \mathrm{~mL}$ of gold colloid solution $\left(0.05 \mathrm{mg} / \mathrm{mL}\right.$ in $\left.\mathrm{H}_{2} \mathrm{O}\right)$ is concentrated to $400 \mu \mathrm{L}$ and was quickly injected to $100 \mu \mathrm{L}$ of pre-purified CCMV coat protein solution (15 20 mg/mL of protein). The solution is mechanically mixed for 2 minutes and stored at $4{ }^{\circ} \mathrm{C}$ over-night. The resulting gold-protein cage hybrid nanoparticles were purified by using preparative FPLC chromatography. Before injection into the FPLC, samples were pre-filtered by a syringe filter with a pore size of $200 \mathrm{~nm}$. To test if DTT was

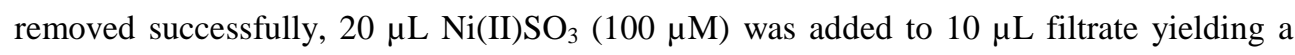
transparent solution. 


\section{Chapter 3}

Gold-protein cage hybrid NPs for reaction. The hybrid nanoparticles were washed 3 times with MilliQ water using a 10k MWCO centrifuge filter. The concentration was determined by UV-vis spectroscopy. No aggregation was found both from DLS and by inspection with the naked eyes.

General protocol for reductions. The concentration of gold/gold-protein nanoparticles was determined by UV-vis spectroscopy and either concentrated by using centrifuge filter or diluted with MilliQ. $30 \mu \mathrm{L}$ of $2 \mathrm{mM}$ nitroarene solutions in MilliQ were prepared and added to $170 \mu \mathrm{L}$ of gold/gold-protein colloid with different concentrations. $150 \mu \mathrm{L}$ of freshly prepared $30 \mathrm{mM}$ solution of sodium borohydride in MilliQ was added immediately before analysis. The reductions were monitored by UV-vis spectroscope at $\lambda=200 \mathrm{~nm}$ to $450 \mathrm{~nm}$ the reactions were ended when there was no change absorption. 
Nitroarene Reduction by a Virus Protein Cage Based Nanoreactor

\subsubsection{Data Appendix}

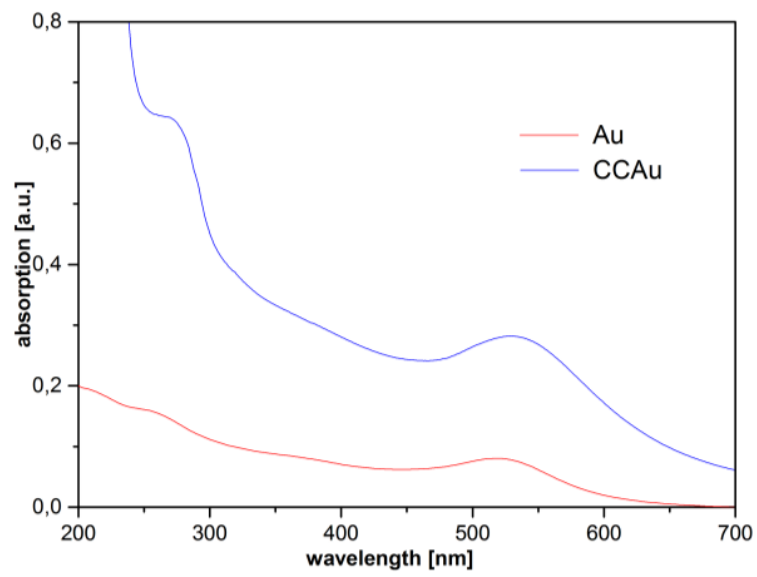

Figure 3.8. UV/Vis spectra of gold nanoparticles $(\mathrm{Au})$ and CCMV-Au core/shell particles.

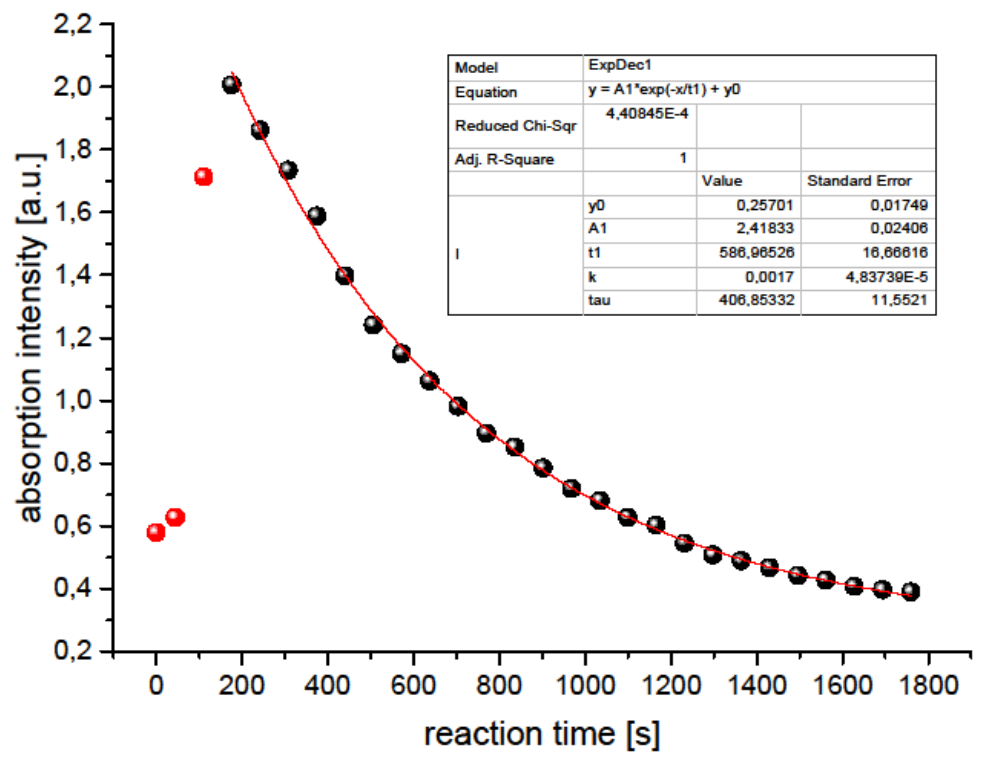

Figure 3.9. Determination of the initial absorption intensity ( $\left.\mathrm{I}=100 \% ; \mathrm{A}_{0}\right)$ of the reduction of NBS (2mM). 
Chapter 3

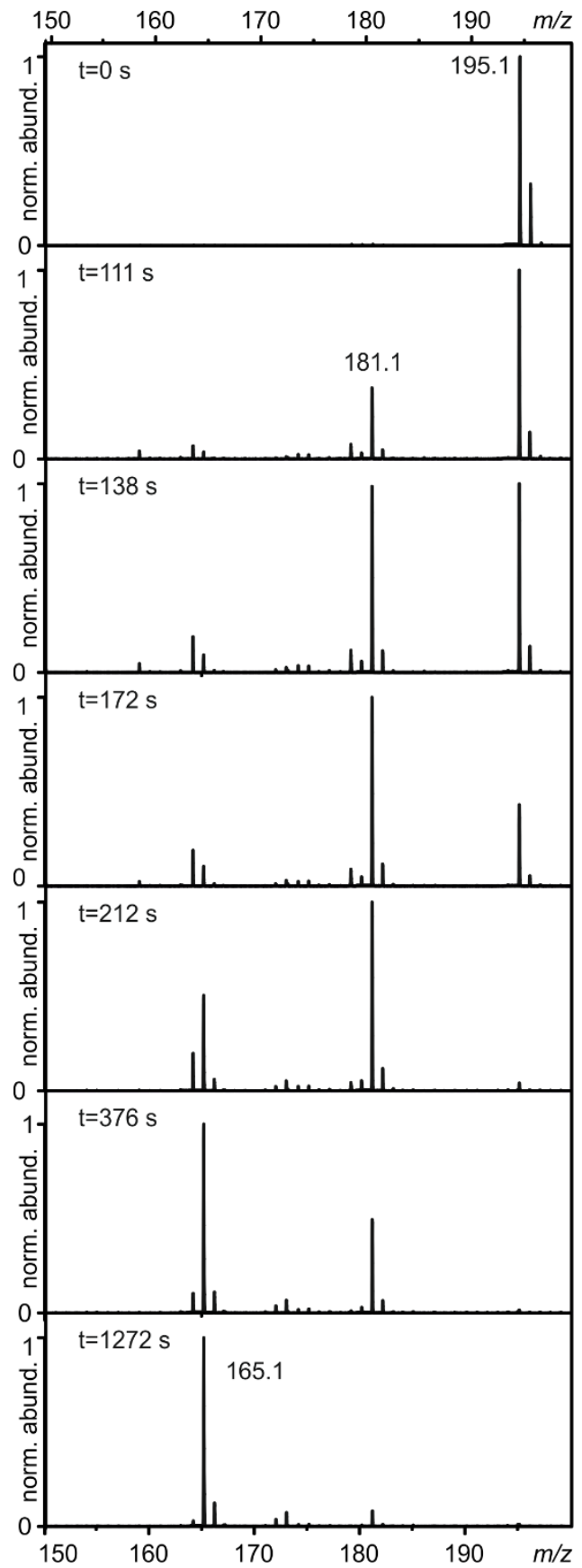

Figure 3.10. MS analysis of the reduction of $2 \mathrm{mM}$ NTA with CCMV-Au catalyst. 

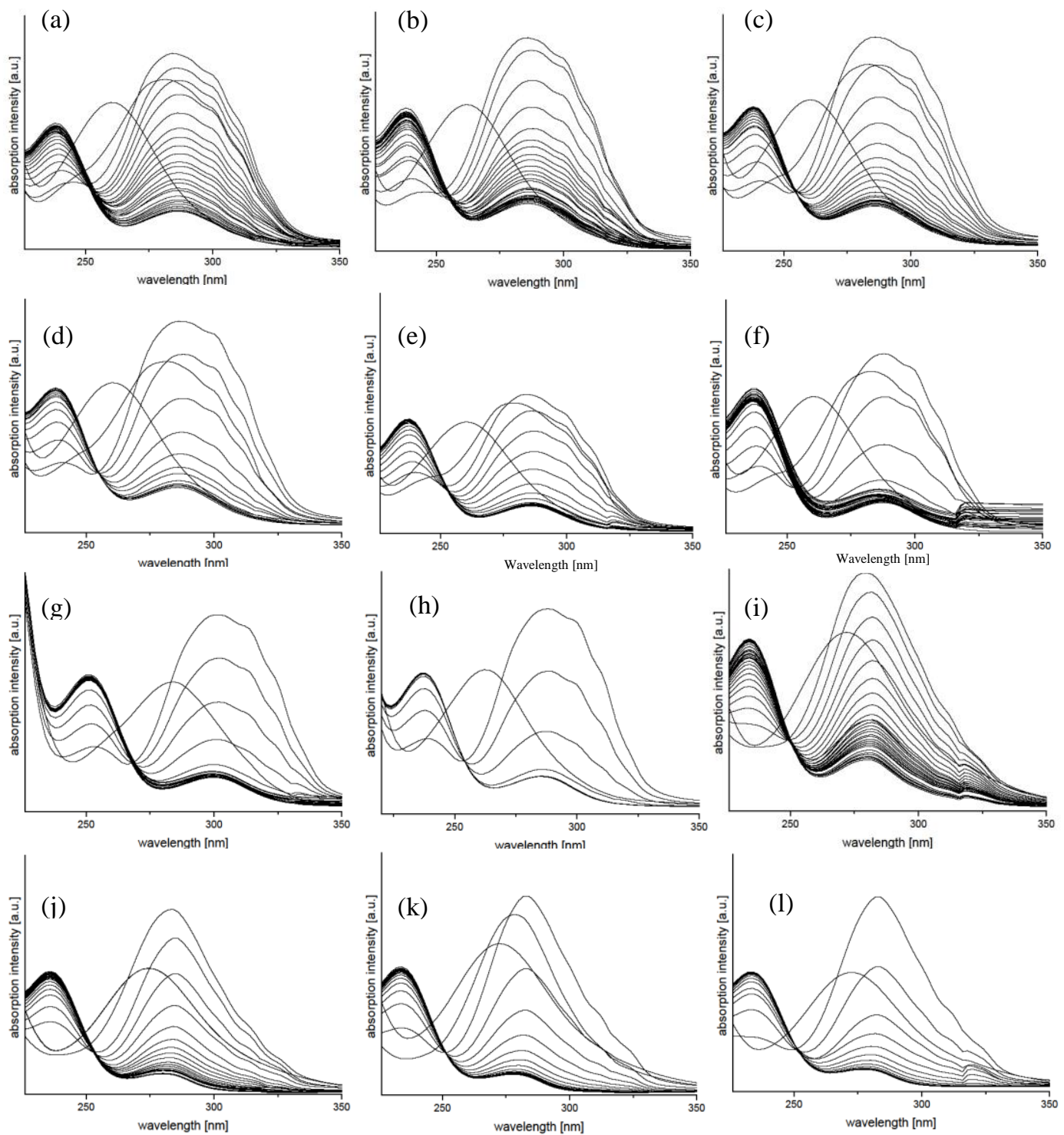
Chapter 3
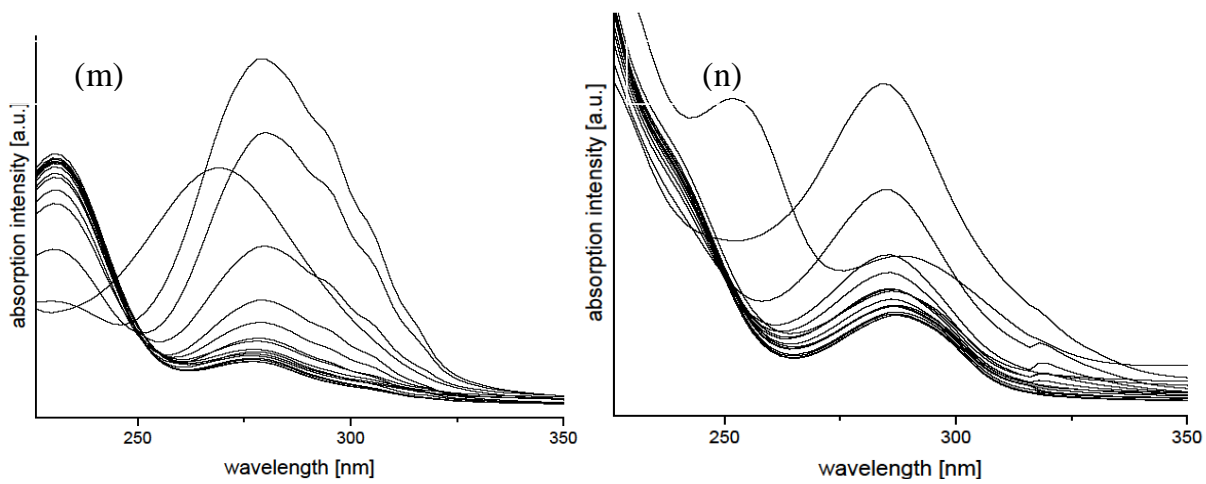

Figure 3.11. UV/Vis spectra of: the reduction of $2 \mathrm{mM}$ NBS using (a) $0.74 \mathrm{nM}$ CCMV-Au. (b) 1.12 nM CCMV-Au. (c) $1.49 \mathrm{nM} \mathrm{CCMV-Au.} \mathrm{(d)} 2.23 \mathrm{nM} \mathrm{CCMV-Au} \mathrm{catalyst;} \mathrm{the} \mathrm{reduction} \mathrm{of} 2 \mathrm{mM}$ NTA using (e) $0.74 \mathrm{nM} \mathrm{CCMV-Au.} \mathrm{(f)} 1.12 \mathrm{nM}$ CCMV-Au. (g) $1.49 \mathrm{nM}$ CCMV-Au catalyst. (h) $2.23 \mathrm{nM}$ CCMV-Au; the reduction of $2 \mathrm{mM}$ NTT using (i) $0.74 \mathrm{nM} \mathrm{CCMV-Au.} \mathrm{(j)} 1.12 \mathrm{nM} \mathrm{CCMV-Au.} \mathrm{(k)}$ $1.49 \mathrm{nM}$ CCMV-Au. (1) $2.23 \mathrm{nM} \mathrm{CCMV-Au}$; the reduction of $2 \mathrm{mM} \mathrm{NB}$ using (m) $2.23 \mathrm{nM} \mathrm{CCMV-}$ $\mathrm{Au}$; (n) the reduction of $2 \mathrm{mM} \mathrm{NP}$ using $2.23 \mathrm{nM}$ CCMV-Au catalyst.

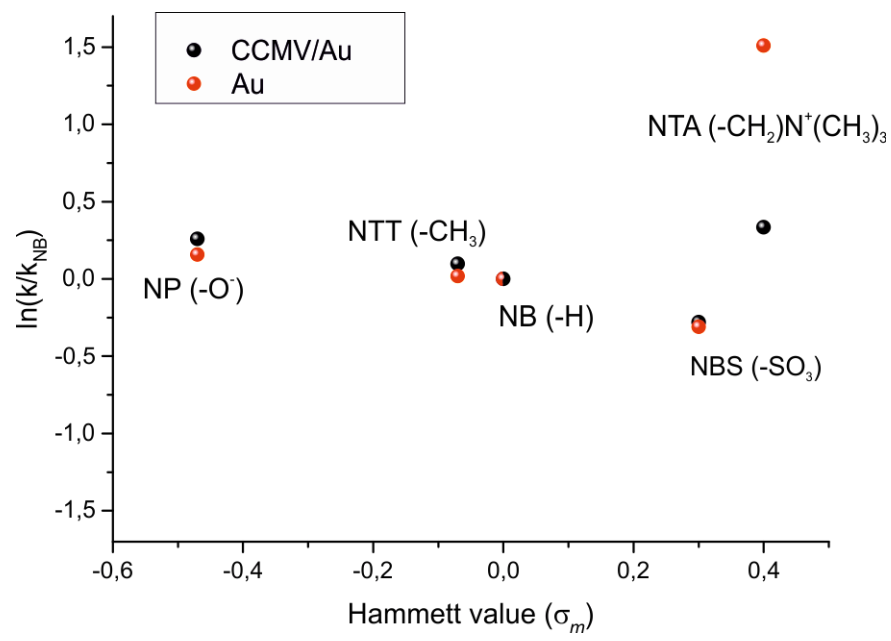

Figure 3.12. Hammett plot of the reduction of $2 \mathrm{mM}$ NTA, NTT, NBS, nitrobenzene (NB) or nitrophenol (NP) using CCMV-Au and Au catalyst. NB has been chosen as reference for normalization of and is thus located at a sigma value of 0 . 

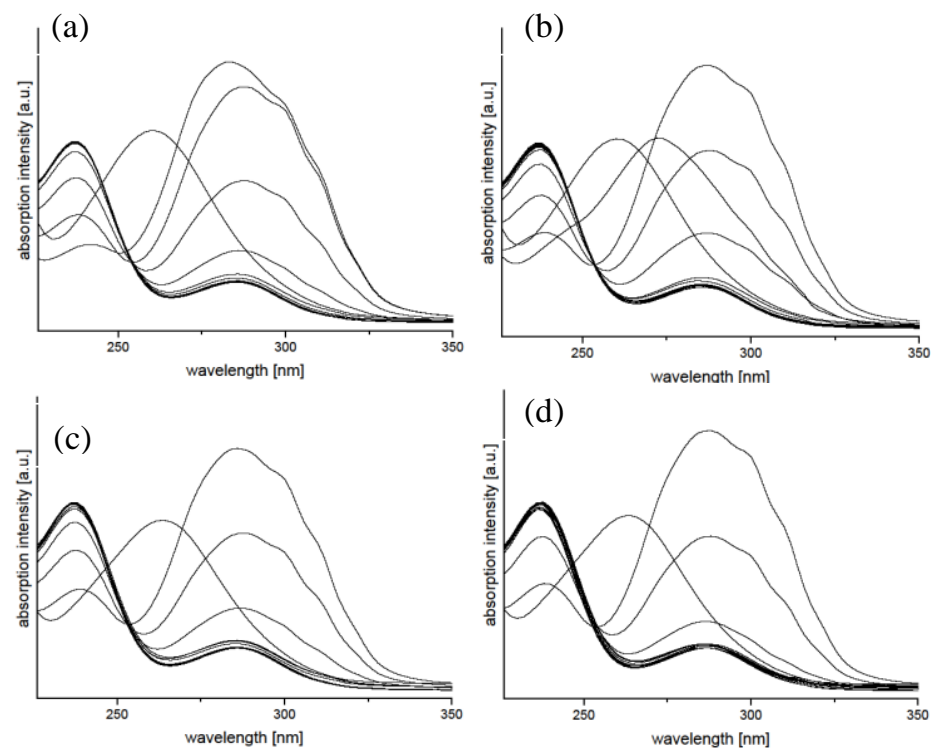

Figure 3.13. UV/Vis spectra of the reduction of $2 \mathrm{mM}$ NTA using $1.49 \mathrm{nM}$ CCMV-Au catalyst (a) recycled 0; (b) cycle1; (c) cycle2; (d) cycle3.

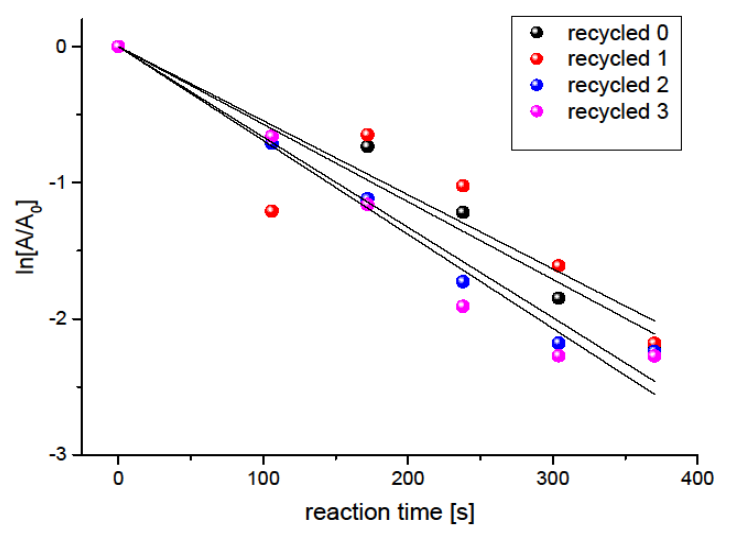

Figure 3.14. Plotted absorption maxima obtained during the reduction of N,N,N-trimethyl-1-(3nitrophenyl) methanaminium (NTA), with gold nanoparticle-loaded T=1 cowpea chlorotic mottle virus cage nanoreactors.. Recycled nanoreactors have been used. 
Chapter 3

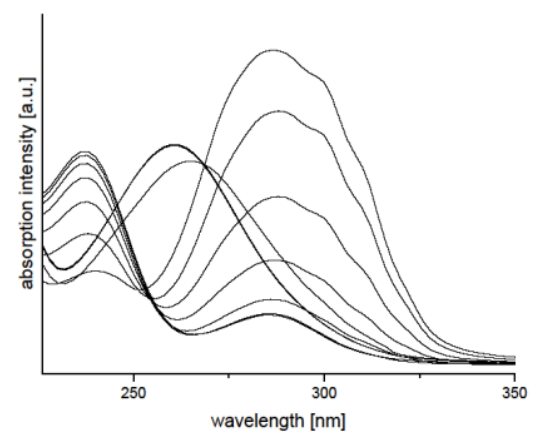

Figure 3.15. UV/Vis spectra of the reduction of $2 \mathrm{mM}$ NTA using $1.49 \mathrm{nM}$ disassembled and reassembled CCMV-Au catalyst (re-encapsulation 1).

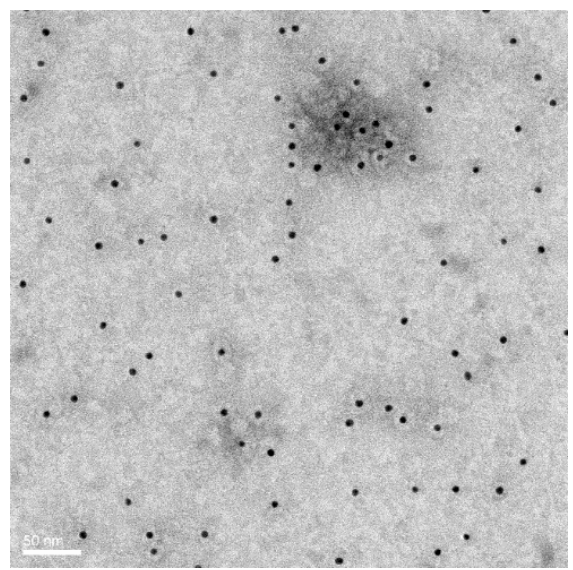

Figure 3.16. TEM image of CCMV-Au disassembly.

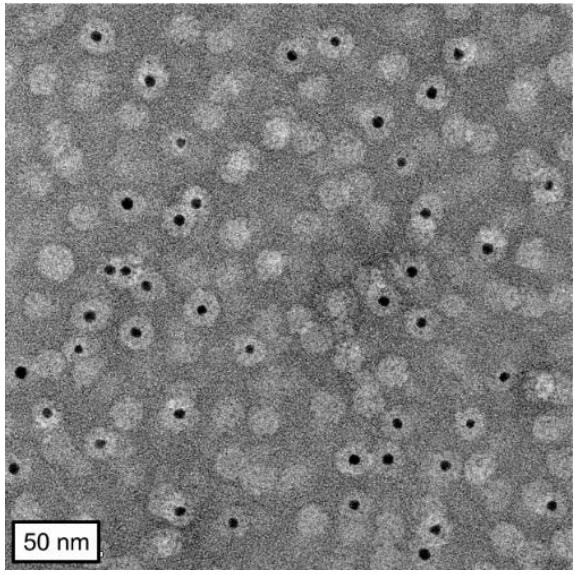

Figure 3.17. TEM image after CCMV-Au disassembly and reassembly. 


\subsection{References}

1. Mitsudome, T.; Kaneda, K., Gold nanoparticle catalysts for selective hydrogenations. Green Chemistry 2013, 15 (10), 2636-2654.

2. Takale, B. S.; Bao, M.; Yamamoto, Y., Gold nanoparticle (AuNPs) and gold nanopore (AuNPore) catalysts in organic synthesis. Organic \& Biomolecular Chemistry 2014, 12 (13), 2005-2027.

3. Mikami, Y.; Noujima, A.; Mitsudome, T.; Mizugaki, T.; Jitsukawa, K.; Kaneda, K., Highly Efficient Gold Nanoparticle Catalyzed Deoxygenation of Amides, Sulfoxides, and Pyridine N-Oxides. Chemistry - A European Journal 2011, 17 (6), 1768-1772.

4. Chen, Y.; Qiu, J.; Wang, X.; Xiu, J., Preparation and application of highly dispersed gold nanoparticles supported on silica for catalytic hydrogenation of aromatic nitro compounds. Journal of Catalysis 2006, 242 (1), 227-230.

5. (a) Corma, A.; Serna, P., Chemoselective Hydrogenation of Nitro Compounds with Supported Gold Catalysts. Science 2006, 313 (5785), 332-334; (b) Zhao, P.; Feng, X.; Huang, D.; Yang, G.; Astruc, D., Basic concepts and recent advances in nitrophenol reduction by gold- and other transition metal nanoparticles. Coordination Chemical Reviews 2015, 287, 114-136.

6. Wunder, S.; Lu, Y.; Albrecht, M.; Ballauff, M., Catalytic Activity of Faceted Gold Nanoparticles Studied by a Model Reaction: Evidence for Substrate-Induced Surface Restructuring. ACS Catalysis 2011, 1 (8), 908-916.

7. Wu, S.; Dzubiella, J.; Kaiser, J.; Drechsler, M.; Guo, X.; Ballauff, M.; Lu, Y., Thermosensitive Au-PNIPA Yolk-Shell Nanoparticles with Tunable Selectivity for Catalysis. Angewandte Chemie International Edition 2012, 51 (9), 2229-2233.

8. Liu, X.; Li, C.; Xu, J.; Lv, J.; Zhu, M.; Guo, Y.; Cui, S.; Liu, H.; Wang, S.; Li, Y., Surfactant-Free Synthesis and Functionalization of Highly Fluorescent Gold Quantum Dots. The Journal of Physical Chemistry C 2008, 112 (29), 10778-10783.

9. (a) Wunder, S.; Polzer, F.; Lu, Y.; Mei, Y.; Ballauff, M., Kinetic Analysis of Catalytic Reduction of 4-Nitrophenol by Metallic Nanoparticles Immobilized in Spherical Polyelectrolyte Brushes. The Journal of Physical Chemistry C 2010, 114 (19), 8814-8820; (b) Liu, H.; Wang, J.; Feng, Z.; Lin, Y.; Zhang, L.; Su, D., Facile Synthesis of Au Nanoparticles Embedded in an Ultrathin Hollow Graphene Nanoshell with Robust Catalytic Performance. Small 2015, 11 (38), 5059-5064; (c) Zhang, Y.; Xiang, S.; Zhou, Y.; Xu, Y.; Zhang, Z.; Sheng, X.; Wang, Q.; Zhang, C., Enhanced catalytic activity with high thermal stability based on multiple Au cores in the interior of mesoporous Si-Al shells. RSC Advance 2015, 5 (60), 48187-48193; (d) Bolisetty, S.; Arcari, M.; Adamcik, J.; Mezzenga, R., Hybrid Amyloid Membranes for Continuous Flow Catalysis. Langmuir 2015, 31 (51), 13867-13873; (e) Liu, G.; Wang, D.; Zhou, F.; Liu, W., Electrostatic Self-Assembly of Au Nanoparticles onto Thermosensitive Magnetic Core-Shell Microgels for Thermally Tunable and Magnetically Recyclable Catalysis. Small 2015, 11 (23), 2807-2816.

10. (a) Cao, Z.; Chen, H.; Zhu, S.; Chen, Z.; Xu, C.; Qi, D.; Ziener, U., Inverse miniemulsion-based preparation of raspberry-like $\mathrm{Au} / \mathrm{SiO} 2$ nanocomposite particles with high catalytic activity towards reduction of p-nitrophenol. Colloids and Surfaces A 2016, 489, 223-233; (b) Lee, J.; Park, J. C.; Song, H., A Nanoreactor Framework of a Au@ @iO2 Yolk/Shell Structure for Catalytic Reduction of p-Nitrophenol. Advanced Material 2008, 20 (8), 1523-1528. 
11. Mitschang, F.; Schmalz, H.; Agarwal, S.; Greiner, A., Tea-Bag-Like Polymer Nanoreactors Filled with Gold Nanoparticles. Angewandte Chemie International Edition 2014, 53 (19), 4972-4975.

12. Zou, H.; Wang, R.; Dai, J.; Wang, Y.; Wang, X.; Zhang, Z.; Qiu, S., Amphiphilic hollow porous shell encapsulated Au@Pd bimetal nanoparticles for aerobic oxidation of alcohols in water. Chemical Communication 2015, 51 (78), 14601-14604.

13. Yu, Y.; Kant, K.; Shapter, J. G.; Addai-Mensah, J.; Losic, D., Gold nanotube membranes have catalytic properties. Microporous Mesoporous Materials 2012, 153, 131136.

14. (a) Zhao, Y.; Sakai, F.; Su, L.; Liu, Y.; Wei, K.; Chen, G.; Jiang, M., Progressive Macromolecular Self-Assembly: From Biomimetic Chemistry to Bio-Inspired Materials. Advanced Materials 2013, 25 (37), 5215-5256; (b) Zelzer, M.; Ulijn, R. V., Next-generation peptide nanomaterials: molecular networks, interfaces and supramolecular functionality. Chemical Sociaty Review 2010, 39 (9), 3351-3357; (c) Patterson, D. P.; Prevelige, P. E.; Douglas, T., Nanoreactors by Programmed Enzyme Encapsulation Inside the Capsid of the Bacteriophage P22. ACS Nano 2012, 6 (6), 5000-5009; (d) Bode, S. A.; Minten, I. J.; Nolte, R. J. M.; Cornelissen, J. J. L. M., Reactions inside nanoscale protein cages. Nanoscale 2011, 3 (6), 2376-2389; (e) Douglas, T.; Young, M., Host-guest encapsulation of materials by assembled virus protein cages. Nature 1998, 393 (6681), 152-155; (f) Ueno, T.; Suzuki, M.; Goto, T.; Matsumoto, T.; Nagayama, K.; Watanabe, Y., Size-Selective Olefin Hydrogenation by a Pd Nanocluster Provided in an Apo-Ferritin Cage. Angewandte Chemie International Edition 2004, 116 (19), 2581-2584; (g) Capehart, S. L.; Coyle, M. P.; Glasgow, J. E.; Francis, M. B., Controlled Integration of Gold Nanoparticles and Organic Fluorophores Using Synthetically Modified MS2 Viral Capsids. Journal of the American Chemical Society 2013, 135 (8), 3011-3016; (h) Wang, T.; Zhang, Z.; Gao, D.; Li, F.; Wei, H.; Liang, X.; Cui, Z.; Zhang, X.-E., Encapsulation of gold nanoparticles by simian virus 40 capsids. Nanoscale 2011, 3 (10), 4275-4282; (i) Loo, L.; Guenther, R. H.; Basnayake, V. R.; Lommel, S. A.; Franzen, S., Controlled Encapsidation of Gold Nanoparticles by a Viral Protein Shell. Journal of the American Chemical Society 2006, 128 (14), 4502-4503; (j) Huang, X.; Bronstein, L. M.; Retrum, J.; Dufort, C.; Tsvetkova, I.; Aniagyei, S.; Stein, B.; Stucky, G.; McKenna, B.; Remmes, N.; Baxter, D.; Kao, C. C.; Dragnea, B., Self-Assembled Virus-like Particles with Magnetic Cores. Nano Letter 2007, 7 (8), 2407-2416; (k) Sun, J.; DuFort, C.; Daniel, M.-C.; Murali, A.; Chen, C.; Gopinath, K.; Stein, B.; De, M.; Rotello, V. M.; Holzenburg, A.; Kao, C. C.; Dragnea, B., Core-controlled polymorphism in virus-like particles. Proceedings of the National Academy of Sciences 2007, 104 (4), 1354-1359.

15. (a) van Rijn, P.; Boker, A., Bionanoparticles and hybrid materials: tailored structural properties, self-assembly, materials and developments in the field. The Journal of Material. Chemistry A 2011, 21 (42), 16735-16747; (b) Jutz, G.; van Rijn, P.; Santos Miranda, B.; Böker, A., Ferritin: A Versatile Building Block for Bionanotechnology. Chemical Review 2015, 115 (4), 1653-1701; (c) Culver, J. N.; Brown, A. D.; Zang, F.; Gnerlich, M.; Gerasopoulos, K.; Ghodssi, R., Plant virus directed fabrication of nanoscale materials and devices. Virology 2015, 479-480, 200-212; (d) Slocik, J. M.; Naik, R. R.; Stone, M. O.; Wright, D. W., Viral templates for gold nanoparticle synthesis. Journal of Materials Chemistry 2005, 15 (7), 749-753. 
16. Patterson, D. P.; McCoy, K.; Fijen, C.; Douglas, T., Constructing catalytic antimicrobial nanoparticles by encapsulation of hydrogen peroxide producing enzyme inside the P22 VLP. Journal of Materials Chemistr B 2014, 2 (36), 5948-5951.

17. (a) Bedwell, G. J.; Zhou, Z.; Uchida, M.; Douglas, T.; Gupta, A.; Prevelige, P. E., Selective Biotemplated Synthesis of TiO2 Inside a Protein Cage. Biomacromolecules 2015, 16 (1), 214-218; (b) Klem, M. T.; Young, M.; Douglas, T., Biomimetic synthesis of [small beta]-TiO2 inside a viral capsid. Journal of Materials Chemistry 2008, 18 (32), 3821-3823.

18. Jordan, P. C.; Patterson, D. P.; Saboda, K. N.; Edwards, E. J.; Miettinen, H. M.; Basu, G.; Thielges, M. C.; Douglas, T., Self-assembling biomolecular catalysts for hydrogen production. Nature Chemistry 2016, 8 (2), 179-185.

19. Shin, Y.; Dohnalkova, A.; Lin, Y., Preparation of Homogeneous Gold-Silver Alloy Nanoparticles Using the Apoferritin Cavity As a Nanoreactor. The Journal of Physical Chemistry C 2010, 114 (13), 5985-5989.

20. Jutz, G.; van Rijn, P.; Santos Miranda, B.; Böker, A., Ferritin: A Versatile Building Block for Bionanotechnology. Chemical Reviews 2015, 115 (4), 1653-1701.

21. (a) Ueno, T.; Suzuki, M.; Goto, T.; Matsumoto, T.; Nagayama, K.; Watanabe, Y., Size-Selective Olefin Hydrogenation by a Pd Nanocluster Provided in an Apo-Ferritin Cage. Angewandte Chemie International Edition 2004, 43 (19), 2527-2530; (b) Annal. Phy.Maity, B.; Fujita, K.; Ueno, T., Use of the confined spaces of apo-ferritin and virus capsids as nanoreactors for catalytic reactions. Current Opinion in Chemical Biology 2015, 25, 88-97.

22. Hu, H.; Xin, J. H.; Hu, H.; Wang, X.; Miao, D.; Liu, Y., Synthesis and stabilization of metal nanocatalysts for reduction reactions - a review. Journal of Materials Chemistry A 2015, 3 (21), 11157-11182.

23. Verduin, B. J. M., The preparation of CCMV-protein in connection with its association into a spherical particle. FEBS Letter 1974, 45 (1-2), 50-54.

24. Soto, C. M.; Ratna, B. R., Virus hybrids as nanomaterials for biotechnology. Current Opinion in Biotechnology 2010, 21 (4), 426-438.

25. (a) Verwegen, M.; Cornelissen, J. J. L. M., Clustered Nanocarriers: The Effect of Size on the Clustering of CCMV Virus-Like Particles With Soft Macromolecules. Macromolecular Bioscience 2015, 15 (1), 98-110; (b) Sikkema, F. D.; Comellas-Aragones, M.; Fokkink, R. G.; Verduin, B. J. M.; Cornelissen, J. J. L. M.; Nolte, R. J. M., Monodisperse polymer-virus hybrid nanoparticles. Organic and Biomolecular Chemistry 2007, 5 (1), 5457; (c) de la Escosura, A.; Verwegen, M.; Sikkema, F. D.; Comellas-Aragones, M.; Kirilyuk, A.; Rasing, T.; Nolte, R. J. M.; Cornelissen, J. J. L. M., Viral capsids as templates for the production of monodisperse Prussian blue nanoparticles. Chemical Communications 2008, (13), 1542-1544; (d) Comellas-Aragones, M.; Engelkamp, H.; Claessen, V. I.; Sommerdijk, N. A. J. M.; Rowan, A. E.; Christianen, P. C. M.; Maan, J. C.; Verduin, B. J. M.; Cornelissen, J. J. L. M.; Nolte, R. J. M., A virus-based single-enzyme nanoreactor. Nature Nanotechnology 2007, 2 (10), 635-639; (e) Hommersom, C. A.; Matt, B.; van der Ham, A.; Cornelissen, J. J. L. M.; Katsonis, N., Versatile post-functionalization of the external shell of cowpea chlorotic mottle virus by using click chemistry. Organic \& Biomolecular Chemistry 2014, 12 (24), 4065-4069; (f) Minten, I. J.; Hendriks, L. J. A.; Nolte, R. J. M.; Cornelissen, J. J. L. M., Controlled Encapsulation of Multiple Proteins in Virus Capsids. Journal of Ammericon Chemical Sociaty 2009, 131 (49), 17771-17773; (g) Garmann, R. F.; Sportsman, R.; Beren, C.; Manoharan, V. N.; Knobler, C. M.; Gelbart, W. M., A Simple RNA-DNA Scaffold Templates the Assembly of Monofunctional Virus-Like Particles. Journal of 
Ammericon Chemical Sociaty 2015, 137 (24), 7584-7587; (h) Allen, M.; Bulte, J. W. M.; Liepold, L.; Basu, G.; Zywicke, H. A.; Frank, J. A.; Young, M.; Douglas, T., Paramagnetic viral nanoparticles as potential high-relaxivity magnetic resonance contrast agents. Magnetic Resonance in Medicine 2005, 54 (4), 807-812; (i) Suci, P. A.; Klem, M. T.; Arce, F. T.; Douglas, T.; Young, M., Assembly of Multilayer Films Incorporating a Viral Protein Cage Architecture. Langmuir 2006, 22 (21), 8891-8896; (j) Cadena-Nava, R. D.; Hu, Y.; Garmann, R. F.; Ng, B.; Zelikin, A. N.; Knobler, C. M.; Gelbart, W. M., Exploiting Fluorescent Polymers To Probe the Self-Assembly of Virus-like Particles. Journal of Physical Chemisty B 2011, 115 (10), 2386-2391.

26. Garmann, R. F.; Comas-Garcia, M.; Knobler, C. M.; Gelbart, W. M., Physical Principles in the Self-Assembly of a Simple Spherical Virus. Accounts of Chemical Research 2016, 49 (1), 48-55.

27. Renggli, K.; Baumann, P.; Langowska, K.; Onaca, O.; Bruns, N.; Meier, W., Selective and Responsive Nanoreactors. Advanced Functinal Materials 2011, 21 (7), 12411259.

28. Verduin, B. J. M., Degradation of Cowpea Chlorotic Mottle Virus Ribonucleic Acid in situ. Journal of General Virology 1978, 39 (1), 131-147.

29. Sun, J.; DuFort, C.; Daniel, M.-C.; Murali, A.; Chen, C.; Gopinath, K.; Stein, B.; De, M.; Rotello, V. M.; Holzenburg, A.; Kao, C. C.; Dragnea, B., Core-controlled polymorphism in virus-like particles. Proceedings of the National Academy of Sciences 2007, 104 (4), 1354-1359.

30. Speir, J. A.; Munshi, S.; Wang, G.; Baker, T. S.; Johnson, J. E., Structures of the native and swollen forms of cowpea chlorotic mottle virus determined by X-ray crystallography and cryo-electron microscopy. Structure 1995, 3 (1), 63-78.

31. Bancroft, J. B.; Hills, G. J.; Markham, R., A study of the self-assembly process in a small spherical virus formation of organized structures from protein subunits in vitro. Virology 1967, 31 (2), 354-379.

32. Traulsen, C. H. H.; Kunz, V.; Heinrich, T.; Richter, S.; Holzweber, M.; Schulz, A.; von Krbek, L. K. S.; Scheuschner, U. T. J.; Poppenberg, J.; Unger, W. E. S.; Schalley, C. A., Synthesis and Coordinative Layer-by-Layer Deposition of Pyridine-Functionalized Gold Nanoparticles and Tetralactam Macrocycles on Silicon Substrates. Langmuir 2013, 29 (46), 14284-14292.

33. (a) Prinsen, P.; van der Schoot, P.; Gelbart, W. M.; Knobler, C. M., Multishell Structures of Virus Coat Proteins. Journal of Physical Chemistry B 2010, 114 (16), 55225533; (b) Konecny, R.; Trylska, J.; Tama, F.; Zhang, D.; Baker, N. A.; Brooks, C. L.; McCammon, J. A., Electrostatic properties of cowpea chlorotic mottle virus and cucumber mosaic virus capsids. Biopolymers 2006, 82 (2), 106-120.

34. (a) Downing, R. S.; Kunkeler, P. J.; van Bekkum, H., Catalytic syntheses of aromatic amines. Catalysis Today 1997, 37 (2), 121-136; (b) Layek, K.; Kantam, M. L.; Shirai, M.; Nishio-Hamane, D.; Sasaki, T.; Maheswaran, H., Gold nanoparticles stabilized on nanocrystalline magnesium oxide as an active catalyst for reduction of nitroarenes in aqueous medium at room temperature. Green Chemistry 2012, 14 (11), 3164-3174; (c) Wienhöfer, G.; Sorribes, I.; Boddien, A.; Westerhaus, F.; Junge, K.; Junge, H.; Llusar, R.; Beller, M., General and Selective Iron-Catalyzed Transfer Hydrogenation of Nitroarenes without Base. Journal of Americon Chemical Sociaty 2011, 133 (32), 12875-12879; (d) García, N.; García-García, P.; Fernández-Rodríguez, M. A.; Rubio, R.; Pedrosa, M. R.; 
Arnáiz, F. J.; Sanz, R., Pinacol as a New Green Reducing Agent: Molybdenum- Catalyzed Chemoselective Reduction of Sulfoxides and Nitroaromatics. Advanced Synthetical Catalysis 2012, 354 (2-3), 321-327; (e) Pozun, Z. D.; Rodenbusch, S. E.; Keller, E.; Tran, K.; Tang, W.; Stevenson, K. J.; Henkelman, G., A Systematic Investigation of p-Nitrophenol Reduction by Bimetallic Dendrimer Encapsulated Nanoparticles. Journal of Physical Chemistry C 2013, 117 (15), 7598-7604.

35. Xu, W.; Kong, J. S.; Chen, P., Single-Molecule Kinetic Theory of Heterogeneous and Enzyme Catalysis. Journal of Physical Chemistry C 2009, 113 (6), 2393-2404.

36. (a) Esumi, K.; Isono, R.; Yoshimura, T., Preparation of PAMAM- and PPI-Metal (Silver, Platinum, and Palladium) Nanocomposites and Their Catalytic Activities for Reduction of 4-Nitrophenol. Langmuir 2004, 20 (1), 237-243; (b) Saha, S.; Pal, A.; Kundu, S.; Basu, S.; Pal, T., Photochemical Green Synthesis of Calcium-Alginate-Stabilized Ag and $\mathrm{Au}$ Nanoparticles and Their Catalytic Application to 4-Nitrophenol Reduction. Langmuir 2010, 26 (4), 2885-2893; (c) Gao, Y.; Ding, X.; Zheng, Z.; Cheng, X.; Peng, Y., Templatefree method to prepare polymer nanocapsules embedded with noble metal nanoparticles. Chemical Communication 2007, (36), 3720-3722.

37. Fountoulaki, S.; Daikopoulou, V.; Gkizis, P. L.; Tamiolakis, I.; Armatas, G. S.; Lykakis, I. N., Mechanistic Studies of the Reduction of Nitroarenes by $\mathrm{NaBH} 4$ or Hydrosilanes Catalyzed by Supported Gold Nanoparticles. ACS Catalysis 2014, 4 (10), 35043511.

38. Hansch, C.; Leo, A.; Taft, R. W., A survey of Hammett substituent constants and resonance and field parameters. Chemical Review 1991, 91 (2), 165-195.

39. Gill, R.; Goeken, K.; Subramaniam, V., Fast, single-step, and surfactant-free oligonucleotide modification of gold nanoparticles using DNA with a positively charged tail. Chemical Communication 2013, 49 (97), 11400-11402. 


\section{Chapter 4}

\section{Immobilization of Catalytic Virus-like Particles in a Flow Reactor}

A functional microfluidic reactor is constructed by the immobilization of gold containing virus-based protein cages that reduce nitro-arenes with high efficiency.

The contents of this chapter is partly published in: A. Liu, M. Verwegen, M. V. de Ruiter, S. J. Maassen, C.H.-H. Traulsen, J. J. L. M. Cornelissen, J. Phys. Chem. B., 2016, 120 (26), 6352-6357. A. Liu, L. Yang, C. H.-H. Traulsen, J. J. L. M. Cornelissen, Chem. Commun., 2017, 53,7632-7634. 


\subsection{Introduction}

Gold nanoparticles (Au NP) have attracted attention in a variety of different aspects of materials science due to their unique optical, electronic and catalytic properties. For example, mild conditions in reduction reactions can be achieved by gold nanoparticles supported on silica. ${ }^{1}$ For the transformation to larger scale processes, especially in batch reactions, an excellent particle stability as well as a facile recovery of catalytic particles are needed. Various approaches exist to stabilize colloidal (gold) particles. ${ }^{2}$ Besides synthetic stabilizing agents, carriers based on biological materials have recently gained increased attention. In particular protein cages such as apoferritin and virus capsids have been used in this context, allowing for an unchallenged degree of uniformity in size and surface chemistry. ${ }^{2 b, 3}$ The protein cage derived from the Cowpea Chlorotic Mottle Virus (CCMV) has shown to be a versatile building block in materials chemistry. ${ }^{4}$ Recently, we prepared CCMV based protein cages containing gold nanoparticles as cargo. A high encapsulation efficiency was formed for bis(psulfonatophenyl)phenylphosphine (BSPP) stabilized 7nm gold nanoparticles (Au7B NPs) in CCMV (CCMV-Au7B), ${ }^{5}$ which is also active as a reduction catalysts. ${ }^{6}$ It turns out, however, it faces same challenge as other colloidal catalysts, catalysts are hard to recover from the reaction mixture. This issue can be addressed by immobilizing the catalytic nanoparticles on solid supports such as microfluidic channels. ${ }^{6-7}$ Continuous flow reactions are user- and environmental friendly, because of their multiple use and the easy collection of products, sometimes even without additional purification steps. ${ }^{8}$ For heterogeneous catalysis, packed bed, monolithic and wall coated microreactors have been reported. An advantage for wall coated microreactors is that the reaction conditions can be adjusted and fine-tuned in a straightforward fashion by changing the flow dynamics. ${ }^{9}$

The deposition of (catalytic) Au NPs can be achieved by physisorption, by complexation with transition metals and by covalent bonding on a surface. ${ }^{10}$ However, direct immobilization of $\mathrm{Au}$ NPs reduces the available surface area for substrate adsorption and conversion. Meanwhile, the physisorption strategy also suffers from the instability of particle immobilization. In the recently reported CCMV-Au7B 


\section{Chapter 4}

example, Au NPs were encapsulated by protein cages, which keep the available surface area of catalyst. Meanwhile, by taking advantage of functional groups on the exterior surface of protein cages, CCMV-Au7B can be steadily immobilized in glass channels without particle loss.

\subsection{Results and discussion}

\subsubsection{Encapsulation of gold nanoparticles}

Negatively charged NPs, such as Au NPs be can easily encapsulated into viral protein cages. Encapsulation of Au NPs with various size was reported in our previous work, and the highest encapsulation efficiency was found for $7 \mathrm{~nm}$ Au NPs. Therefore $7 \mathrm{~nm}$ of Au NPs with various physisorbed surfactants were chosen to construct hybrid nanoparticles (CCMV$\mathrm{Au}$ ) and used for further immobilization and catalytic studies.

Citrate acid and/or tannic acid stabilized Au NPs are commercially available, and these 7 $\mathrm{nm}$ of $\mathrm{Au}$ NPs were used for encapsulation with a large excess of coat protein was used (see method). ${ }^{11}$ Citrate acid stabilized Au NPs are denoted as Au7C NPs and the corresponding VLPs as CCMV-Au7C, tannic acid stabilized Au NPs is referred to Au7T NPs and their corresponding VLPs as CCMV-Au7T.

The mixture of protein and Au NPs was purified and investigated by FPLC (shown in Figure 4.1a \& b). FPLC funs of CCMV-Au7C solutions elutes fractions at 8, 12 and $17.5 \mathrm{~mL}$ corresponding to aggregated particles and larger assemblies, intact and isolated hybrid particles as well as pristine capsomeres, respectively (Figure 4.1a). The second fraction was collected for TEM and DLS analysis. Besides single Au NP encapsulated in the formed protein cage, multiple Au NPs within capsid and non-coated (or partially coated) Au NPs were also observed (Figure 4.1b). While for CCMV-Au7T solutions, no aggregation was found, instead, fraction eluting at $12 \mathrm{~mL}$ indicates successful encapsulation inside $\mathrm{T}=1$ like hybrid NPs (Figure 4.1c). TEM images reveal monodisperse core-shell hybrid VLPs (Figure 4.1d) in line with the DLS analysis pointing to VLP with D = $18 \mathrm{~nm}$ (Figure 4.1e). For CCMV-Au7C, DLS showed a broad peak at an average of D $=25 \mathrm{~nm}$, corresponding to single-Au NPs or multi-Au NPs encapsulated VLPs, and a larger peak at D = $120 \mathrm{~nm}$, presumably because of aggregation of non-coated Au NPs. During the encapsulation, Au7C NPs aggregate under the applied conditions, likely due to the reduced electrostatic repulsion 
at relatively high salt concentrations $(0.1 \mathrm{M} \mathrm{NaCl})$, while $\mathrm{Au} 7 \mathrm{~T}$ can tolerate this salt concentration and yielding monodisperse gold encapsulated hybrid VLP with high yield of $96.5 \pm 1.5 \%$ (Figure 4.1f).

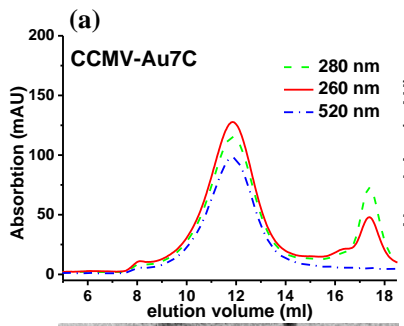

(c)
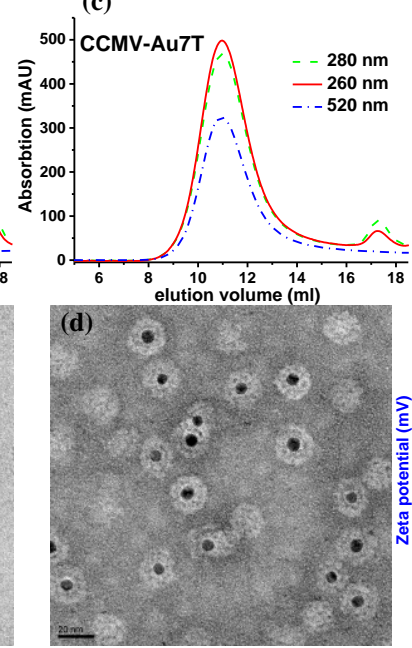

(e)

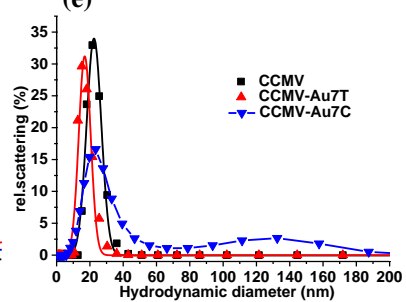

(f)

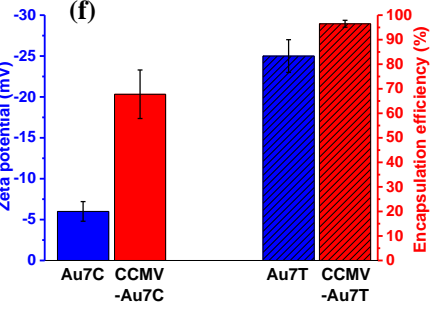

Figure 4.1. Encapsulation of citrate (a \& b) or tannic acid (c \& d) stabilized gold NPs. (a) \& (c) FPLC chromatograms of citrate stabilized gold NPs (Au7C) and tannic acid stabilized gold NPs (Au7T), respectively; (b) \& (d) TEM images of CCMV-Au7C NPs and CCMV-Au7T NPs, respectively; (e) DLS analysis of CCMV and CCMV-Au NPs; (f) zeta potential of Au7C NPs and Au7T NPs and their encapsulation efficiency. The encapsulation efficiency $=\mathrm{CCMV}-\mathrm{Au}$ NP/total Au NPs in TEM images. 100 NPs were count for Au7C and 200 NPs were count for Au7T.

$\mathrm{Au}$ NPs with a core diameter of $7 \mathrm{~nm}$ stabilized with tannic acid yield highly monodisperse particles with superior encapsulation efficiency. However, the assembly of hybrid VLPs using tannic acid stabilized Au NPs yielded a significant amount of capsids without Au NPs cargo (Figure 4.1d). The formation of these particles is likely templated by tannic acid molecules which are no longer bound by the gold NPs core but free in solution. Due to the large amount of hydroxyl groups, strong non-covalent interactions such as hydrogen bonds with the CCMV coat protein are expected. ${ }^{12}$ Thus we speculate, that proteintannic acid seeds form, which act as a nucleating center for further self-assembly. We investigated this issue in more detail by using only tannic acid during the capsid formation. According to DLS, FPLC and TEM (Figure 4.2), tannic acid filled capsids can be formed. Although this remarkable property of tannic acid has not been observed before, it hampers the efficient formation of gold-protein hybrid VLPs. 

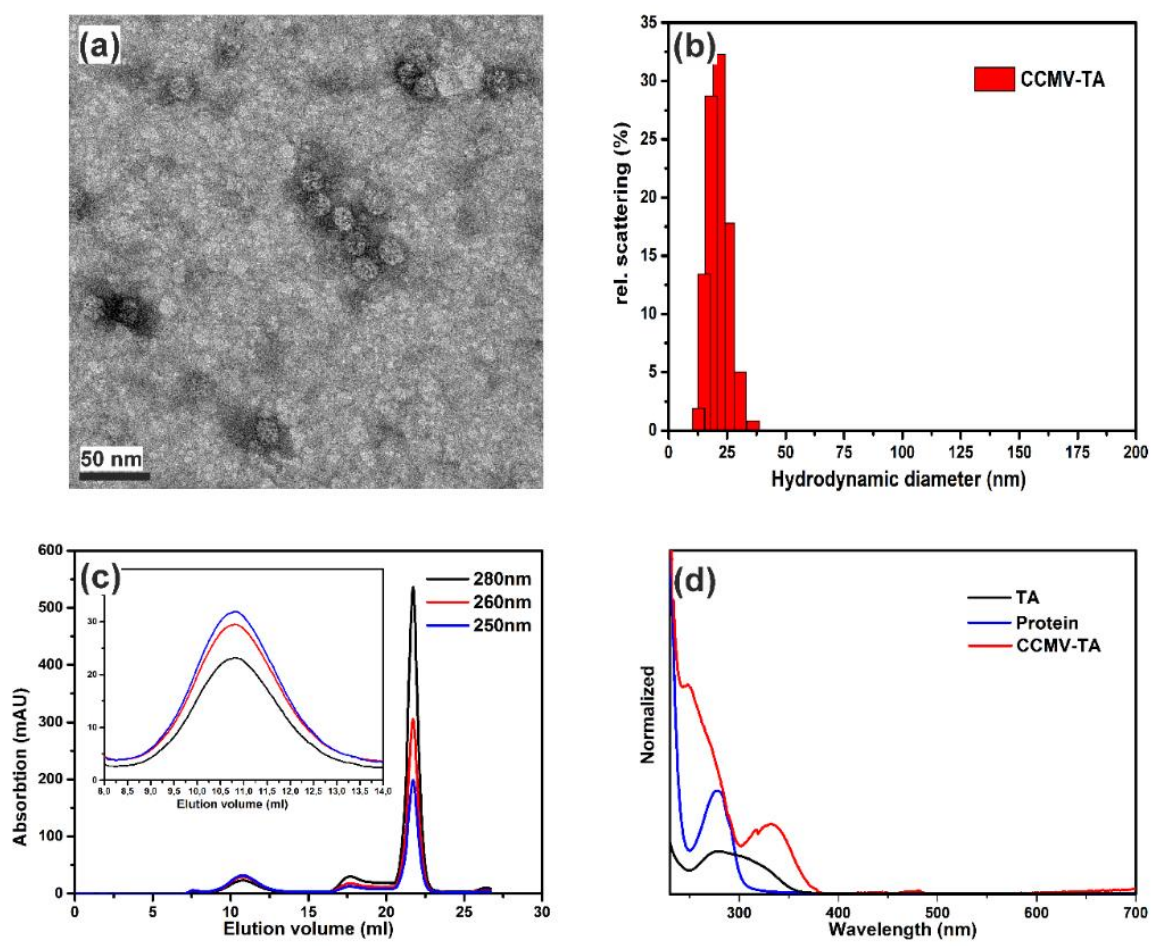

Figure 4.2. (a) TEM image of CCMV-TA; (b) Dynamic light scattering (DLS) analysis of CCMV-TA; (c) FPLC analysis of CCMV-TA and (d) UV-vis of tannic acid (TA), free coat protein and tannic acid encapsulated hybrid nanoparticles (CCMV-TA).

\subsubsection{Ligand exchange}

Aiming at an improved encapsulation, we now introduce bis-p-(sulfonatophenyl) phelylphosphine (BSPP) as stabilizing ligand for gold nanoparticles (Au7B). ${ }^{5}$ The binding affinity of BSPP to the Au NPs is stronger than citric acid and tannic acid. In contrast to tannic acid, a single negatively charged BSPP molecule is too small to be a nucleating center for coat protein self-assembly. Ligand exchange of citric acid stabilized gold nanoparticles is carried out by spin filtration with excess of BSPP. Excess BSPP is removed by dialysis, the resulting particles with zeta potential of $\xi=-25 \mathrm{mV}$, the negative charge density was highly increased compare to citric acid stabilized Au NPs (Au7C, $\xi=-6 \mathrm{mV})$. Au7B particles 
are used for the formation of CCMVAu7B as stated above. Analysis is carried out using FPLC and TEM (Figure 4.3).

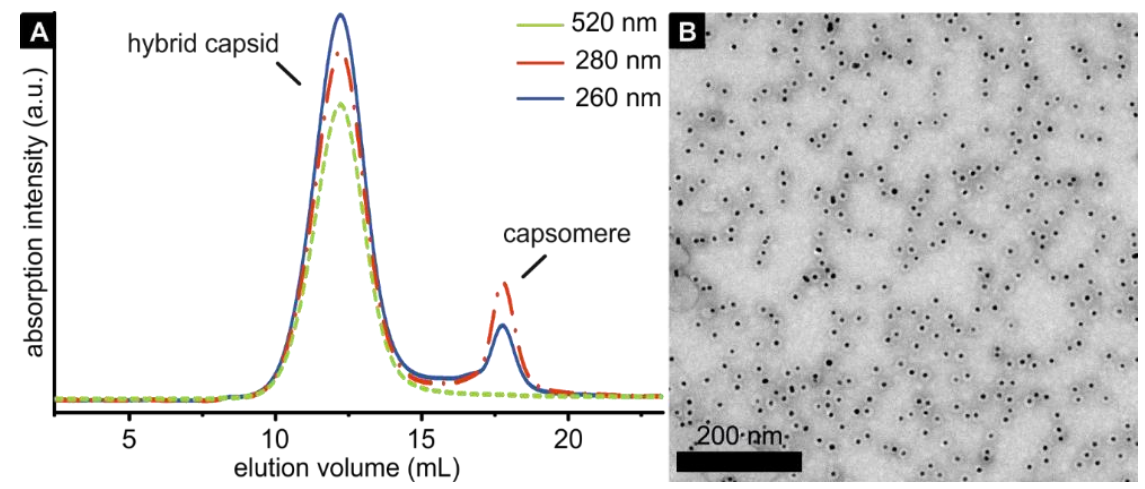

Figure 4.3. Encapsulation of bis-p-(sulfonatophenyl) phelylphosphine (BSPP) stabilized gold nanoparticles with a core diameters of $7 \mathrm{~nm}$. A) FPLC chromatogram of CCMVAu7B. B) TEM image of CCMVAu7B.

CCMVAu7B are formed without pronounced formation of nanoparticle aggregates because no fraction could be collected with an elution volume of $8 \mathrm{~mL}$ using FPLC (Figure 4.3a). Nicely uniform particles of $18 \mathrm{~nm}$ diameter are assembled as determined by TEM (Figure 4.3b). In contrast to tannic acid stabilized templates, BSPP as surfactant excludes the formation capsids without Au NPs. In this context, the issue of charge matching between capsids and cargo of e.g. bromovirus has been addressed by the group of Dragnea and others in great detail. ${ }^{11,13}$ To estimate the charge match between the particles and the capsid we estimated the surface area of Au NP with a diameter of $7 \mathrm{~nm}\left(\mathrm{~A}=154 \mathrm{~nm}^{2}\right)$ that is covered by BSPP $\left(\mathrm{A}=0.5 \mathrm{~nm}^{2}\right)$ by MM@ force field calculations yielding 306 BSPP molecules per nanoparticle (Figure 4.4). Due to the doubly charged BSPP about 612 negative charges are present at the Au NP interface. This number nicely matches the number of positively charged N-terminus inside a $\mathrm{T}=1$ particle (600). 


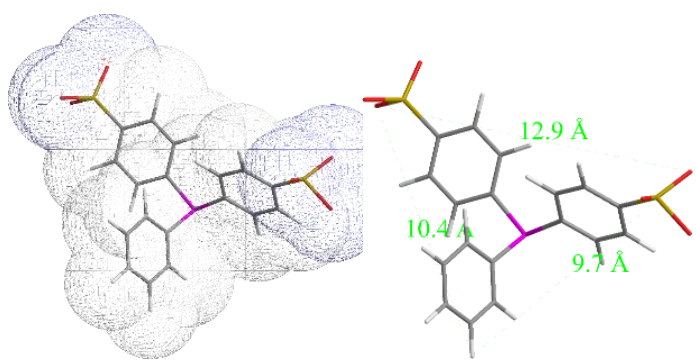

Figure 4.4. MM2 force field calculations of BSPP.

\subsubsection{CCMV-Au7B immobilized flow reactor}

In the present study we have immobilized CCMVAu7B into flow reactor channels and studied the reduction of nitro-arenes to amines as a proof of principle (Figure 4.5). A reactive self-assembled monolayer consisting of perfluorophenyl 11-(triethoxysilyl)undecanoate (PFPS) is used for the immobilization of hybrid virus-like particles (VLPs). The terminal pentafluorophenole ester enables the covalent attachment of amines via peptide bond formation. In contrast to more commonly applied succinimidyl-esters, pentafluorophenol esters are more stable and do not degrade as fast under basic conditions. ${ }^{14}$

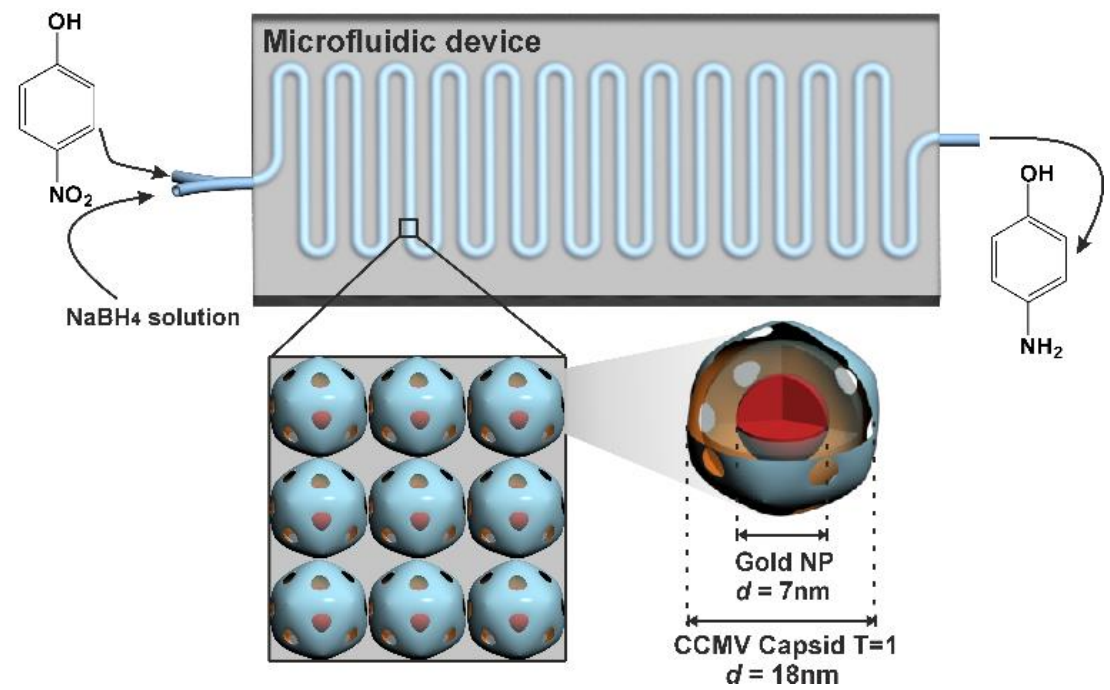

Figure 4.5. CCMV-Gold hybrid NPs immobilized flow reactor. 
The successful immobilization of CCMVAu7B can be directly observed by the naked eye by a reddish coloring of the microreactor and was further confirmed by UV-Vis spectroscopy (Figure 4.6). The modified channel has an absorption at $\lambda=526 \mathrm{~nm}$ which belongs to gold nanoparticles in the VLPs, ${ }^{6}$ while no UV-Vis signal was detected for the pristine microreactor. After immobilization of CCMVAu7B, the surface was exposed to a buffered succinaldehyde solution to further stabilize the VLPs.

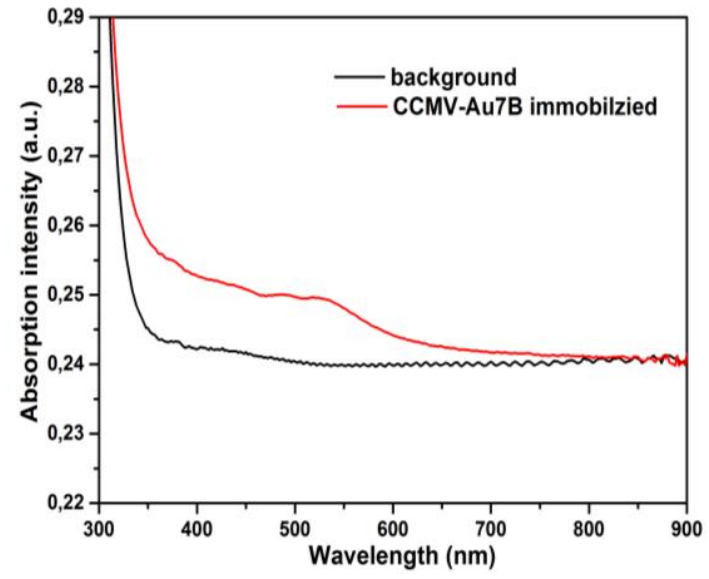

Figure 4.6. UV/Vis analysis of microreactor before (black line) and after immobilization of CCMVAu7B.

Given difficult characterization of CCMVAu7B nanoparticles in the closed microfluidic channels, we initially modified flat glass substrates employing the same procedure. A similar behavior (e.g. coverage) of CCMVAu7B in the microreactor and the flat glass substrate was assumed based on literatures. ${ }^{15}$ The deposition of CCMVAu7B nanoparticles on the glass substrate was evidenced using a range of surface analytics. The immobilization of nanoparticles on this substrate was confirmed by UV-vis spectroscopy and contact-angle analysis (Figure 4.7). With the hydrophilic virus cages being exposed, the water contact angle decreased from $80^{\circ}$ to $35^{\circ}$ upon CCMVAu7B deposition. Atomic force microscopy (AFM) analysis revealed CCMVAu7B hybrid nanoparticles to be deposited on the glass substrate with coverage of $82 \pm 2 \%$ (Figure $4.8 \mathrm{a}$ ). The particles are nicely spherical with an average diameter $\mathrm{D}=23 \mathrm{~nm}$ (Figure 4.8b) which is slightly larger than the value ( $\mathrm{D}=18 \mathrm{~nm}$ ) obtained previously using DLS and TEM. The deviation should originate from deformation of the particles during covalent attachment and a drying induced flattening of spherical particles. 


\section{Chapter 4}

Furthermore, the AFM tip edge may pronounce this effect. To observe the gold nanoparticles inside the soft VLPs, we applied a high-resolution cross sectional SEM, showing the gold core of the immobilized nanoreactors (Figure 4.8c).
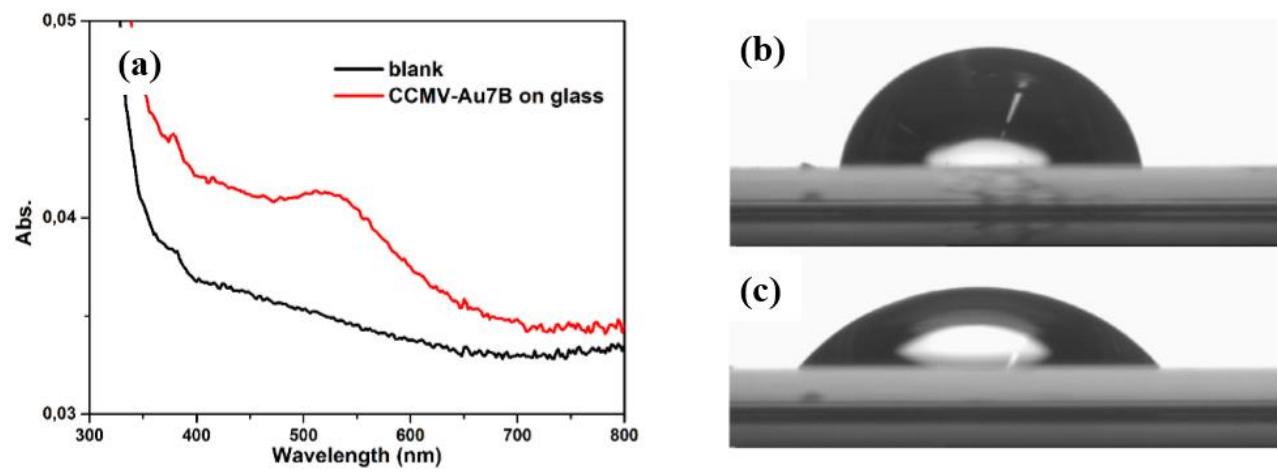

Figure 4.7. Analysis of flat substrates modified with PFPS and CCMVAu7B. (a) UV/Vis analysis (PFPS substrate as black line and CCMVAu7B as red line). Water contact angle analysis of substrates modified with PFPS (b) and CCMVAu7B (c).
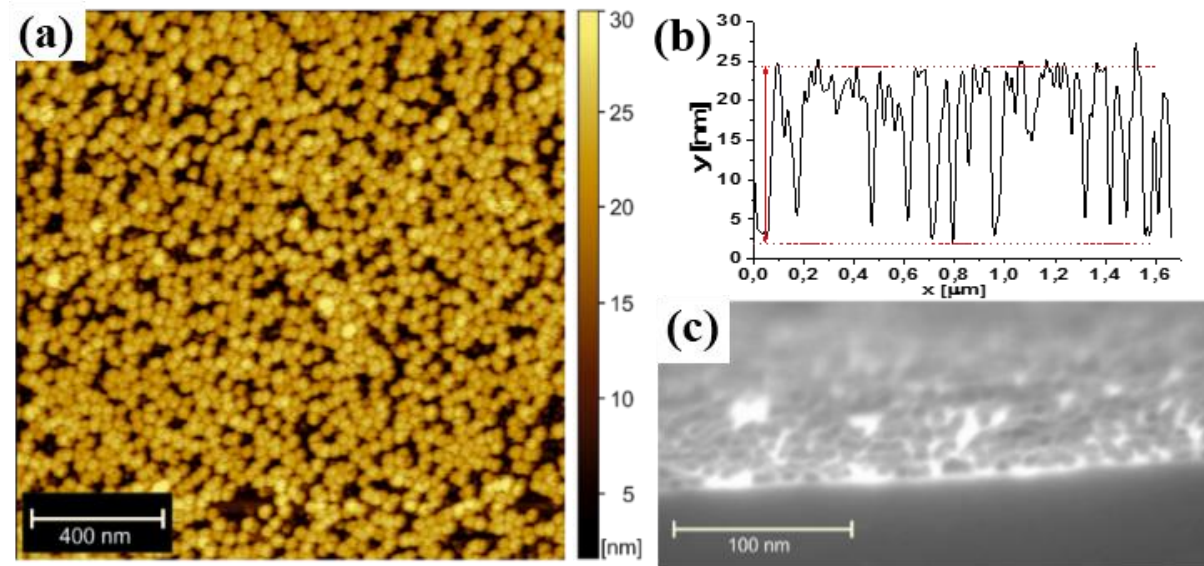

Figure 4.8. Analysis of CCMVAu7B deposited on a PFPS SAM substrate. a) Peak-force tapping AFM data shows a high surface coverage and, b) height of monolayer, and (c) cross section SEM image reveals the gold nanoparticles inside the virus-cages.

To study the catalytic activity of the flow reactor, a reduction reaction with 4-nitrophenol (4NP) as a substrate and $\mathrm{NaBH}_{4}$ as a reductant was carried out. Reduction of $4 \mathrm{NP}$ is generally taken as a model reaction to study the reactivity of Au catalysts. ${ }^{16} 4 \mathrm{NP}$ exhibits a pronounced absorption band at $\lambda \max =400 \mathrm{~nm}$ under the reaction conditions applied. Solutions were passed through a $13 \mu \mathrm{L}$ internal volume microreactor with flow rates changed between $v=$ 
0.5 and $18 \mu \mathrm{L} \cdot \mathrm{min}^{-1}$. The reaction progress was monitored on-line using a light absorption detector. As the flow rate decreased, a decrease of the absorption band at $\lambda=400 \mathrm{~nm}$, accompanied by an increase of a new band at $\lambda=300 \mathrm{~nm}$ (Figure 4.9), indicates the formation of aminophenol. The assignment is in line with numerous studies on similar reduction reaction. ${ }^{17}$

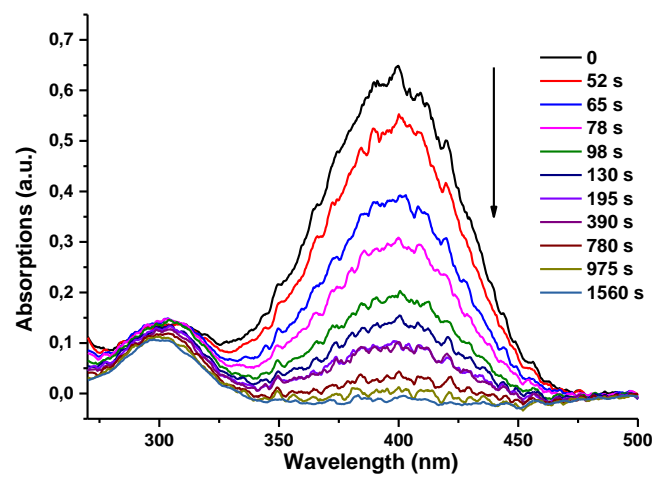

Figure 4.9. UV/Vis spectroscopy on the reduction of 4-nitrophenol using a microreactor coated with CCMVAu7B.

(a)

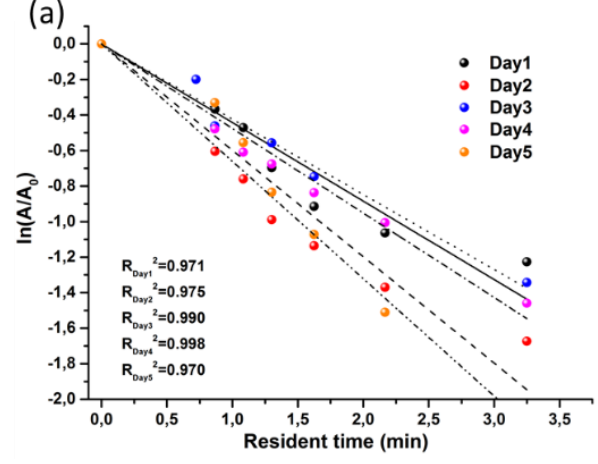

(b)

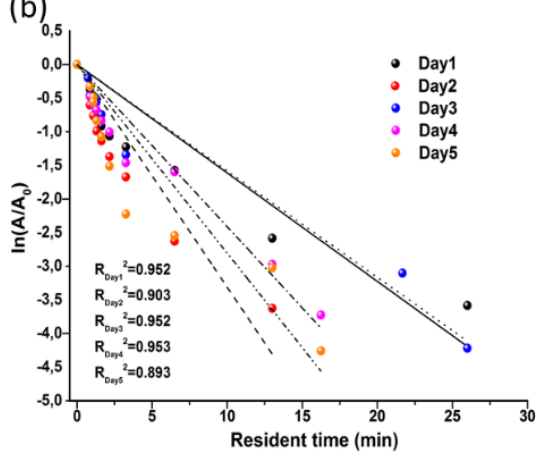

Figure 4.10. Plotted absorption maxima with a linear fit to determine the reaction rate constants of (a) the initial stage and (b) the overall reaction.

We determined the reaction rate by plotting the absorption maxima (normalized, log. Scale) vs. the residence time in the microfluidic channel (Figure 4.10). Two different stages in the reaction were observed: initially, NP is reduced fast. Extended residence times $(\mathrm{t}>3.5$ min) lead to a decrease of the reaction rate, which may due to an increased self-hydrolysis of $\mathrm{NaBH}_{4}$ and the concomitant release of hydrogen gas reducing the available catalyst surface by bubble formation (Figure 4.11). Values of the initial reaction rate and the overall averaged 
reaction rate for different residence times are summarized in Table 1. The reaction rate in the microfluidic channel deviated slightly after 5 days running ( 6 hrs per day).

Table 1. Reduction rates obtained for continuous flow reactions using a microreactor coated with CCMVAu7B.

\begin{tabular}{c|cc}
\hline running time $[\mathrm{h}]$ & $\mathrm{k}_{\text {innitial }}\left[\mathrm{s}^{-1}\right]$ & $\mathrm{k}_{\text {overall }}\left[\mathrm{s}^{-1}\right]$ \\
\hline 6 & $0.74 \cdot 10^{-2} \pm 2.26 \cdot 10^{-4}$ & $5.50 \cdot 10^{-3} \pm 5.30 \cdot 10^{-4}$ \\
12 & $1.00 \cdot 10^{-2} \pm 6.80 \cdot 10^{-5}$ & $2.63 \cdot 10^{-3} \pm 1.21 \cdot 10^{-4}$ \\
18 & $0.71 \cdot 10^{-2} \pm 4.96 \cdot 10^{-5}$ & $4.01 \cdot 10^{-3} \pm 1.92 \cdot 10^{-4}$ \\
24 & $1.10 \cdot 10^{-2} \pm 3.08 \cdot 10^{-4}$ & $4.67 \cdot 10^{-3} \pm 5.00 \cdot 10^{-4}$ \\
30 & $1.24 \cdot 10^{-2} \pm 6.85 \cdot 10^{-4}$ & $2.37 \cdot 10^{-3} \pm 5.20 \cdot 10^{-4}$ \\
\hline
\end{tabular}

The reduction rate in the microfluidic channel deviated slightly after 5 days running (6 hrs per day). The conversion is already quantitative (>99\%) when the residence time is 26 min. This high values was maintained even after 5 days online-reduction (Figure 4.12).

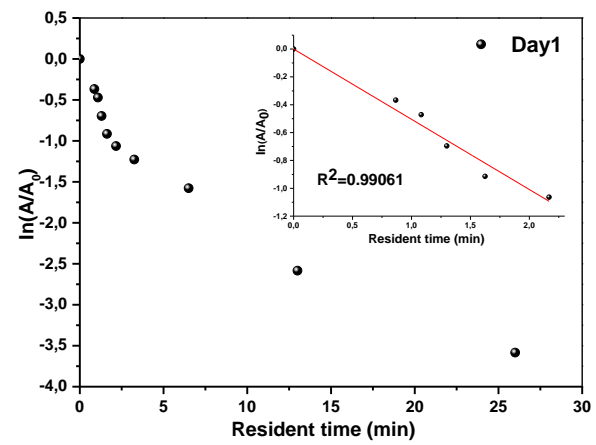

Figure 4.11. Plotted absorption maxima and linear fit to determine the reaction rate constants. Inset: regression analysis of the initial stage of the catalytic reaction.

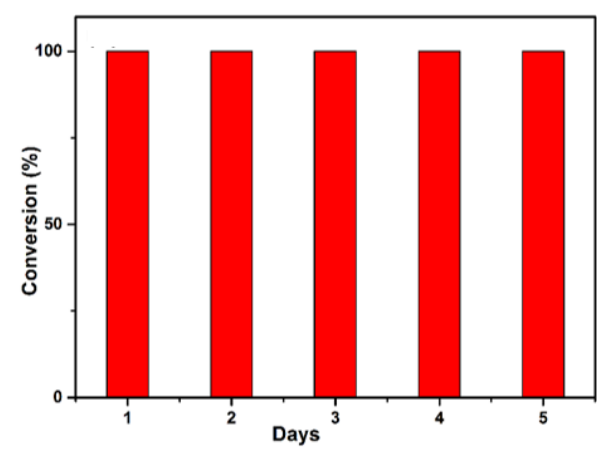

Figure 4.12. Conversion efficiency of the catalytic action of CCMV-Au7B in the microreactor converting the nitro-phenol to the corresponding amine. The reactor is run in continuous flow mode and the conversion is determined by measuring the residual phenol by in-situ UV-Vis spectroscopy. 
In control experiments, the initial reduction rates of $4 \mathrm{NP}$ by the CCMVAu7B catalysts in solution and on the flat glass substrate were compared (Figure 4.13). The rate constant dropped by half upon immobilization of the CCMVAu7B on the glass surface, probably due to a longer diffusion time of the substrate compared to disperse particles. On the other hand, for the catalysts inside the flow reactor the initial rate constant was about 7 times higher compared to CCMVAu7B on glass with same amount of Au atoms (see Table 2), which can be attributed to a higher surface to volume ratio in the flow reactor. It turns out that the catalytic VLPs have the highest efficiency when immobilized inside a flow reactor. It should be noted that the VLPs in the flow reactor are highly stable, no particle loss was observed after reaction, which was confirmed by AFM analysis and UV-vis spectroscopy (Figure 4.14).
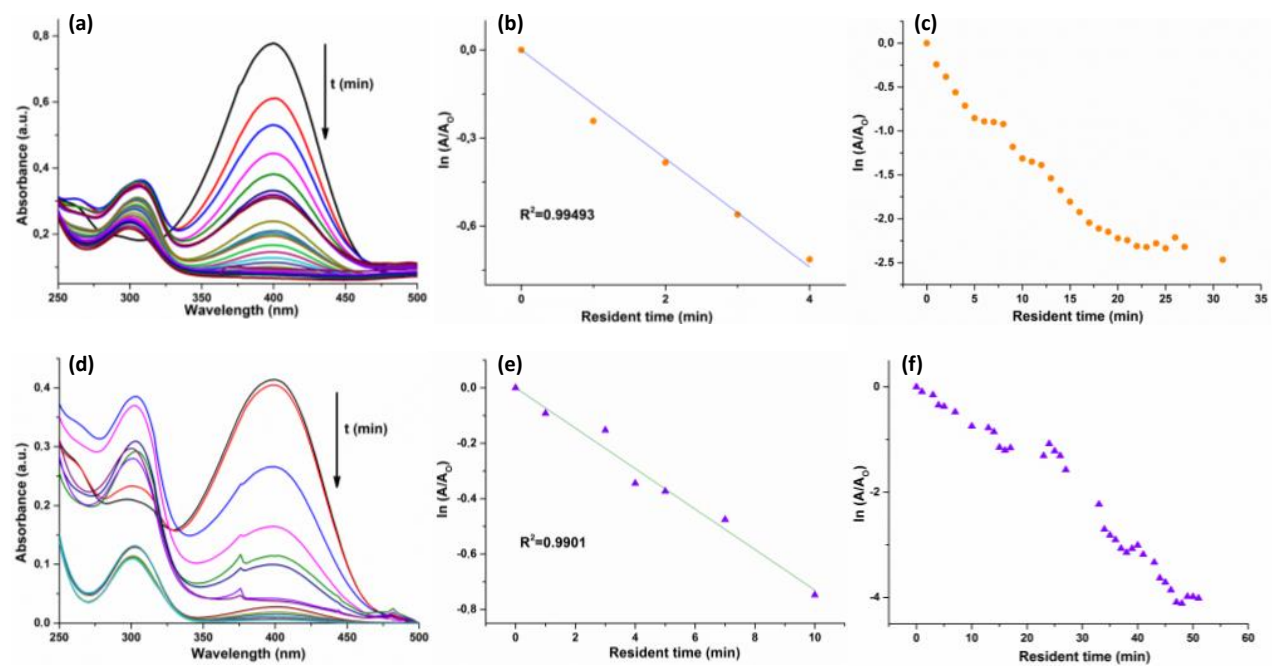

Figure 4.13. 4NP reduction catalyzed by CCMV-Au7B free particles: (a) UV-Vis spectra of 4NP reduction; (b) plotted absorption maxima to resident time at initial stage with a linear fit to determine the reaction rate constants and (c) plotted absorption maxima to resident time for the overall reaction. 4NP reduction catalyzed by CCMV-Au7B immobilized on flat glass substrate: (d) UV-Vis spectra of 4NP reduction; (e) plotted absorption maxima to resident time at initial stage with a linear fit to determine the reaction rate constants and (f) plotted absorption maxima to resident time for the overall reaction. 
Table 2. Comparison of the catalytic free NPs, immobilized NPs on flat glass substrate and in flow reactor.

\begin{tabular}{ccc} 
Sample name & $\begin{array}{c}\text { Rate constant (initial) } \\
\left(\mathrm{s}^{-1}\right)\end{array}$ & $\begin{array}{c}\text { Total Au atoms } \\
(\mathrm{nmol})\end{array}$ \\
\hline $\begin{array}{c}\text { CCMV-Au7B NPs } \\
\text { CCMV-Au7B immobilized } \\
\text { flat glass substrate }\end{array}$ & $3.08 \times 10^{-3} \pm 9.80 \times 10^{-5}$ & 12.4 \\
$\begin{array}{c}\text { CCMV-Au7B immobilized } \\
\text { flow reactor }\end{array}$ & $1.21 \times 10^{-3} \pm 4.60 \times 10^{-5}$ & 9.6 \\
& $1.10 \times 10^{-2} \pm 3.08 \times 10^{-5}$ & 13
\end{tabular}

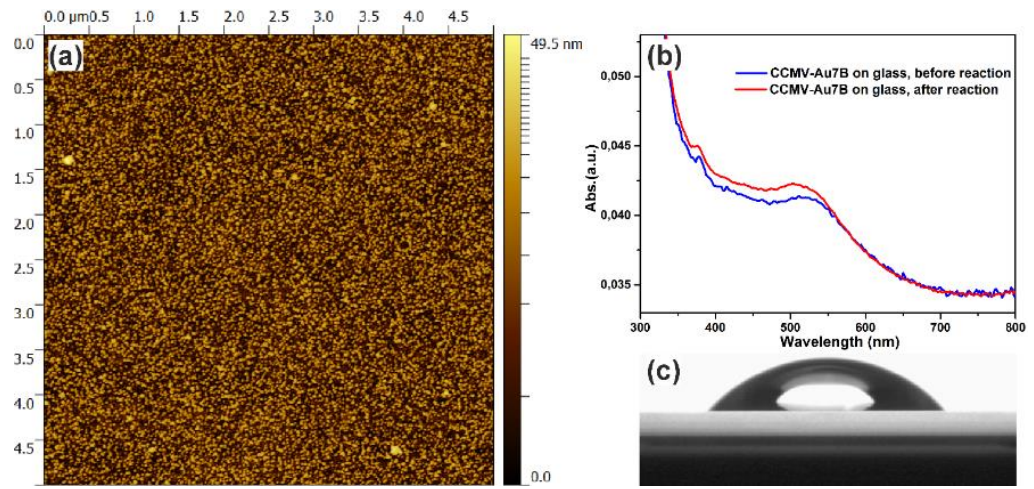

Figure 4.14. CCMV-Au7B on glass substrates after the catalytic reaction, a) AFM analysis; b) UV-vis analysis before and after the model catalytic reaction and c) contact angle analysis.

\subsubsection{Preparation and encapsulation of Au-Pd bimetallic NPs}

The catalytic activity of the microfluidic device can be further optimized by including core-shell bimetallic NPs. These materials have unique optical, electrical and catalytic properties with potential applications in biomedical devices, information storage and catalysis. The most distinct advantages of core-shell bimetallic NPs are the tunable structure and electronic properties compared with their monometallic counterparts, depending on the composition, core size and shell thickness. ${ }^{18}$

To further investigate the scope of the immobilized catalyst containing protein cages, we prepared Au-Pd core-shell NPs. The lattice strain effect of the Au core on the deposited Pd shell, imposed by the Pd matching the Au lattice upon deposition. This leads to an upward shift of the Pd d-band center and consequently it changes the electronic properties of the 
surface, yielding improved properties compared to alloyed bimetallic NPs or mixtures of monometallic NPs. ${ }^{19}$
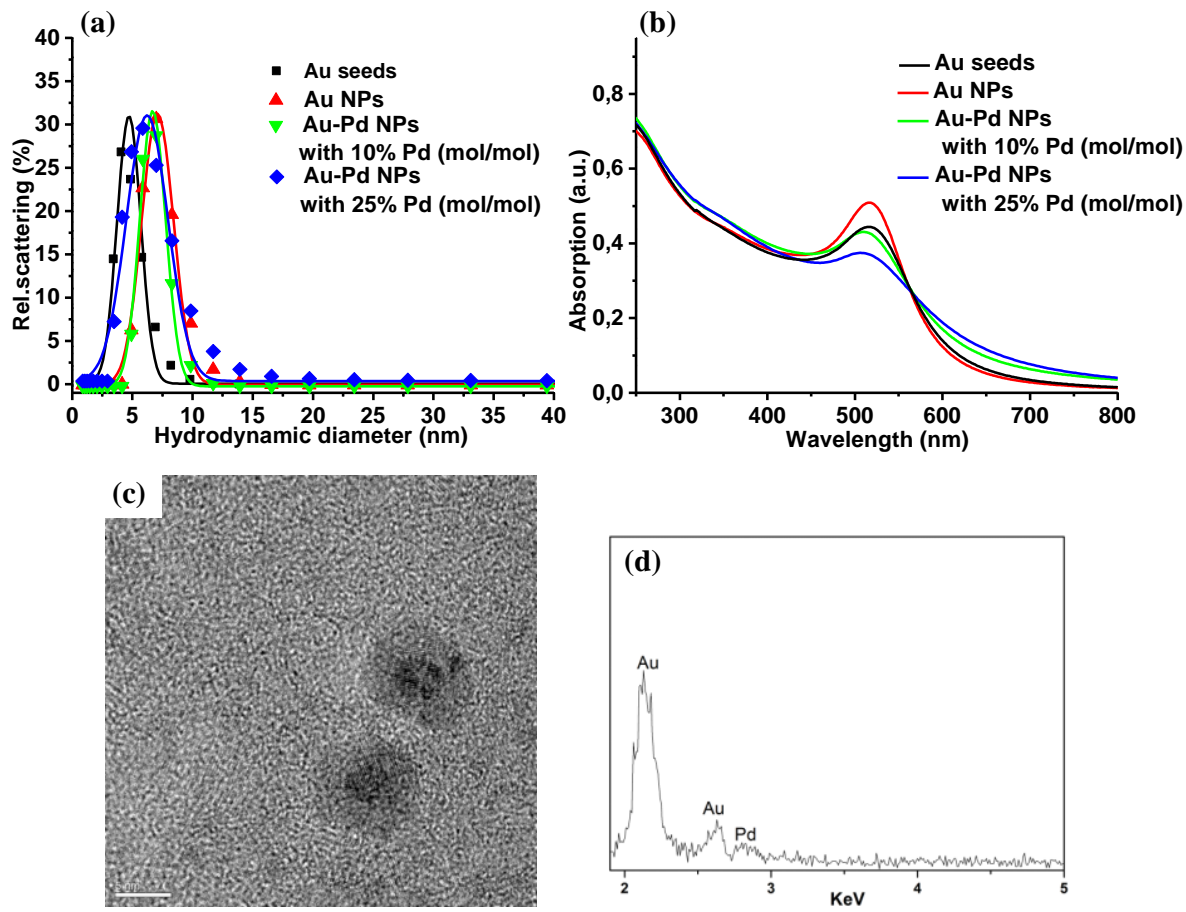

Figure 4.15. (a) \& (b) DLS and UV-Vis measurements of Au seeds, Au NPs and Au-Pd core shell NPs with $10 \% \mathrm{~mol} / \mathrm{mol}$ of Pd and $25 \% \mathrm{~mol} / \mathrm{mol}$ of Pd. (c) TEM analysis of Au-Pd (10\% Pd) core shell NPs, scale bar $5 \mathrm{~nm}$ and (d) Energy-dispersive X-ray spectroscopy (EDX) of confirming the $\mathrm{Au}$ and $\mathrm{Pd}$ composition.

The preparation of Au NPs and Au-Pd core-shell NPs was carried out by the seeded growth method. First, Au seeds were prepared using gold (III) chloride trihydrate as gold source and sodium citrate as reducing agent and stabilizer. This is followed by the addition of a gold source or a palladium source to form Au NPs or Au-Pd core-shell NPs. By controlling the molar ratio between the gold and palladium source, a Pd content $10 \%$ and 25 $\% \mathrm{~mol} / \mathrm{mol}$ respectively was calculated. The produced NPs were analyzed with DLS, UVVis, TEM and EDX techniques. DLS analysis points to monodisperse Au seeds with a size of $4 \mathrm{~nm}$, resulting in Au NPs and Au-Pd NPs (10\%) with diameters of D = 7.0 and D = 6.6 $\mathrm{nm}$, respectively. With increasing Pd content, a broadend peak was found for Au-Pd NPs $(25 \%)$ with an average $\mathrm{D}=6.3 \mathrm{~nm}$. Zeta-potentials were determined for the Au NPs $\xi=-16$ 


\section{Chapter 4}

$\mathrm{mV}$, Au-Pd NPs (10\%) $\xi=-6 \mathrm{mV}$ and Au-Pd NPs $(25 \%) \xi=0 \mathrm{mV}$. With increasing amount of Pd, the stability of the core-shell NPs presumably decreased, which would also explained the broader peak for Au-Pd NPs (25\%) in the DLS. A lower affinity of citrate to Pd might account for these observations, as with an increasing Pd content the stability becomes less. UV-Vis confirmed the successful growth of gold or palladium. With an increasing particle size, the absorption of the gold seeds at $\lambda=516 \mathrm{~nm}$ was increased with no peak shift. While coating of the Au seeds with Pd resulted in a peak shift to $\lambda=509 \mathrm{~nm}$ for Au-Pd (10\%) and $\lambda=506 \mathrm{~nm}$ for Au-Pd NPs (25\%) with lower intensity. TEM shows monodisperse Au-Pd core-shell NPs, with Au-Pd (10\%) shown as a typical example and the Au-Pd composition was confirmed by EDX (Figure 4.15d).

Au-Pd (10\%) NPs was used for encapsulation in the CCMV based protein age. The mixed solution was purified and characterized by FPLC (Figure 4.16a), followed by DLS and TEM analysis. The same procedure as for the encapsulation of Au NPs was followed. From the FPLC 3fractions eluted at $\mathrm{V}=8,11.5$ and $18 \mathrm{~mL}$. Based on the expected elution volume of intact capsid, the second fraction was collected for further study. DLS shows monodisperse materials with an average size of $\mathrm{D}=18 \mathrm{~nm}$ (Figure 4.16b). This is confirmed by TEM analysis (Figure 4.16c), however, due to low stability of Au-Pd, also protein particles containing multi Au-Pd NPs were found.

(a)

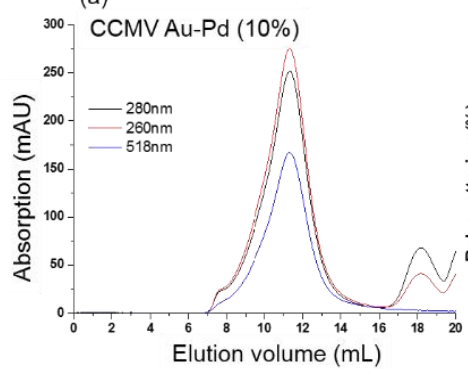

(b)

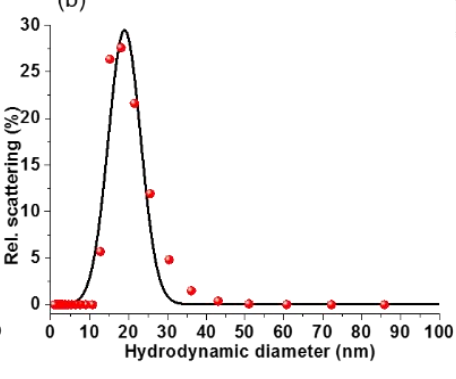

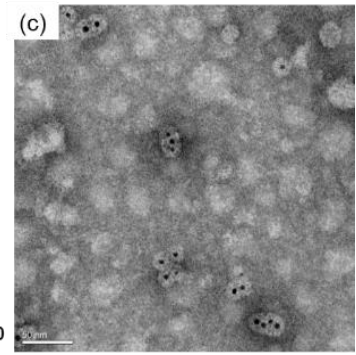

Figure 4.16. Analytical data of the assembly of CCMV Au-Pd (10\%). (a) FPLC chromatogram; (b) DLS and (c) TEM analysis, scale bar $=50 \mathrm{~nm}$. 


\subsection{Conclusions}

In conclusion, we have successfully fabricated a microfluidic reactor by immobilizing catalytic VLPs on the inner surface. The VLPs, based on CCMV protein cages with gold nanoparticles encapsulated inside, were shown to be efficiently immobilized with high stability. A model reduction reaction was carried out successfully in the reactor, which was used 5 days in continuous flow without loss of conversion, highlighting the stability of this virus-like particle based flow reactor. The presented approach is not limited to specific catalysts, and is adaptable to other (bio) organic nanocontainers within which a variety of functional nanoparticles encapsulated. In preliminary studies this is exemplified by the inclusion of Au-Pd core shell NPs, with an expected enhanced catalytic activity. It is anticipated that the adoption of this strategy can move the industrial application of catalytic virus-like nanoparticles forward.

\subsection{Acknowledgments}

Dr. Christoph Traulsen is gratefully acknowledged for the synthesis and characterization of PFPS, and Dr. Liulin Yang is gratefully acknowledged for his help during manuscript preparation. Many thanks to Dr. Roberto Ricciardi and Mr. Marcel de Bruine for their scientific and technical supports.

\subsection{Materials and Methods}

All reagent and reactants have been purchased by Sigma Aldrich. (3Nitrobenzyl)trimethylammonium chloride and sodium borohydride were used as received without further purification. Water used for buffer solutions and reaction process was of MilliQ quality (Millipore, $\mathrm{R}=18.2{\mathrm{M} \Omega C M^{-1}}^{\text {) }}$. Citric acid stabilized gold nanoparticles have been purchased from NanoComposix ( $7 \mathrm{~nm}$ gold core, $0.05 \mathrm{mg} / \mathrm{ml}$ ) and were dispersed in MilliQ water. Quartz glass cuvette were purchased from Hellma-analytics, Quartz SUPRASIL (QS). Diced borofloat wafers (Schott) and polished silicon wafers $(\mathrm{p}++)$ were 


\section{Chapter 4}

used for studies on flat substrates. Amicon Ultra centrifuge filter with 10K MWCO from Pall Microsep $^{\mathrm{TM}}$ Advance Centrifuge Device with Omega Membrane were used for particle preparation.

Bis-p-(sufonatophenyl) phenyl phosphine (BSPP) ligand exchange. BSPP capped nanoparticles are prepared according to a modified procedure. ${ }^{20}$ Briefly, BSPP (4 mg, 7.5 $\mu \mathrm{mol})$ is dissolved in Milli-Q ( $1 \mathrm{~mL})$ added to an aqueous solution of citrate stabilized gold nanoparticles $(10 \mathrm{~mL})$ and stirred overnight at $\mathrm{r}$. t. Citric acid is removed using a $30 \mathrm{kD}$ MWCO centrifuge filter and washing three times with aqueous BSPP (1 mM). The particles were concentrated $(1.5 \mathrm{~mL}, 0.33 \mathrm{mg} / \mathrm{mL})$.

Synthesis of Au seeds. To preparation of colloidal gold seeds, $1 \mathrm{~mL}$ of $1 \%$ aqueous $\mathrm{HAuCl}_{4} \cdot 3 \mathrm{H}_{2} \mathrm{O}(3.2 \mathrm{mM})$ was added to $12.5 \mathrm{~mL}$ of $\mathrm{H} 2 \mathrm{O}$. After one minute $1 \mathrm{ml}$ of $1 \%$ aqueous $\mathrm{Na} 3$ citrate was added. After an additional minute $1 \mathrm{ml}$ of prepared a minute earlier $0.075 \%$ $\mathrm{NaBH} 4$ in $1 \% \mathrm{Na}_{3}$ citrate $\left(7.5 \mathrm{mg}\right.$ of $\mathrm{NaBH}_{4}+0.1 \mathrm{~g}$ of $1 \% \mathrm{Na}_{3}$ citrate $+10 \mathrm{~mL}$ of $\left.\mathrm{H} 2 \mathrm{O}\right)$ was added. Then the solution was stirring still for 5 minutes and store at $4^{\circ} \mathrm{C}$.Synthesis of Au NPs and Au-Pd core-shell NPs.

Au NPs. First, $2 \mathrm{~mL}$ of $1 \%$ aqueous $\mathrm{HAuCl}_{4} \cdot 3 \mathrm{H}_{2} \mathrm{O}(3.2 \mathrm{mM})$ was added to $25 \mathrm{~mL}$ of $\mathrm{H}_{2} \mathrm{O}$. After one minute $250 \mu \mathrm{L}$ of $1 \%$ aqueous $\mathrm{Na}_{3}$ citrate was added. After an additional minute $1 \mathrm{ml}$ of prepared a minute earlier $0.075 \% \mathrm{NaBH}_{4}$ in $1 \% \mathrm{Na}_{3}$ citrate $\left(7.5 \mathrm{mg}\right.$ of $\mathrm{NaBH}_{4}+0.1 \mathrm{~g}$ of $1 \% \mathrm{Na}_{3}$ citrate $+10 \mathrm{~mL}$ of $\mathrm{H}_{2} \mathrm{O}$ ) was added. Then the solution was stirring still for 5 minutes and store at $4^{\circ} \mathrm{C}$. Next, $5 \mathrm{ml}$ of prepared solution was taken and add $500 \mu \mathrm{L}$ of $\mathrm{Na}_{3}$ citrate. After one minute $100 \mu \mathrm{L}$ of $2 \mathrm{mM} \mathrm{HAuCl}_{4}$ was added. After next two minutes 50 $\mu \mathrm{L}$ of $\mathrm{H}_{2} \mathrm{O}_{2}$. Then it was 2 hours of reaction at room temperature with stirring. After this time the solution was centrifuged three times with miliQ water, two times with aqueous $0.1 \%$ $\mathrm{Na}_{3}$ citrate.

Au-Pd core-shell NPs. First, the solution was prepared by mixing $5 \mathrm{~mL}$ of gold seed solution with $500 \mu \mathrm{L}$ of $\mathrm{Na}_{3}$ citrate. After one minute $100 \mu \mathrm{L}$ of $\mathrm{Na}_{2} \mathrm{PdCl}_{4}$ was added. After next two minutes $50 \mu \mathrm{l}$ of $\mathrm{H}_{2} \mathrm{O}_{2}$. Then it was 2 hours of reaction at room temperature with stirring. After this time the solution was centrifuged three times with miliQ water, two times with aqueous $0.1 \% \mathrm{Na}_{3}$ citrate.

Hybrid particle formation. In a typical experiment Au NP or Au-Pd core-shell NPs solution ( $\left.400 \mu \mathrm{L}, 0.5 \mathrm{mg} / \mathrm{mL} ; \mathrm{H}_{2} \mathrm{O}\right)$ is added to a solution of CCMV coat protein $(100 \mu \mathrm{L}, 15 \mathrm{mg} / \mathrm{mL}$; 
$\mathrm{pH} 7.5 ; 50 \mathrm{mM}$ Tris, $500 \mathrm{mM} \mathrm{NaCl}$ ) and allowed to incubate for $5 \mathrm{~min}$ at r.t. The reaction mixture is subsequently resulting VLPs are purified using preparative FPLC.

FPLC. FPLC size exclusion chromatography samples, ranging from $100 \mu \mathrm{L}$ up to $500 \mu \mathrm{L}$ dialyzed overnight to the coat protein buffer ( $\mathrm{pH} 7.5 ; 50 \mathrm{mM}$ Tris, $500 \mathrm{mM} \mathrm{NaCl}$ ). The were measured on an Aktapurifier (Box-900) equipped with a $24 \mathrm{~mL}$ Superose 6 10/100 GL column (GE Healthcare) at $0.5 \mathrm{~mL} / \mathrm{min}$ flow and collected by fractionation (Frac-950).

UV-Vis. Samples are prepared from $500 \mu \mathrm{L}$ fresh sample solutions. They were measured in a $1 \mathrm{~cm}$ quartz cuvette in a PerkinElmer Lambda 850 UV/VIS Spectrometer.

(S)TEM. The TEM samples are prepared by drop casting $5 \mu \mathrm{L}$ of a freshly made sample solution onto a formvar carbon coated copper grid. After 5 min incubation the remaining liquid is removed by tipping the grid onto low lint paper (Kimtech science precision wipes). The samples are stained using $5 \mu \mathrm{L}$ of a $1 \%$ uranyl acetate solution which is removed after $30 \mathrm{~s}$ to provide optimal contrast. Samples are imaged using a Philips CM300ST-FEG TEM or a Zeiss Merlin (S)TEM. The resulting images are analyzed using ImageJ software to determine the sizes of the total particles and the gold core

DLS. Each sample is measured five times for 120 seconds using an Anaspec nanotrack wave dynamic light scattering instrument, using a refractive index of 1.54 for the hybrid particles and the viscosity of water. The average of 5 measurements is used for further analysis.

Zeta-potential. The $\zeta$-potential of the Au NPs with different ligands at $\mathrm{pH} 7.5$ was characterized by a Zetasizer Nano ZS ZEN3600 instrument (Malvern Instruments) at $25^{\circ} \mathrm{C}$ with $633 \mathrm{~nm}$ laser.

Flow reactor apparatus. CCMV-Au7B nanoparticles are immobilize in microreactor chip using a PHD 22/2000 series syringe pump (Harvard Apparatus, United Kingdom) equipped with $250 \mu \mathrm{L}$ flat tip syringes (Hamilton). Syringes were connected to fused silica capillaries (100 $\mu$ m i.d., $362 \mu$ m o.d., Polymicro Technologies) using Upchurch Nanoport ${ }^{\mathrm{TM}}$ assembly parts (i.e., Nano-Tight ${ }^{\mathrm{TM}}$ unions and fittings, Upchurch Scientific Inc., USA). The glass microreactor was placed in a chip holder (Upchurch Nanoport ${ }^{\mathrm{TM}}$ ). A glass microreactor with a residual volume of $13 \mu \mathrm{L}$ (dimensions: $150 \mu \mathrm{m}$ width and $150 \mu \mathrm{m}$ depth) were purchased from Micronit Microfluidics.

Immobilization of CCMV-Au7B. Substrates and microreactors were rinsed with water and activated by immersion/cycling piranha solution $\left(\mathrm{H}_{2} \mathrm{SO}_{4}: \mathrm{H}_{2} \mathrm{O}_{2}=3: 1\right)$ and then rinsed with 
water and ethanol, dried with a steam of nitrogen. !Caution: Piranha solution reacts violently with organic material and has to be treated with utmost care! Perfluorophenyl-11(triethoxysilyl)undecanoate (PFPS) was deposited by substrate immersion into a PFPS solution (DCM, $10 \mathrm{mM}$ ) for $24 \mathrm{~h}$ at r.t. under argon atmosphere. Microreactors are functionalized by cycling the solution for $6 \mathrm{~h}$ at a flow rate of $0.05 \mu \mathrm{L} / \mathrm{min}$ at room temperature through the device. Both glass wafer and microreactor was rinsed with DCM to remove unreacted reagent and dried in a steam of $\mathrm{N}_{2}$.

CCMV-Au7B hybrid nanoparticles are deposited from buffered (0.2 M phosphate, $\mathrm{pH} 7.2$ ) water. The particles are drop-coated on flat glass substrate overnight in a closed vessel to avoid solvent evaporation. Microreactors were wall coated by cycling the solution for $12 \mathrm{~h}$ at a flow rate of $0.05 \mu \mathrm{L} / \mathrm{min}$ at r.t. Both glass substrate and microreactor were rinsed with buffer solution to remove unreacted nanoparticles.

\section{Estimation of the gold quantity during the different reaction conditions in order to compare to activity:}

\section{Total number of Au atoms in free CCMV-Au7B solution}

Reaction condition: $150 \mu \mathrm{L}$ of CCMV-Au7B solution with $\mathrm{A}_{520}=0.280$ was added into $4 \mathrm{NP}$ and sodium borohydride mixed solution, result in $0.5 \mathrm{mM}$ of $4 \mathrm{NP}$ and $600 \mu \mathrm{L}$ total reaction solution. Reaction was monitored by UV-Vis spectrometer right after adding catalyst.
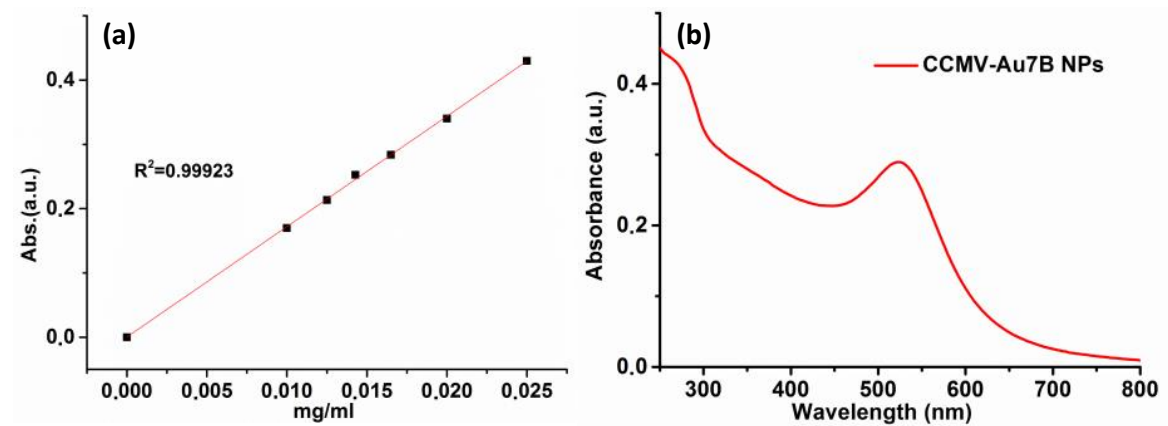

Figure 4.17. (a) Linear fit of UV-Vis absorption of Au7B at $\lambda=520 \mathrm{~nm}$ with different concentrations; (b) UV-Vis spectrum of CCMVAu-7B in MQ for concentration calculation.

\section{Known:}

1. $0.025 \mathrm{mg} / \mathrm{mL}$ of Au7B with absorption of $\mathrm{A}_{520}=0.43002$ contained $0.85 \times 10^{13}$ particles $/ \mathrm{mL}$; 
2. The concentration of Au NPs and the absorption at $\lambda=520 \mathrm{~nm}$ are in linear relationship (Figure 4.17a).

Therefore: CCMV-Au7B in MQ for reaction with $\mathrm{A}_{520}=0.280$ contained $0.0163 \mathrm{mg} / \mathrm{mL}$ of Au7B; with a volume $\mathrm{V}=150 \mu \mathrm{L}$ and $\mathrm{Mw}(\mathrm{Au})=197 \mathrm{~g} / \mathrm{mol}$, the total amount of $\mathrm{Au}$ atoms in reaction solution is $=\mathrm{c} \times \mathrm{V} / \mathrm{Mw}=(0.0163 \mathrm{mg} / \mathrm{ml} \times 150 \mu \mathrm{L}) /(197 \mathrm{~g} / \mathrm{mol})=12.4 \mathrm{nmol}$.

\section{Total number of Au atoms on flat glass substrate}

Reaction condition: CCMV-Au NPs immobilized glass substrate was added into $400 \mu \mathrm{L}$ of 4NP (contain 4NP of $0.5 \mathrm{Mm}$ ) and sodium borohydride mixed solution. Reaction was monitored by UV-Vis spectrometer right after adding glass substrate.

Known: Area of the CCMV-Au NPs immobilized glass surface: $2.0 \mathrm{~cm} \times 1.0 \mathrm{~cm}$, corresponding to $2.0 \times 10^{14} \mathrm{~nm}^{2}$, while the coverage of CCMV-Au7B on glass substrate is $82 \%$ (see manuscript).

Total number of CCMV-Au7B particles $=\left(\mathrm{S}_{\text {immobilzied glass surface }} / \mathrm{S}_{\mathrm{CCMV} \text {-Au7B cross-sectional area }}\right) \times$ $82 \%=2.0 \times 10^{14} \mathrm{~nm}^{2} /\left(\pi \cdot 9^{2} \mathrm{~nm}^{2} /\right.$ particle $) \times 82 \%$.

Therefore: the total number of CCMV-Au7B particles on glass surface $=6.45 \times 10^{11}$, while the mass of a single particles is: $0.025 \mathrm{mg} / 0.85 \times 10^{13}$. The mass of the Au7B particles on flat glass substrate $=\left(6.45 \times 10^{11} / 0.85 \times 10^{13}\right) \times 0.025 \mathrm{mg}=1.897 \times 10^{-6} \mathrm{~g}$. The total amount of Au atoms on glass substrate $=1.897 \times 10^{-6} \mathrm{~g} /(197 \mathrm{~g} / \mathrm{mol})=9.6 \mathrm{nmol}$.

\section{Total number of Au atoms in flow reactor}

Known: The flow channel with a length of $58 \mathrm{~cm}$, a diameter of $150 \mu \mathrm{m}$, resulting in an inner surface area, $\mathrm{A}=2.73 \times 10^{14} \mathrm{~nm}^{2}$ with an assumed coverage of CCMV-Au7B on glass surface of $82 \%$ (see manuscript).

The total number of CCMV-Au7B particles $=\left(\mathrm{S}_{\text {inner surface area of flow channel }} / \mathrm{S}_{\mathrm{CCMV} \text {-Au7B cross-sectional }}\right.$ area $) \times 82 \%=2.73 \times 10^{14} \mathrm{~nm}^{2} /\left(\pi \cdot 9^{2} \mathrm{~nm}^{2} /\right.$ particle $) \times 82 \%$

Therefore the total number of CCMV-Au7B particles on inner surface $=8.8 \times 10^{11}$, while the mass of a single particles is: $0.025 \mathrm{mg} / 0.85 \times 10^{13}$; the total amount of Au7B particles in flow reactor $=\left(8.8 \times 10^{11} / 0.85 \times 10^{13}\right) \times 0.025 \mathrm{mg}=2.588 \times 10^{-6} \mathrm{~g}$. The total amount of $\mathrm{Au}$ atoms in flow reactor $=2.588 \times 10^{-6} \mathrm{~g} /(197 \mathrm{~g} / \mathrm{mol})=13.1 \mathrm{nmol}$. 


\subsection{References}

1. Chen, Y. Y.; Qiu, J. S.; Wang, X. K.; Xiu, J. H., Preparation and application of highly dispersed gold nanoparticles supported on silica for catalytic hydrogenation of aromatic nitro compounds. J. Catal. 2006, 242 (1), 227-230.

2. $\quad$ (a) Zou, H.; Wang, R.; Dai, J.; Wang, Y.; Wang, X.; Zhang, Z.; Qiu, S., Amphiphilic hollow porous shell encapsulated Au@Pd bimetal nanoparticles for aerobic oxidation of alcohols in water. Chem. Commun. 2015, 51 (78), 14601-14604; (b) Shin, Y.; Dohnalkova, A.; Lin, Y., Preparation of Homogeneous Gold-Silver Alloy Nanoparticles Using the Apoferritin Cavity As a Nanoreactor. The Journal of Physical Chemistry C 2010, 114 (13), 5985-5989; (c) Zhang, Y.; Xiang, S.; Zhou, Y.; Xu, Y.; Zhang, Z.; Sheng, X.; Wang, Q.; Zhang, C., Enhanced catalytic activity with high thermal stability based on multiple Au cores in the interior of mesoporous Si-Al shells. RSC Adv. 2015, 5 (60), 48187-48193; (d) Cao, Z.; Chen, H.; Zhu, S.; Chen, Z.; Xu, C.; Qi, D.; Ziener, U., Inverse miniemulsion-based preparation of raspberry-like $\mathrm{Au} / \mathrm{SiO} 2$ nanocomposite particles with high catalytic activity towards reduction of p-nitrophenol. Colloids and Surfaces A: Physicochemical and Engineering Aspects 2016, 489, 223-233; (e) Lee, J.; Park, J. C.; Song, H., A Nanoreactor Framework of a Au@SiO2 Yolk/Shell Structure for Catalytic Reduction of p-Nitrophenol. Adv. Mater. 2008, 20 (8), 1523-1528; (f) Liu, H.; Wang, J.; Feng, Z.; Lin, Y.; Zhang, L.; Su, D., Facile Synthesis of Au Nanoparticles Embedded in an Ultrathin Hollow Graphene Nanoshell with Robust Catalytic Performance. Small 2015, 11 (38), 5059-5064; (g) Mitschang, F.; Schmalz, H.; Agarwal, S.; Greiner, A., Tea-Bag-Like Polymer Nanoreactors Filled with Gold Nanoparticles. Angewandte Chemie International Edition 2014, 53 (19), 4972-4975; (h) Lu, Y.; Mei, Y.; Ballauff, M.; Drechsler, M., Thermosensitive Core-Shell Particles as Carrier Systems for Metallic Nanoparticles. J. Phys. Chem. B 2006, 110 (9), 3930-3937; (i) Zhao, Y.; Sakai, F.; Su, L.; Liu, Y.; Wei, K.; Chen, G.; Jiang, M., Progressive Macromolecular Self-Assembly: From Biomimetic Chemistry to Bio-Inspired Materials. Advanced Materials 2013, 25 (37), 5215-5256.

3. Patterson, D. P.; Prevelige, P. E.; Douglas, T., Nanoreactors by Programmed Enzyme Encapsulation Inside the Capsid of the Bacteriophage P22. ACS Nano 2012, 6 (6), 5000-5009.

4. Wen, A. M.; Steinmetz, N. F., Design of virus-based nanomaterials for medicine, biotechnology, and energy. Chemical Society Reviews 2016, 45 (15), 4074-4126.

5. Liu, A.; Verwegen, M.; de Ruiter, M. V.; Maassen, S. J.; Traulsen, C. H. H.; Cornelissen, J. J. L. M., Protein Cages as Containers for Gold Nanoparticles. The Journal of Physical Chemistry B 2016, 120 (26), 6352-6357.

6. $\quad$ Liu, A.; Traulsen, C. H. H.; Cornelissen, J. J. L. M., Nitroarene Reduction by a Virus Protein Cage Based Nanoreactor. ACS Catalysis 2016, 6 (5), 3084-3091.

7. (a) Bolisetty, S.; Arcari, M.; Adamcik, J.; Mezzenga, R., Hybrid Amyloid Membranes for Continuous Flow Catalysis. Langmuir 2015, 31 (51), 13867-13873; (b) Ricciardi, R.; Huskens, J.; Verboom, W., Influence of the Au/Ag ratio on the catalytic activity of dendrimer-encapsulated bimetallic nanoparticles in microreactors. Journal of Flow Chemistry 2015, 5 (4), 228-233.

8. (a) Gutmann, B.; Cantillo, D.; Kappe, C. O., Continuous-Flow Technology-A Tool for the Safe Manufacturing of Active Pharmaceutical Ingredients. Angew. Chem. Int. Ed. 2015, 54 (23), 6688-6728; (b) Asanomi, Y.; Yamaguchi, H.; Miyazaki, M.; Maeda, H., 
Enzyme-Immobilized Microfluidic Process Reactors. Molecules 2011, 16 (7), 6041; (c) Kim, D.; Herr, A. E., Protein immobilization techniques for microfluidic assays. Biomicrofluidics 2013, 7 (4), 041501; (d) Munirathinam, R.; Huskens, J.; Verboom, W., Supported Catalysis in Continuous-Flow Microreactors. Advanced Synthesis \& Catalysis 2015, 357 (6), 1093 1123; (e) Ricciardi, R.; Huskens, J.; Verboom, W., Nanocatalysis in Flow. ChemSusChem 2015, 8 (16), 2586-2605; (f) Nagasawa, Y.; Tanba, K.; Tada, N.; Yamaguchi, E.; Itoh, A., A Study of Aerobic Photooxidation with a Continuous-Flow Microreactor. Synlett 2015, 26 (03), 412-415.

9. Zhang, M.; Wei, L.; Chen, H.; Du, Z.; Binks, B. P.; Yang, H., Compartmentalized Droplets for Continuous Flow Liquid-Liquid Interface Catalysis. Journal of the American Chemical Society 2016.

10. Zhang, H.; Li, X.; Chen, G., Ionic liquid-facilitated synthesis and catalytic activity of highly dispersed Ag nanoclusters supported on TiO2. Journal of Materials Chemistry 2009, 19 (43), 8223-8231.

11. Sun, J.; DuFort, C.; Daniel, M.-C.; Murali, A.; Chen, C.; Gopinath, K.; Stein, B.; De, M.; Rotello, V. M.; Holzenburg, A.; Kao, C. C.; Dragnea, B., Core-controlled polymorphism in virus-like particles. Proceedings of the National Academy of Sciences 2007, 104 (4), 1354-1359.

12. Van Buren, J. P.; Robinson, W. B., Formation of complexes between protein and tannic acid. Journal of Agricultural and Food Chemistry 1969, 17 (4), 772-777.

13. Daniel, M.-C.; Tsvetkova, I. B.; Quinkert, Z. T.; Murali, A.; De, M.; Rotello, V. M.; Kao, C. C.; Dragnea, B., Role of Surface Charge Density in Nanoparticle-templated Assembly of Bromovirus Protein Cages. ACS Nano 2010, 4 (7), 3853-3860.

14. Lockett, M. R.; Phillips, M. F.; Jarecki, J. L.; Peelen, D.; Smith, L. M., A Tetrafluorophenyl Activated Ester Self-Assembled Monolayer for the Immobilization of Amine-Modified Oligonucleotides. Langmuir 2008, 24 (1), 69-75.

15. Costantini, F.; Bula, W. P.; Salvio, R.; Huskens, J.; Gardeniers, H. J. G. E.; Reinhoudt, D. N.; Verboom, W., Nanostructure Based on Polymer Brushes for Efficient Heterogeneous Catalysis in Microreactors. Journal of the American Chemical Society 2009, 131 (5), 1650-1651.

16. Seo, Y. S.; Ahn, E.-Y.; Park, J.; Kim, T. Y.; Hong, J. E.; Kim, K.; Park, Y.; Park, Y., Catalytic reduction of 4-nitrophenol with gold nanoparticles synthesized by caffeic acid. Nanoscale Research Letters 2017, 12, 7.

17. Wunder, S.; Polzer, F.; Lu, Y.; Mei, Y.; Ballauff, M., Kinetic Analysis of Catalytic Reduction of 4-Nitrophenol by Metallic Nanoparticles Immobilized in Spherical Polyelectrolyte Brushes. J. Phys. Chem. C 2010, 114 (19), 8814-8820.

18. Huang, X.; Wu, H.; Pu, S.; Zhang, W.; Liao, X.; Shi, B., One-step room-temperature synthesis of $\mathrm{Au} @ \mathrm{Pd}$ core-shell nanoparticles with tunable structure using plant tannin as reductant and stabilizer. Green Chemistry 2011, 13 (4), 950-957.

19. Chen, D.; Li, C.; Liu, H.; Ye, F.; Yang, J., Core-shell Au@Pd nanoparticles with enhanced catalytic activity for oxygen reduction reaction via core-shell $\mathrm{Au} @ \mathrm{Ag} / \mathrm{Pd}$ constructions. Scientific Reports 2015, 5, 11949.

20. Liu, M.; Fang, L.; Li, Y.; Gong, M.; Xu, A.; Deng, Z., "Flash" preparation of strongly coupled metal nanoparticle clusters with sub-nm gaps by Ag+ soldering: toward effective plasmonic tuning of solution-assembled nanomaterials. Chemical Science 2016, 7 (8), 5435-5440. 


\section{Chapter 5}

\section{Compartmentalized Thin Films with Tunable Functionality via Interfacial Cross-linking of Protein Cages}

Hybrid thin films with a high loading and homogeneous dispersion of functional nanoparticles (and/or molecules) might find application in (bio)sensors and electronic devices. The fabrication, however, of such hybrid thin films remains a challenge. To address this challenge, we report a facile strategy to create compartments within thin films through the interfacial cross-linking of viral protein cages. Taking advantage of these protein cages, functional cargos such as gold nanoparticles, quantum dots and the enzyme horseradish peroxidase were first encapsulated separately into virus-like particles and then cross-linked to form monolayer films to sub-micron size. These compartmentalized thin films not only ensure that the cargo is homogeneously dispersed, but they also display good catalytic activity. Furthermore, by taking advantage of the robust formation of these thin films, more complex hybrid systems can be constructed by employing protein cages with different cargo or structures.

A. Liu, W. Zhu, M.V. de Ruiter, S. J. Maassen, R. M. Putri, C. J. Brinker, L. Yang and J. J. L. M. Cornelissen. Interfacial Crosslinking of Viral Protein Cage-inspired Free-Standing Thin Films with Tunable Functionalities, to be submitted. 


\subsection{Introduction}

Hybrid thin films with integrated nanoparticles (NPs) find interesting applications in material science and nano-devices, e.g. selective separation, ${ }^{1}$ catalysis ${ }^{2}$ and sensors. ${ }^{3}$ This integration of functional NPs, large molecules, or bioactive enzymes into thin films offers numerous advantages to tailor the structural and functional properties by well-defined design. To date, several strategies have been developed to prepare such hybrid thin films including surfactant templating, ${ }^{4}$ spinning-assisted assembly, ${ }^{5}$ layer-by-layer deposition and crosslinking. ${ }^{6}$ Most of the reported methods, however, have limited applicability due to the complex and varied surface and physicochemical properties of the individual NPs or the substantial loss of enzyme activity during crosslinking. ${ }^{8}$ As an alternative strategy, the use of a uniform and adaptable nanocarrier with the capacity to encapsulate various 'cargos' without affecting the surface properties or activities, is suggested. In principal, the self-assembly of this kind of nanocarrier into thin films with a densely 2- or 3-dimensional (3D) packing, virtually allows that any type of functional NP or nanoassembly can be organized into larger hierarchical architectures relevant to applications such as energy transduction, sensing, catalysis, smart membrane, etc. ${ }^{7,9}$ In this chapter the use of a virus-based protein cage as nanocarrier, for the formation of functional thin films, is investigated.

Viral protein cages, such as the Cowpea Chlorotic Mosaic Virus (CCMV), are a natural biomaterials that are formed by the controlled self-assembly of (often identical) coat proteins into NPs with uniform size that can be functionalized in a robust and well-defined manner. ${ }^{8}$ By taking advantage of the reversible-assembly property of CCMV, the inner space can be loaded with inorganic NPs, enzymes, and organic aggregates resulting in functional viruslike particles (VLPs). ${ }^{9}$ Combining the encapsulation abilities of VLPs with their diverse surface chemistry, we explored the strategy to prepare viral protein cage-based (freestanding) thin films with different functionalities based on the interfacial crosslinking the constituent proteins. The abundant number of amine groups on CCMV exterior surface allows the interfacial polymerization with cross-linking, ${ }^{10}$ and via the careful control of reactant concentration and reaction time, films can form on an water/oil interface, and tunable from monolayer thickness to sub-micron size. Moreover, due to the versatile loading ability of CCMV for various cargos, gold NPs (Au NPs), silicon quantum dots (Si QDs) and 


\section{Chapter 5}

horseradish peroxidase (HRP) enzymes as model systems have been efficiently integrated into thin films. The resultant gold-based plasmonic film and the ultra-thin enzymatic HRP film display catalytic activity, indicating that functionality can be introduced easily and versatilely. Additionally, by further integrating the viral protein cage-based free-standing films with other functional systems, such as drug delivery and gene editing, etc. Taken together, we believe our novel VLPs-based interfacial self-assembly strategy will greatly promote the design of new viral protein cage-inspired functional nanoarchitectures for a wide range of applications.

\subsection{Results and discussion}

Thin films based on CCMV protein cages were prepared by interfacial crosslinking at the oil-water interface by using trimesoyl chloride (TMC) as a cross linker (Scheme 1). CCMV protein cages were dispersed in phosphate buffer ( $\mathrm{PB}, \mathrm{pH}$ 7.2) at the bottom layer, while TMC was dissolved in hexane at the top layer. A (free-standing) thin film was formed at the interface via the formation of amide groups between the carboxyl chlorides and amine groups on exterior surface of viral capsid. VLPs containing functional nanoparticles such as Au NPs, Si QDs and HRP enzymes were cross-linked into thin films using the same strategy.

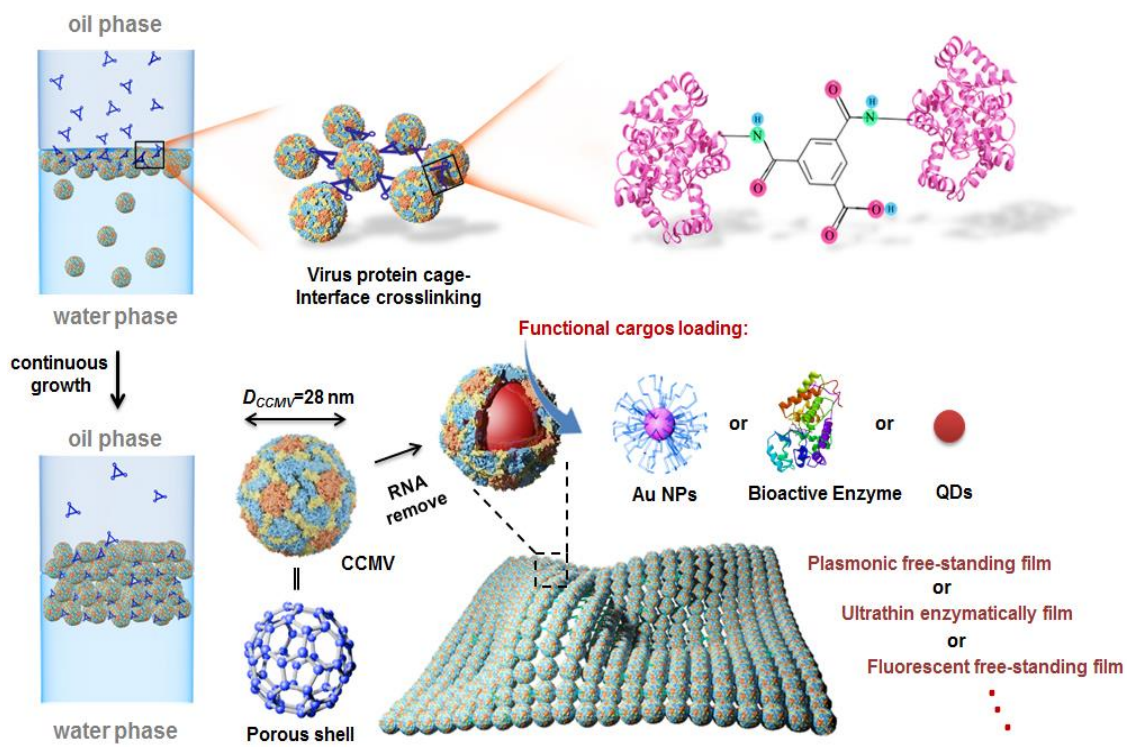

Scheme 1. Schematic representation of the formation of compartmentalized thin films based on CCMV protein cages or the corresponding VLPs prepared by interfacial cross-linking. 


\subsubsection{Characterization of CCMV based thin film}

The thin film formed at the water/oil interface was visible by the naked eye upon formation and its presence was further confirmed by a water droplet test. When a droplet of aqueous Black T solution was dropped into the hexane top layer of the reaction mixture, the droplet stayed at the interface between two phases (Figure 5.1a), indicating the presence of a barrier. Moreover, the thin film can tolerate a certain extent of deformation without rupture when the droplet on top of the film is lightly poked (Figure 5.1b). In a control experiment, the droplet went through the interface of a hexane/buffer system without virus and cross linker (Figure 5.1c). Furthermore, when transferred to a copper grid, a transparent, freestanding thin film was observed by optical microscopy (Figure 5.1d).
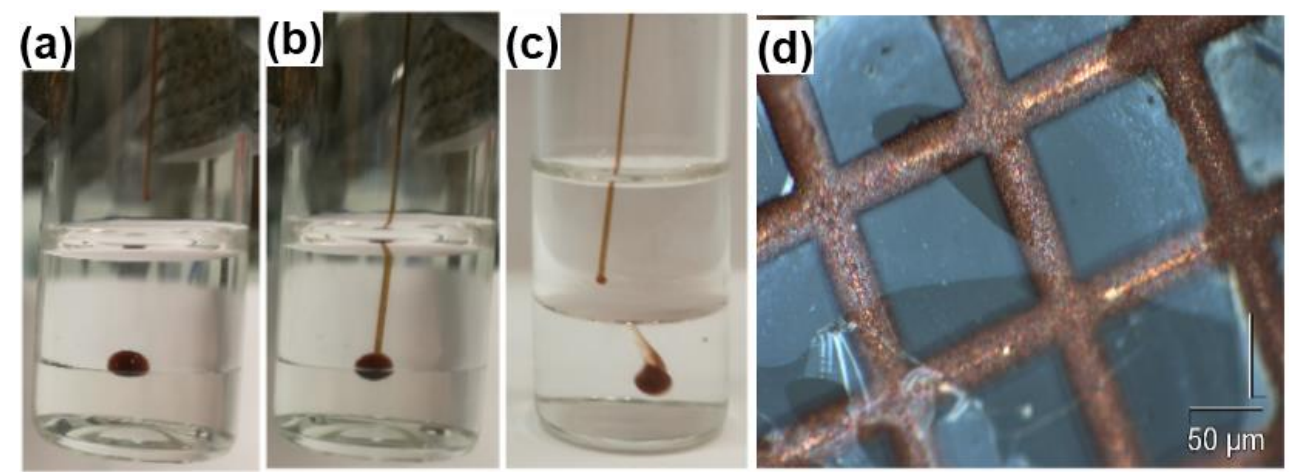

Figure 5.1. Optical images of (a) An aqueous drop on top of the cross linked CCMV thin film in the hexane layer. (b) Deformation of thin film when poked the droplet. (c) An aqueous drop that penetrates the aqueous phase in the absence of the cross linked CCMV thin film. (c) CCMV thin film (after 15 min reaction) on a copper grid.

Studies by infrared (IR) spectroscopy show that, as expected, the TMC concentration and reaction time influence the degree of CCMV cross linking. The obtained films were transferred to polyacrylonitrile ultrafiltration membranes (PAN, SolSep, Netherlands) for the IR studies. The $\mathrm{C} \equiv \mathrm{N}$ stretching mode $\left(v=2242 \mathrm{~cm}^{-1}\right)$ from PAN was set as an internal reference, while the degree of cross linking of the film was monitored by the increasing signal originating from the amide $\left(\mathrm{N}-\mathrm{H}_{\text {bend }} v=1650 \mathrm{~cm}^{-1}, \mathrm{C}=\mathrm{O}_{\text {stretch }} v=1540 \mathrm{~cm}^{-1}\right){ }^{2}$ The amide absorption bands initially increased with increasing TMC concentration, while beyond 0.25 wt $\%$ the intensity levelled off (Figure 5.2a, and Figure 5.2c upper image). The cross-linking between virus particles and TMC faces competition with the hydrolysis of TMC, which decreases the available cross-linkers and furthermore acidifies the aqueous solution. The 
latter reduces the reactivity of the basic, amine groups present on the virus shell by protonation. At a low concentrations of TMC $(<0.125 \mathrm{wt} \%)$, the amount of TMC at the interface is insufficient to crosslink the virus particles, while at higher concentrations $>0.25$ $\mathrm{wt} \%$, the excess TMC molecules at the interface passivate most of the reactive amine groups on the virus shell and prevent them from cross-linking.

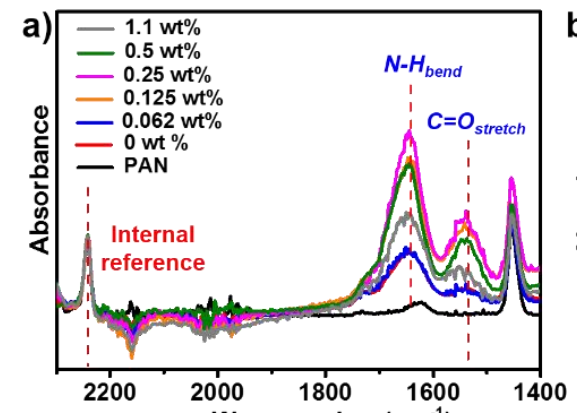

c)
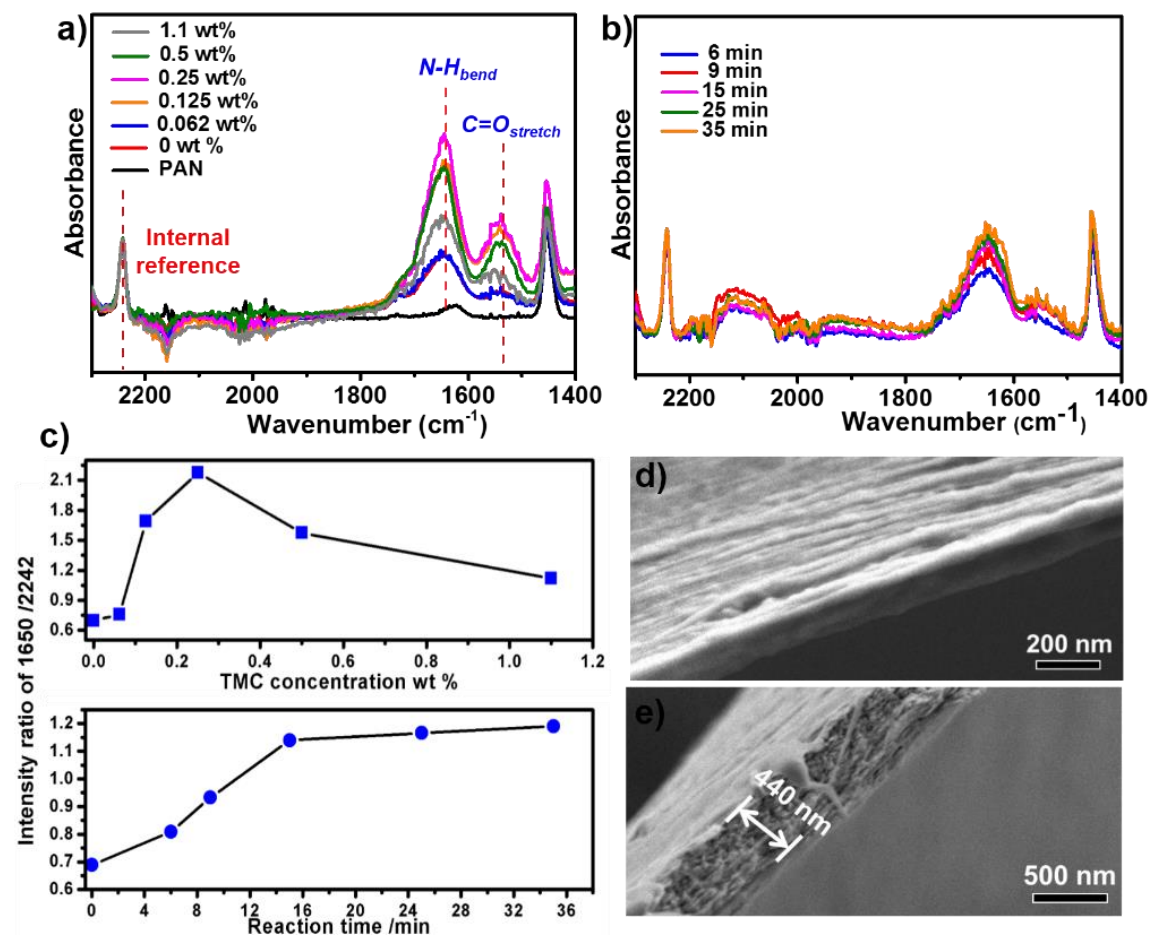

Figure 5.2. FTIR absorbance spectra of (a) PAN support and PAN supported films with varying TMC concentrations in hexane ranging from $0.062 \mathrm{wt} \%$ to $1.1 \mathrm{wt} \%$ and CCMV in PB buffer with $1.5 \mathrm{mg} / \mathrm{ml}$; (b) varied reaction time; (c top) varied interfacial polymerization time with $1.1 \mathrm{wt} \%$ of TMC in hexane and $1.5 \mathrm{mg} / \mathrm{ml}$ of CCMV PB buffer with $\mathrm{pH} 7.2$; (c bottom) intensity ratio at the location of 1650 to $2242 \mathrm{~cm}^{-1}$ according to varied reaction time. Scanning electron microscopy (SEM) images of the film formed after a reaction time of (d) 15 mins and (e) 14 hours.

The degree of cross linking, and presumably the film thickness, also depend on the reaction time. As shown in Figure 5.2b, and Figure 5.2c (bottom image), the IR intensity of the amide group increases within the first $15 \mathrm{~min}$ of the reaction. After $15 \mathrm{~min}$, the increase of IR signal levels off, indicating a decreasing growth and / or cross linking of the film. After the initial $15 \mathrm{~min}$ of reaction the thickness of the film as measured by SEM is in line with virus nanoparticles (Figure 5.2d). After 14 hrs, the thickness of the film reached $440 \mathrm{~nm}$, 
which contained about 15 layers of CCMV NPs (Figure 5.2e). The slower film growth after 15 min is likely due to a barrier effect of the formed monolayer film that hampers the diffusion of TMC molecules and virus particles across this film and in that way inhibits the cross-linking.

Films obtained in this way can be given different properties by cross linking VLPs with functional cargo. This allows for the straight forward quantification of the loading inside the film and an increased stability. Furthermore, since the surface properties of the protein cage remain the same with various cargos, the chemistry established in this paragraph can be applied to construct films with different functionalities. Three representative examples are given to show the versatility of this strategy.

\subsubsection{Compartmentalized thin film loaded with gold nanoparticles}

In the first example, CCMV based VLPs containing $7 \mathrm{~nm}$, Bis(psulfonatophenyl)phenylphosphine (BSPP) stabilized, gold nanoparticles were cross linked. The Au NPs were encapsulated in CCMV protein cages following procedures reported in Chapter $4 .^{9 \mathrm{a}}$ The obtained hybrid VLPs (CCMV-Au7B) were monodisperse as shown by transmission electron microscopy (TEM) and dynamic light scattering (DLS) (Figure 5.3a). The protein nanoparticles were subsequently cross linked at interface following the same method as for native CCMV (Figure 5.3b).

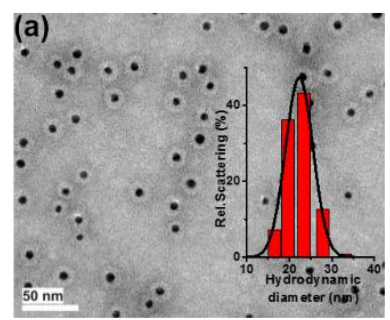

(b)

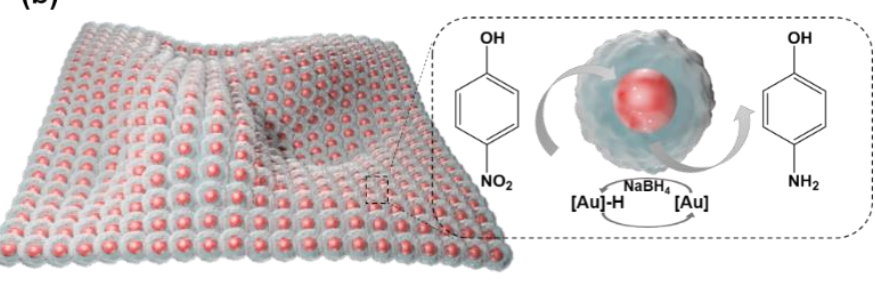

Figure 5.3. (a) TEM image of negatively stained CCMV-Au7B, inset: DLS analysis CCMV-Au7B; (b) schematic represntation of CCMV-Au7B cross-linked monolayer film with trimesoyl chloride as the linker.

The formed thin films were analyzed by TEM, SEM and AFM. TEM with a low magnification showed a folded film on top of the grid (Figure 5.4a). Upon zooming, the $\mathrm{Au}$ NPs were found to be dispersed and densely packed but without aggregation in this film (Figure 5.4b).The formed material has a characteristic absorption band at $\lambda=532 \mathrm{~nm}$ in the 


\section{Chapter 5}

UV-Vis spectrum (Figure 5.4c), which originates from the dipolar interaction of the localized surface plasmon resonance (LSPR) of adjacent gold nanoparticles in close proximity to each other. ${ }^{11}$ The observed absorption band is slightly red-shifted compared to dissolved CCMVAu7B NPs with $\lambda=525 \mathrm{~nm}$, pointing to a substantial part of the gold nanoparticles being densely packed in the film. In a control experiment, the red-shift was not observed for a film prepared from VLPs containing tannic acid stabilized gold nanoparticles (Figure 5.5). In that case, the empty VLPs present in these samples dilute the gold nanoparticles in the film and consequently increase the gold-gold distance diminishing the LSPR effect. All of the results verify that the compartments in the film originating from the protein cages can effectively separate and stabilize gold nanoparticles at high concentrations without aggregation.
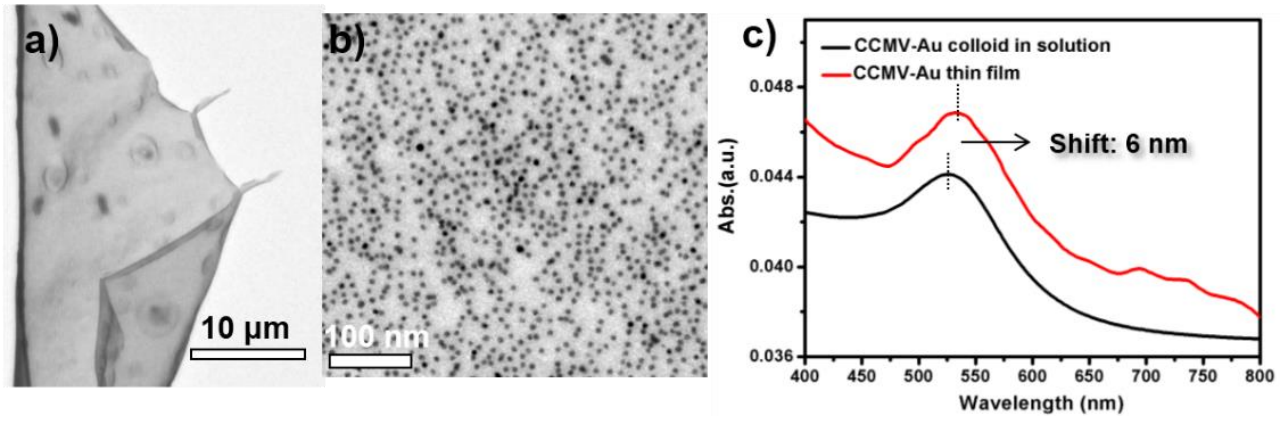

Figure 5.4. TEM images of CCMV-Au7B films with (a) low magnification and (b) high magnification; (c) UV-vis spectra of CCMV-Au7B NPs in buffer solution and in the film;
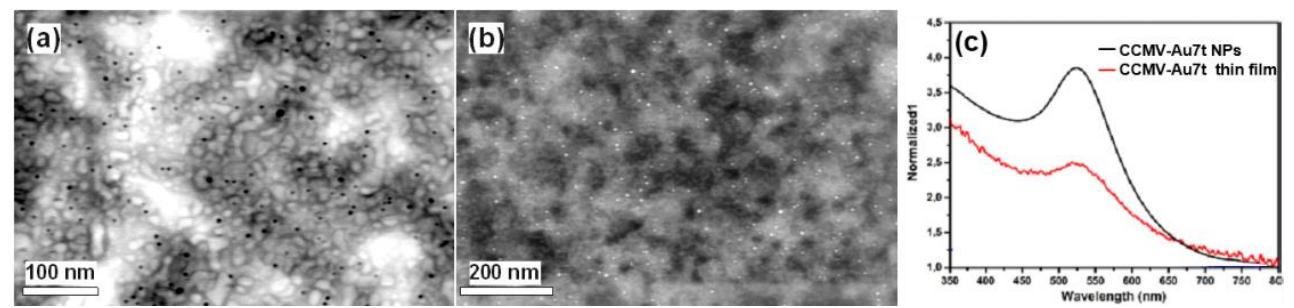

Figure 5.5. STEM images of CCMV-Au7T formed thin film (a) and (b), UV-vis analysis of thin film (c). 

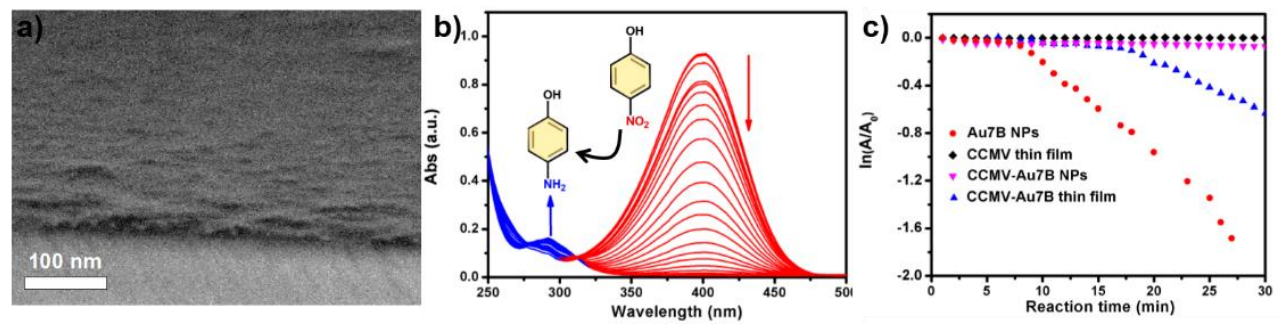

Figure 5.6. (a) SEM image of monolayer film of CCMV-Au7B NPs; (b) Reduction of 4-nitrophenol monitored by UV-vis spectroscopy; (c) Kinetic study of reductions carried out by Au NPs, CCMVAu7B VLPs, CCMV film and CCMV -Au7B film.

Catalytic activity of CCMV-Au7B monolayer film was explored. The structure was confirmed by SEM analysis (Figure 5.6a) and AFM (see appendix, Figure 5.16). The reduction of 4-nitrophenol (4NP) to 4-aminophenol, as a model reaction, was monitored by UV-vis spectroscopy (Figure 5.6b). As the reaction proceeds, the absorption of $4 \mathrm{NP}$ at $\lambda=$ $400 \mathrm{~nm}$ decreases, accompanied by an increase of the absorption at $\lambda=292 \mathrm{~nm}$, in line with the generation of the product 4-aminophenol (Figure 5.6b). In control experiments, the reduction of $4 \mathrm{NP}$ catalyzed by CCMV-Au7B VLPs and CCMV thin film was carried out under the same conditions. Reaction rates were calculated from plotting $\ln \left(\mathrm{A} / \mathrm{A}_{0}\right)$ versus the reaction time, in which $\mathrm{A}_{0}$ is the initial absorption intensity at $\lambda=400 \mathrm{~nm}$, and $\mathrm{A}$ is the realtime absorption intensity at the same wavelength (see appendix). For the CCMV film without gold nanoparticles, as expected, no catalytic activity was observed (Figure 5.6c). For CCMVAu7B VLPs, after a 12 min induction time, the initial reaction rate constant was calculated to be $k_{\mathrm{ccmv}-\mathrm{Au} 7 \mathrm{~B}}=2.1 \cdot 10^{-3} \pm 6.14 \cdot 10^{-5} \mathrm{~min}^{-1}$. This rate constant is lower than in the one found for bare Au NPs $\left(k_{\mathrm{Au}}=8.20 \cdot 10^{-2} \pm 2.49 \cdot 10^{-3} \mathrm{~min}^{-1}\right)$, presumably due to the diffusion barrier of protein shell. ${ }^{8 \mathrm{~d}}$ Surprisingly, the CCMV-Au7B film showed a higher catalytic activity compared to CCMV-A7b with $k_{\mathrm{ccmv}-\mathrm{Au} 7 \mathrm{~B} \text { film }}=4.29 \cdot 10^{-2} \pm 7.18 \cdot 10^{-4} \mathrm{~min}^{-1}$ (detail calculation see appendix), although the induction time was increased to $17 \mathrm{~min}$. The relatively high activity of the film might be caused a more acidic local environment compared to the bulk solution, resulting from the conversion of basic amine groups in the protein shell by crosslinking and additional carboxylic acids from hydrolysis of partially reacted TMC molecules. Such a local acidic environment can also promote the hydrolysis of $\mathrm{NaBH}_{4}$ which further facilitates the reaction. ${ }^{12}$ These results indicate that the catalytic activity of Au NPs can be 
maintained in the compartments within the films created by protein cages, which allows for further applications in, e.g., catalytic or sensor devices. ${ }^{13}$

\subsubsection{Compartmentalized thin film loaded with silicon quantum dots}

In this section, we chose to further explore the organizing capacity of the protein cage based films with silicon quantum dots (Si QDs). Si QDs show size controlled fluorescence and are stable against photo bleaching, while having a low toxicity compared to heavy metal containing QDs. ${ }^{14}$ Si QDs find applications as light-emitting diodes, in photovoltaics and especially as luminescent markers in bio-imaging. ${ }^{15} \mathrm{Here}$, the encapsulation of negatively charged Si QDs (referred to CCMV-Si), their optical properties and cross linked films are studied.
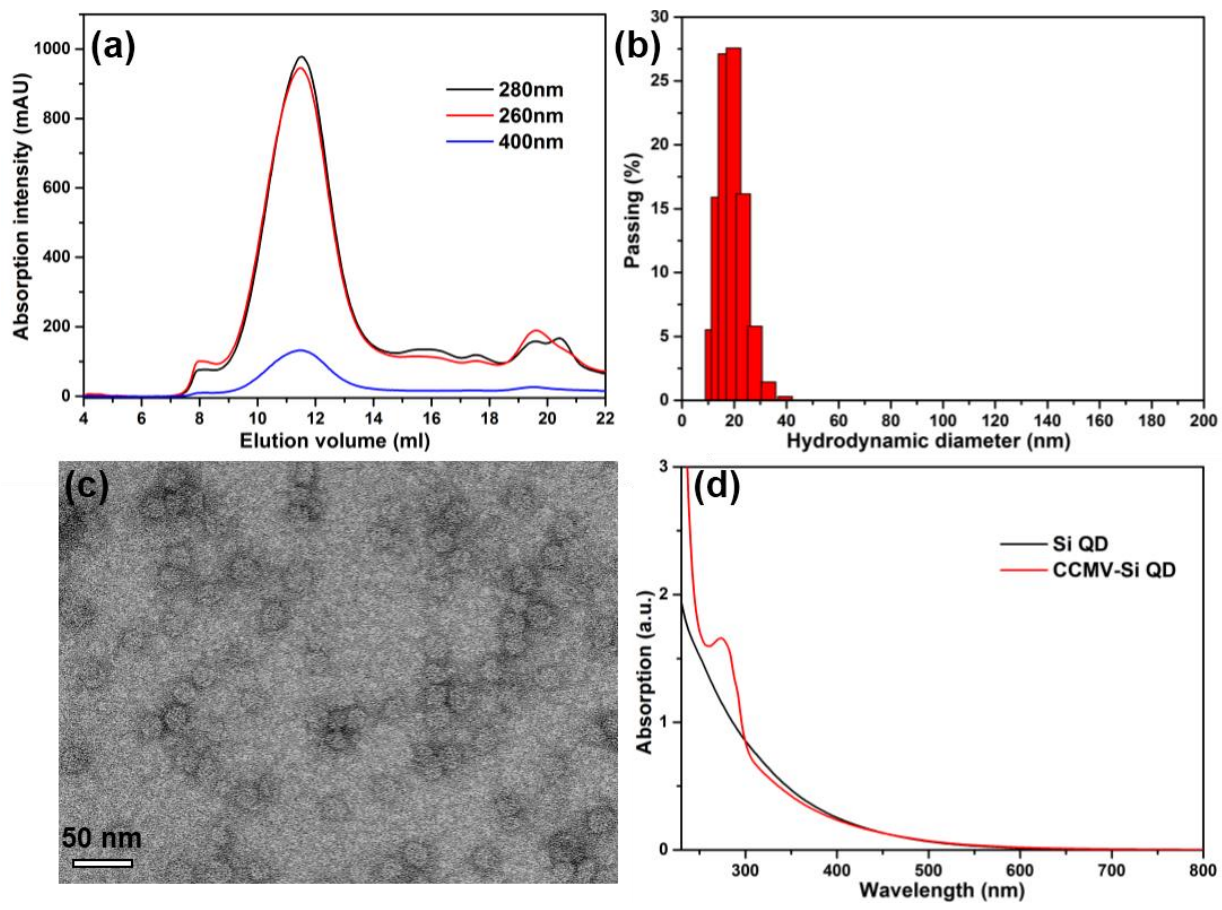

Figure 5.7. Characterization of CCMV-Si hybrid nanoparticles: (a) FPLC analysis; (b) DLS analysis; (c) TEM analysis with uranyl acetate stain; (d) UV-vis of Si QDs and CCMV-Si QDs.

Negatively charged Si QDs were successfully encapsulated into CCMV based protein cages following our established protocol. Fast protein liquid chromatography (FPLC) was 
used for purification and analysis (Figure 5.7a), after $11.5 \mathrm{~mL}$ the particles eluted from the column. This fraction exhibit absorption bands at $\lambda=400 \mathrm{~nm}$ resulting from the silicon quantum dots and bands at $\lambda=260 \mathrm{~nm}$ and $\lambda=280 \mathrm{~nm}$ that belong to the CCMV coat protein. ${ }^{10}$, ${ }^{16}$ Dynamic light scattering (DLS) of the purified material revealed a hydrodynamic diameter of $\mathrm{D}=18 \mathrm{~nm}$ (Figure $5.7 \mathrm{~b}$ ). This size was confirmed by TEM, showed monodisperse CCMV$\mathrm{Si}$ with presumably a $\mathrm{T}=1$ structure (Figure $5.7 \mathrm{c}$ ). From the $\mathrm{UV}$-vis spectra, the additional absorption at $\lambda=270 \mathrm{~nm}$ can be attributed to the protein in CCMV-Si. No peak was observed for the unmodified Si QDs (Figure 5.7d).

The fluorescence of Si QDs and CCMV-Si at various excitation wavelengths $\left(\lambda_{\mathrm{ex}}\right)$ was measured. When the Si QDs were excited at $\lambda_{\mathrm{ex}}=375 \mathrm{~nm}$ the emission at $\lambda=480 \mathrm{~nm}$ had the highest intensity. The emission wavelength shows a red-shift with decreasing intensity when $\lambda_{\text {ex }}$ was increased (Figure 5.8a). This observed shift may originate from different optical properties of Si QDs of slightly different size, however, a detailed analysis of this is beyond the scope of this Chapter. CCMV-Si showed an emission at $\lambda=365 \mathrm{~nm}$ with $\lambda_{\mathrm{ex}}=$ $290 \mathrm{~nm}$, which is expected to originate from aromatic amino acid residues in the coat protein. When $\lambda_{\mathrm{ex}}=365-435 \mathrm{~nm}$ a similar emission pattern as for Si QDs was observed, albeit with a broader peak shape. In contrast to Si QDs, a shoulder appeared at $\lambda=595 \mathrm{~nm}$, when $\lambda_{\mathrm{ex}} \geq$ $410 \mathrm{~nm}$, of which the origin is still under investigation (Figure 5.8b). In a control experiment, polystyrene sulfonate (PSS) was encapsulated, which shows no fluorescence other than when $\lambda_{\text {ex }} \geq 290 \mathrm{~nm}$ (Figure 5.8c).
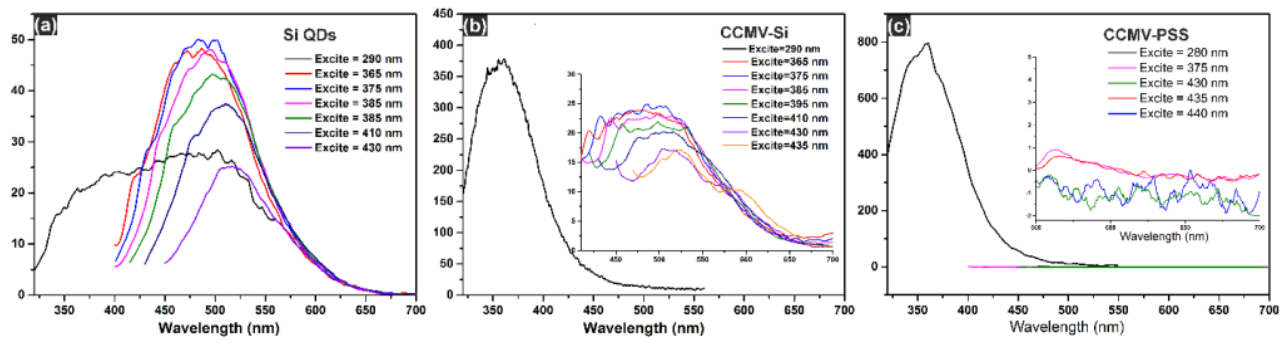

Figure 5.8. Fluorescence spectra of (a) Si QDs; (b) CCMV-Si and (c) PSS containing VLPs. 


\section{Chapter 5}

CCMV-Si was cross linked into a film with the method introduced previously in this Chapter, yielding a fluorescent film as observed by fluorescence and confocal microscopy (Figure 5.9).
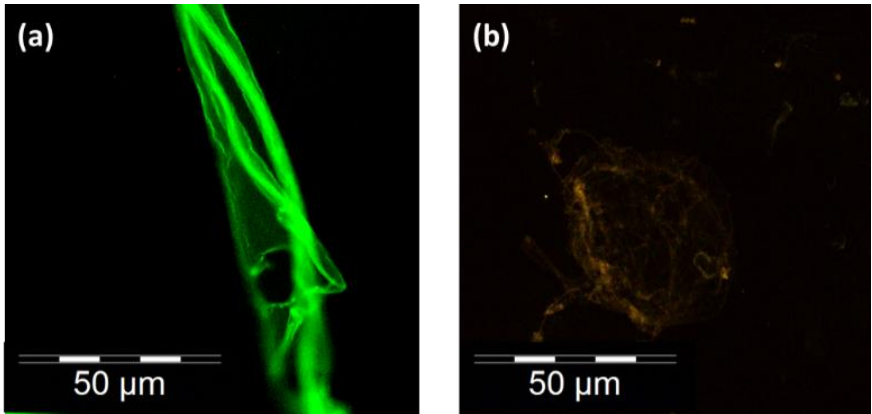

Figure 5.9. (a) Fluorescence microscopy image the CCMV-Si film, excited at $\lambda_{\mathrm{ex}}=430 \mathrm{~nm}$ and $\lambda_{\mathrm{em}}=$ $535 \mathrm{~nm}$. (b) Confocal microscopy image of CCMV-Si film with $\lambda_{\mathrm{ex}}=405 \mathrm{~nm}$.

\subsubsection{Compartmentalized thin film loaded with an enzyme}

To further demonstrate the tunable functionality of protein cage based compartmentalized films, horseradish peroxidase (HRP) was introduced as a representative enzyme. To encapsulate HRP into the CCMV based protein capsid, HRP was first functionalized with negatively charged polystyrene sulfonate (PSS). HRP was equipped with PSS and encapsulated in analogy with the procedure reported by Brasch et al. ${ }^{17}$ To this end the polymer prepared by ATRP from a disulfide based initiator (PSS-SS-PSS) was in situ reduced and coupled to HRP modified with a reactive maleimide moiety. HRP, HRPPSS and CCMV-HRPPSS were purified and studied by FPLC. HRP eluted at V $=18 \mathrm{~mL}$ (Figure 5.10 top image). The elution volume of HRP $\mathrm{PSS}_{\mathrm{PS}}$ was the same, while the absorption at $\lambda=260 \mathrm{~nm}$ increased (Figure 5.10 middle image), in line with the conjugating of PSS. The excess of PSS eluted at $\mathrm{V}=13 \mathrm{~mL}$, presumably in aggregated form. The $\mathrm{HRP}_{\mathrm{PPS}}$ fraction with $\mathrm{V}=18-19$ $\mathrm{mL}$ was collected for encapsulation. From the HRP $\mathrm{PSS}_{-}$-coat protein reaction mixture 3 fractions were isolated: $1 . \mathrm{V}=9.5 \mathrm{~mL}$ likely corresponding to aggregates or T=3 VLPs; $2 \mathrm{~V}$ $=12.5 \mathrm{~mL}$ is corresponding to $\mathrm{T}=1 \mathrm{CCMV}-\mathrm{HRP}_{\mathrm{PSS}} ; 3 \mathrm{~V}=18.5 \mathrm{~mL}$ corresponding to nonencapsulated HRP (Figure 5.10 bottom image). 
Protein Cage Based Functional Thin Films

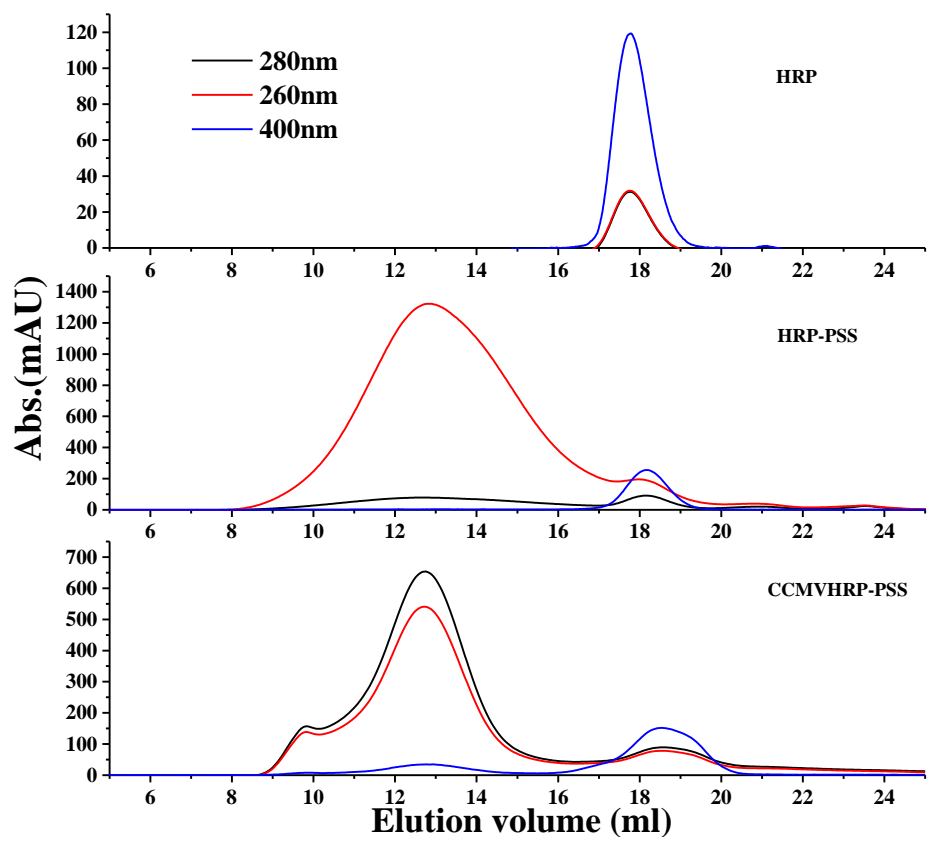

Figure 5.10. FPLC chromatograms of HRP, HRP-PSS and CCMV-HRPPSs.
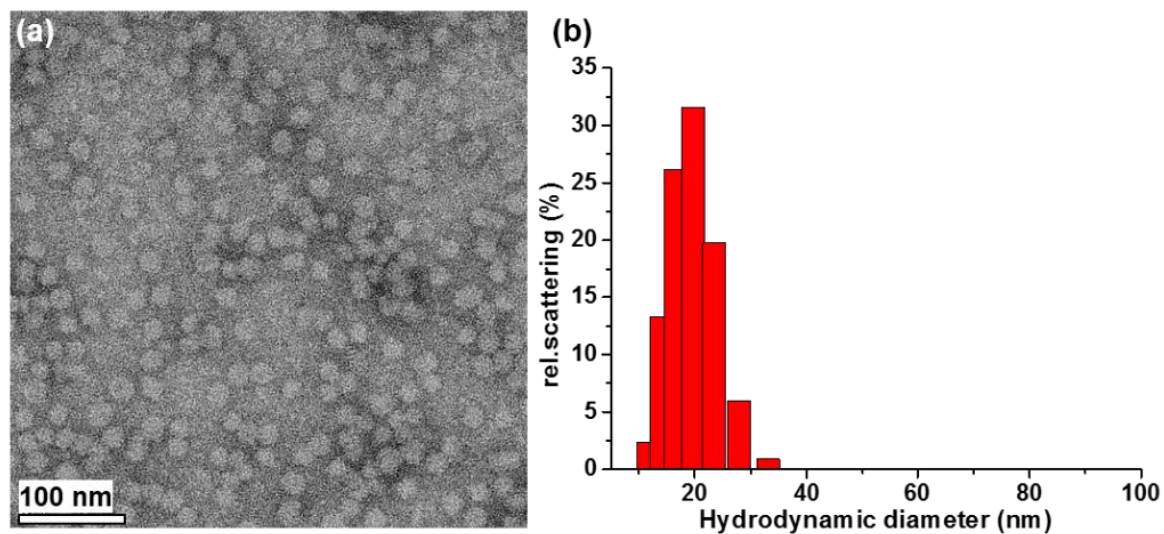

Figure 5.11. (a) TEM image of CCMV-HRPPss with $1 \%$ uranyl acetate staining; (b) DLS analysis of CCMV-HRPPSS.

Fraction 2 (Figure 5.10 bottom) was analyzed by TEM and DLS, which both pointed to the formation of $\mathrm{T}=1$ VLPs with $\mathrm{D}=18 \mathrm{~nm}$ (Figure 5.11). The presence of the HRP was further confirmed by UV-vis spectroscopy, showing the characteristic absorption of the heme group at $\lambda=403 \mathrm{~nm}$ and by SDS PAGE (Figure 5.12). 


\section{Chapter 5}

(a)

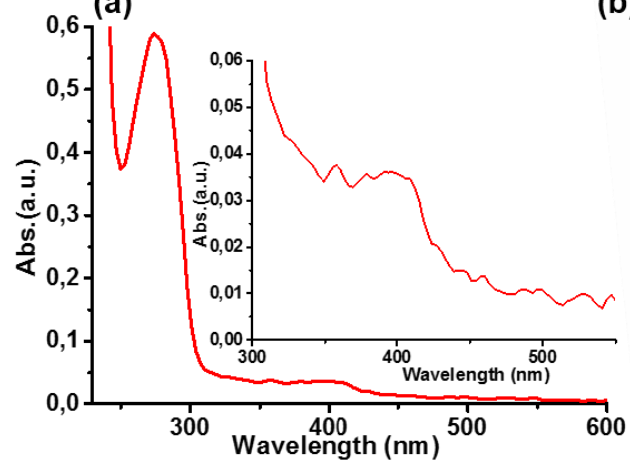

(b)

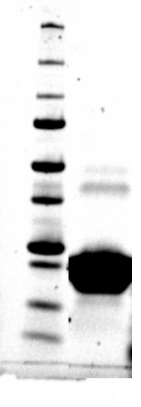

Figure 5.12. (a) UV-vis spectra of CCMV-HRPPss, inset: characteristic absorption at $\lambda=403 \mathrm{~nm}$ of HRP. (b) SDS-PAGE analysis of CCMV coat protein at $20 \mathrm{kDa}$, HRP at $44 \mathrm{kDa}$.
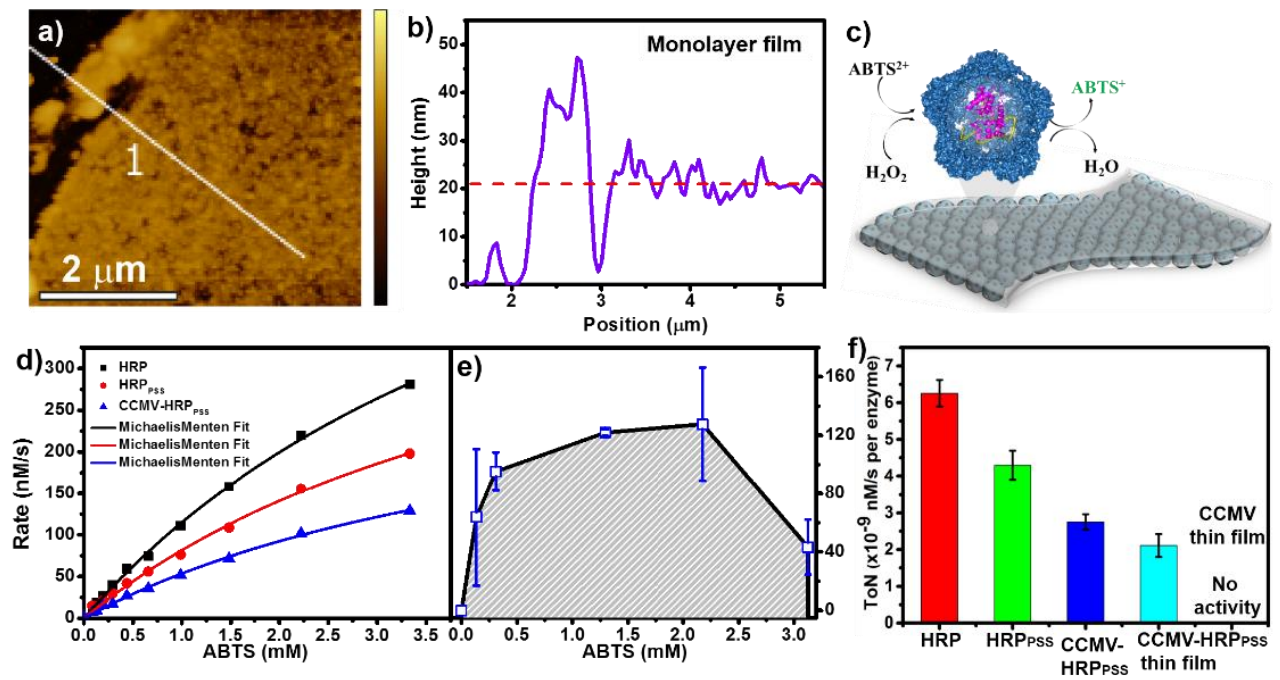

Figure 5.13. (a) and (b) AFM image and thickness measurement of CCMV-HRPPss film. (c) Scheme of ABTS assay study with CCMV-HRPPSs thin film. (d) Kinetic study of ABTS assay with HRP, HRPPss, and CCMV-HRPPSs (e) Kinetic study of ABTS assay with CCMV-HRPPSs thin film; (f) Turn over number (ToN) of different HRP systems.

A CCMV-HRP based film was prepared as described for the other protein cage systems, yielding with average thickness of $21.3 \pm 3.5 \mathrm{~nm}$, which was obtained from AFM analysis (Figure 5.13a, b). This is close to the particle diameter $\mathrm{D}=18 \mathrm{~nm}$, pointing to a CCMVHRPPss monolayer. The HRP activity in its different forms was studied by the 2,2'-azinobis(3-ethylbenzothiazoline-6-sulphonic acid) (ABTS) (Figure 5.13c). All reactions were carried out in Tris-HCl buffer (10 mM Tris, $10 \mathrm{mM} \mathrm{NaCl}, \mathrm{pH} 7.5)$ and monitored by $\mathrm{UV}$-vis, 
following the characteristic ABTS radical cation absorption at $\lambda=420 \mathrm{~nm}$. $100 \mu \mathrm{L}$ of a catalyst dispersion, with a concentration of $2 \mathrm{nM}$ HRP (total number of enzymes, $1.20 \cdot 10^{11}$ ) was used to determine the reaction rate as a function of substrate concentration (Figure 5.13d). HRP, HRP-PSS and CCMV-HRPPss all follow Michaelis-Menten kinetics with $\mathrm{V}_{\max }$ of $750.77 \mathrm{nM} / \mathrm{s}, 515.64 \mathrm{nM} / \mathrm{s}$ and $330.33 \mathrm{nM} / \mathrm{s}$, respectively. The reduction in reaction rate is tentatively ascribed to hampered accessibility of the substrate to the enzyme its active site by the polymer and/or the protein cage. The CCMV-HRPPss film initially showed an increasing reactivity with increasing $\mathrm{ABTS}$ concentration $(0-2.18 \mathrm{mM})$, but the reaction rate decreases when the concentration exceeds $3.13 \mathrm{mM}$, probably due to product inhibition. ${ }^{18}$ The highest rate with $\mathrm{v}=196.26 \pm 28.66 \mathrm{nM} / \mathrm{s}$ was found at $[\mathrm{ABTS}]=2.18 \mathrm{mM}$ (Figure 5.13e). And the corresponding turn over numbers for HRP, HRP ${ }_{P S S}, C C M V-H R P_{P S S}$ and their thin film were calculated as $4.3 \pm 0.4,2.7 \pm 0.2$ and $2.2 \pm 0.3 \mathrm{nM} \cdot\left(\mathrm{s} \cdot\right.$ per enzyme) ${ }^{-1}$, respectively (Figure 5.13f). These analysis show that the activities of the different HRP systems are within the same order of magnitude. It is evident from the data that upon the incorporation of HRP in the protein cage based films, still sufficient transport of substrates and products is possible while potentially reusable.

\subsubsection{Functional particles @ compartmentalized thin film}

In the above sections, it is shown that protein cages can be the building blocks for functional protein based films. With the availability of different types of protein cages, cross linking moieties and loading strategies a diversity of such films with tunable properties are potentially possible. While our examples, so far, consisting of free standing films, furthermore, by taking the advantages of high flexibility of protein cages integrated (hybrid) thin films, complex systems with high designable functionalities can be obtained through the conformal contact (that is, shape-fitting contact) with various functional objects can be efficiently generated to extend their potential applications. 


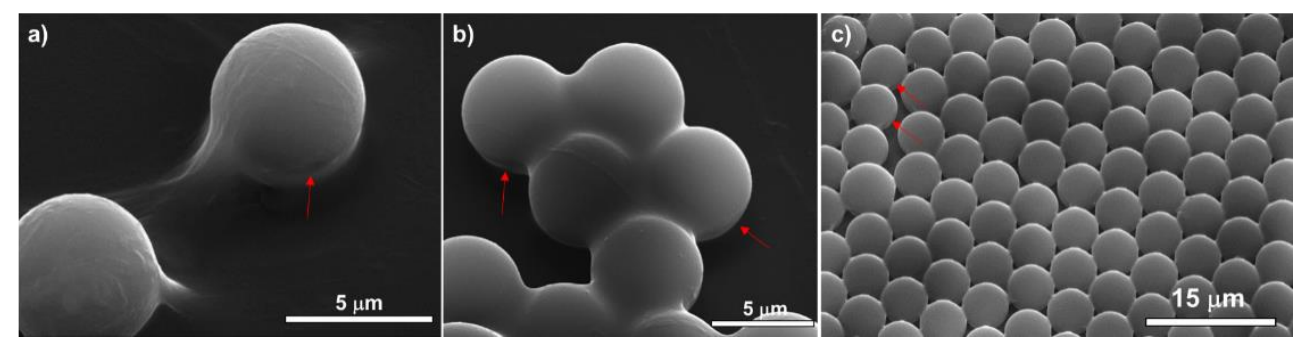

Figure 5.14. SEM analysis of CCMV thin film coating on polymer beads arrays, forming Janus like particles.

In order to investigate the scope of the concept, we coated a CCMV film on fluorescent polymer beads (Figure 5.14). The polymer beads are only partially coated with the film and form Janus-like particles (Figure 5.14, arrows show partial coating). If these polymer beads are organized in an array first, 2D photonic Janus films are obtained (Figure 5.14c) after coating with the CCMV films. In principle the properties of these films can be further tuned by loading different functional materials, this part of work will be continued in the future.

In the second example, a CCMV film was applied on mesoporous silica nanoparticles (MSNs). MSNs were selected as a model system because of their use as a nanocarrier for drug delivery, ${ }^{19}$ of which hybrid materials between silica and other functional inorganic materials are of particular interest. Taking a great advantage of CCMV protein cage is the easy loading of RNA or DNA, through the fusion of CCMV-based free-standing thin film to MSN core with large surface area and high drug loading capability, ${ }^{19}$ a new kind of drug nanocarriers with multifunctional compartments for potential drug delivery, cancer therapy, or even gene editing, can be easily developed (shown in Figure 5.15a). In brief, hybrid MSNs containing a Prussian blue core with a cross section of $400 \mathrm{~nm}$ were obtained and functionalized with 3-aminopropy-triethoxysilne (APTES) for further use (Figure 5.15b). To coat with CCMV thin films, interfacial crosslinking of CCMV thin film was performed first, then MSNs in hexane was added onto top layer of oil-water face, MSN could partially cross linked with CCMV thin film based on the availability of $-\mathrm{NH}_{2}$ groups on the silica surface by trimesoyl chloride. After then, particles were centrifuged down to allow coating of CCMV film onto MSNs surface (denote as MSN@CCMVfilm, Figure 5.15c). 


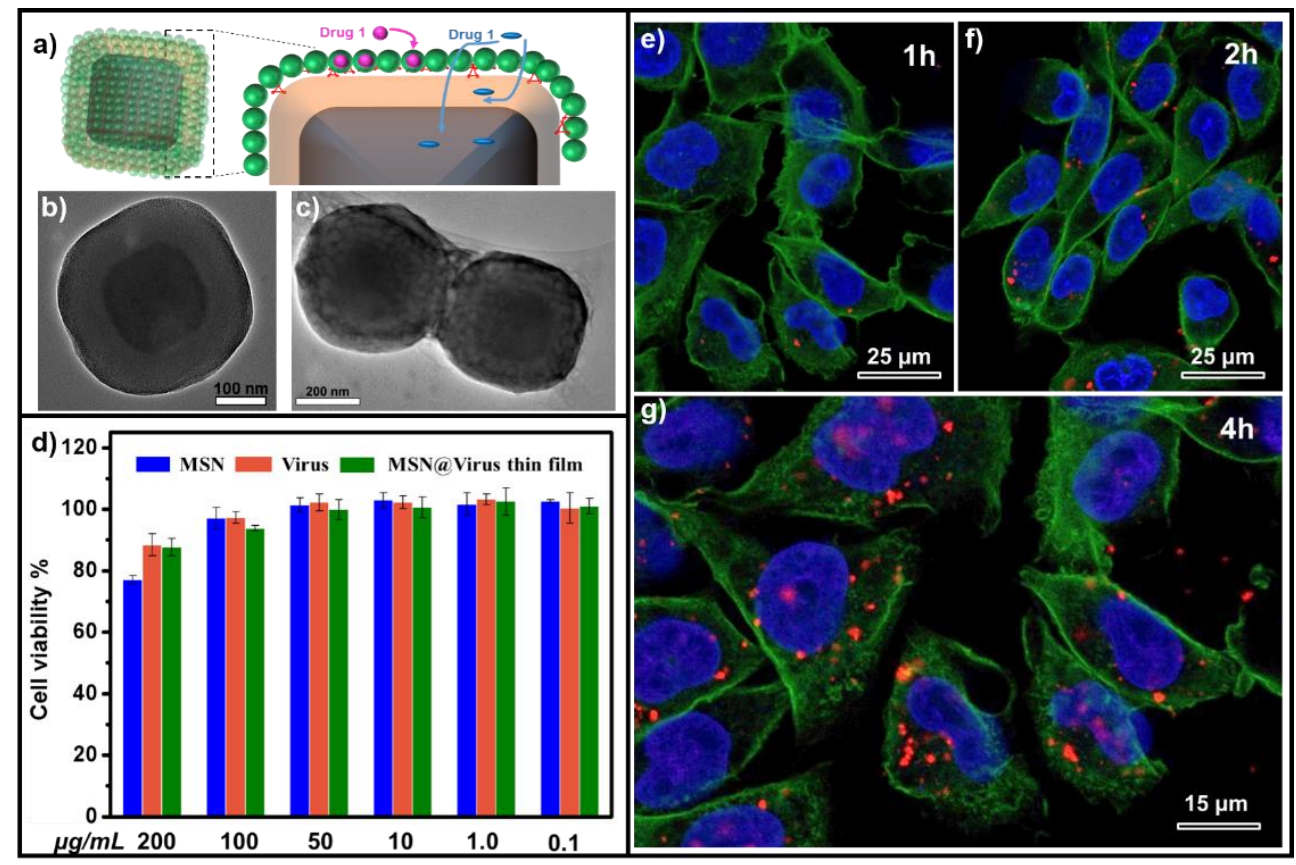

Figure 5.15. (a) Schematic illustration of structure of MSN@CCMVfilm complex systems (b) TEM analysis of mesoporous silica nanoparticles (MSN); (c) TEM analysis of CCMV thin film coated MSN multi-functional hybrid NPs (MSN@CCMVfilm); (d) Cytotoxicity of MSN, CCMV NPs and MSN@CCMVfilm hybrid NPs were studied by CellTiter-Glo® 2.0 cell viability assays. Confocal fluorescence microscopy images of MSN@CCMVfilm uptake process by Hela cells of (e) $1 \mathrm{~h}$, (f) $2 \mathrm{~h}$, and $(\mathrm{g}) 4 \mathrm{~h}$;

To prove the possibility of the derived multicomparment nanocarrier for drug delivery, the biocompatibility of MSN@CCMVfilm supraparticle, CCMV, and MSN NP were checked by Cell Titer-Glo® 2.0 cell viability assays and conducted to examine the cytotoxicity against of HeLa cells after $24 \mathrm{~h}$ treatment. As shown in Figure 5.15d, for all types of NPs, even for the highest treatment of $200 \mu \mathrm{g}$ NPs, the cell viabilities were still high enough for drug delivery. As a proof-of-concept, the drug delivery capability of MSN@CCMVfilm supra-particles loaded with model cargo (rhodamine isothiocyanate) was investigated. The drug-loaded NPs were incubated with HeLa cells for different time interval to evaluate cellular internalization. The cellular membranes and nuclei were stained with fluorescent probes of Alexa Fluor 488 Wheat Germ Agglutinin and Hoechst 33342, respectively, and then the internalization process was confirmed by confocal fluorescence microscopy (Figure 5.15e-g). At the first 1 and $2 \mathrm{~h}$, only a few internalized supraparticles 


\section{Chapter 5}

were observed. However, after the incubation time for $4 \mathrm{~h}$, a large number of nanoparticles could be effectively internalized by HeLa cells (Figure 5.15g). All these information suggest that the uptake of MSN@CCMVfilm supraparticles in our case is time-dependent and our synthesized CCMV-based multi-compartment NPs are able to deliver drugs into cells efficiently.

\subsection{Conclusions}

We have successfully constructed compartmentalized films by simple and straightforward interfacial cross-linking of viral protein cages. The thickness of the films can be controlled through reaction conditions. The employment of the CCMV protein cage provides materials with defined compartments in the free-standing thin films, which not only helps to quantify and stabilize the cargo, but also equips the films with different functionality. Functional cargo, such as gold nanoparticles, silicon quantum dots and the enzyme HRP were effectively integrated into CCMV protein cage based films, which display catalytic activity in the case of gold and HRP. The protein films could, furthermore, be applied on MSNs as a model system, to show the formation of complex multi-functional hybrid materials that might find applications in biosensors, wastewater treatment and biomedical materials.

\subsection{Acknowledgments}

We acknowledge Films in Fluids group for supplying the PAN membrane and fruitful discussion; Stan Maasen for the kind donation of PSS-SS-PSS; Dr. Jos Paulusse for the kind donation of Si QDs; Dr. Wei Zhu for the kind donation of MSN and for the performing the cell studies; many thanks to Dr. Liulin Yang, Mark de Ruiter for fruitful discussion and help.

\subsection{Materials and methods}

\subsubsection{Materials}

All reagents and reactants were purchased from Sigma Aldrich and used without further purification. Water used for buffers and reactions was of MilliQ quality (Millipore, $\mathrm{R}=18.2$

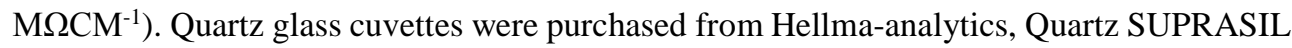


(QS), for UV-Vis analysis. Tannic acid and citric acid stabilized gold nanoparticles were purchased from NanoComposix with a mass concentration of $0.05 \mathrm{mg} / \mathrm{mL}$, dispersed in MilliQ water. Amicon Ultra centrifuge filters with 10 kDa MWCO from Pall Corporation. Polyacrylonitril ultrafiltration membranes (PAN) were purchased from SolSep, Netherlands.

Native CCMV and coat protein isolation see Chapter 3, coat protein with concentration of $18 \mathrm{mg} / \mathrm{mL}$ was prepared for further use.

Bis-p-(sufonatophenyl) phenyl phosphine (BSPP) ligand exchange see Chapter 4 of this thesis.

CCMV-Au see chapters chapter $3 \& 4$ of this thesis.

HRP-PSS (HRPPSS) conjugation $10.8 \mathrm{mg}$ of disulfide linked polystyrene sulfonate (PSSSS-PSS) (20 kDa) and $4 \mathrm{mg}$ DTT (PSS:DTT=1:50, mol/mol) were dissolved in PBS buffer (10 mM PB, 0.1 M NaCl). The solution was incubated for $2 \mathrm{hrs}$ at $\mathrm{r}$.t to reduce the disulfide bond. Subsequently, DTT was removed by washing with PBS buffer (at least 3 times) through Amicon Ultra centrifuge filters (2 kDa MWCO). In parallel, sulfo-EMCS modified HRP was prepared. $510 \mu \mathrm{g}$ of HRP $\left(1.26 \cdot 10^{-8} \mathrm{~mol}\right)$ and $370 \mu \mathrm{g}$ of sulfo-EMCS $\left(9 \cdot 10^{-7} \mathrm{~mol}\right)$ were dissolved in $0.5 \mathrm{~mL}$ of PBS buffer, separately. The above two solutions were then mixed and incubated at r.t for $1 \mathrm{hr}$ on a roller bank. After that, the excess of sulfo EMCS was removed by using Zeba Spin Desalting Columns (7kDa MWCO). Sulfo-EMCS modified HRP was mixed with PSS-HS and incubated for 1-2 hrs at r.t on the roller bank. Purification of HRPPSS was carried out by fast protein liquid chromatography (FPLC) with elution buffer (25 mM Tris, $25 \mathrm{mM} \mathrm{NaCl}, 5 \mathrm{mM} \mathrm{KCl,} 2.5 \mathrm{mM} \mathrm{MgCl}$, $\mathrm{pH} 7.5$ ).

CCMV-HRPPss HRP Pss and free coat protein (in $250 \mathrm{mM}$ Tris, $250 \mathrm{mM} \mathrm{NaCl}, 50 \mathrm{mM} \mathrm{KCl}$, $25 \mathrm{mM} \mathrm{MgCl}_{2}, \mathrm{pH} 7.5$ ) were mixed in a volume ratio of $5: 1$, the final molar ratio of HRP PSS to coat protein is $1: 180$. The mixture was incubated for at least $3 \mathrm{hrs}$ at $4^{\circ} \mathrm{C}$, afterwards, purification was carried out by FPLC with elution buffer $(50 \mathrm{mM}$ Tris, $50 \mathrm{mM} \mathrm{NaCl}, 10 \mathrm{mM}$ $\mathrm{KCl}, 5 \mathrm{mM} \mathrm{MgCl} 2, \mathrm{pH} 7.5)$.

Compartmentalized thin film based on CCMV Thin films were prepared by interfacial cross-linking. ${ }^{2}$ The bottom aqueous phase contained $1.5 \mathrm{mg} / \mathrm{mL}$ of CCMV nanoparticles in $0.2 \mathrm{M}$ phosphate buffer ( $\mathrm{PB}, \mathrm{pH} 7.2)$ and the top oil phase contained trimesoyl chloride 
(TMC) solution in hexane. In the reactant concentration-dependent study, the TMC concentration was varied from $0.125 \mathrm{wt} \%$ to $1.1 \mathrm{wt} \%$. In the time-dependent study, the reaction time was varied till $35 \mathrm{~min}$. The formed thin films were transferred to PAN for further study.

CCMV-Au film $300 \mu \mathrm{L}$ of CCMV-Au solution $(0.05 \mathrm{mg} / \mathrm{mL}$ Au in $0.2 \mathrm{M}$ PB buffer, pH7.2) was added into a quartz cuvette. The same volume of a $0.25 \mathrm{wt} \% \mathrm{TMC}$ solution in hexane was added on the top and the reaction was continued for $15 \mathrm{~min}$. Afterwards, removed the solutions and rinsed the thin film with PB buffer once (be careful! the film may be removed together with the washing solution). Afterwards, the film was transferred for further analysis or left in the cuvette for further study. I

CCMV-HRPpss film $100 \mu \mathrm{L}$ of CCMV-HRP PsS solutions (in $0.2 \mathrm{M}$ PB buffer, pH7.2) with various concentrations were added into a quartz cuvette or in a Corning flat bottom 96 well UV transparent plate. $0.25 \mathrm{wt} \%$ of TMC hexane solution was added on the top. The reaction was allowed to run for $15 \mathrm{~min}$. Both solutions were removed and the resultant films was washed once (be careful! The film may be removed together with the washing solution) before further study.

Polymer beads-based with CCMV film coating $50 \mu \mathrm{L}$ (1 wt \%) of polymer beads in water solution was added to a Piranha solution-treated glass slide. After drying, the polymer beadsbased arrays with ordered packing spontaneously formed. For the film coating, a presynthesized CCMV film (see described above) was gently transferred to the glass slide by slowly decreasing the water level. After drying, the fabricated film was coated with a thin layer of Au by sputter coating for SEM characterization.

MSN nanoparticle synthesis First, prussian blue nanoparticle (PB) as core were synthesized according to a reported method. ${ }^{20}$ In a typical procedure, polyvineypirrolydone (PVP, K30, $3.8 \mathrm{~g}), \mathrm{K}_{4} \mathrm{Fe}(\mathrm{CN})_{6} \cdot 3 \mathrm{H}_{2} \mathrm{O}(0.11 \mathrm{~g})$, and rhodamine dye $(0.011 \mathrm{~g})$ were added to a $\mathrm{HCl}$ solution $(0.1 \mathrm{M}, 50 \mathrm{~mL})$ under magnetic stirring. After the mixing was stirred for $30 \mathrm{~min}$, a clear solution was obtained. The mixture was then transferred to oil bath at $80{ }^{\circ} \mathrm{C}$ for $24 \mathrm{~h}$. The obtained particles were centrifuged down and washed several times with deionized water and finally dispersed into ethanol for further use. 
For the coating of mesoporous silica shell, $5 \mathrm{mg}$ of the synthesized PB nanoparticles was added into the mixed solution containing $33.0 \mathrm{~mL}$ of $\mathrm{H}_{2} \mathrm{O}, 21.0 \mathrm{~mL}$ of methanol, and $0.25 \mathrm{~g}$ of 2-methyl imidazole. The mixture was then sonicated for $3 \mathrm{~min}$, followed by injecting of $0.55 \mathrm{~mL}$ of cetyltrimethylammonium chloride solution (CTAC, $12.5 \mathrm{wt} \%$ ) aqueous solution and stirring for $20 \mathrm{~min}$. Then $0.4 \mathrm{~mL}$ of tetraethyl orthosilicate (TEOs) was added to the mixture dropwise. The final mixture was stirred for another $3 \mathrm{~h}$, and then centrifuged down and washed by water and ethanol many times. The synthesized particles were dried under vacuum overnight for later using. For cell uptake study, the synthesized particles were functionalized with $0.1 \mathrm{wt} \%$ 3-Aminopropyl- triethoxysilane (APS) in anhydrous toluene overnight at $80^{\circ} \mathrm{C}$, and then labeled with rhodamine B isothiocyanate dye before using.

CCMV thin film coated MSN nanoparticle fabrication CCMV-TMC free-standing thin film was first fabricated as described above. Then rhodamine B isothiocyanate dye-labeled MSN nanoparticle $100 \mu \mathrm{g}$ in hexane was added onto the top layer. After $30 \mathrm{~min}$, the particles were centrifuged down to allow the coating of CCMV-TMC film onto MSN nanoparticle surface, and then washed by $0.2 \mathrm{M}$ phosphate buffer (PB, pH7.2) for several times before using.

\subsubsection{Methods}

Reduction reaction catalyzed by Au NPs, CCMV-Au and CCMV-Au film $1.2 \mathrm{~mL}$ of Milli-Q was added into a quartz cuvette with a thin film attached on one inner side, UV-vis recording was started right after adding of $300 \mu \mathrm{L}$ of $\mathrm{NaBH}_{4}$ and 4-nitrophenol (4NP) mixture. Total number of $\mathrm{Au}$ NPs in thin film was calculated (see 3.2.2). In a control experiment, $1.2 \mathrm{~mL}$ of Au NPs or CCMV-Au (containing the same number of Au NPs as in the thin film) was mixed with $300 \mu \mathrm{L}$ of a $\mathrm{NaBH}_{4}$ and 4-nitrophenol (4NP) mixture and the catalytic reaction was monitored by UV-Vis.

Kinetic study of reactions catalyzed by HRP, HRPPS, CCMV-HRPPS and CCMVHRPPss by multi-plate reader All reactions catalyzed by HRP, HRP ${ }_{\mathrm{PSS}}$, CCMV-HRP PSS free VLPs and the corresponding thin films were performed in Tris- $\mathrm{HCl}$ buffer, which is 25 $\mathrm{mM}$ Tris, $25 \mathrm{mM} \mathrm{NaCl}, 5 \mathrm{mM} \mathrm{KCl}, 2.5 \mathrm{mM} \mathrm{MgCl}$, $\mathrm{pH}$ 7.5. 


\section{a) HRP, HRPPSS, CCMV-HRPPSS:}

$50 \mu \mathrm{L}$ solutions with $4 \mathrm{nM}$ HRP (or HRPPSs, CCMV-HRPPss) and $10 \mathrm{mM} \mathrm{H}_{2} \mathrm{O}_{2}$ were added into 96 well plates, the monitoring of the reaction by UV-vis on a TECAN I-control multiplate reader was started immediately after adding $50 \mu \mathrm{L}$ of ABTS substrates with various concentrations.

\section{b) CCMV-HRPpss thin films:}

$100 \mu \mathrm{L}$ of $5 \mathrm{mM} \mathrm{H}_{2} \mathrm{O}_{2}$ was added into the well which contained the CCMV-HRPPSs films. The kinetic assay was performed by adding $18 \mathrm{mM}$ of ABTS with various volumes to obtain various final concentration of substrates. The concentration changes of CCMV-HRPPSS and $\mathrm{H}_{2} \mathrm{O}_{2}$ were negligible since only a small volume $(<10 \mu \mathrm{L})$ of ABTS solution was added.

Cell culture Cell culture was performed using standard procedures (atcc.org). Briefly, HeLa (CCL-2) were obtained from American Type Culture Collection (ATCC) and maintained in media containing $10 \% \mathrm{FBS}$ at $37^{\circ} \mathrm{C}$ and $5 \% \mathrm{CO}_{2}$. Cells were passaged at approximately $80 \%$ confluency. For coating purposes, Living adherent HeLa cells were removed from plate bottom using Trypsin-EDTA $(0.25 \%)$ and then suspended in culture media.

Nanoparticles Cytotoxicity Assay Hela cells were used to evaluate the cytotoxicity of nanoparticles (CCMV particle, MSN nanoparticle, and MSN@CCMV-TMC nanoparticle) by MTT assays according to the reported method. When the cell confluency reached $\sim 70 \%$, $100 \mu \mathrm{L}$ of cells were seeded into 96 -well plates at a density of $1 \times 10^{5}$ cells $/ \mathrm{mL}$. After $24 \mathrm{~h}$, culture media were replaced with fresh media containing a different number of nanoparticles (200 $\mu \mathrm{g} / \mathrm{mL}, 100 \mu \mathrm{g} / \mathrm{mL}, 50 \mu \mathrm{g} / \mathrm{mL}, 10 \mu \mathrm{g} / \mathrm{mL}, 1 \mu \mathrm{g} / \mathrm{mL}$, and $0.1 \mu \mathrm{g} / \mathrm{mL})$. After another 24 $\mathrm{h}$ of incubation, $10 \mu \mathrm{L}$ of $5 \mathrm{mg} / \mathrm{mL}$ filtered MTT stock solution was added to each well, and unreacted dye was removed by aspiration after $4 \mathrm{~h}$. The formazan crystals were dissolved in $100 \mu \mathrm{L}$ of DMSO per well and were measured on an Infinite M200 microplate reader (Tecan, Switzerland) at a wavelength of $570 \mathrm{~nm}$. The cell viability was expressed as a relative percentage of the untreated cells.

Nanoparticle uptake HeLa cells were plated at $5 \times 10^{5}$ cells per well into 6-well Lab-Tek I chambered coverglass slides and allowed to adhere overnight. Cells were then incubated with $20 \mu \mathrm{g} / \mathrm{mL}$ of rhodamine dye labeled MSN@CCMV-TMC nanoparticle at $37{ }^{\circ} \mathrm{C}$ in a $5 \% \mathrm{CO}_{2}$ 
atmosphere for different times ( $1 \mathrm{~h}, 2 \mathrm{~h}$, and $4 \mathrm{~h})$. Following this, the cells were gently washed with PBS three times and fixed with $4 \%$ paraformaldehyde for $30 \mathrm{~min}$ at room temperature. Nuclei and membranes were stained with Hoechst $33342\left(2 \mu \mathrm{g} \mathrm{mL}^{-1}\right)$ and Alexa Fluor 488 Wheat Germ Agglutinin $\left(5 \mu \mathrm{g} \mathrm{mL}^{-1}\right)$, respectively. After staining, the cells were washed with PBS twice and stored in PBS prior to fluorescence microscope imaging.

\subsubsection{Appendix}

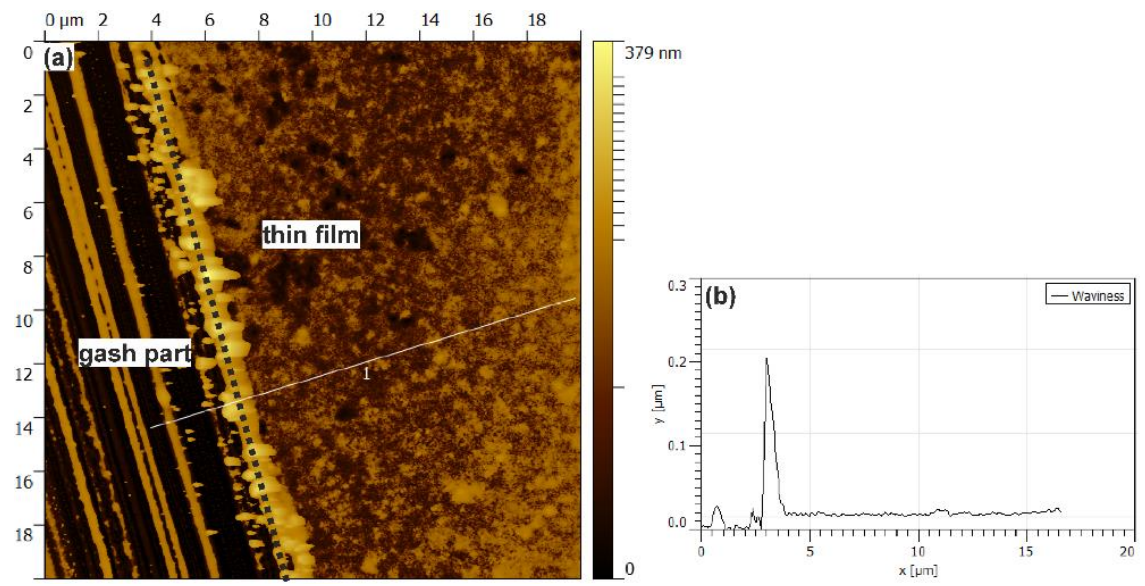

Figure 5.16. AFM analysis of CCMV-Au7B thin film thickness that formed with gold concentration of $0.07 \mathrm{mg} / \mathrm{mL}$. overage height of thin film is $20 \mathrm{~nm}$, indicate monolayer of CCMV-Au7B $(18 \mathrm{~nm})$ thin film.

\section{Calculation of total number of Au7B in the thin film and the study of catalytic activity}
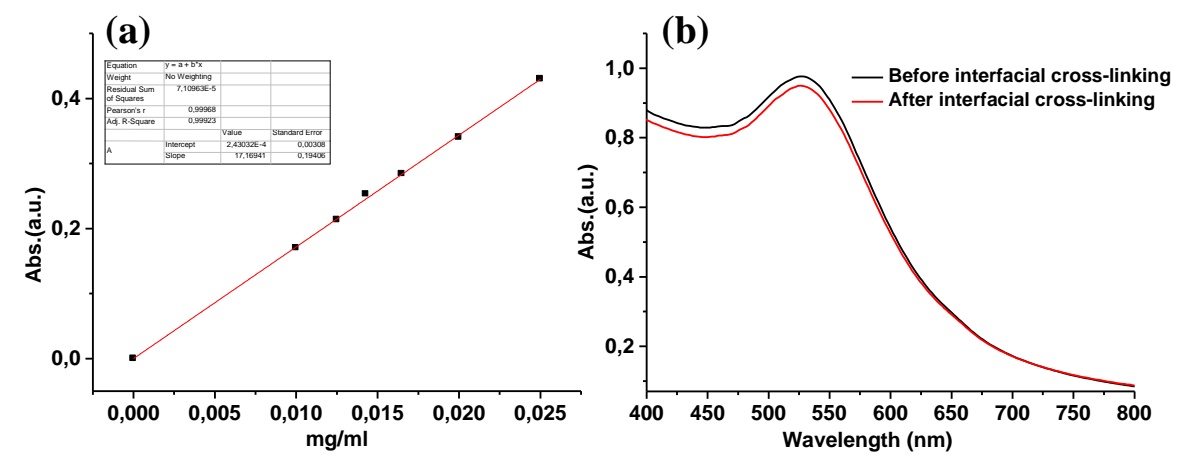

Figure 5.17. (a) UV-Vis absorption at $\lambda=520 \mathrm{~nm}$ of $\mathrm{Au} 7 \mathrm{~B}$ with different concentrations and the linear fit. (b) Concentration change of CCMVAu-7B before and after cross-linking characterized by UV-Vis spectroscopy. 


\section{Chapter 5}

$300 \mu \mathrm{L}$ of CCMV-Au solution (in 0.2 M PB buffer, $\mathrm{pH} 7.2$ ) was put into a quartz cuvette for the thin film preparation.

$$
\begin{aligned}
& \mathrm{A}=\varepsilon \mathrm{LC}, \mathrm{C}=\mathrm{A} /(\varepsilon \mathrm{L}), \mathrm{C}_{\text {before }}-\mathrm{C}_{\text {after }}=\left(\mathrm{A}_{\text {before }}-\mathrm{A}_{\text {after }}\right) /(\varepsilon \mathrm{L}) ; \\
& \Delta \mathrm{A}=0.97691-0.94973=0.02718(\text { Figure } 5.16 \mathrm{~b})
\end{aligned}
$$

Number of particles in the thin film: $N=\left(C_{\text {before }}-C_{a f t e r}\right) V, V=300 \mu \mathrm{L}$.

\section{Known:}

1. $0.025 \mathrm{mg} / \mathrm{mL}$ of $\mathrm{Au} 7 \mathrm{NPs}$ with absorption of $\mathrm{A}_{520}=0.43002$ contained $1.7 \mathrm{E}+13$ particles/mL;

2. The concentration of AuNPs and the absorption at $520 \mathrm{~nm}$ are in linear relationship (Figure 5.16a).

\section{Therefore:}

Solution with $\Delta \mathrm{A}=0.02718$ contained $1.0745 \mathrm{E}+12$ particles $/ \mathrm{mL}$; with a volume $\mathrm{V}=300$ $\mu \mathrm{L}$, the total number of AuNPs in the thin film: $\mathrm{n}=3.223 \mathrm{E}+11$ particles.

4-Nitrophenol reduction condition: $1.2 \mathrm{~mL} \mathrm{MQ}$, or Au NPs, or CCMV-Au NPs was added into a quartz cuvette with a thin film inside, $40 \mu \mathrm{L}$ of $2 \mathrm{mM} 4 \mathrm{NP}$ solution was added subsequently. UV-Vis monitor was started right after adding $260 \mu \mathrm{L}$ of $30 \mathrm{mM} \mathrm{NaBH}$ solution.
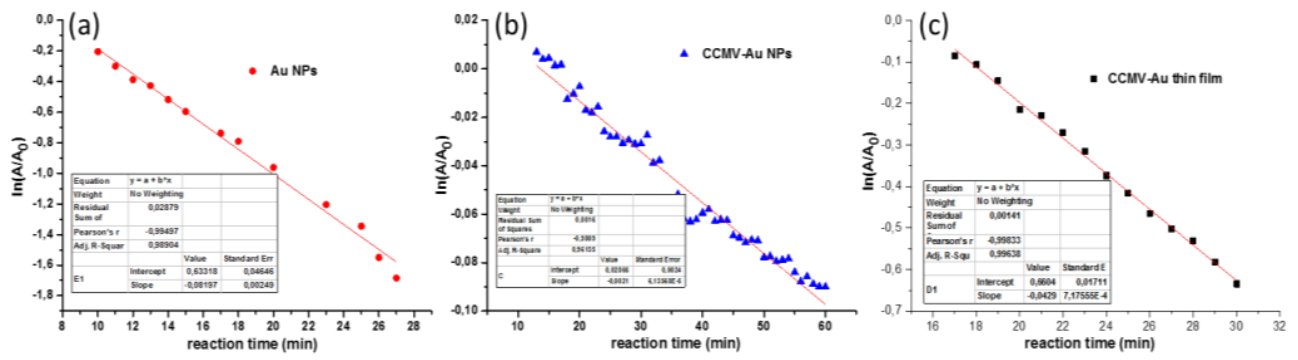

Figure 5.18. In $\left(A / A_{0}\right)$ versus time plots of AuNPs, CCMV-Au NPs and CCMV-Au thin film. 


\subsection{References}

1. (a) Hong, J.; Lee, S.; Seo, J.; Pyo, S.; Kim, J.; Lee, T., A Highly Sensitive Hydrogen Sensor with Gas Selectivity Using a PMMA Membrane-Coated Pd Nanoparticle/SingleLayer Graphene Hybrid. ACS Applied Materials \& Interfaces 2015, 7 (6), 3554-3561; (b) Jimenez-Solomon, M. F.; Song, Q.; Jelfs, K. E.; Munoz-Ibanez, M.; Livingston, A. G., Polymer nanofilms with enhanced microporosity by interfacial polymerization. Nature Materials 2016, 15, 760-767..

2. Raaijmakers, M. J. T.; Schmidt, T.; Barth, M.; Tutus, M.; Benes, N. E.; Wessling, M., Enzymatically Active Ultrathin Pepsin Membranes. Angewandte Chemie International Edition 2015, 54 (20), 5910-5914.

3. (a) Lin, Y.; Skaff, H.; Böker, A.; Dinsmore, A. D.; Emrick, T.; Russell, T. P., Ultrathin Cross-Linked Nanoparticle Membranes. Journal of the American Chemical Society 2003, 125 (42), 12690-12691; (b) Troyano, J.; Castillo, O.; Amo-Ochoa, P.; FernandezMoreira, V.; Gomez-Garcia, C. J.; Zamora, F.; Delgado, S., A crystalline and free-standing silver thiocarboxylate thin-film showing high green to yellow luminescence. Journal of Materials Chemistry C 2016, 4 (36), 8545-8551.

4. Yang, G.; Hu, L.; Keiper, T. D.; Xiong, P.; Hallinan, D. T., Gold Nanoparticle Monolayers with Tunable Optical and Electrical Properties. Langmuir 2016, 32 (16), 40224033.

5. Vozar, S.; Poh, Y.-C.; Serbowicz, T.; Bachner, M.; Podsiadlo, P.; Qin, M.; Verploegen, E.; Kotov, N.; Hart, A. J., Automated spin-assisted layer-by-layer assembly of nanocomposites. Review of Scientific Instruments 2009, 80 (2), 023903.

6. (a) Shim, T. S.; Estephan, Z. G.; Qian, Z.; Prosser, J. H.; Lee, S. Y.; Chenoweth, D. M.; Lee, D.; Park, S.-J.; Crocker, J. C., Shape changing thin films powered by DNA hybridization. Nature Nanotechnology 2017, 12 (1), 41-47; (b) Zhang, J.; Yuan, B.; Wang, Z.; Chen, T., Fabrication of free-standing multilayer films by using $\mathrm{pH}$-responsive microgels as sacrificial layers. Colloid and Polymer Science 2014, 292 (5), 1235-1240; (c) Estephan, Z. G.; Qian, Z.; Lee, D.; Crocker, J. C.; Park, S.-J., Responsive Multidomain Free-Standing Films of Gold Nanoparticles Assembled by DNA-Directed Layer-by-Layer Approach. Nano Letters 2013, 13 (9), 4449-4455; (d) Andryszewski, T.; Iwan, M.; Hołdyński, M.; Fiałkowski, M., Synthesis of a Free-Standing Monolayer of Covalently Bonded Gold Nanoparticles. Chemistry of Materials 2016, 28 (15), 5304-5313.

7. Russell, J. T.; Lin, Y.; Böker, A.; Su, L.; Carl, P.; Zettl, H.; He, J.; Sill, K.; Tangirala, R.; Emrick, T.; Littrell, K.; Thiyagarajan, P.; Cookson, D.; Fery, A.; Wang, Q.; Russell, T. P., Self-Assembly and Cross-Linking of Bionanoparticles at Liquid-Liquid Interfaces. Angewandte Chemie International Edition 2005, 44 (16), 2420-2426.

8. (a) Soto, C. M.; Ratna, B. R., Virus hybrids as nanomaterials for biotechnology. Current Opinion in Biotechnology 2010, 21 (4), 426-438; (b) Ueno, T.; Suzuki, M.; Goto, T.; Matsumoto, T.; Nagayama, K.; Watanabe, Y., Size-Selective Olefin Hydrogenation by a Pd Nanocluster Provided in an Apo-Ferritin Cage. Angewandte Chemie International Edition 2004, 43 (19), 2527-2530; (c) Jordan, P. C.; Patterson, D. P.; Saboda, K. N.; Edwards, E. J.; Miettinen, H. M.; Basu, G.; Thielges, M. C.; Douglas, T., Self-assembling biomolecular catalysts for hydrogen production. Nature Chemistry 2016, 8 (2), 179-185; (d) Liu, A.; Traulsen, C. H. H.; Cornelissen, J. J. L. M., Nitroarene Reduction by a Virus Protein Cage Based Nanoreactor. ACS Catalysis 2016, 6 (5), 3084-3091; (e) Comellas-Aragones, M.; 
Engelkamp, H.; Claessen, V. I.; Sommerdijk, N. A. J. M.; Rowan, A. E.; Christianen, P. C. M.; Maan, J. C.; Verduin, B. J. M.; Cornelissen, J. J. L. M.; Nolte, R. J. M., A virus-based single-enzyme nanoreactor. Nature Nanotechnology 2007, 2 (10), 635-639; (f) Wen, A. M.; Steinmetz, N. F., Design of virus-based nanomaterials for medicine, biotechnology, and energy. Chemical Society Reviews 2016, 45 (15), 4074-4126.

9. (a) Liu, A.; Verwegen, M.; de Ruiter, M. V.; Maassen, S. J.; Traulsen, C. H. H.; Cornelissen, J. J. L. M., Protein Cages as Containers for Gold Nanoparticles. The Journal of Physical Chemistry B 2016, 120 (26), 6352-6357; (b) Brasch, M.; de la Escosura, A.; Ma, Y.; Uetrecht, C.; Heck, A. J. R.; Torres, T.; Cornelissen, J. J. L. M., Encapsulation of Phthalocyanine Supramolecular Stacks into Virus-like Particles. Journal of the American Chemical Society 2011, 133 (18), 6878-6881; (c) Setaro, F.; Brasch, M.; Hahn, U.; Koay, M. S. T.; Cornelissen, J. J. L. M.; de la Escosura, A.; Torres, T., Generation-Dependent Templated Self-Assembly of Biohybrid Protein Nanoparticles around Photosensitizer Dendrimers. Nano Letters 2015, 15 (2), 1245-1251; (d) Huang, X.; Bronstein, L. M.; Retrum, J.; Dufort, C.; Tsvetkova, I.; Aniagyei, S.; Stein, B.; Stucky, G.; McKenna, B.; Remmes, N.; Baxter, D.; Kao, C. C.; Dragnea, B., Self-Assembled Virus-like Particles with Magnetic Cores. Nano Letters 2007, 7 (8), 2407-2416.

10. Hommersom, C. A.; Matt, B.; van der Ham, A.; Cornelissen, J. J. L. M.; Katsonis, N., Versatile post-functionalization of the external shell of cowpea chlorotic mottle virus by using click chemistry. Organic \& Biomolecular Chemistry 2014, 12 (24), 4065-4069.

11. (a) Huang, X.; El-Sayed, M. A., Gold nanoparticles: Optical properties and implementations in cancer diagnosis and photothermal therapy. Journal of Advanced Research 2010, 1 (1), 13-28; (b) Wustholz, K. L.; Henry, A.-I.; McMahon, J. M.; Freeman, R. G.; Valley, N.; Piotti, M. E.; Natan, M. J.; Schatz, G. C.; Duyne, R. P. V., Structure-Activity Relationships in Gold Nanoparticle Dimers and Trimers for SurfaceEnhanced Raman Spectroscopy. Journal of the American Chemical Society 2010, 132 (31), 10903-10910; (c) Masango, S. S.; Hackler, R. A.; Large, N.; Henry, A.-I.; McAnally, M. O.; Schatz, G. C.; Stair, P. C.; Van Duyne, R. P., High-Resolution Distance Dependence Study of Surface-Enhanced Raman Scattering Enabled by Atomic Layer Deposition. Nano Letters 2016, 16 (7), 4251-4259.

12. (a) Li, M.; Chen, G., Revisiting catalytic model reaction p-nitrophenol/NaBH4 using metallic nanoparticles coated on polymeric spheres. Nanoscale 2013, 5 (23), 1191911927; (b) Choi, S.; Jeong, Y.; Yu, J., Spontaneous hydrolysis of borohydride required before its catalytic activation by metal nanoparticles. Catalysis Communications 2016, 84, 80-84; (c) Lin, F.-h.; Doong, R.-a., Highly efficient reduction of 4-nitrophenol by heterostructured gold-magnetite nanocatalysts. Applied Catalysis A: General 2014, 486, 32-41.

13. (a) Saha, K.; Agasti, S. S.; Kim, C.; Li, X.; Rotello, V. M., Gold Nanoparticles in Chemical and Biological Sensing. Chemical Reviews 2012, 112 (5), 2739-2779; (b) Sharma, R.; Ali, M. A.; Selvi, N. R.; Singh, V. N.; Sinha, R. K.; Agrawal, V. V., Electrochemically Assembled Gold Nanostructures Platform: Electrochemistry, Kinetic Analysis, and Biomedical Application. The Journal of Physical Chemistry C 2014, 118 (12), 6261-6271; (c) Ahmed, S. R.; Kim, J.; Tran, V. T.; Suzuki, T.; Neethirajan, S.; Lee, J.; Park, E. Y., In situ self-assembly of gold nanoparticles on hydrophilic and hydrophobic substrates for influenza virus-sensing platform. Scientific Reports 2017, 7, 44495.

14. Chinnathambi, S.; Chen, S.; Ganesan, S.; Hanagata, N., Silicon Quantum Dots for Biological Applications. Advanced Healthcare Materials 2014, 3 (1), 10-29. 
15. Dohnalova, K.; Poddubny, A. N.; Prokofiev, A. A.; de Boer, W. D. A. M.; Umesh, C. P.; Paulusse, J. M. J.; Zuilhof, H.; Gregorkiewicz, T., Surface brightens up Si quantum dots: direct bandgap-like size-tunable emission. Light: Science \& Applications 2013, 2 , e47. 16. Luque, D.; Escosura, A. d. 1.; Snijder, J.; Brasch, M.; Burnley, R. J.; Koay, M. S. T.; Carrascosa, J. L.; Wuite, G. J. L.; Roos, W. H.; Heck, A. J. R.; Cornelissen, J. J. L. M.; Torres, T.; Castón, J. R., Self-assembly and characterization of small and monodisperse dye nanospheres in a protein cage. Chemical Science. 2014, 5 (2), 575-581.

17. Brasch, M.; Putri, R. M.; de Ruiter, M. V.; Luque, D.; Koay, M. S. T.; Castón, J. R.; Cornelissen, J. J. L. M., Assembling Enzymatic Cascade Pathways inside Virus-Based Nanocages Using Dual-Tasking Nucleic Acid Tags. Journal of the American Chemical Society 2017, 139 (4), 1512-1519.

18. (a) Rao, S. V.; Anderson, K. W.; Bachas, L. G., Controlled layer-by-layer immobilization of horseradish peroxidase. Biotechnology and Bioengineering 1999, 65 (4), 389-396; (b) Limoges, B.; Savéant, J.-M.; Yazidi, D., Quantitative Analysis of Catalysis and Inhibition at Horseradish Peroxidase Monolayers Immobilized on an Electrode Surface. Journal of the American Chemical Society 2003, 125 (30), 9192-9203; (c) Childs, R. E.; Bardsley, W. G., The steady-state kinetics of peroxidase with 2,2'-azino-di-(3-ethylbenzthiazoline-6-sulphonic acid) as chromogen. Biochemical Journal 1975, 145 (1), 93-103. 19. Lu, J.; Liong, M.; Li, Z.; Zink, J. I.; Tamanoi, F., Biocompatibility, Biodistribution, and Drug-Delivery Efficiency of Mesoporous Silica Nanoparticles for Cancer Therapy in Animals. Small 2010, 6 (16), 1794-1805.

20. Ming, H.; Torad, N. L. K.; Chiang, Y.-D.; Wu, K. C. W.; Yamauchi, Y., Size- and shape-controlled synthesis of Prussian Blue nanoparticles by a polyvinylpyrrolidone-assisted crystallization process. CrystEng Comm 2012, 14 (10), 3387-3396. 


\section{Chapter 6}

\section{Construction of Core-Shell Hybrid Nanoparticles Templated by Virus-like Particles}

Plant viruses have been widely used as templates for the synthesis of organic-inorganic (such as silica or titanium oxide) hybrid nanoparticles, however the fine-tuning of hybrid nanoparticle structures, especially the control of where the silication occurs is challenging. By taking the advantage of templating effect of CCMV, we show that the silication at the exterior or interior surface of protein capsids, as well as the resulting structures of silica/virus hybrid nanoparticles can be fine-tuned by $\mathrm{pH}$. Multiple component hybrid virus/nanoparticulate systems, such as CCMV-Au/silica and Au/silica nanoparticles were prepared step-by-step. Upon removal of the CCMV template by thermal degradation obtained a single gold nanoparticle be encapsulated in a hollow silica shell emulating the structure of a baby rattle with an unattached solid particle within a hollow particle. The Au/silica corehollow shell nanoparticles can then be further used as a stable catalyst. It is anticipated that these synthetic methods provide a versatile methodology to prepare core-shell nanomaterials with well-designed structure and functionality.

A. Liu, L. Yang, M. Verwegen, D. Reardon, J. J. L. M. Cornelissen. Construction of Core-Shell Hybrid Nanoparticles Templated by Virus-like Particles, submitted. 


\subsection{Introduction}

Organic-inorganic hybrid nanoparticles (NPs) with combined functionalities have attracted great interest in recent years. ${ }^{1}$ In particular, environmentally friendly and low-cost plant virus based hybrid materials have been widely studied, ${ }^{2}$ due to their promising applications in biomedicines, electronic devices and vaccine storage. ${ }^{3}$ The advantages of using viruses as templates are: (i) these are monodisperse NPs with a high level of symmetry, which is suitable for the construction of uniform nanoparticles; (ii) many of the virus NPs are stable over wide $\mathrm{pH}$ and temperature ranges without surfactant, which make them applicable for the synthesis of hybrid NPs. In particular hybrid protein cage-silica NP are of interest as these combine the robust properties of silica, e.g. structural integrity, with the high level of definition of virus-based protein cages.

Spherical and tube-like viruses have been used as templates for the synthesis of silicavirus hybrid NPs. ${ }^{4}$ Silication has been achieved on the genetically modified protein shell of the Cowpea Mosaic virus (CPMV), ${ }^{4 \mathrm{~b}}$ however, the size of the particles was hard to control due to particle cross-linking of silanol groups. By mimicking natural silica growth, positively charged (3-aminopropyl)triethoxysilane (APTES) was pre-adsorbed onto negatively charged viral NPs surface and hydrolyzed/condensed to form silica nuclei, then tetraethoxysilane (TEOS) was added to promote the growth of the silica shell. ${ }^{4 h, 5}$ Silication on tube-like virus particles, such as the tobacco mosaic virus (TMV) was also reported. ${ }^{4 c, 4 f}$ In this case, the modification of the outer-surface of the virus particles with a polymer is necessary, in order to obtain silica shell with sufficient thickness to tolerate the deposition of metal nanoparticles. $^{4 \mathrm{c}, \mathrm{d}}$

Although the construction of silica-virus hybrid NPs was successful, the fine-tuning of hybrid NP structures, especially the control of silication outside or inside the virus capsid, remains challenging. When the exterior surface of the capsid is negatively charged it can interact with positively charged silica precursors, for example APTES, and thus facilitate the deposition of silica on the exterior surface of capsid. Meanwhile, the porous structure of the protein shell of virus NPs allow foreign molecules, such as the silica precursors/ or silica nuclei, to get access inside the virus cage. In view of these considerations, virus silication can not only take place at the exterior surface but also inside the capsid, leading to structurally 


\section{Chapter 6}

diverse hybrid NPs. ${ }^{6}$ As a representative model system, the Cowpea Chlorotic Mottle Virus (CCMV) consists of 180 protein units, which assemble into a porous capsid shell with singlestranded RNA encapsulated. . $^{\mathrm{a}, \mathrm{b}, 3 \mathrm{~m}, \mathrm{n}, 7}$ The interaction between negatively charged CCMV capsid ( $\mathrm{pI}=3.8$ ) and APTES can be controlled by $\mathrm{pH}$, owing to the $\mathrm{pH}$ dependent of negative charge density of exterior surface of capsid. ${ }^{6,8}$ Meanwhile, the size of CCMV capsid pores (1-2 nm) is close to silica nuclei (1-2 nm $)^{9}$ and is also $\mathrm{pH}$ dependent, which allows the control of accessibility of silica nuclei through the capsid by $\mathrm{pH}$. CCMV NPs are stable at a pH range of 3.0 to 6.0 , where the pore size of the capsid is about $1 \mathrm{~nm}$ in diameter. The capsid starts to swell at $\mathrm{pH} \geq 6.5$, at which the pore size increases to $2 \mathrm{~nm}$, resulting in higher accessibility for foreign molecules. ${ }^{10,11,12}$ Disassembly happens when the $\mathrm{pH} \geq 7.5$ with high ionic strength $(>1 \mathrm{M}) \cdot{ }^{13}$ For the accessibility of the CCMV protein cage three stages were recognized: $\mathrm{pH}<5.5$, low accessibility; $\mathrm{pH}$ 5.5-7, medium accessibility; $\mathrm{pH} \geq 7.5$, high accessibility. ${ }^{14}$ Meanwhile, the net negative charge density of exterior surface of capsid is also $\mathrm{pH}$ dependent. ${ }^{6,8}$ Therefore, it should be possible to control the deposition of silica on both sides of the capsid surface by tuning the $\mathrm{pH}$ of the solution, resulting in hybrid proteinsilica nanoparticles with controlled structure.

To confirm our hypothesis, CCMV NPs were used as a template to construct hybrid nanoparticles under three representative $\mathrm{pH}$ conditions, i.e.: $\mathrm{pH} 4.0,6.0$ and 7.5. The silication at different $\mathrm{pH}$ conditions as well as the structures of the formed hybrid nanoparticles were studied. As a proof-of-concept, the control of silication was further employed to consecutively construct multi-component core-shell nanoparticles, first, hybrid nanoparticles with core-shell structures consisting of Au NPs encapsulated hybrid NPs (CCMV-Au), then silicate multi-shell hybrid NPs (CCMV-Au/silica) and finally after removal of the organic component, a solid Au nanoparticle-hollow silica NPs (Au/silica) rattle structure was obtained. The catalytic activity of Au NPs combined with the stability of silica shell, enabled the formation of highly stable catalytic materials. ${ }^{15}$ 


\subsection{Results and discussion}

\subsubsection{Construction of virus/silica hybrid nanoparticles at different pH}

To prepare virus/silica hybrid NPs, silication was carried out by treating CCMV with APTES, followed by TEOS, at different $\mathrm{pH}$. The reaction solutions were incubated while rotating for 3 days at room temperature, and washed with MilliQ MOhm water several times by centrifugation. Silication and purification of gold containing protein cages was carried out in a similar way.

The silication of virus particles was first confirmed by energy dispersive X-ray spectroscopy (EDX), which shows a silicon signal for all samples (Figure 6.1).
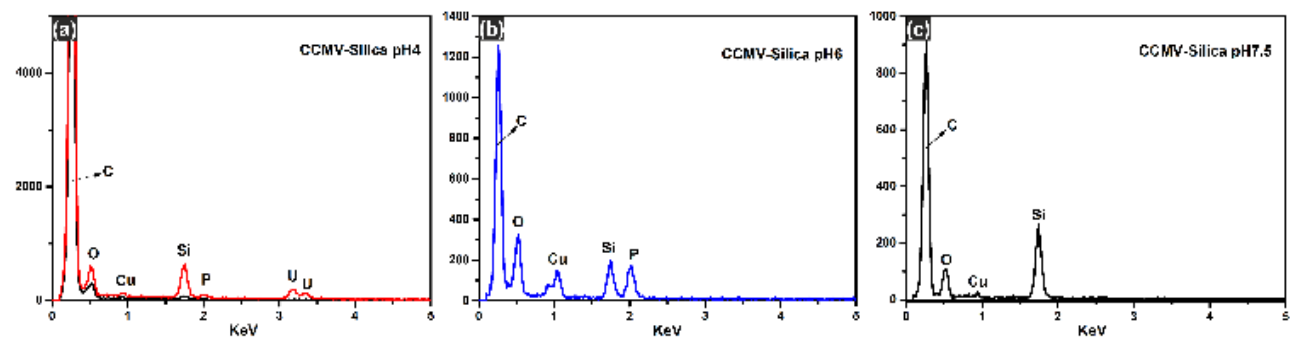

Figure 6.1. EDX analysis of CCMV templated silication under (a) $\mathrm{pH} 4.0$ (CCMV-Silica4), (b) pH 6.0 (CCMV-Silica6), and (c) pH7.5 (CCMV-Silica7.5).

Transmission Electron Microscopy (TEM) characterization further confirmed the successful silication of CCMV (Figure 6.2a). Analysis of stained TEM images with negatively stained CCMV-Silica4 displayed NP with D $=22 \mathrm{~nm}$ in with a dark core of $\mathrm{D}=15 \mathrm{~nm}$ (Figure 6.2b), while non-stained CCMV-Silica4 NPs were hardly visible in TEM (data not shown), indicating a low-density silica on the virus particles which was also confirmed by EDX elemental mapping (Figure 6.3). Stained CCMV-Silica6 showed D = $24 \mathrm{~nm}$ of white particles (Figure 6.2c), while non-stained CCMV-Silica6 NPs showed a much smaller particle size with $\mathrm{D}=14 \mathrm{~nm}$ (Figure 6.2d). Protein shells are hardly visible under TEM without proper staining, but silica, which has a higher contrast than organic protein shell, can be observed. Therefore, these $14 \mathrm{~nm}$ sized NPs from non-stained CCMV-Silica6 are identified as silica particles, indicating that the silication mainly occurred inside of the virus cage at $\mathrm{pH}$ 6.0. Further evidence to support this conclusion is that nanoparticles with a size of $D=14 \mathrm{~nm}$ were retained 


\section{Chapter 6}

after calcination (Figure 6.4). For CCMV-Silica7.5, the stained sample showed white particles with $\mathrm{D}=27 \mathrm{~nm}$ (Figure 6.2e), while the non-stained sample showed particles with average $\mathrm{D}=30 \mathrm{~nm}$ (Figure 6.2f). No clear core-shell structure was found in this case, suggesting silication might have taken place not only inside the protein cage, but also at the exterior surface of capsid or at the interface of the coat proteins. Although some smaller particles with $\mathrm{D}=18 \mathrm{~nm}$ were also observed which may mainly have silication inside protein cages.
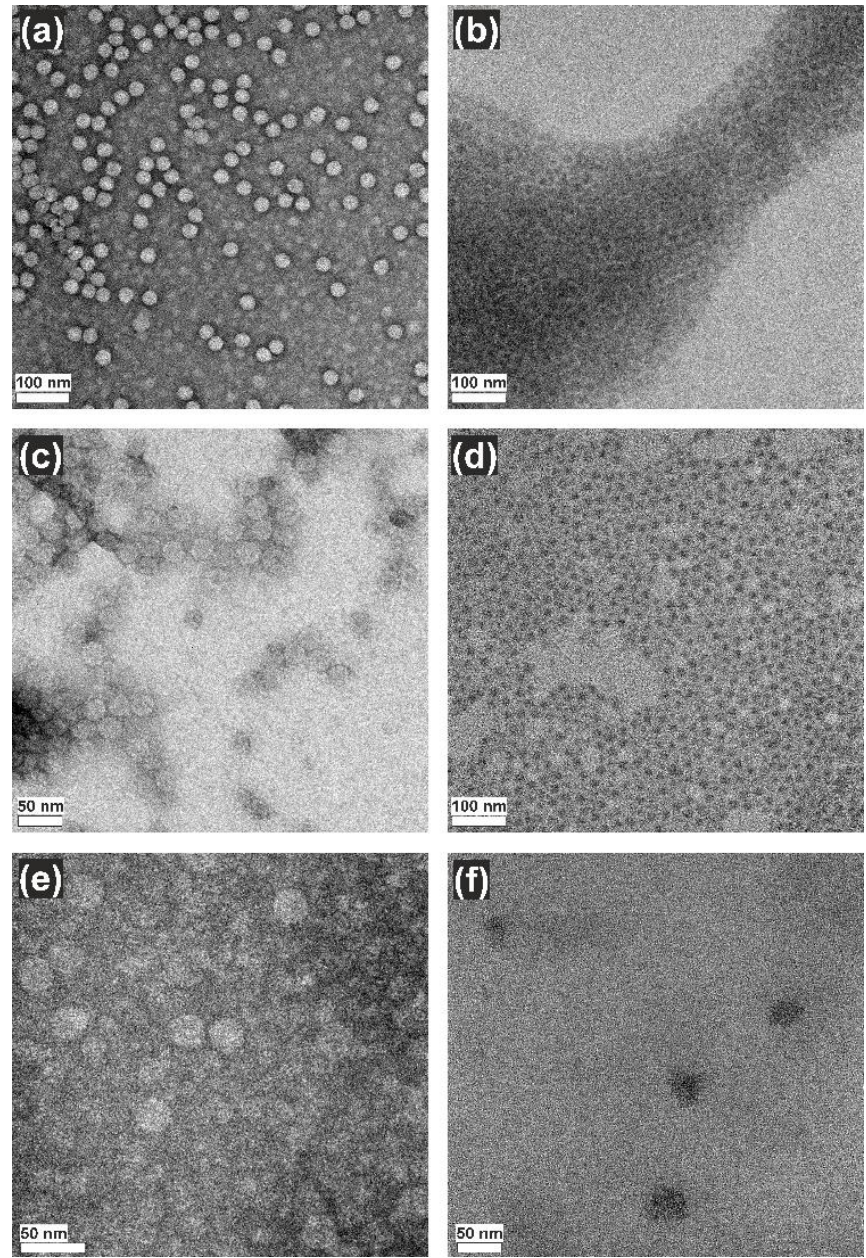

Figure 6.2. TEM image of (a) native CCMV, with staining; (b) CCMV-Silica4 with staining; (c) and (d) CCMV-Silica6 with staining and without staining, respectively; (e) and (f) CCMV-Silica7.5 with staining and without staining, respectively. 
Construction of Core-Shell Hybrid Nanoparticles Templated by Virus-like Particles
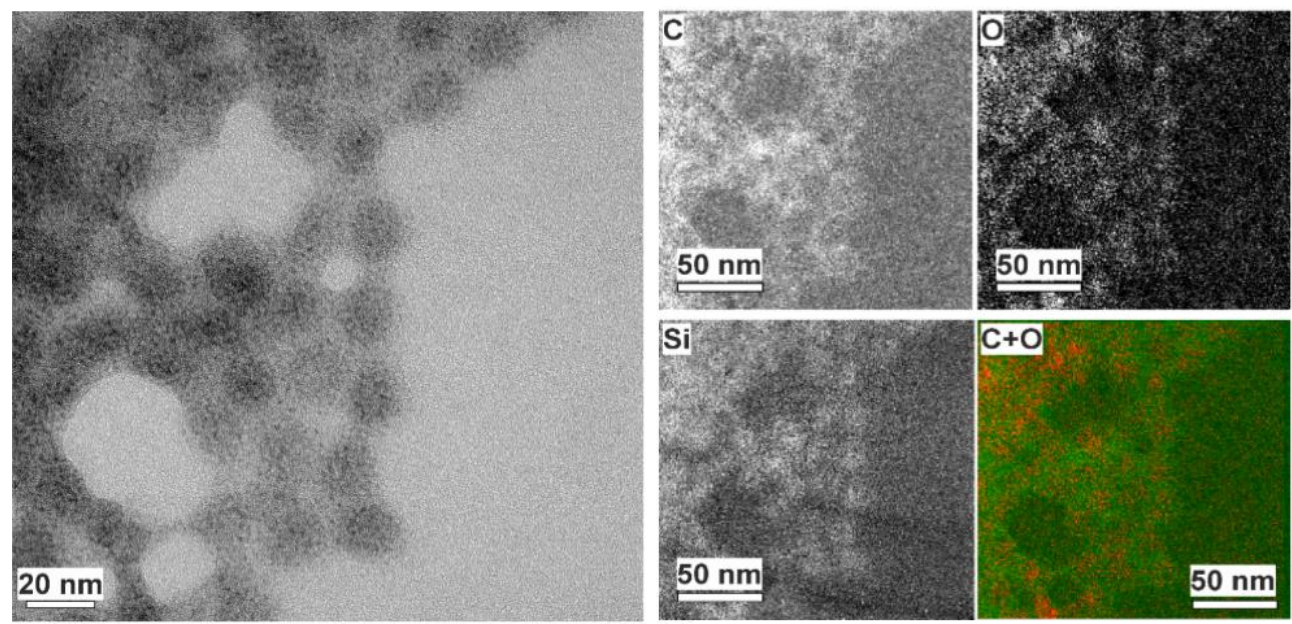

Figure 6.3. TEM elemental mapping of CCMVSilica4(a) carbon; (b) oxygen; (c) silicon and (d) overlap of oxygen and carbon.

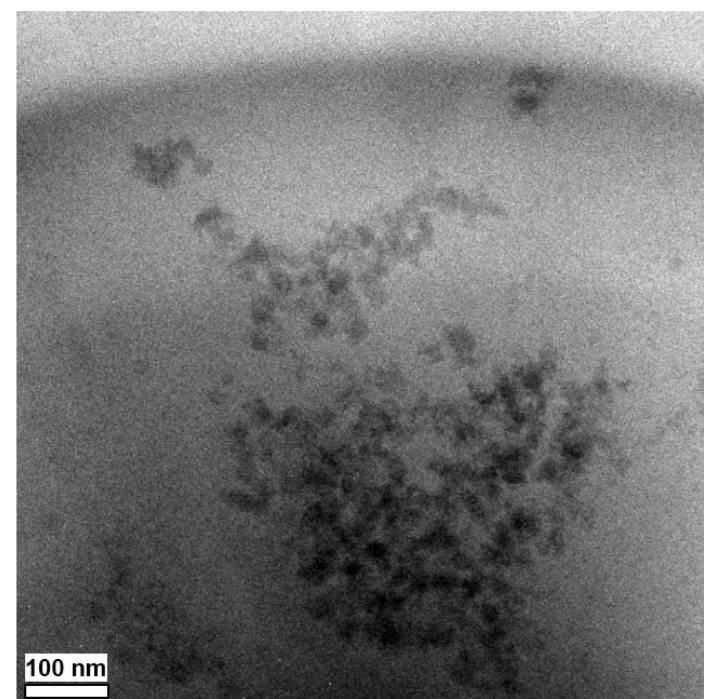

Figure 6.4. TEM image of CCMVSilica6 after high temperature of calcination under $550{ }^{\circ} \mathrm{C}$ for $3 \mathrm{hrs,}$ resulting monodisperse silica nanoparticles with size of $14 \mathrm{~nm}$.

Dynamic light scattering (DLS) results are consistent with TEM analysis. Both CCMV-Silica4 and CCMV-Silica6 show average particle sizes around D $=25 \mathrm{~nm}$ 


\section{Chapter 6}

with narrow distributions. For CCMV-Silica7.5 particles, a relative broader peak with an average diameter of $\mathrm{D}=30 \mathrm{~nm}$ was found in DLS spectrum (Figure 6.5a). The structures of silicated NPs were further studied by sodium dodecyl sulfate polyacrylamide gel electrophoresis (SDS-PAGE) analysis, which shows CCMV protein bands at $20 \mathrm{kDa}$ for CCMV-Silica4 and CCMV-Silica6 (Figure 6.5b). The presence of these CCMV protein band indicates that the capsid shell of these two samples was still exposed after silication and the capsid proteins can be denatured and separated at a high temperature under the applied conditions. For CCMV-Silica7.5, however, no significant protein band at $20 \mathrm{kDa}$ was observed, aggregates remained on top of the stacking gel (Figure 6.5b, line 4), suggesting a robust silica shell that prevents proteins from being released. This increased silica precipitation on the exterior surface could be ascribed to a higher electrostatic interaction between the capsid and APTES at a higher $\mathrm{pH}$.
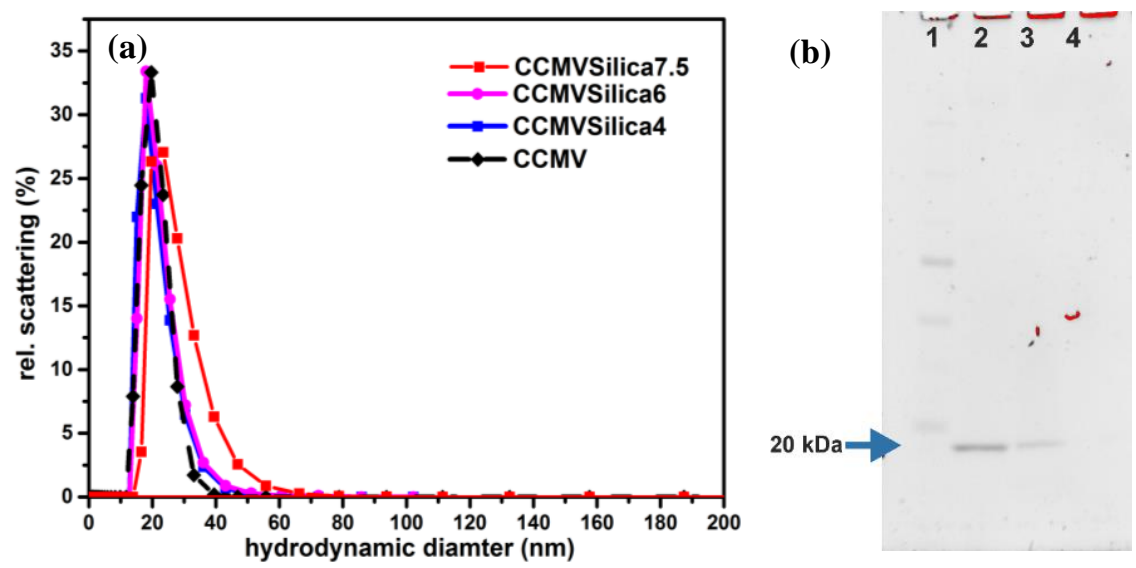

Figure 6.5. (a) Dynamic light scattering (DLS) analysis of native CCMV, CCMV-silica composite NPs prepared under pH 4 (CCMV-Silica4), pH6 (CCMV-Silica6) and pH7.5 (CCMV-Silica7.5). (b) SDSPAGE of line1: standard marker; line2: CCMV-Silica4; line3: CCMV-Silcia6 and line4: CCMVSilica7.5.

Removal of the protein part by calcination resulted in silica nanoparticles with height of $2.5 \mathrm{~nm}, 14 \mathrm{~nm}$ and $20 \mathrm{~nm}$ from CCMV-Silica4, CCMV-Silica6 and CCMV-Silica7.5 respectively as observed by Atomic Force Microscopy (AFM), as shown in Figure 6.6. For CCMV-Silica4 and CCMV-Silica6, the obtained silica nanoparticles were almost homogeneous in size from AFM images, suggesting a good controlled silication in confined viral cavity. 

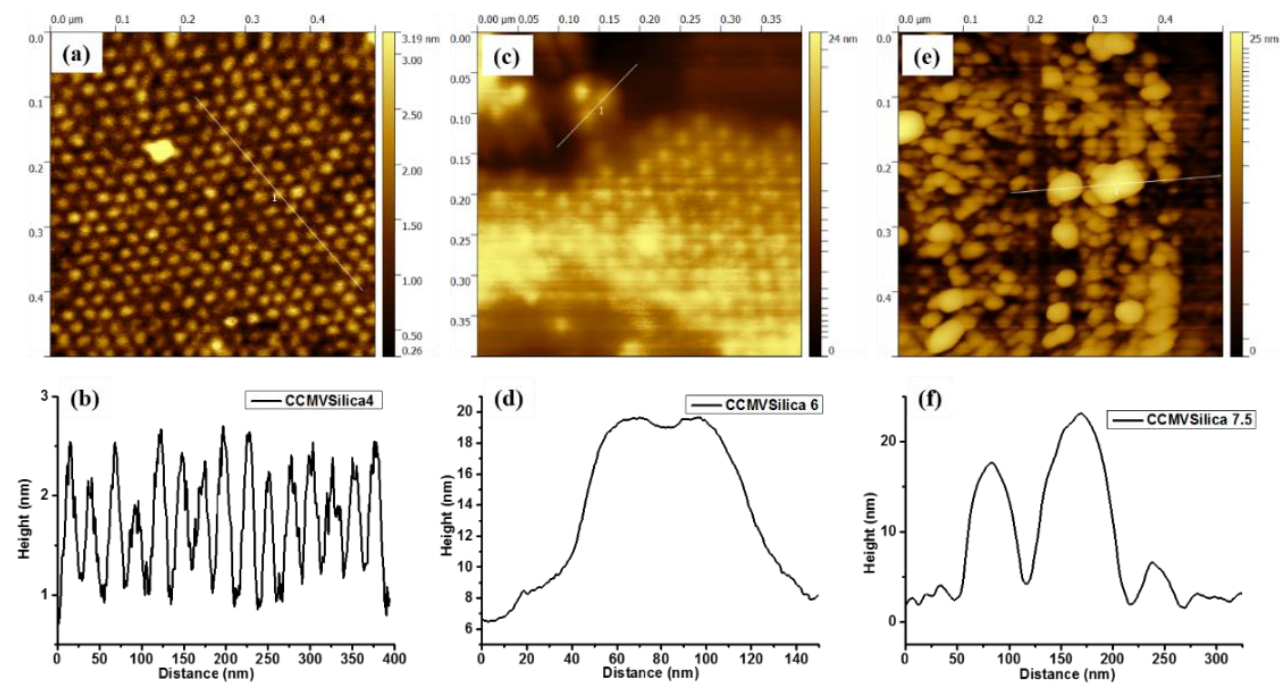

Figure 6.6. AFM image of CCMV-Silica after calcination (a) CCMV-Silica4, (b) height profile of AFM figure 6.6a; (c) CCMV-Silica6, (d) height profile of AFM figure 6.6c; and (e) CCMV-Silica7.5, (f) height profile of AFM figure 6.6e.

The formation of diverse structures of silicated nanoparticles formed at different $\mathrm{pH}$ values in the presence of CCMV is attributed to the $\mathrm{pH}$ dependence of pore size and charge state of the exterior virus surface. Therefore, the access of silica precursors into the protein cages can presumably be controlled by varying the $\mathrm{pH}$ of the system. Moreover, the electrostatic interaction between the negatively charged exterior of protein shell and positively charged APTES induces the silication on the exterior surface of the capsids. The exterior surface of capsids become more negatively charged when the $\mathrm{pH}$ is increased, since the pKa of CCMV is 3.8. ${ }^{11 a}$ Combination of these two factors leads to a competition of silica layer growth between the interior and exterior of the protein cages, resulting in silicated virus particles with fine-tuned core-shell structures.

\subsubsection{Encapsulation of gold nanoparticles and silication}

To construct multifunctional hybrid NPs, we employed the above procedure at neutral or slightly alkaline $\mathrm{pH}$ to gold nanoparticles in CCMV capsids (CCMV-Au) yielding CCMV$\mathrm{Au} /$ silica, and $\mathrm{Au} /$ silica materials. 


\section{Chapter 6}
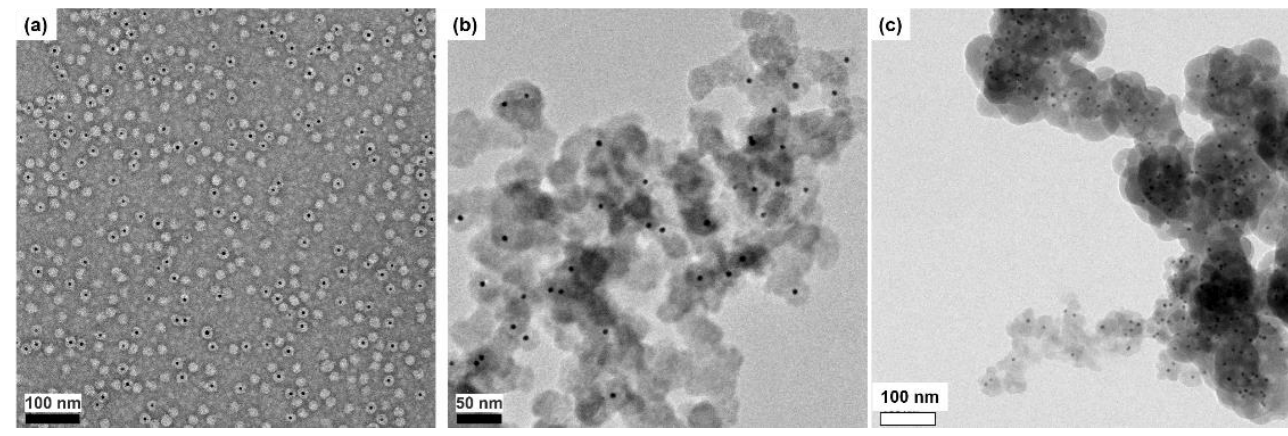

Figure 6.7. TEM images of (a) gold NPs encapsulate inside of the CCMV protein cage (CCMV-Au); (b) silicified CCMV-Au NPs with tannic acid (CCMV-Au/silica). (c) CCMV-Au/Silica without tannic acid in MQ.

Commercial Au NPs stabilized by tannic acid were encapsulated in the protein capsid as previously reported. ${ }^{16}$ The assembly resulted in hybrid CCMV-Au NPs with a core-shell structure, in combination with capsids containing only tannic acid (Figure 6.7a).

Silication of CCMV-Au resulted in CCMV-Au/silica multiple core-shell materials (Figure 6.7b). In this step, additional tannic acid was added into the CCMV-Au solution, the mixed solution was incubated on a rotor for $0.5 \mathrm{~h}$, silica precursor was then added to produce CCMV-Au/silica hybrid NPs. Tannic acid contains large number of phenol groups which can easily combine with carboxyl groups on the exterior surface of capsid through hydrogen bonding. ${ }^{17}$ Moreover, Tannic acid has also been widely used as a guiding reagent for silica growth. ${ }^{18}$ The addition of extra tannic acid resulted in uniform silica coatings on protein capsids, as shown in Figure 6.7b. Silication in the absence of tannic acid resulted only in irregular NPs (Figure 6.7c). Elemental mapping showed a thin layer of silica formed around the capsid layer and, no silica was found in the core of the particles, indicating that the silication on the exterior surface of the capsid was preferred rather than inside the protein cages (Figure 6.8).

Calcination of CCMV/silica resulted in Au/silica core-shell NPs. The organic components were removed by calcination at $550{ }^{\circ} \mathrm{C}$ for $3 \mathrm{hrs}$. The obtained Au/silica materials were characterized by STEM (Figure 6.9a \& b), showing the core-shell structure. The core particle with a higher contrast corresponds to Au NPs, while the shell consists of silica. No individual Au NPs nor aggregates were observed by STEM analysis, suggesting 
that the protein cage induced silica shell acts as a protecting layer to prevent aggregation during the calcination at high temperature.
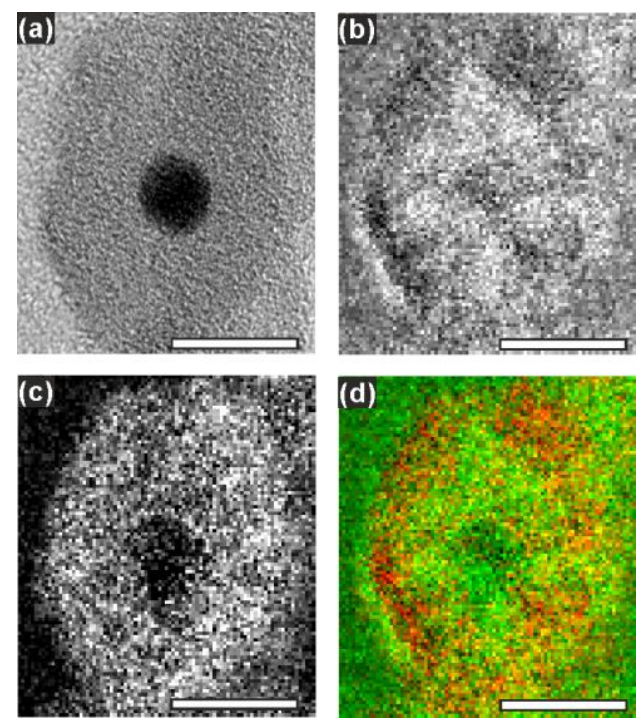

Figure 6.8. TEM elemental mapping of (a) CCMV-Au/silica nanoparticles; (b) carbon; (c) silicon and (d) composite of red: silicon, green: carbon. Scale bar: $10 \mathrm{~nm}$.

The removal of the vaporized organic materials from the silica network, suggests that these are sufficiently porous to allow small molecules to reach the gold core. This prompted us to study the catalytic activity of the encapsulated Au NPs to explore their potential application as nanoreactors. ${ }^{19}$ As a typical example, the reduction of 4-nitrophenol (4NP) was catalyzed by $\mathrm{Au} /$ silica and the progress of the reactions was monitored by UV-vis spectroscopy (Figure 6.9c). The characteristic absorption band of deprotonated 4NP at $\lambda=$ $400 \mathrm{~nm}$ decreased, while a new absorption band at $\lambda=300 \mathrm{~nm}$ - indicating the formation of aminophenol - appears during the reaction. The correlation of $\ln \left(\mathrm{A} / \mathrm{A}_{0}\right)$ versus reaction time (Figure 6.9d) points to pseudo-first-order kinetics with a rate constant of $1.23 \times 10^{-3} \mathrm{~s}^{-1}$ that is comparable to previous studies. ${ }^{20}$ 


\section{Chapter 6}
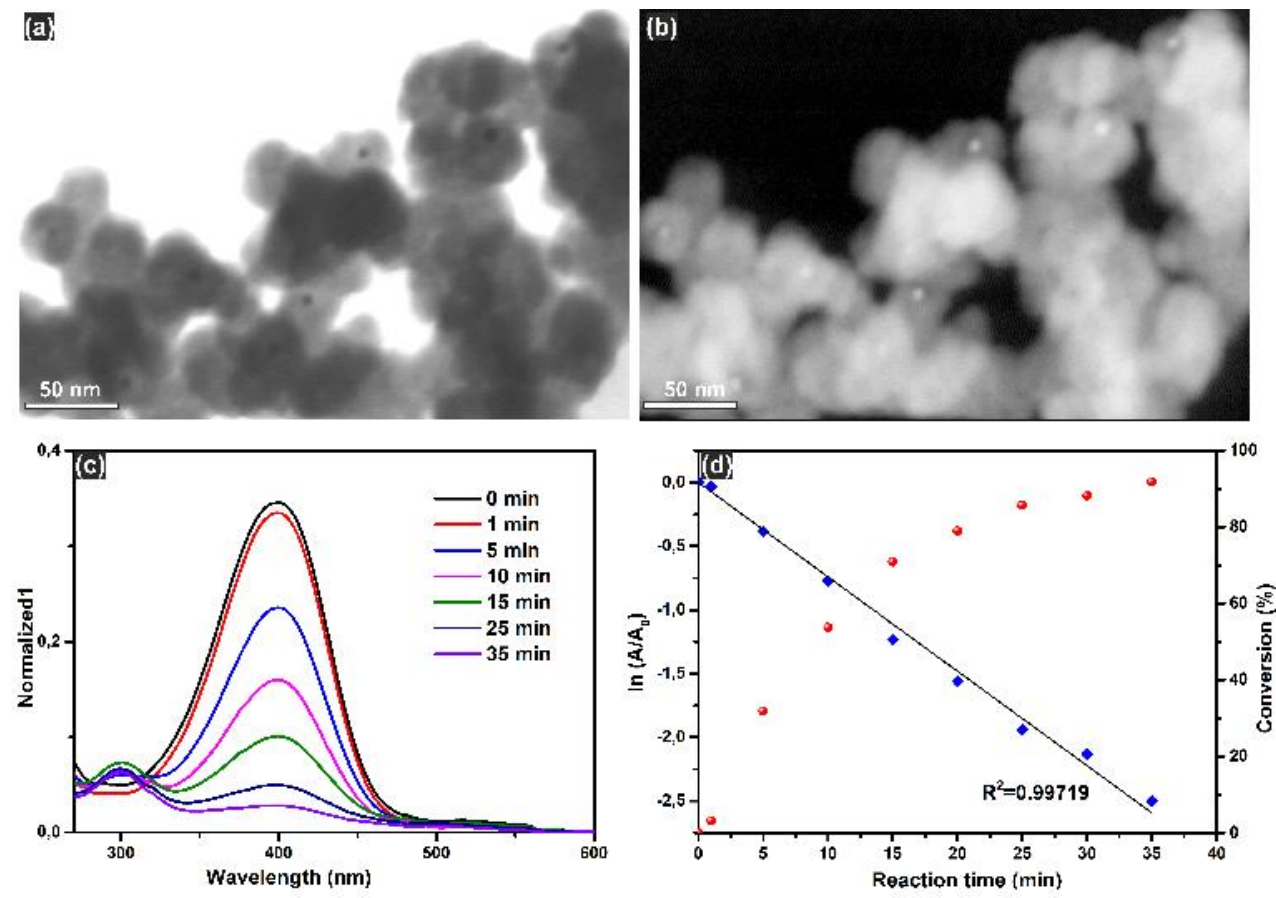

Figure 6.9. STEM images of (a) Bright field of Au/silica core-shell NPs; (b) Dark field of Au/silica core-shell NPs. (c) UV-vis spectrum for kinetic investigation of the catalytic reduction of 4-NP and (d) reduction rate of $\mathrm{Au} / \mathrm{silica}$ (blue dot) and conversion rate (red dot).

\subsection{Conclusions}

Core-shell structures of silica and virus based materials can be constructed by controlling the $\mathrm{pH}$ during the silication process. We have confirmed that at $\mathrm{pH}=6$ silica preferable forms on the inside of the $\mathrm{CCMV}$ virus, while at $\mathrm{pH}=7.5$, a silica shell surrounding the protein cage is observed. By further reducing the $\mathrm{pH}$ the penetration of silica precursors is virtually blocked, so hardly only small particles ( $\mathrm{D}<3 \mathrm{~nm}$ ) are observed. This empirical control over the silica formation with the virus as a template allowed us the construct hybrid silica/gold materials, based on $\mathrm{Au}$ NPs encased in the CCMV protein cage devoid of the genetic material. The resultant Au/protein shell/silica materials could be transformed to gold inside silica core-shell networks that are catalytically active in the reduction of 4-nitrophenol as an example. Considering the diversity of virus (-like) particles nowadays studied in materials 
science and their potential cargos, ${ }^{21}$ this methodology is not only limited to the specific $\mathrm{Au} /$ silica system, but also applicable for the preparation of a series of core-shell nanomaterials. It is anticipated that in that way it paves the way for preparing core-shell hybrid NPs with well-designed structures, towards advanced applications in catalysis, drug delivery, bio-sensor and bio-imaging.

\subsection{Acknowledgements}

Dr. Damien Reardon and Dr. Martijn Verwegen are greatly acknowledged for their scientific discussion. Dr. Liulin Yang is greatly acknowledged for his help during manuscript preparation. Many thanks to Dr. Wei Zhu for fruitful discussion; and thanks to Dr. Rico Keim and Dr. Mark Smithers for TEM and SEM analysis. 


\section{Chapter 6}

\subsection{Materials and methods}

\subsubsection{General}

All chemicals were of analytical quality, and used as purchased without further purification. Ethanol, (3-Aminopropyl)triethoxysilane (APTES), and tetraorthosilicate (TEOS), were all purchased from Sigma-Aldrich. Buffers were prepared with ultrapure water (Milli Q). CCMV NPs were isolated from infected cowpea plant and stored in virus buffer solution under $4{ }^{\circ} \mathrm{C} .{ }^{13}$

Preparation of silica/virus hybrid NPs Native CCMV (4 mg/mL) in $10 \mathrm{mM}$ sodium phosphate (PB) buffer of pH 6 was treated with TEOS and APTES (90:10 mol\%) ethanol solution and left on the rotator for 3 days at room temperature. Considering the limited stability of virus nanoparticles in organic solvent, the final ethanol concentration in water was controlled at $9 \%$. The reaction solution was then dialyzed against buffer overnight, additionally dialyzed against Milli-Q (MQ) for another 3 days to completely remove the nonreacted silane and salt. The silicified CCMV nanoparticles were separated from nontemplated silica by centrifugation at $10 \mathrm{k} \mathrm{rpm}$ for $10 \mathrm{~min}$, and the supernatant was collected and named as CCMV-Silica6. Samples under pH4 of $10 \mathrm{mM}$ sodium acetate buffer and

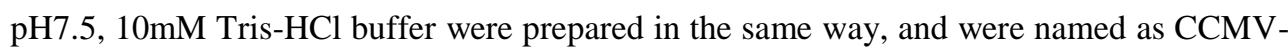
Silica4 and CCMV-Silica7.5, respectively.

Preparation of gold encapsulated CCMV NPs and silication Encapsulation of Gold NPs into CCMV protein cages was carried out according to references, ${ }^{22}$ hybrid NPs were named as Au/capsid. Then gold core-protein-silica-double shell hybrid nanoparticles (Au/capsid/silica) were prepared and templated by Au/capsid NPs. In detail, Au/capsid NPs were washed against MQ water with centrifuge filter for three times to completely remove salt, then a certain amount of tannic acid was added into the solution, the mixture was left on the rotor bank for $0.5 \mathrm{~h}$ (silication without tannic acid was also conducted). Further silication method is same as preparing of silica/virus hybrid NPs. 
Catalytic activity of Au/silica: drop $100 \mu \mathrm{L} \mathrm{CCMV-Au/silica} \mathrm{solution} \mathrm{(contain} 0.0127$ $\mathrm{mg} / \mathrm{mL}$ of $\mathrm{Au} \mathrm{NPs}$ ) on silicon wafer and dried under vacuum, calcination were then performed to form Au/silica NPs. This substrate was then used for catalytic reaction by mixing with $510 \mu \mathrm{L}$ of Milli-Q water, $90 \mu \mathrm{L}$ of $2 \mathrm{mM}$ of $4 \mathrm{NP}$ and $450 \mu \mathrm{L}$ of sodium borohydride. UV-Vis monitor was started immediately after mixing.

\section{Characterization}

Poly Acrylamide Gel Electrophoresis (PAGE) was performed in the presence of sodium dodecyl sulfate (SDS). Samples were heated at $99^{\circ} \mathrm{C}$ for $10 \mathrm{~min}$ in the presence of 2mercaptoethanol and $1 \%$ SDS.

Transmission electron microscopy (TEM) analysis was performed using Philips CM300 microscope operating at $300 \mathrm{kV}$. Samples for imaging were deposited onto a 200 mesh copper grid and left for 2 min, after which the excess buffer or water was blotted away with filter paper. Samples were negatively stained by applying $5 \mu \mathrm{L}$ of stain $(1 \% \mathrm{w} / \mathrm{v}$ uranyl acetate in Milli Q water) onto the grid for $30 \mathrm{~s}$ and the excess water was blotted away with filter paper as well. Samples were dried overnight before imaging. Samples without staining were prepared in a similar way.

Dynamic light scattering (DLS) analysis was performed with Nanotrac by Anaspec operating with a Microtrac FLEX Operating Software at $25^{\circ} \mathrm{C}$, using a laser wavelength of $780 \mathrm{~nm}$ at a scattering angle of $180^{\circ}$. The observed sizes and standard derivations of the nanoparticles were calculated by taking an average of 5 measurements.

Scanning transmission electron microscopy (STEM) analysis was taken with a Carl-Zeiss 1550 Gemini field emission scanning electron microscope. Samples were prepared in the same way as for TEM analysis. Calcination of particles were carried out with increasing temperature of $2{ }^{\circ} \mathrm{C} / \mathrm{min}$, hold at $550{ }^{\circ} \mathrm{C}$ for $3 \mathrm{hrs}$. Samples were drop-casted on the silicon wafers which were pre-cleaned with oxygen plasma and dried overnight in the vacuum oven before calcination.

Atomic Force Microscopy (AFM) measurements were performed using a Multimode AFM (Bruker Nano Surfaces, Santa Barbara, CA, USA) with a NanoScope V controller with tapping mode. Samples were drop-casted on the silicon wafers which were pre-cleaned with oxygen plasma and dried overnight in the vacuum oven before measurement. 


\section{Chapter 6}

Muffle furnace Calcination of particles were carried out with increasing temperature of $2^{\circ} \mathrm{C} / \mathrm{min}$, hold at $550^{\circ} \mathrm{C}$ for $3 \mathrm{hrs}$. Samples were drop-casted on the silicon wafers which were pre-cleaned with oxygen plasma and dried overnight in the vacuum oven before calcination.

\subsection{References}

(1) (a) Liu, Y.; Xu, Y.; Zhu, Y.; Culver, J. N.; Lundgren, C. A.; Xu, K.; Wang, C. ACS Nano 2013, 7, 3627(b) Chen, X.; Gerasopoulos, K.; Guo, J.; Brown, A.; Wang, C.; Ghodssi, R.; Culver, J. N. ACS Nano 2010, 4, 5366(c) Zhou, K.; Li, F.; Dai, G.; Meng, C.; Wang, Q. Biomacromolecules 2013, 14, 2593(d) Liu, Y.; Zhang, W.; Zhu, Y.; Luo, Y.; Xu, Y.; Brown, A.; Culver, J. N.; Lundgren, C. A.; Xu, K.; Wang, Y.; Wang, C. Nano Letters 2013, 13, 293(e) Chiang, C.-Y.; Epstein, J.; Brown, A.; Munday, J. N.; Culver, J. N.; Ehrman, S. Nano Letters 2012, 12, 6005(f) Fernandes, D.; Krysmann, M. J.; Kelarakis, A. Chemical Communications 2016, 52, 8294(g) Ertem, E.; Murillo-Cremaes, N.; Carney, R. P.; Laromaine, A.; Janecek, E.-R.; Roig, A.; Stellacci, F. Chemical Communications 2016, 52, 5573.

(2) (a) Cormode, D. P.; Jarzyna, P. A.; Mulder, W. J. M.; Fayad, Z. A. Advanced Drug Delivery Reviews 2010, 62, 329(b) Lee, S. W.; Lee, S. K.; Belcher, A. M. Advanced Materials 2003, 15, 689(c) Chen, P.-Y.; Dang, X.; Klug, M. T.; Qi, J.; Dorval Courchesne, N.-M.; Burpo, F. J.; Fang, N.; Hammond, P. T.; Belcher, A. M. ACS Nano 2013, 7, 6563(d) Cumbo, A.; Lorber, B.; Corvini, P. F. X.; Meier, W.; Shahgaldian, P. Nature Communications 2013, 4, 1503(e) Parker, A. R.; Townley, H. E. Nature Nanotechnology 2007, 2, 347(f) Daaboul, G. G.; Lopez, C. A.; Chinnala, J.; Goldberg, B. B.; Connor, J. H.; Ünlü, M. S. ACS Nano 2014, 8, 6047(g) Tseng, R. J.; Tsai, C.; Ma, L.; Ouyang, J.; Ozkan, C. S.; Yang, Y. Nature Nanotechnology 2006, 1, 72(h) Kanbak-Aksu, S.; Nahid Hasan, M.; Hagen, W. R.; Hollmann, F.; Sordi, D.; Sheldon, R. A.; Arends, I. W. C. E. Chemical Communications 2012, 48, 5745(i) Shin, Y.; Dohnalkova, A.; Lin, Y. The Journal of Physical Chemistry C 2010, 114, 5985(j) Ueno, T.; Suzuki, M.; Goto, T.; Matsumoto, T.; Nagayama, K.; Watanabe, Y. Angewandte Chemie International Edition 2004, 43, 2527(k) Suzuki, M.; Abe, M.; Ueno, T.; Abe, S.; Goto, T.; Toda, Y.; Akita, T.; Yamada, Y.; Watanabe, Y. Chemical Communications 2009, 4871(1) Slocik, J. M.; Naik, R. R.; Stone, M. O.; Wright, D. W. Journal of Materials Chemistry 2005, 15, 749(m) Hong, S.; Lee, M. Y.; Jackson, A. O.; Lee, L. P. Light: Science \& Applications 2015, 4, e267(n) Bronstein, L. M. Small 2011, 7, 1609.

(3) (a) Jackson, E.; Ferrari, M.; Cuestas-Ayllon, C.; Fernández-Pacheco, R.; PerezCarvajal, J.; de la Fuente, J. M.; Grazú, V.; Betancor, L. Langmuir 2015, 31, 3687(b) Ravera, E.; Martelli, T.; Geiger, Y.; Fragai, M.; Goobes, G.; Luchinat, C. Coordination Chemistry Reviews(c) Ma, D.; Li, M.; Patil, A. J.; Mann, S. Advanced Materials 2004, 16, 1838(d) Kerkhofs, S.; Leroux, F.; Allouche, L.; Mellaerts, R.; Jammaer, J.; Aerts, A.; Kirschhock, C. E. A.; Magusin, P. C. M. M.; Taulelle, F.; Bals, S.; Van Tendeloo, G.; Martens, J. A. RSC 
Advances 2014, 4, 25650(e) Liu, Z.; Xu, X.; Tang, R. Advanced Functional Materials 2016, 26, 1862(f) Heinemann, S.; Coradin, T.; Desimone, M. F. Biomaterials Science 2013, 1, 688(g) Foglia, M. L.; Camporotondi, D. E.; Alvarez, G. S.; Heinemann, S.; Hanke, T.; Perez, C. J.; Diaz, L. E.; Desimone, M. F. Journal of Materials Chemistry B 2013, 1, 6283(h) Navarro-Tovar, G.; Palestino, G.; Rosales-Mendoza, S. Expert Review of Vaccines 2016, 1(i) Cho, W. K.; Yang, S. H. European Journal of Inorganic Chemistry 2015, 2015, 4481(j) Lee, J.; Choi, J.; Park, J. H.; Kim, M.-H.; Hong, D.; Cho, H.; Yang, S. H.; Choi, I. S. Angewandte Chemie International Edition 2014, 53, 8056(k) Arcos, D.; Vallet-Regí, M. Acta Biomaterialia 2010, 6, 2874(1) Wang, S.; Wang, X.; Draenert, F. G.; Albert, O.; Schröder, H. C.; Mailänder, V.; Mitov, G.; Müller, W. E. G. Bone 2014, 67, 292(m) Klem, M. T.; Young, M.; Douglas, T. Journal of Materials Chemistry 2008, 18, 3821(n) Jolley, C.; Klem, M.; Harrington, R.; Parise, J.; Douglas, T. Nanoscale 2011, 3, 1004.

(4) (a) Kumar, K.; Kumar Doddi, S.; Kalle Arunasree, M.; Paik, P. Dalton Transactions 2015, 44, 4308(b) Steinmetz, N. F.; Shah, S. N.; Barclay, J. E.; Rallapalli, G.; Lomonossoff, G. P.; Evans, D. J. Small 2009, 5, 813(c) Royston, E. S.; Brown, A. D.; Harris, M. T.; Culver, J. N. Journal of Colloid and Interface Science 2009, 332, 402(d) Royston, E.; Lee, S.-Y.; Culver, J. N.; Harris, M. T. Journal of Colloid and Interface Science 2006, 298, 706(e) Liu, B.; Cao, Y.; Huang, Z.; Duan, Y.; Che, S. Advanced Materials 2015, 27, 479(f) Fowler, C. E.; Shenton, W.; Stubbs, G.; Mann, S. Advanced Materials 2001, 13, 1266(g) Altintoprak, K.; Seidenstücker, A.; Welle, A.; Eiben, S.; Atanasova, P.; Stitz, N.; Plettl, A.; Bill, J.; Gliemann, H.; Jeske, H.; Rothenstein, D.; Geiger, F.; Wege, C. Beilstein Journal of Nanotechnology 2015, 6, 1399(h) Wang, G.; Wang, H.-J.; Zhou, H.; Nian, Q.-G.; Song, Z.; Deng, Y.-Q.; Wang, X.; Zhu, S.-Y.; Li, X.-F.; Qin, C.-F.; Tang, R. ACS Nano 2015, 9, 799(i) Niu, Z.; Kabisatpathy, S.; He, J.; Lee, L. A.; Rong, J.; Yang, L.; Sikha, G.; Popov, B. N.; Emrick, T. S.; Russell, T. P.; Wang, Q. Nano Research 2009, 2, 474.

(5) Wang, G.; Zhou, H.; Nian, Q.-G.; Yang, Y.; Qin, C.-F.; Tang, R. Chemical Science 2016, 7, 1753.

(6) Konecny, R.; Trylska, J.; Tama, F.; Zhang, D.; Baker, N. A.; Brooks, C. L.; McCammon, J. A. Biopolymers 2006, 82, 106.

(7) (a) Hommersom, C. A.; Matt, B.; van der Ham, A.; Cornelissen, J. J. L. M.; Katsonis, N. Organic \& Biomolecular Chemistry 2014, 12, 4065(b) Bedwell, G. J.; Zhou, Z.; Uchida, M.; Douglas, T.; Gupta, A.; Prevelige, P. E. Biomacromolecules 2015, 16, 214.

(8) (a) Suci, P. A.; Klem, M. T.; Douglas, T.; Young, M. Langmuir 2005, 21, 8686(b) Michen, B.; Graule, T. Journal of Applied Microbiology 2010, 109, 388.

(9) (a) Carcouët, C. C. M. C.; van de Put, M. W. P.; Mezari, B.; Magusin, P. C. M. M.; Laven, J.; Bomans, P. H. H.; Friedrich, H.; Esteves, A. C. C.; Sommerdijk, N. A. J. M.; van Benthem, R. A. T. M.; de With, G. Nano Letters 2014, 14, 1433(b) Wijnen, P. W. J. G.; Beelen, T. P. M.; Rummens, C. P. J.; van Santen, R. A. Journal of Non-Crystalline Solids 1991, 136, 119.

(10) Adolph, K. W. Journal of General Virology 1975, 28, 137.

(11) (a) Bruinsma, R. F.; Comas-Garcia, M.; Garmann, R. F.; Grosberg, A. Y. Physical Review E 2016, 93, 032405(b) Tama, F.; Brooks, C. L. J Mol Biol 2002, 318, 733.

(12) Speir, J. A.; Munshi, S.; Wang, G.; Baker, T. S.; Johnson, J. E. Structure (London, England : 1993) 1995, 3, 63.

(13) Lavelle, L.; Michel, J.-P.; Gingery, M. Journal of Virological Methods 2007, 146, 311. 


\section{Chapter 6}

(14) Adolph, K. W. European Journal of Biochemistry 1975, 53, 449.

(15) Chen, J.; Zhang, R.; Han, L.; Tu, B.; Zhao, D. Nano Research 2013, 6, 871.

(16) Liu, A.; Traulsen, C. H. H.; Cornelissen, J. J. L. M. ACS Catalysis 2016, 6, 3084.

(17) (a) Oh, H. I.; Hoff, J. E.; Armstrong, G. S.; Haff, L. A. Journal of Agricultural and Food Chemistry 1980, 28, 394(b) Van Buren, J. P.; Robinson, W. B. Journal of Agricultural and Food Chemistry 1969, 17, 772.

(18) (a) Gao, J.; Lei, H.; Han, Z.; Shi, Q.; Chen, Y.; Jiang, Y. 2017, 7, 45215(b) Gao, Z.; Zharov, I. Chemistry of Materials 2014, 26, 2030.

(19) (a) Chen, Y.; Chen, H.; Sun, Y.; Zheng, Y.; Zeng, D.; Li, F.; Zhang, S.; Wang, X.; Zhang, K.; Ma, M.; He, Q.; Zhang, L.; Shi, J. Angewandte Chemie 2011, 123, 12713(b) Colombo, M.; Carregal-Romero, S.; Casula, M. F.; Gutierrez, L.; Morales, M. P.; Bohm, I. B.; Heverhagen, J. T.; Prosperi, D.; Parak, W. J. Chemical Society Reviews 2012, 41, 4306(c) Croissant, J. G.; Zhang, D.; Alsaiari, S.; Lu, J.; Deng, L.; Tamanoi, F.; AlMalik, A. M.; Zink, J. I.; Khashab, N. M. Journal of Controlled Release 2016, 229, 183.

(20) (a) Ciganda, R.; Li, N.; Deraedt, C.; Gatard, S.; Zhao, P.; Salmon, L.; Hernandez, R.; Ruiz, J.; Astruc, D. Chemical Communications 2014, 50, 10126(b) Kuroda, K.; Ishida, T.; Haruta, M. Journal of Molecular Catalysis A: Chemical 2009, 298, 7.

(21) (a) Putri, R. M.; Cornelissen, J. J. L. M.; Koay, M. S. T. ChemPhysChem 2015, 16, 911(b) Brasch, M.; de la Escosura, A.; Ma, Y.; Uetrecht, C.; Heck, A. J. R.; Torres, T.; Cornelissen, J. J. L. M. Journal of the American Chemical Society 2011, 133, 6878(c) de la Escosura, A.; Verwegen, M.; Sikkema, F. D.; Comellas-Aragones, M.; Kirilyuk, A.; Rasing, T.; Nolte, R. J. M.; Cornelissen, J. J. L. M. Chemical Communications 2008, 1542.

(22) (a) Douglas, T.; Young, M. Nature 1998, 393, 152(b) Liu, A.; Verwegen, M.; de Ruiter, M. V.; Maassen, S. J.; Traulsen, C. H. H.; Cornelissen, J. J. L. M. The Journal of Physical Chemistry B 2016, 120, 6352. 
Construction of Core-Shell Hybrid Nanoparticles Templated by Virus-like Particles 


\section{Chapter 7}

\section{Cowpea Chlorotic Mottle Virus Templated Nanoporous Silica Thin Film}

A Cowpea Chlorotic Mottle Virus (CCMV) templated ordered honeycomblike nanoporous silica film was prepared by removal of the organic components through calcination. The porosity and the thickness of the film can be tuned by varying the ratio between the silica precursor and the CCMV particles and their concentration. This nanoporous silica film may have various applications, of which its use as an anti-reflective coating is explored.

A. Liu, L. Yang, C. H.-H. Traulsen, J. J. L. M. Cornelissen. Cowpea Chlorotic Mottle Virus Templated Nanoporous Silica Thin Film, in preparation. 


\subsection{Introduction}

Ordered nanoporous (silica) films have large surface areas, pore volumes and high stability in various environments. ${ }^{1}$ These properties make them interesting candidates in material science with numerous potential applications, such as functional coatings (e.g. antireflective or antifogging coating), ${ }^{2}$ catalysis,${ }^{3}$ low-k dielectric materials, ${ }^{4}$ photovoltaics and thermoelectrics, ${ }^{5}$ and energy storage. ${ }^{6}$ To prepare ordered nanoporous silica materials with uniform pore size often self-assembling surfactant ${ }^{1 \mathrm{~b}, 7}$ or liquid crystal based templates ${ }^{8}$ are used. Biomacromolecules, such as DNA and cellulose ${ }^{1 \mathrm{~b}}$ as well as viruses ${ }^{9,10}$ are also employed to control silica mineralization, leading to materials with different levels of nanoscale organization. It remains challenging, however, to construct nanoporous films with long range ordering.

Porous silica thin films with a high degree of ordering can be prepared using electroassisted self-assembly (EASA). ${ }^{1 a}$ However, a conductive sacrificial layer is needed in this method, which increases the cost for potential industrial applications. A different two-step method was also developed, in which first a continuous film is prepared by dip-coating and/or spin-coating with a silica precursor or mesoporous silica nanoparticles (NPs). In the second step evaporation-induced self-assembly (EISA) or drying-mediated self-assembly ${ }^{11}$ generated a thin film with patterned pores. ${ }^{12}$

We report in this chapter a silica film with long range patterned nanopores, using uniform CCMV protein particles as porogen. We first synthesized monodisperse virus-silica hybrid nanoparticles (NPs) and subsequently prepared an organized film by using drying-mediated self-assembly. After removal of the CCMV templating particles, a nanoporous silica thin film with a honeycomb-like structure was obtained. CCMV, as well as other virus particles, can be produced in large quantities and is easily scaled-up for industrial use. ${ }^{13}$ Therefore, virus NPs are uniform and low cost porogens for preparation of inorganic films with nanoscale organization. 


\subsection{Results and discussion}

\subsubsection{CCMV thin film}

To screen for an optimal method to prepare porous silica films with native CCMV as a template, three methods to prepare the templating layer were explored. 1) Covalent bonding method. Glass or silicon substrates were first functionalized with the linker perfluorophenyl11-(triethoxysilyl)undecanoate (PFPS), the advantages of using PFPS compared to other linkers are discussed in Chapter 4. CCMV was subsequently immobilized on the surface to form thin films through the formation of amide bonds. Only a monolayer of NPs, however, can be obtained by this approach. Other molecular linkers, such as succinaldehyde, are needed to prepare multilayer arrays of NPs. 2) Layer-by-layer $(L B L)$ method. Substrates were functionalized with a positively charged polymer first, such as linear-poly-lysine. Negatively charged CCMV (the $\mathrm{pI}$ is 3.8) were next coated on the polymer layer. Multi-layers of NPs can be easily obtained by repeating the above two steps. 3) Drying mediated self-assembly. A droplet of a dilute CCMV solution was applied on a clean substrates and left to dry (or use dip-coating or spin coating to obtain a homogenous layer first, and then leave it to dry). However, the concentration of NPs and drying conditions need to be controlled in order to form a well assembled monolayer or multi-layers of VNPs. Schematic representations of these three methods are shown in Figure 7.1.

1. Covalent approach
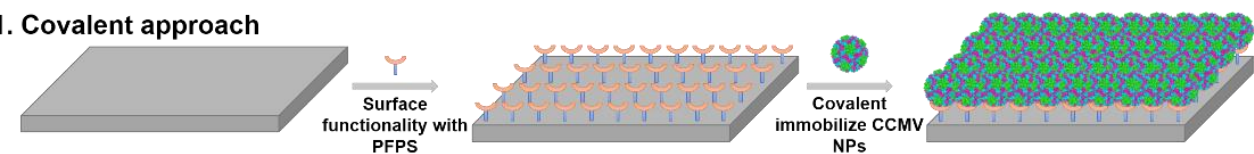

PFPS

NPs

2. Layer-by-Layer
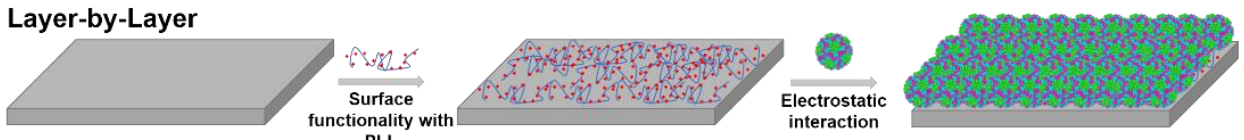

PLL

\section{Self-assembly}
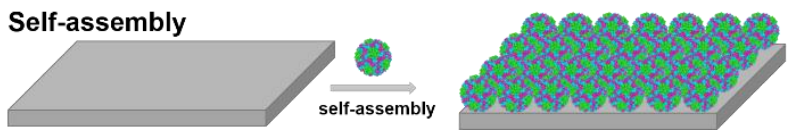

Figure 7.1. CCMV films prepared by 1). Covalent bonding; 2). Layer-by-layer and 3). Drying mediated self-assembly. 

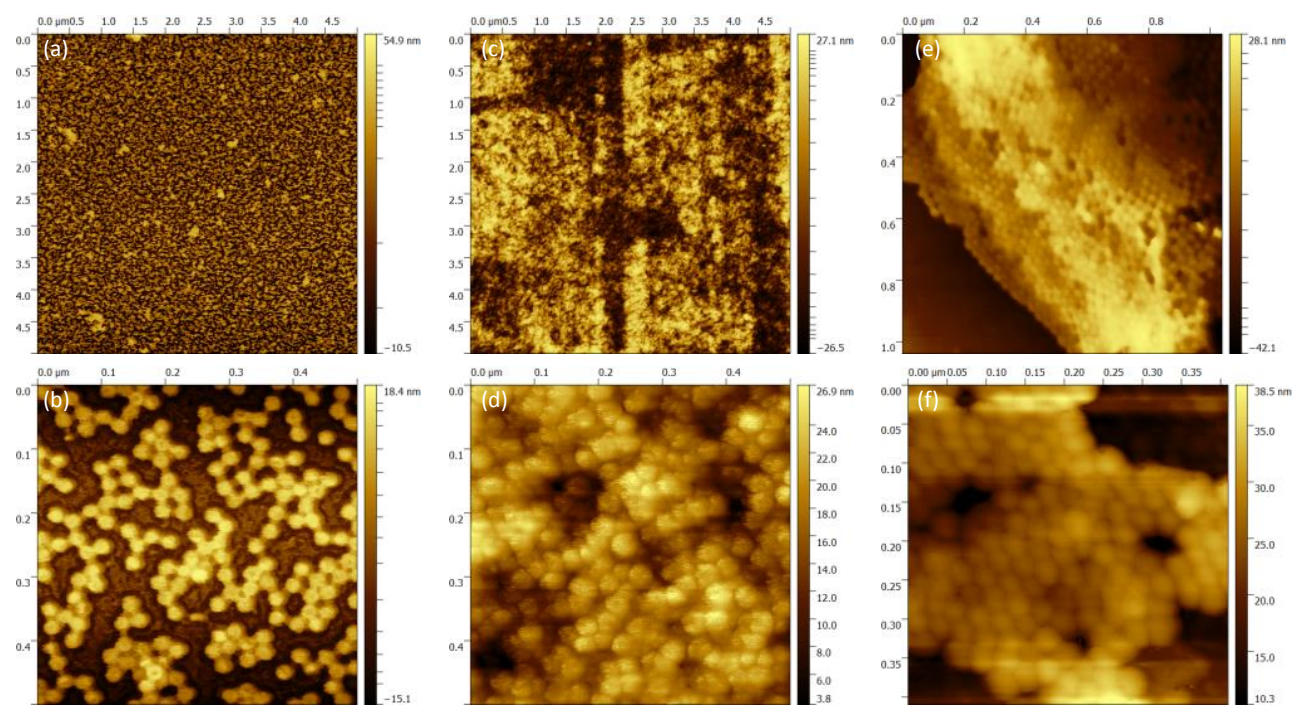

Figure 7.2. AFM analysis of (a) and (b): covalently immobilized CCMV; (c) and (d): layer-by-layer assembled CCMV; (e) and (f): drying-mediated self-assembled CCMV.

Thin films were analyzed by atomic force microscopy (AFM, Figure 7.2). Covalently immobilized CCMV with a surface coverage of $65 \%$ was obtained (Figure $7.2 \mathrm{a} \& \mathrm{~b}$ ). It appears that the surface coverage is independent from the concentration of virus solution, when the concentration is higher than $0.04 \mathrm{mg} / \mathrm{mL}$ (see appendix Figure 7.11). However, it is difficult to form a film with full surface due to the immobility of NPs when covalently bound. In the case of the layer-by-layer approach, a thin film with high surface roughness, close but non-ordered packed NPs was obtained (Figure 7.2c \& d), which may be due to an ill-defined polymer layer and the strong electrostatic interaction between polymers and CCMV. Moreover, given the time-consuming layer-by-layer method, a simpler and more efficient method is preferred for industrial use. Spin-coating/or dip-coating assistant dryingmediated self-assembly of CCMV resulted in a layered film instead of a monolayer (Figure 7.2e). After zooming in, a well-ordered structure was clearly observed (Figure 7.2f). The mechanism of drying-mediated self-assembly was studied by Brus et al. ${ }^{14}$ In this presumed non-equilibrium process, relatively weak attractions between the NPs, which are screened in solution, become more prominent as the solvent evaporates and this initiates the assembly of the particles. Well patterned arrays of CCMV with beyond the micron scale can be obtained under the chosen conditions; a continuous well-ordered thin film can be obtained by further 
controlling the type of solvent, the relative humidity and evaporation rate (or aging time). In this chapter, we selected the drying-mediated self-assembly method for preparation of nanoporous silica thin films templated by CCMV.

\subsubsection{CCMV-Silica thin film}

Previous studies reported in Chapter 6 of this thesis show that silica in various structures can be generated inside the CCMV cavity as a function of $\mathrm{pH}$. The smallest silica particles (D $<3 \mathrm{~nm}$ ) were formed when at $\mathrm{pH}<4$ during the silication process. Therefore, the described silication experiments were all carried out at $\mathrm{pH}<4$. To grow silica on the exterior surface of CCMV (or to grow silica outside the cavity), two methods were applied: 1. Cover the exterior of the CCMV protein cages with molecules (or oligomers, polymers etc.) to screen the negative charges; 2 . feed the silica precursor slowly and continuously.

Here, we chose pyrrole to cover the negatively charged domain on the CCMV surface, of which the possible mechanism is shown in Figure 7.3. Pyrrole is a weak base with a pKa of -3.8 , which is capable of forming $\mathrm{C}=\mathrm{O} \cdots \mathrm{HN}$ inter-molecular bridges with virus via its carboxylic acids and amide groups. ${ }^{15}$ Pyrrole is not stable, these monomers can be easily oxidized into oligomers when exposed to air and light. The oligomers remain attached to the surface covering the negative charges and assisting silica growth.
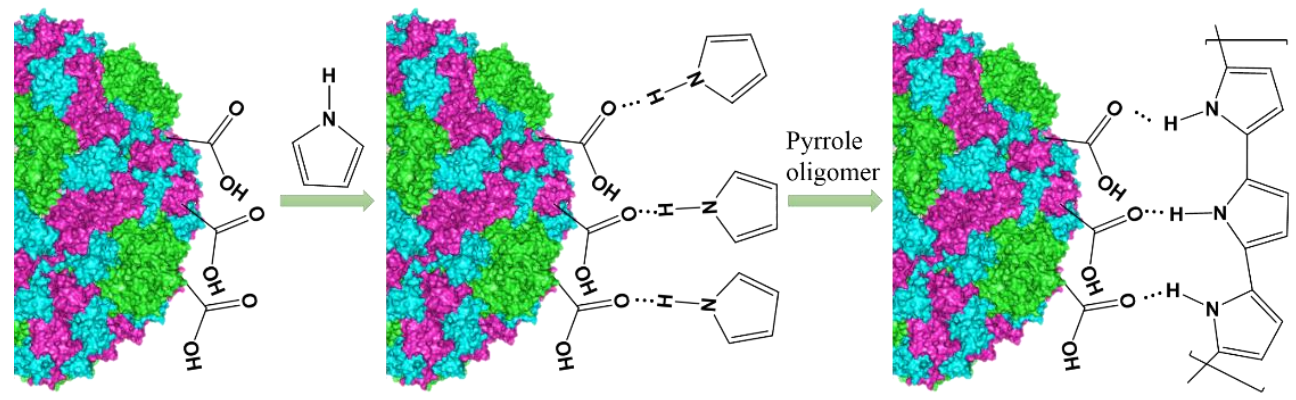

Figure 7.3. Schematic representation of the mechanism of oligo-pyrrole formation on the CCMV surface to mask the negative charges.

Using a syringe pump to continually feed the silica precursor and keep the concentration of TEOS low, enables a short particle nucleation period and it narrows the size distribution of the resulting particles by generating nuclei of similar sizes. ${ }^{16,17}$ Further feeding of the silica precursor drives the silica nuclei into larger silica particles, also avoiding small silica nuclei to penetrate into viral cages. 
Combing these two approaches, the resultant CCMV-Silica hybrid NPs were formed and dispersed in ethanol for further analysis. TEM images revealed monodisperse CCMV-Silica with a size of $\mathrm{D}=20 \mathrm{~nm}$ (Figure 7.4a \& b), which is smaller than native CCMV (D = 28 $\mathrm{nm})$. The decrease in size may be due to protein denaturation and silica condensation in ethanol. EDX analysis confirmed the presence of silica in CCMV-Silica particles (Figure 7.4c). However, both from TEM and EDX, the location of silica either on the exterior surface, the inner surface or inside the cavity is difficult to be determined.
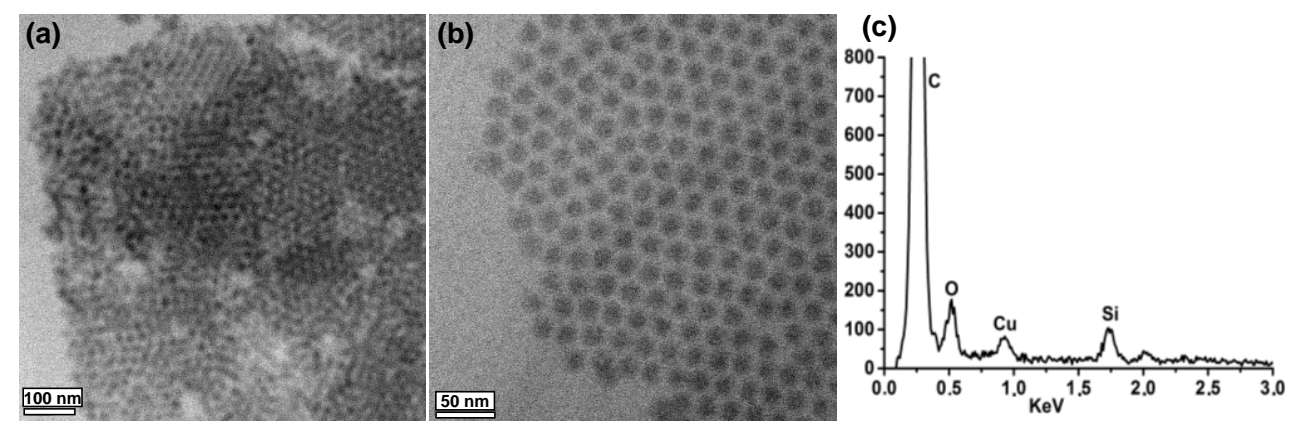

Figure 7.4. TEM images of CCMV-Silica (a) and (b) e; (c) EDX study to confirm the presence of silica on CCMV.

Further analysis of CCMV-Silica was performed by STEM. Hollow silica shells with irregular black holes were observed (denote as CCMV-Silica1), as shown in Figure 7.5a. If the ratio of silica precursor to CCMV is increased, monodispersed CCMV-Silica (referred to as CCMV-Silica2) with a gel like layer around the virus can be found (Figure 7.5c), (this was also confirmed by SEM analysis see appendix, Figure 7.12). In a control experiment, the same amount of silica precursor was quickly added (denote as CCMV-Silica3). As expected, fast addition of silica precursor resulted in a large number of silica nuclei and consequently structures with small silica particles (or silica nuclei) surrounding a darker core were obtained. The darker cores suggest that a silica particles were formed inside the CCMV cavity, which were denser than the surrounding particles (Figure 7.5e). This result further confirmed our assumption in chapter 6 that silica nuclei prefer to enter the CCMV cavity and grow inside of the cavity first, and then grow at the interface and/or exterior of the protein cages. The inserted schematic images are the suggested structures of CCMV-Silica1, 2 and 3. 
Hybrid CCMV-Silica were dispersed on silicon wafers and the templating protein cages were removed by calcination at $550{ }^{\circ} \mathrm{C}$ for $3 \mathrm{hrs}$. SEM analysis showed silica particles (D = $20 \mathrm{~nm}$ ) and fused silica shells that result in a porous monolayer film for CCMV-Silica1. For CCMV-Silica2, porous silica particles (shells) were found with an average $\mathrm{D}=26 \mathrm{~nm}$ (Figure 7.5d). And for CCMV-Silica3, after calcination, the fused silica nuclei form a dense layer of NPs with $\mathrm{D}=15 \mathrm{~nm}$ dispersed in a silica matrix (Figure 7.5f).
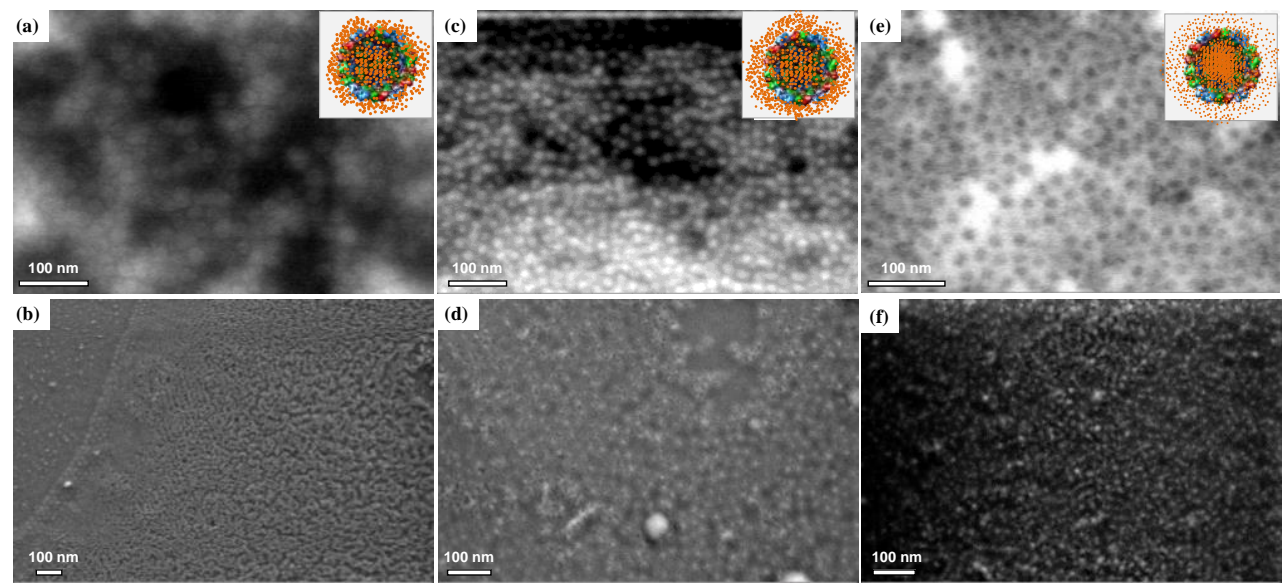

Figure 7.5. S(T)EM images of (a) \& (b) CCMV-Silica1 before and after calcination; (c) \& (d) CCMVSilica2 before and after calcination; (e) \& (f) CCMV-Silica3 before and after calcination.

CCMV-Silica was dispersed on silicon wafers and analyzed by AFM. Thin films with well order patterning of NPs were found for all CCMV-Silica samples. A film with a single domain crystal-like ordering was found for CCMV-Silical (Figure 7.6a), while two domains with defects on the boundary were found for CCMV-Silica2 (Figure 7.6c). Finally, a film with multi-domains was found for CCMV-Silica3 (Figure 7.6e), which may result from a more complex system containing silica nuclei-CCMV binary particles. Similar phenomena were found in bulk assembled CCMV-Silica3 materials (see in appendix, Figure 7.13). However, particles patterns were reorganized under further heating process (Figure 7.6b, d, f). After calcination at $550{ }^{\circ} \mathrm{C}$, the morphology of the resultant silica was consistent with SEM data. Fine and monodisperse silica NPs were found for CCMV-Silica1, including broken hollow silica particles (shown in appendix, Figure 7.14). The largest porous silica particles were observed for CCMV-Silica2 (Figure 7.6d). A film with high surface roughness was obtained, however, which is probably due to the relative poly-disperse silica particles after calcination which are more difficult to organize. CCMV-Silica3 showed NPs covered 
by a thin silica layer were observed by AFM (Figure 7.6f), which is comparable to the SEM results.
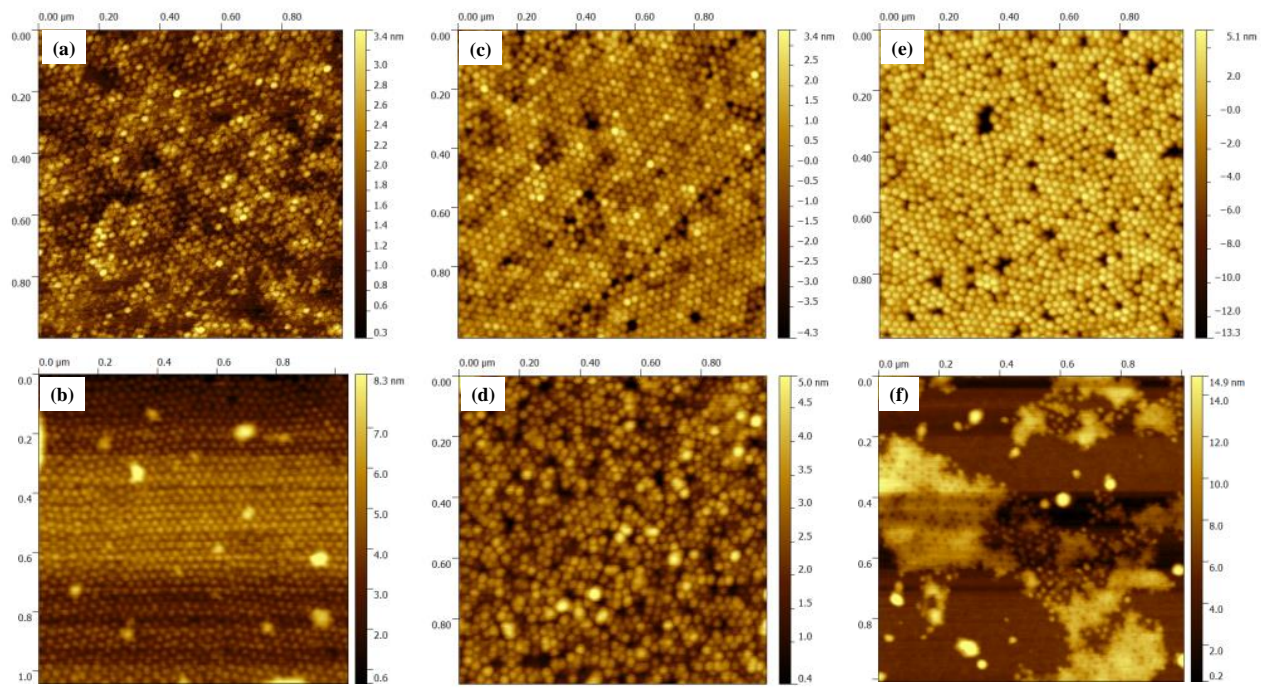

Figure 7.6. AFM images of (a) \& (b) CCMV-Silica1 before and after calcination; (c) \& (d) CCMVSilica2 before and after calcination; (e) \& (f) CCMV-Silica3 before and after calcination.

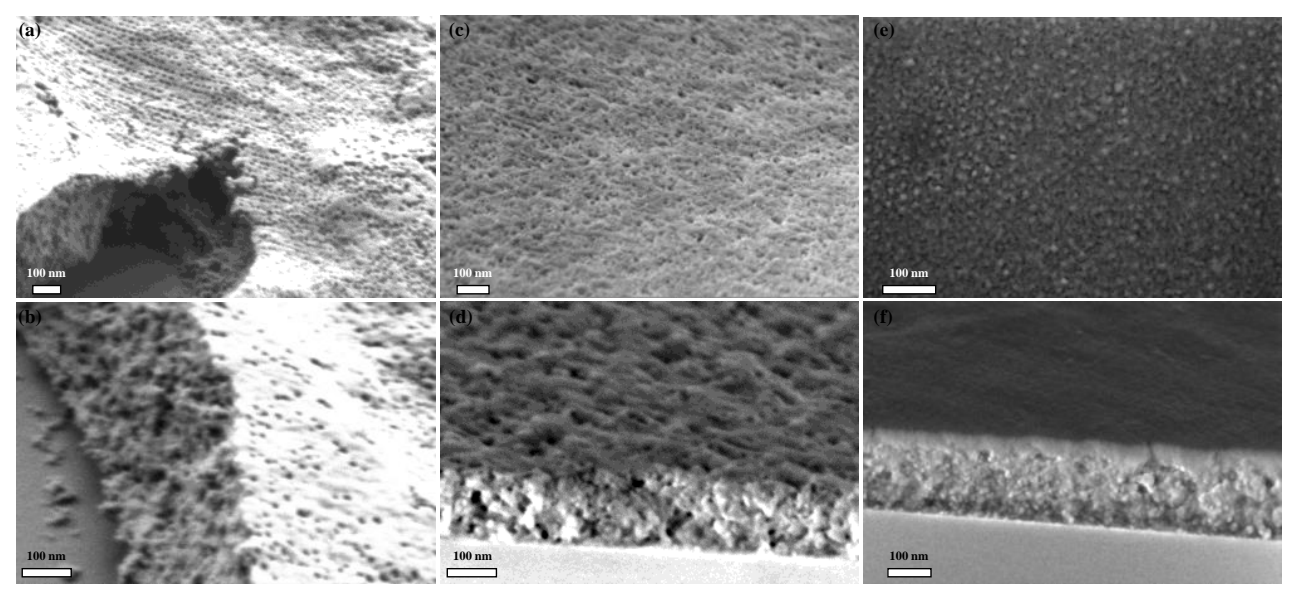

Figure 7.7. SEM image of CCMV-Silica thin films on silicon substrates after calcination: (a) \& (b) CCMV-Silica1; (c) \& (d) CCMV-Silica2 and (e) \& (f) CCMV-Silica3.

The thickness of the films can be increased by increasing the CCMV-Silica concentration. The formed films were calcined, resulting in a honeycomb-structured nanoporous silica film with an average pore size of $\mathrm{D}=18 \mathrm{~nm}$ in the case of CCMV-Silica1 (Figure 7.7a, image with larger magnification is shown in appendix-Figure 7.15). The porous structure was 


\section{Chapter 7}

confirmed by imaging the cross-section of the film (Figure 7.7b). A porous film was also obtained from CCMV-Silica2, although with irregular pores (or particles) and different pore sizes were found from both the top view and the cross-section of the film (Figure 7.7c\&d). For CCMV-Silica3, silica nanoparticles regularly dispersed in a silica matrix were observed from the top view of the film (Figure 7.7e), however the cross-section of the film indicated a dense packing of silica NPs (Figure 7.7f). This is likely the result of fusing of the silica formed inside the CCMV cavity and small silica particles (or silica nuclei) that are dispersed around the protein shell. Therefore, because of the decomposition of the organic parts during calcination, small pores can still be observed from the top of the film. The above results indicate that by applying pyrrole on the virus surface and by the slow feeding of the silica precursor, CCMV-Silica with minimal amounts of silica inside the viral cavity can be obtained. Upon removing the organic component by calcination, a porous silica film is formed of which the porosity can be controlled by the ratio of silica precursor to CCMV.

\subsubsection{Anti-reflective coating}

Theoretical back ground Antireflection coatings (ARCs) are widely used to increase transmission and reduce the glare resulted from coatings or substrates. ARCs can be widely used in buildings, displays, and solar cells.

Considering the high preparation cost of multi-layered coating (each having a different refractive index that varies from the air to glass gradually), here, only single-layer coating was studied in order to provide a new route that is straight forward and potentially cheaper or faster to apply. The reflection (R) from any given interface at $\pi / 2$ incidence is ${ }^{18}$

$$
R=\left[\frac{\left(n_{0}-n_{m}\right)^{2}}{\left(n_{0}+n_{m}\right)^{2}}\right] \times 100 \%,
$$

in which the refractive index of the glass substrate $\mathrm{n}_{\mathrm{m}}=1.56$, and the refractive index of air $\mathrm{n}_{0}=1$. Therefore, the incident light reflected on one side of the glass substrate is about $4 \%$ and $8 \%$ in total from both sides regardless the thickness of glass substrate. ${ }^{2 b}$ The aim of the thin film coating on the glass substrate is to reduce the reflection and increase transmission, as is schematically shown in Figure 7.8. 


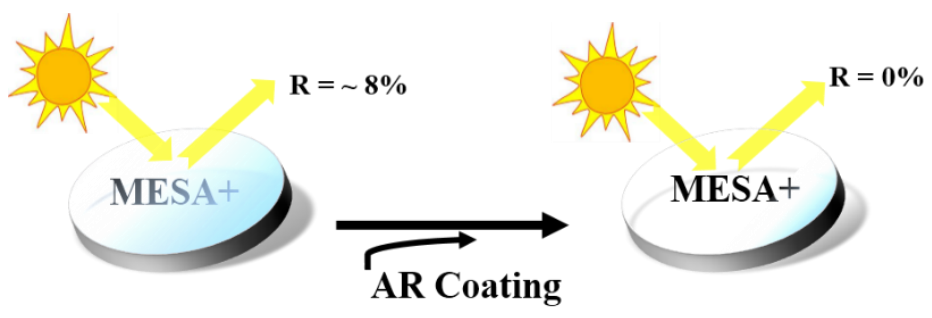

Figure 7.8. Antireflective coating on glass substrate.

Determination of the optimal film thickness For one-layer ARC with refractive index of $n_{1}$, the reflectance is

$$
R=\left[\frac{n_{1}^{2}\left(n_{0}-n_{m}\right)^{2} \cos ^{2} k_{0} h+\left(n_{0} n_{m}-n_{1}^{2}\right)^{2} \sin ^{2} k_{0} h}{n_{1}^{2}\left(n_{0}+n_{m}\right)^{2} \cos ^{2} k_{0} h+\left(n_{0} n_{m}+n_{1}^{2}\right)^{2} \sin ^{2} k_{0} h}\right] \times 100 \%,
$$

where $k_{0}$ is the phase angle of the incoming light and $h$ is the optical thickness of the film. With the optimal conditions for $\mathrm{R}=0$ when $k_{0} h=\pi / 2$, and the thickness of the film $\mathrm{d}=$ $\lambda_{0} /\left(4 n_{1}\right)$, equation 2 becomes

$$
R=\frac{\left(n_{0} n_{m}-n_{1}^{2}\right)^{2}}{\left(n_{0} n_{m}+n_{1}^{2}\right)^{2}} .
$$

Therefore, when $n_{1}=\left(n_{0} n_{m}\right)^{1 / 2}, R=0$.

For a coating on a glass substrate $\left(n_{m}=1.56\right)$, the perfect refractive index is $n_{1}=1.23$, with the thickness of thin film $\mathrm{d}=91.5$ to $132 \mathrm{~nm}$, under the wavelength $\lambda_{0}=$ $450 \mathrm{~nm}$ to $650 \mathrm{~nm}$. However, no natural materials are found with such a refractive index; and for synthetic dense materials, it is either technically difficult or expensive. A porous film, with low preparation costs, is able to achieve this goal.

Determination of the optimal porosity The refractive index of thin films can be determined by techniques such as ellipsometric porosimetry, the relation between the refractive index and the properties of the porous film can be described by the Lorentz-Lorenz equation

$$
P_{V}=\frac{n_{p}^{2}-1}{n_{p}^{2}+2}
$$

where $P_{V}$ is the effective polarzability of a unit of volume of the porous thin film, ${ }^{18}$ while $n_{p}$ is the measured refractive index of the porous film.

The volume polarizability of each thin film can be determined for the following examples: 
A dense substrate with a refractive index of $n_{d}$.

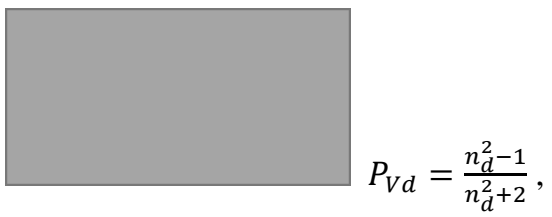

A porous thin film filled with air with a refractive index of $n_{p}$ :

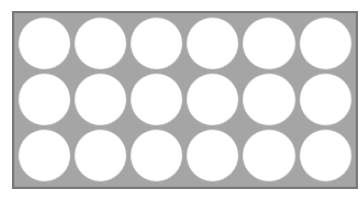

$$
\begin{aligned}
& P_{V P}=\frac{n_{p}^{2}-1}{n_{p}^{2}+2}=\left[V \cdot \frac{n_{a i r}^{2}-1}{n_{a i r}^{2}+2}+(1-V) \cdot \frac{n_{d}^{2}-1}{n_{d}^{2}+2}\right] \\
& =(1-V) \cdot \frac{n_{d}^{2}-1}{n_{d}^{2}+2},
\end{aligned}
$$

where $\mathrm{n}_{\mathrm{d}}, \mathrm{n}_{\mathrm{p}}$ and thin film thickness can be determined by ellipsometric porosimetry, therefore, the porosity of thin film can be determined according to equation 5 and 6 :

$$
V=1-\left(\frac{n_{p}^{2}-1}{n_{p}^{2}+2}\right) /\left(\frac{n_{d}^{2}-1}{n_{d}^{2}+2}\right)
$$

In the present study, the refractive index for the glass matrix $\mathrm{n}_{\mathrm{m}}=1.56$, and we assume that the formed film (with thickness $90-130 \mathrm{~nm}$ ) has a perfect adhesion the on substrate. Therefore the relation between $\mathrm{R}$ and the porosity $\mathrm{V}$ can be calculated according to equation 3 and 7:

$$
R=\frac{(1.1499 V-0.58988)^{2}}{(2.70212-0.14212 V)^{2}} \times 100 \%
$$

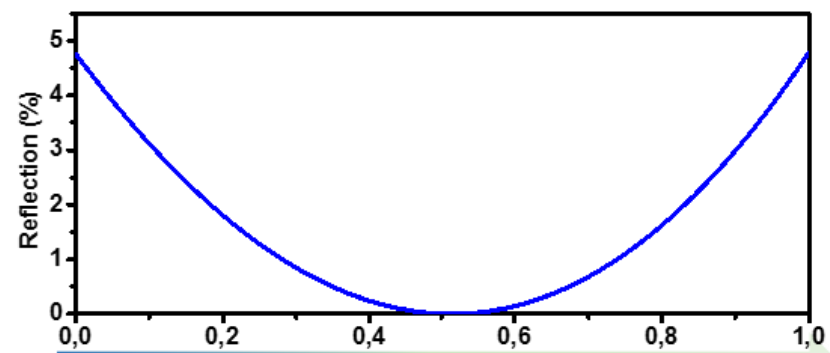

Porosity: V

Figure 7.9. The relation between reflection and thin film porosity. 
From this theoretical analysis, we expect an optimal effect of the ARC at a porosity of $51 \%$.

CCMV templated anti-reflective coatings We anticipated that silica films templated by VLPs could be good candidates for ARC. As shown in the previous sections porous films can be obtained, that in principle have a tunable porosity. Because of their will-defined size and structure, but in particular because of the natural availability of VLPs in a range of sizes, these protein cages are ideal porogens. Towards these CCMV templated ARC - with ideally a thickness of $\mathrm{d}=90-140 \mathrm{~nm}$ and a porosity of $50 \%$ (see above) - two strategies are followed: 1) cast a CCMV film first and subsequently coat it with the silica sol or 2) cast CCMV-silica particles and then perform the coating step.

In the first method, CCMV particles were coated on one side of a glass substrate, afterwards, a silica sol was coated by spin-coating. The resulting CCMV-Silica films were dried under vacuum at $60^{\circ} \mathrm{C}$ overnight before calcination or analysis. A monolayer of a silica coated CCMV film was visualized by SEM (Figure 7.10a). The organic components were removed by calcination, however, instead of a porous silica film, aggregated hollow silica nanoparticles (see inserted image, Figure 7.10b) were obtained, which may be due to low surface adhesion. The transmission of this film of hollow silica nanoparticles deposited on a glass substrate increased about $1.5 \%$ in the wavelength range of $\lambda=550-700 \mathrm{~nm}$ (Figure 7.10c).
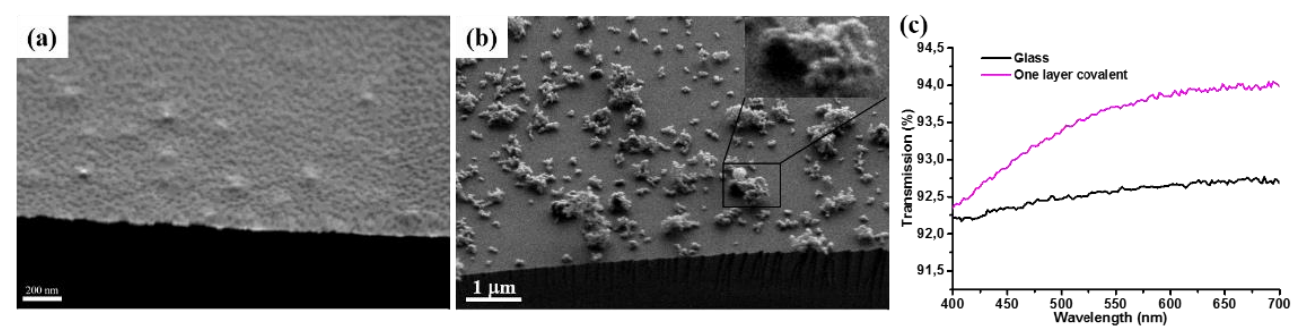

Figure 7.10. SEM analysis of (a) the silica coated CCMV monolayer film and (b) the silica film after calcination on glass substrates. (c) Transmission spectra of this single-side silica coated glass substrate. 

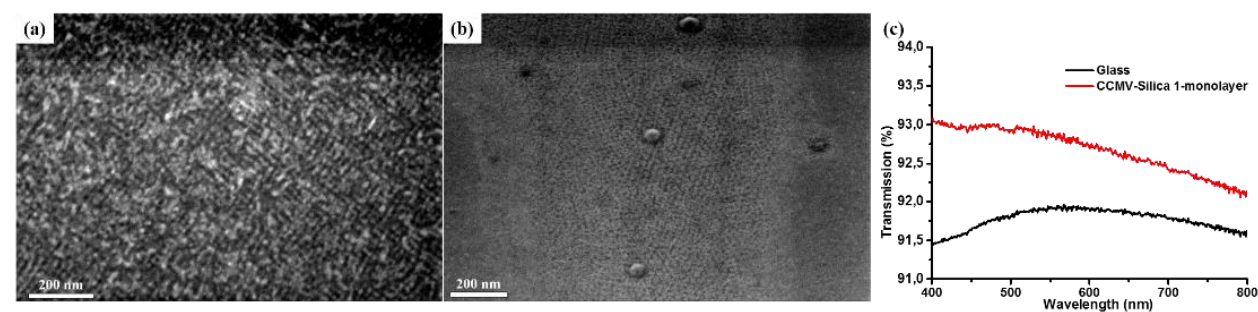

Figure 7.11. SEM analysis of (a) \& (b) CCMV-Silica1 single-side coated glass substrate after calcination. (c) Transmission spectra of this single-side silica coated glass substrate.

In the second method, CCMV-Silica1 formed an organized film on the glass substrate as was already shown in Figure $2 \mathrm{e} \& \mathrm{f}$ and calcination did not disrupt this organization. SEM imaging of calcination shows some silica fragments presenting on the silica film (Figure 7.11a \& b). A clean area clearly shows the organization of the NPs (Figure 7.11b), which is in line with the AFM analysis (Figure 7.6b). The obtained single-side coated glass substrate shows an increase in the light transmission of about $1 \%$ (Figure $7.11 \mathrm{c}$ ).

The initial results presented above indicate that CCMV indeed can act as a porogen for the formation of an ARC. The data also show that a more homogenous and organized film is obtained when a silica layer is applied on the CCMV before film formation, although this is a much more laborious method compared with the casting pristine CCMV. Although a proofof-concept is provided, the analysis of the films by microscopy and transmission spectroscopy clearly shows that further optimization towards the parameters resulting from the theory is needed.

\subsection{Conclusions and outlook}

In this chapter, we have developed a new approach to prepare porous silica films by employing CCMV particles as sacrificial templates, with the ultimate aim to construct antireflective coatings. The approach is potentially extendable to other viral nanoparticles and viral templated inorganic porous thin films. We first compared CCMV film formation and its particle coating using covalent linking, layer-by-layer and drying-mediated self-assembly as techniques to organize the virus particles. The last approach is promising for the formation of highly ordered coatings, so this method was used for the preparation of exemplary CCMVSilica films. Upon calcination, nanoporous thin films were obtained. These films can be used 
as anti-reflection coating; however, the thickness of coating needs to be controlled (and extended) to achieve higher transmissions. Furthermore, based on the theoretical considerations given, ellipsometric porosimetry can be a very helpful tool to further optimize the anti-reflective coatings obtained by the methods described here.

As discussed in the previous chapters, CCMV particles are widely used containers in nanotechnology. Functional nanoparticles, such as gold or quantum dots, can be easily encapsulated in the protein cages, forming hybrid functional virus like particles. With the same silication and film preparation methods, such functional NPs can be integrated into silica films for specific applications such as catalysis, solar cells, electrical device, etc.

\subsection{Acknowledgements}

Dr. Damien Reardon is greatly acknowledged for his scientific discussion. Dr. Liulin Yang is greatly acknowledged for his help during manuscript preparation. Many thanks to Dr. Wei Zhu for fruitful discussion; and thanks to Dr. Rico Keim and Dr. Mark Smithers for TEM and SEM analysis.

\subsection{Materials and Methods}

\subsubsection{Materials}

All chemicals were of analytical quality, and used as purchased without further purification. Ethanol, pyrrole, APTES ((3-Aminopropyl) triethoxysilane, and TEOS (tetraorthosilicate, were all purchased from Sigma-aldrich. Pyrrole was pre-distilled before use. Buffers were prepared with ultrapure water (MilliQ).

CCMV-covalently coated thin film procedures are same as introduced in Chapter4.

CCMV-LBL coating The substrate was activated by oxygen plasma first, then coated with positively charged poly-l-lysine in buffer solution, $\mathrm{pH} 4.8$. After $0.5 \mathrm{~h}$, the coated substrate was rinsed with buffer, $\mathrm{pH} 4.8$ for $1 \mathrm{~min}$. Next, CCMV in buffer solution, $\mathrm{pH} 4.8$ was applied and the system incubated for another $0.5 \mathrm{~h}$. Finally this substrate was rinsed with buffer solution and dried carefully under $\mathrm{N}_{2}$ flow. 


\section{Chapter 7}

CCMV-Silica1, CCMV-Silica2, CCMV-Silica3 preparation for CCMV-Silica1 and CCMV-Silica2, $100 \mu \mathrm{L}$ of $4 \mathrm{mg} / \mathrm{mL}$ of CCMV (in $10 \mathrm{mM}$ of sodium acetate buffer, $\mathrm{pH} 4$ ) was incubated with pyrrole for $0.5 \mathrm{~h}$ first; after then silica precursor (ATPES/TEOS=1/9, ethanol solution) as added slowly by using a pump with flow rate of $1 \mu \mathrm{L} / \mathrm{min}$ while stirring. The reaction mixture was stirred for 3 days, after which the resultant solution was dialyzed against $10 \mathrm{mM}$ sodium acetate buffer $(\mathrm{pH} 4)$ for 1day and subsequently dialyzed against MQwater for another 5 days to completely remove the silica precursor. CCMV-Silica3 was prepared in a same way but the silica precursor was added instanteneously. The ratio between silica precursor/CCMV-NH 2 groups, CCMV-Silica1 is 30/1 mol/mol; CCMV-Silica2 is 90/1 $\mathrm{mol} / \mathrm{mol}$; CCMV-Silica3 is $90 / 1 \mathrm{~mol} / \mathrm{mol}$.

Atomic Force Microscopy (AFM) measurements AFM measurements were performed using a Multimode AFM (Bruker Nano Surfaces, Santa Barbara, CA, USA) with a NanoScope V controller in tapping mode. Samples were drop-casted on the silicon wafers which were pre-cleaned with oxygen plasma and dried overnight in the vacuum oven before measuring.

Muffle furnace Calcination of particles was carried out by increasing the temperature at $2^{\circ} \mathrm{C} / \mathrm{min}$ and subsequent heating at $550^{\circ} \mathrm{C}$ for $3 \mathrm{hrs}$. Samples were drop-casted on the silicon wafers which were pre-cleaned with oxygen plasma and dried overnight in the vacuum oven before calcination. 


\subsubsection{Appendix}

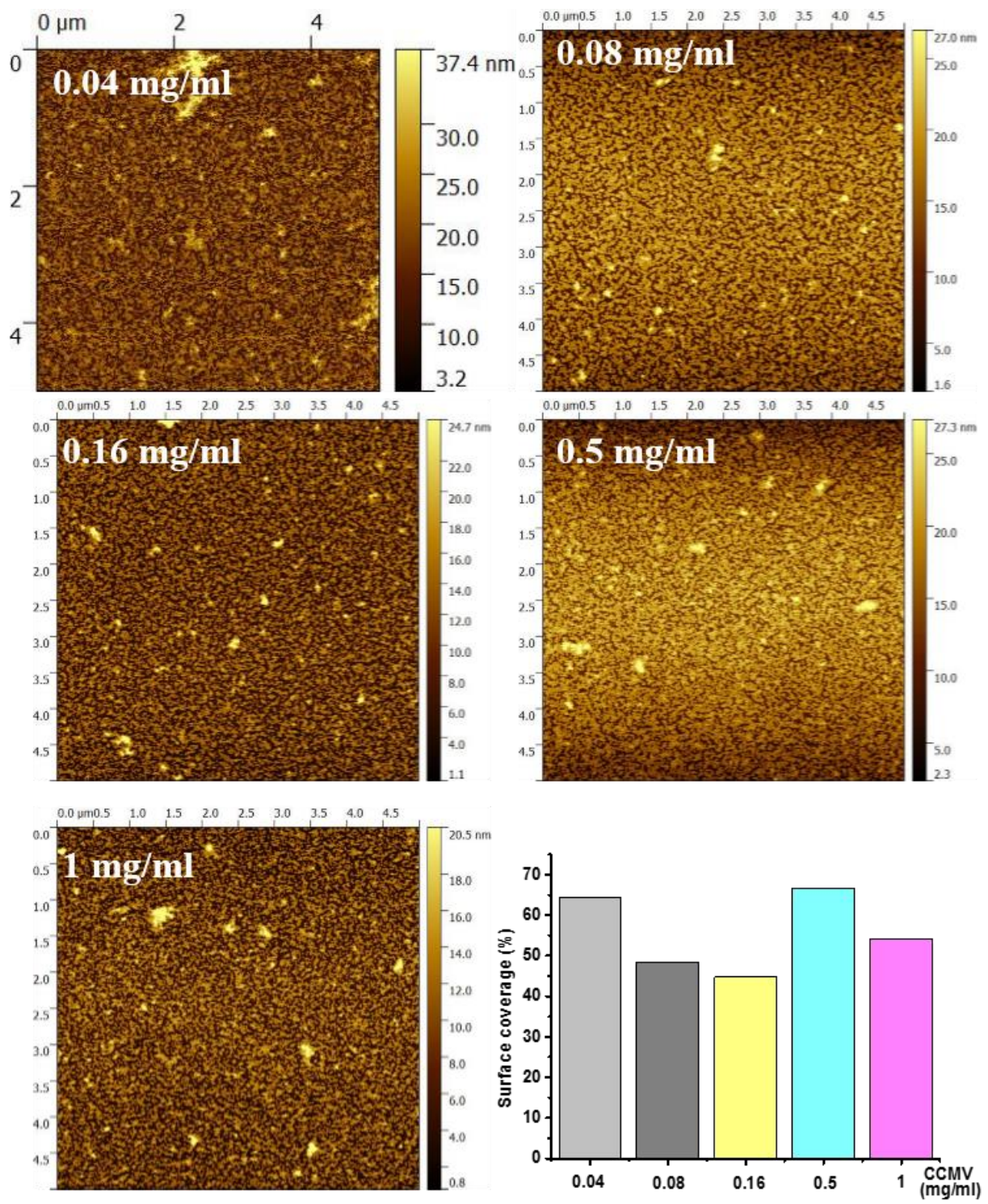

Figure 7.11. AFM images of CCMV coating by PFPS covalent linking, surface coverage versus of CCMV solution concentration for coating. 
Chapter 7

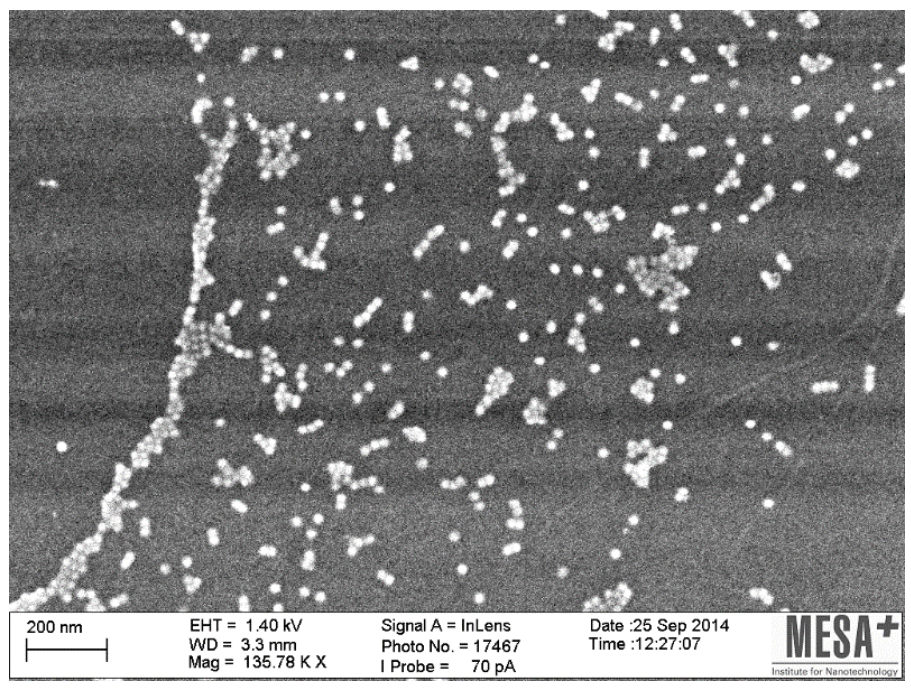

Figure 7.12. SEM image of CCMV-Silica2.

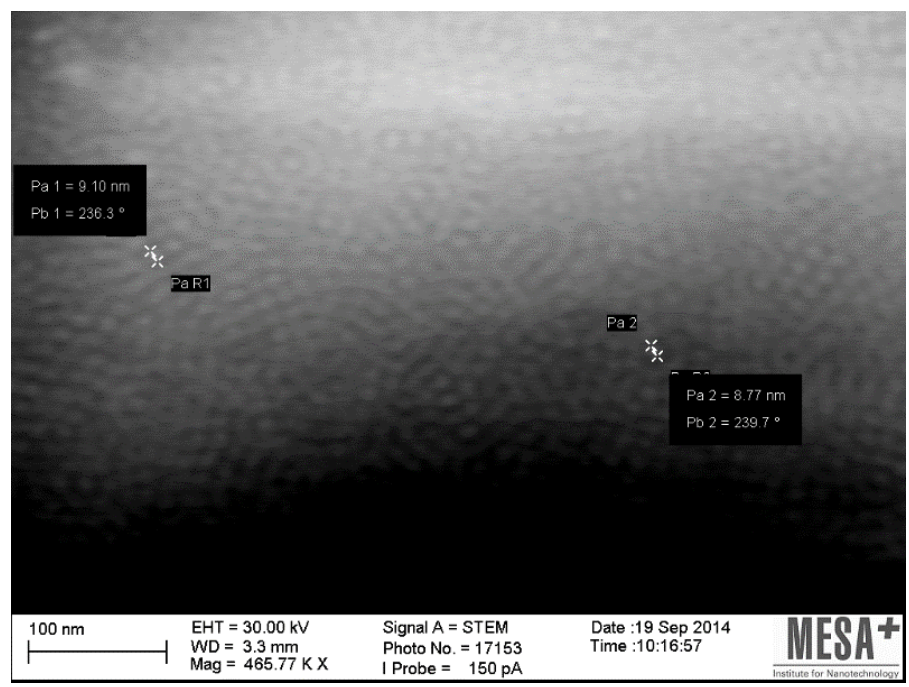

Figure 7.13. STEM image of CCMV-Silica3. 
Virus Templated Nanoporous Silica Thin Film

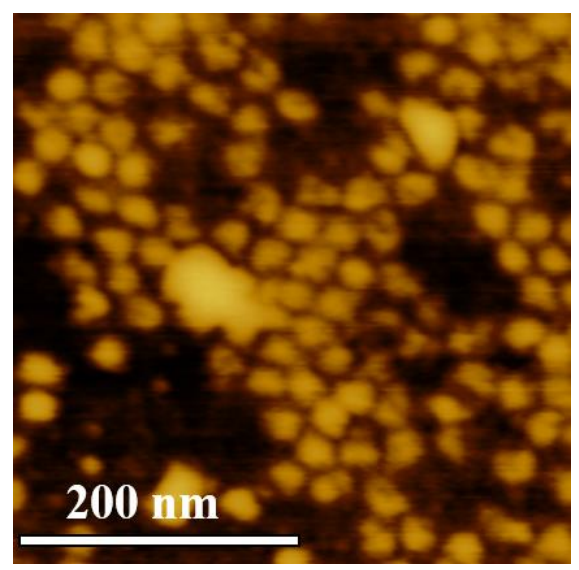

Figure 7.14. AFM image of CCMV-Silica1 after calcination.

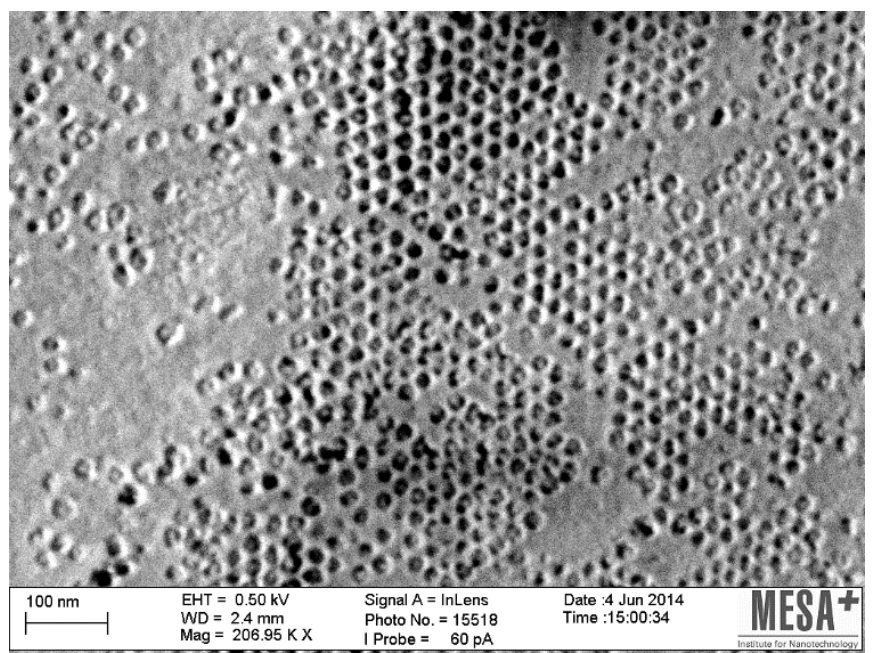

Figure 7.15. SEM image of top view of CCMV-Silica1 thin film after calcination.

\subsection{References}

1. (a) Cheng, J.; Rathi, S. J.; Stradins, P.; Frey, G. L.; Collins, R. T.; Williams, S. K. R., Free standing silica thin films with highly ordered perpendicular nanopores. $R S C$ Advances 2014, 4 (15), 7627-7633; (b) Wan, Y.; Zhao, On the Controllable Soft-Templating Approach to Mesoporous Silicates. Chemical Reviews 2007, 107 (7), 2821-2860. 
2. (a) Eshaghi, A.; Mojab, M., Fabrication of antireflective antifogging nano-porous silica thin film on glass substrate by layer-by-layer assembly method. Journal of NonCrystalline Solids 2014, 405, 148-152; (b) Moghal, J.; Kobler, J.; Sauer, J.; Best, J.; Gardener, M.; Watt, A. A. R.; Wakefield, G., High-Performance, Single-Layer Antireflective Optical Coatings Comprising Mesoporous Silica Nanoparticles. ACS Applied Materials \& Interfaces 2012, 4 (2), 854-859; (c) Mizoshita, N.; Tanaka, H., Versatile Antireflection Coating for Plastics: Partial Embedding of Mesoporous Silica Nanoparticles onto Substrate Surface. ACS Applied Materials \& Interfaces 2016, 8 (45), 31330-31338; (d) Guldin, S.; Kohn, P.; Stefik, M.; Song, J.; Divitini, G.; Ecarla, F.; Ducati, C.; Wiesner, U.; Steiner, U., Self-Cleaning Antireflective Optical Coatings. Nano Letters 2013, 13 (11), 5329-5335.

3. Rafti, M.; Brunsen, A.; Fuertes, M. C.; Azzaroni, O.; Soler-Illia, G. J. A. A., Heterogeneous Catalytic Activity of Platinum Nanoparticles Hosted in Mesoporous Silica Thin Films Modified with Polyelectrolyte Brushes. ACS Applied Materials \& Interfaces 2013, 5 (18), 8833-8840.

4. Shamiryan, D.; Abell, T.; Iacopi, F.; Maex, K., Low-k dielectric materials. Materials Today 2004, 7 (1), 34-39.

5. Wei, T.-C.; Hillhouse, H. W., Mass Transport and Electrode Accessibility Through Periodic Self-Assembled Nanoporous Silica Thin Films. Langmuir 2007, 23 (10), 56895699 .

6. Lang, X.; Hirata, A.; Fujita, T.; Chen, M., Nanoporous metal/oxide hybrid electrodes for electrochemical supercapacitors. Nat Nano 2011, 6 (4), 232-236.

7. $\quad$ Cagnol, F.; Grosso, D.; Soler-Illia, G. J. d. A. A.; Crepaldi, E. L.; Babonneau, F.; Amenitsch, H.; Sanchez, C., Humidity-controlled mesostructuration in CTAB-templated silica thin film processing. The existence of a modulable steady state. Journal of Materials Chemistry 2003, 13 (1), 61-66.

8. (a) Kresge, C. T.; Leonowicz, M. E.; Roth, W. J.; Vartuli, J. C.; Beck, J. S., Ordered mesoporous molecular sieves synthesized by a liquid-crystal template mechanism. Nature 1992, 359 (6397), 710-712; (b) Shopsowitz, K. E.; Qi, H.; Hamad, W. Y.; MacLachlan, M. J., Free-standing mesoporous silica films with tunable chiral nematic structures. Nature 2010, 468 (7322), 422-425.

9. $\quad$ Fowler, C. E.; Shenton, W.; Stubbs, G.; Mann, S., Tobacco Mosaic Virus Liquid Crystals as Templates for the Interior Design of Silica Mesophases and Nanoparticles. Advanced Materials 2001, 13 (16), 1266-1269.

10. Niu, Z.; Kabisatpathy, S.; He, J.; Lee, L. A.; Rong, J.; Yang, L.; Sikha, G.; Popov, B. N.; Emrick, T. S.; Russell, T. P.; Wang, Q., Synthesis and characterization of bionanoparticle-Silica composites and mesoporous silica with large pores. Nano Research 2009, 2 (6), 474-483.

11. Brinker, C. J.; Lu, Y.; Sellinger, A.; Fan, H., Evaporation-Induced Self-Assembly: Nanostructures Made Easy. Advanced Materials 1999, 11 (7), 579-585.

12. Alberius, P. C. A.; Frindell, K. L.; Hayward, R. C.; Kramer, E. J.; Stucky, G. D.; Chmelka, B. F., General Predictive Syntheses of Cubic, Hexagonal, and Lamellar Silica and Titania Mesostructured Thin Films. Chemistry of Materials 2002, 14 (8), 3284-3294.

13. Wen, A. M.; Steinmetz, N. F., Design of virus-based nanomaterials for medicine, biotechnology, and energy. Chemical Society Reviews 2016, 45 (15), 4074-4126.

14. Rabani, E.; Reichman, D. R.; Geissler, P. L.; Brus, L. E., Drying-mediated selfassembly of nanoparticles. Nature 2003, 426 (6964), 271-274. 
15. Beattie, D.; Wong, K. H.; Williams, C.; Poole-Warren, L. A.; Davis, T. P.; BarnerKowollik, C.; Stenzel, M. H., Honeycomb-Structured Porous Films from PolypyrroleContaining Block Copolymers Prepared via RAFT Polymerization as a Scaffold for Cell Growth. Biomacromolecules 2006, 7 (4), 1072-1082.

16. Riccio, D. A.; Nugent, J. L.; Schoenfisch, M. H., Stöber Synthesis of Nitric OxideReleasing S-Nitrosothiol-Modified Silica Particles. Chemistry of materials : a publication of the American Chemical Society 2011, 23 (7), 1727-1735.

17. X. Lei, B. Yu, H. L. Cong, C. Tian, Y. Z. Wang, Q. B. Wang, C. K. Liu, Synthesis of Monodisperse Silica Microspheres by a Modified Stöber Method. Integrated Ferroelectrics 2014, 154 (1), 142-146.

18. Baklanov, M. R.; Mogilnikov, K. P., Non-destructive characterisation of porous low-k dielectric films. Microelectronic Engineering 2002, 64 (1-4), 335-349. 


\section{Summary}

Natural proteins, are essential ingredients in living life, which involve almost all fundamental processes including catalysis, metabolism, transcription and translation, transport and structural integrity. Nature builds up proteins by a bottom-up approach from the amino acids to large protein chains with tertiary three dimensional structures, and use proteins as highly efficient molecular machines that control many of the functions of living cell. Proteins that assemble in a well-defined way have attracted great interests in as building blocks in nanotechnology and materials science. Among these protein assemblies, virus particles have shown great advantages as they exist in various sizes and shapes, but with high monodispersity and symmetry. In addition, they can be easily produced in various methods at a large scale for laboratory research and the resultant products can potentially be scaled up for daily life applications. Based on the natural properties of virus coat proteins, they have been widely used for controlled drug loading and delivery, as size selective catalyst platforms, and confined nanoreactors for controlled growth of inorganic or organic materials. The research presented in this thesis describes strategies to take full advantages of virus protein capsids to develop functional materials.

This thesis provides insight into the impact of viral particles as scaffolds for functional materials; these are factors such as the surface electrostatic potential and pore size of the virus capsids, the chemical modification of the capsid surfaces and the high degree of monodispersity of these protein nanoparticles. In a model catalytic reaction, i.e. the reduction of nitro aromatics under the influence of gold nanoparticles encased in the capsid, the effect of the electrostatic potential and the pore size of virus-based protein cages on the accessibility of substrates with different charge and shape was studied first (Chapter 3). By taking advantage of the functional groups on the exterior surface of capsids, the gold/protein hybrid nanoparticles were immobilized in flow channels, a reactor that can be easily handled and be used under continuous flow can be obtained, the functionality of the individual hybrid nanoparticles is maintained (Chapter 4). Alternatively, cross-linking of the gold loaded protein on a liquid-liquid interface cages resulted in free standing thin films. The catalytic properties of these thin films were studied for potential application in bio-sensors. Also the 
biocompatibility of these thin films was studied, to reveal the possibility of in vivo applications, such as dynamic photo-thermotherapy by gold loaded thin films (Chapter 5).

In addition to construction hybrid nanoparticles based on the virus capsid and gold, the protein cages were also used as templates for controlled synthesis of inorganic, silica particles, where the growth was fine-tuned by controlling the $\mathrm{pH}$ When using gold loaded protein cages as template for silication, gold core-silica hollow shell nanostructures were formed after removing of organic components by high temperature calcination (Chapter 6). Finally, viruses and their hybrid nanoparticles were assembled into high ordered twodimensional (2D) thin films on a surface. These results demonstrate that the virus particles can be used as environmental friendly porogens for the fabrication anti-reflective coatings (Chapter 7).

Overall, we have developed virus-based protein cage functional materials for catalysis and optical coatings. The unique properties of the viral particles, such as in vitro reversible self-assembly with functional nanoparticles or molecules incorporated, their capability of chemical or genetic modification and the ability to self-assembly into high-order structures, were employed to introduce new or different functions into these catalytic and/or optical materials. These studies help to gain further insight in the development of virus-based materials. 


\section{Samenvatting}

Natuurlijke eiwitten zijn essentiële componenten voor levende wezens en ze zijn nodig voor bijna alle belangrijke processen zoals katalyse, metabolisme, transcriptie, translatie, transport en structurele integriteit. De natuur bouwt eiwitten op vanuit aminozuren tot grote eiwit ketens met tertiaire driedimensionale structuren die gebruikt worden als erg efficiënte moleculaire machines welke controle hebben op een divers spectrum van functies in levende cellen. Eiwitten die op een goed-gedefinieerde manier kunnen assembleren hebben de interesse gewekt om ze te gebruiken als bouwstenen voor in nanotechnologie en materiaalkunde. Ten opzichte van andere geassembleerde ewitstructuren hebben virus deeltjes grote voordelen, zij komen namelijk voor in verschillende groottes en structuren, hierbij zijn deze erg monodispers en hebben ze een gedefinieerde symmetrie. Daarnaast kunnen deze, in potentie, gemakkelijk met behulp van verschillende methoden geproduceerd worden op grote schaal. Dit is vooral van belang als er producten mee gemaakt worden met toepassingen in het dagelijkse leven. Door de natuurlijke eigenschappen van de capside eiwitten van een virus, zijn ze in eerdere onderzoeken al gebruikt voor het gecontroleerd laden en afgeven van medicijnen, als selectieve katalytische systemen en als nano-reactoren voor de gecontroleerde groei van inorganische of organische materialen. Het onderzoek in deze thesis beschrijft verschillende strategieën om alle voordelen van virus capside eiwitten te gebruiken in de ontwikkeling van functionele materialen.

Deze thesis geeft inzicht over de toegevoegde waarde van virus deeltjes in functionele materialen, met betrekking tot de oppervlakte lading, grote van de poriën, chemische modificaties en de hoge mate van monodisperiteit. van de virus capsiden. Dit word in eerste instantie gedaan door een 'standaard' katalytische reactie, die van de reductie van nitro aromaten, te bestuderen onder invloed van goud nanodeeltjes gencapsuleerd in de virus capside. Hierbij is er een effect van het elektrische potentiaal en porie grote, afkomstig van de virus capside, op de toegang van de substraten met verschillende vormen en lading (hoofdstuk 3). Door gebruikt te maken van de functionele groepen op het oppervlak van de capsides konden hybride goud/eiwit nano-deeltjes geïmmobiliseerd worden in kleine vloeistof kanalen. Hiermee is een reactor verkregen die gemakkelijk handelbaar is en onder 
continue vloeistofstroming gebruikt kan worden met behoud van de individuele hybride nano-deeltjes (Hoofdstuk 4). Bij een alternatieve strategie werden deze, in eiwit gencapsuleerde goud deeltjes, met elkaar chemisch verknoopt bij een vloeistof-vloeistof oppervlak. Wat resulteerde in vrijstaande dunne films. De katalytische eigenschappen van deze dunne films werden verder bestudeerd voor toepassingen in biosensoren. Daarnaast gaf een bio-compatibiliteit studie met deze dunne filmpjes als resultaat dat deze geschikt zijn voor in vivo toepassingen, een voorbeeld hiervoor is photo-thermischetherapie met behulp van met goud geladen dunne filmpjes (Hoofdstuk 5).

Naast het maken van goud en virus capside gebaseerde hybride deeltjes, zijn de capsides ook gebruikt voor gecontroleerde synthese van anorganische siliciumoxidedeeltjes, waarbij de groei geoptimaliseerd is als functie van $\mathrm{pH}$. Deze synthese is ook toegepast op virus capsides met goud aan de binnenkant, wat, na calcinatie op hoge temperatuur resulteerde in holle-schil siliciumoxide nano-structuren met een gouden kern (Hoofdstuk 6). Uiteindelijk werden de virussen en hun verschillende hybride structuren op een oppervlak geassembleerd in tweedimensionale dunne film structuren met hoge ordening. Deze resultaten laten zien dat virus deeltjes gebruikt kunnen worden als natuurvriendelijke porogeen voor de fabricage van anti-reflectie coatings (Hoofdstuk 7).

Over het geheel hebben we virus-gebaseerde eiwit kooien gebruikt voor functionele materialen, te gebruiken in katalyse en optische coatings. De unieke eigenschappen van de virus deeltjes, zoals de reversibele in vitro zelf-assemblage met functionele nano deeltjes of moleculen, de mogelijkheid om ze zowel chemisch als genetisch te modificeren en de mogelijkheid om de deeltjes in hogere orde structuren te assembleren, zijn gebruikt om nieuwe of andere eingenschappen te geven aan catalytische en/of optische materialen. Deze studies zijn dus zeker van bijdrage voor de ontwikkeling en begrip van virus-gebaseerde materialen. 


\section{Acknowledgements}

At the end of this dissertation, I would like to take this opportunity to thank everyone who has supported and accompanied me through the journey of my $\mathrm{PhD}$.

First, I would like to thank my supervisor, Prof. Dr. Jeroen J.L.M. Cornelissen for offering me the opportunity to pursue my PhD study in the BNT group. Jeroen, many thanks for your guidance, for your immense knowledge about my research and especially for your great patience during my thesis writing process. You always gave me freedom and support to allow me to develop my own ideas and perform the research. I learned so much from both the successes and failures, and I believe that this part of the experience will be a cornerstone for my future life in research. Thank you for the motivation and positive encouragement - I really enjoyed working in the BNT group.

I would like to sincerely thank all my committee members: Prof. Roeland J. M. Nolte from the Radboud University Nijmegen, Prof. Xian-En Zhang from the Chinese Academy of Science, Dr. Damien Reardon from DSM N.V., Prof Nieck E. Benes, and Prof Han Gardeniers from the University of Twente.

My sincere gratitude to the staff of MNF/BNT cluster: Jurriaan, I admire you a lot, especially for your critical, smart and scientific questions during colloquium. I really enjoyed your Supramolecular lecture a lot. Tibor, thank you for your patience, kindness, and your encouragement for my AFM study. Many thanks to Pascal, Jos, Nathalie, Melissa and Wim for scientific advice during colloquia.

I'd like to thank Regine, Richard, Marcel and Bianca for your scientific and technical help. Regine, thanks a lot for the biotechnology and laboratory equipment use and safety introductions. Marcel, thank you for experimental equipment set-up. Richard, thank you for giving me useful experimental tips. Bianca, thank you for your support in the lab.

Many thanks to Nicole and Izabel for all the arrangements you have made; from my visa application to the meetings, conferences and business travel plans during four years, and ending with arrangements for my graduation. I could not have focused on my research and studies without your help. 
Grateful acknowledgements to Rianne and Martijn - thank you for introducing me to the BNT group and enlightening me on the research of viral particles at the first glance. Sarah, thank you for introducing me to research life, both in and outside of the lab; I hope that you enjoy your new job. Supitch, thank you for being my roommate for almost one and half years at the beginning of my $\mathrm{PhD}$ life; you are always my learning model, thanks for your encouragement and advise. Rindia, we started our $\mathrm{PhD}$ almost at the same time, and now we are going to finish our work at the UT soon. Thanks a lot for sharing your biochemical knowledge with me over this past four years. Andrea, we also started together, thank you for patiently answering all my questions in chemistry. Thanks also for listening to and asking questions on my work, which helped me to clarify my ideas and map my research. I wish to thank Stan and Mark, thank you for all your suggestions and feedback during meetings, virus lunches, for reading and correcting manuscripts. Thanks for always helping me with my questions on Dutch letters. Mark, thank you for your help with my Samenvatting. Shuqin and Robin, thank you for the time we have had in the lab together and thank you for all the useful suggestions during meetings. Thanks to Liang, Yao, Xiu and He for being good friends, and thanks for the cheerful talks we had together, I wish you all the best. Andrea, Alejandro, Jenny, Shirish and Laura, thank you for inviting me to join the bike road trip to Amsterdam, I enjoyed it a lot and learned how to cycle as part of a team. Raquel, thank you for inviting me to the parties and dinners that you have held; I have really enjoyed spending time with you and will always remember your cheerful laugh. Emanuela, Janneke, Rianne, and Nathalie, thank you for letting me join the work-week committees, I have learned a lot from you about planning and organization, and I admire your efficient work.

I would like to thank Christoph Traulsen, Liulin Yang, Wei Zhu and Jie Zhu, for sharing expertise, and for the sincere and valuable guidance and encouragement that you have extended to me. Christoph, thanks for training me to be scientific, and to be critical about myself as a researcher. Thank you for your assistance in my earlier research life and all the collaborative work. Liulin, you are a really patient and smart scientist who is full of experience, and are always so kind, friendly, and helpful to everyone who comes to you for help. Wei Zhu, you are a creative scientist, thanks for supporting me and helping me out, 
and thanks for all the inspiring chats. Jie Zhu, thank you for all the positive and helpful chats, especially for sharing your knowledge on catalysts.

I wish to express my special thanks to my paranymphs, Supaporn (Meow) and Shuqin (Jenny). Meow, you are the smartest and the cutest Thai girl, thank you for being a supportive friend. Shuqin, thank you for all the funny jokes and the delicious food you made us. I wish you both all the best for your future.

I give grateful thanks to the lab 3 members, Raquel, Laura, Alejandro, Carmen, Mark, Maike, Daniele, Jacopo and Shuqin; lab 3 is always a cheerful environment because of you. I express my gratitude to the help from members of neighbouring groups (MTP, BST and PCS). Thank you for sharing the instruments and facilities. I would like to thank Dr. Rico Keim for your help with TEM measurements and Dr. Mark Smithers for your help with SEM measurements. I would like to thank all the members and former members of the BNT/MnF cluster during my study in UT: Wouter, Gülistan, Alexander M., Nico, Almudena, Sara, Andreas, Erik, Nicole, Pramond, Pia, Rachel, Disraëli, Federico, Gaurav, Alberto, Alexander, Maike, Maaike, Naomi, Muhabbat, Ines, Sander, Dhanya, Salmeen, Tushar, Jenny, Ben, Alexis, Liuyi, Tom, Pauline, Wilfred, Shyam and others.

I truly appreciate the support and company of many friends I met in Enschede: Kaihuan, Shanqiu, Jinfeng, Boyang, Qi-ao, Minmin, Junwen, Hairong, Xiumei, Yin Tao, Chao Wang, Yunlong, Qinqian, Lijie, Yanbo, Xinwu, Haishan, Jianfeng, Yawei, Mendy, Youwen, Xiaohua, Kenan, Ying Du, Lantian, Jiahui, Xichen, Leilei, Wanshu and so on. Thank you for the joyful time we spent together.

Finally, I would like to thank my beloved family and friends who have supported me along the way.

特别感谢爸爸, 妈妈, 姐姐, 姐夫的大力支持, 感谢王毅的支持和陪伴, 感谢叔叔阿 姨, 堂哥, 堂姐和表姐们的祝福。

\section{刘爱洁}

Aijie Liu

Enschede, 2017 


\section{About the author}

Aijie Liu was born on $30^{\text {th }}$ of July 1988 in Zhejiang, China. She pursued her bachelor degree in Polymer Science and Engineering, in department of Material Science and Engineering at the Harbin University of Science and Technology, China, and graduated in July 2011. She did her bachelor's project at the University of Ulsan as an exchange student; during her bachelor project, she studied the preparation of metal nanoparticles by electrical explosion of wire and high energy ball milling, under the supervision of Prof. Jin-Chun Kim and Prof. Li-Zhu Liu. Afterwards, in August 2013, she received her master degree in Material Science and Engineering at the University of Ulsan. Her master's research, entitled "Preparation and Characterization of Metal-Polypyrrole Nanocomposite Materials" was carried out in the Green Powder NanoMetallurgy Group, University of Ulsan under the supervision of Prof. Jin-Chun Kim.

Since $1^{\text {st }}$ of October 2013, she started her $\mathrm{PhD}$ programme in the Biomolecular Nanotechnology group under the supervision of Prof. Jeroen Cornelissen. The aim of her project is to engineer protein cages into functional hybrid materials. The results of this project are described in this thesis. 


\section{List of publications}

1. Aijie Liu, Mark V. de Ruiter, Stan J. Maassen, Jeroen J.L.M. Cornelissen. Nanoreactors via encapsulation of catalytic gold nanoparticles within cowpea chlorotic mottle virus, in press. "Protein Scaffolds: Design, Synthesis, and Applications", in the lab protocol series 'Methods in Molecular Biology', Andrew K. Udit, Eds.; Humana Press: Springer Science + Business Media New York, USA.

2. Aijie Liu, Liulin Yang, Christoph H.-H. Traulsen, Jeroen J.L.M. Cornelissen. Immobilization of catalytic virus-like particles in a flow reactor. Chem Commun., 2017, 53, 7632-7634.

3. Aijie Liu, Christoph H.-H. Traulsen (co-first author), Jeroen J.L.M. Cornelissen. Nitroarene Reduction by a Virus Protein Cage Based Nanoreactor, ACS Catalysis 2016, 6(5), 3084-3091.

4. Aijie Liu, Martijn Verwegen, Mark V. de Ruiter, Stan J. Maassen, Christoph H.-H. Traulsen, Jeroen J.L.M. Cornelissen. Protein Cages as Containers for Gold Nanoparticles, J. Phys. Chem. B, 2016, 120 (26), 6352-6357.

5. Liulin Yang, Aijie Liu, Shuqin Cao, Rindia M. Putri, Pascal Jonkheijm, Jeroen J.L.M. Cornelissen. Self-assembly of Proteins: Towards Supramolecular Materials, Chem. Eur. J., 2016, 22, 15570-15582.

\section{Publications in preparation}

6. Aijie Liu, Liulin Yang, Martijn Verwegen, Damien Reardon, Jeroen J.L.M. Cornelissen. Construction of Core-Shell Hybrid Nanoparticles Templated by Viruslike Particles, submitted.

7. Aijie Liu, Wei Zhu, Mark V. de Ruiter, Stan J. Maassen, Rindia M. Putri, Liulin Yang, C. Jeffrey Brinker and Jeroen J.L.M. Cornelissen. Interfacial Crosslinking of Viral Protein Cage-inspired Free-Standing Thin Films with Tunable Functionalities, to be submitted. 
8. Aijie Liu, Liulin Yang, Christoph. H.-H. Traulsen, Jeroen J.L.M. Cornelissen. Cowpea Chlorotic Mottle Virus Templated Nanoporous Silica Thin Film, in preparation.

9. Aijie Liu, Liulin Yang, Jeroen J.L.M. Cornelissen. Protein Cage-Inorganic Hybrid Nanocomposite Materials, in preparation.

10. Liulin Yang, Aijie Liu, Mark V. de Ruiter, Catharina. A. Hommersom, Pascal Jonkheijm, Jeroen J.L.M. Cornelissen, Compartmentalized Supramolecular Hydrogels Based on Virus-like Nanoparticles towards Sophisticated Cargo Quantification, stabilization and Controlled Release, submitted.

11. Rindia M. Putri, Daniel Luque, Robin Klem, Aikaterini A. Rousou, Aijie Liu, Christoph H.-H. Traulsen, W. Frederik Rurup, Melissa S.T. Koay, José R. Castón and Jeroen J.L.M. Cornelissen. Structural Characterization of Native and Modified Encapsulins as Nanoplatforms for Catalysis and Cellular Uptake, submitted to ACS Nano.

\section{Other publications}

1. Aijie Liu, Luong Huu Bac, Ji-Soon Kim, Byoung-Kee Kim, Jin-Chun Kim, Synthesis and Characterization of Conducting Polyaniline-Copper Composites. J Nanosci Nanotechnol. 2013, 13 (11), 7728-7733;

2. Aijie Liu, Luong Huu Bac, Ji-Soon Kim, Jin-Chun Kim, Preparation and comparative study of polyaniline/copper and polyaniline/silver composites by Electrical Explosion of Wire. (2012, IFOST Conference paper);

3. Aijie Liu, Luong Huu Bac, Jin-Chun Kim, and Lizhu Liu, Synthesis and Characterization of Polyaniline-Copper Composites by Electrical Explosion of Wire, Journal of Nanosci. Nanotechnol. 2012, 12 (7), 6031-6035;

4. Aijie Liu, Luong Huu Bac, Jin-Chun Kim and Lizhu Liu, Preparation and Characterization of Polymer - Copper Composites by Electrical Explosion of Wire. (2011, IFOST Conference paper). 
